$$
\begin{aligned}
& \text { ANGEIT GASIS }
\end{aligned}
$$

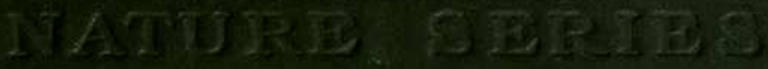
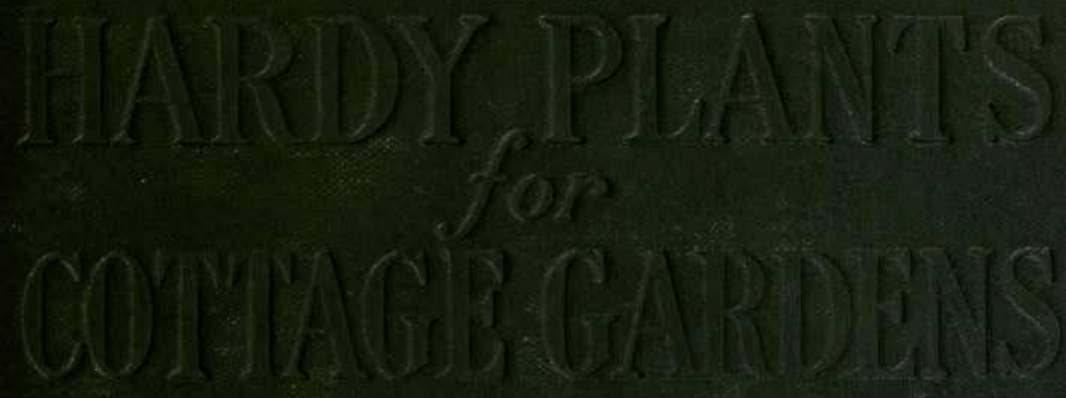

BELWN IR. ATBRE 


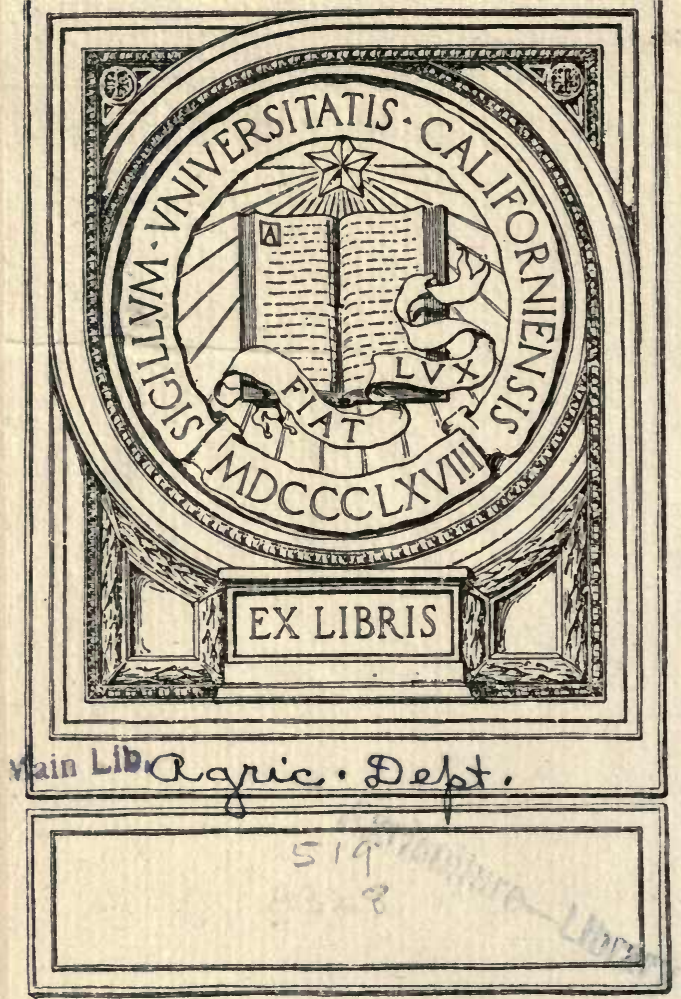








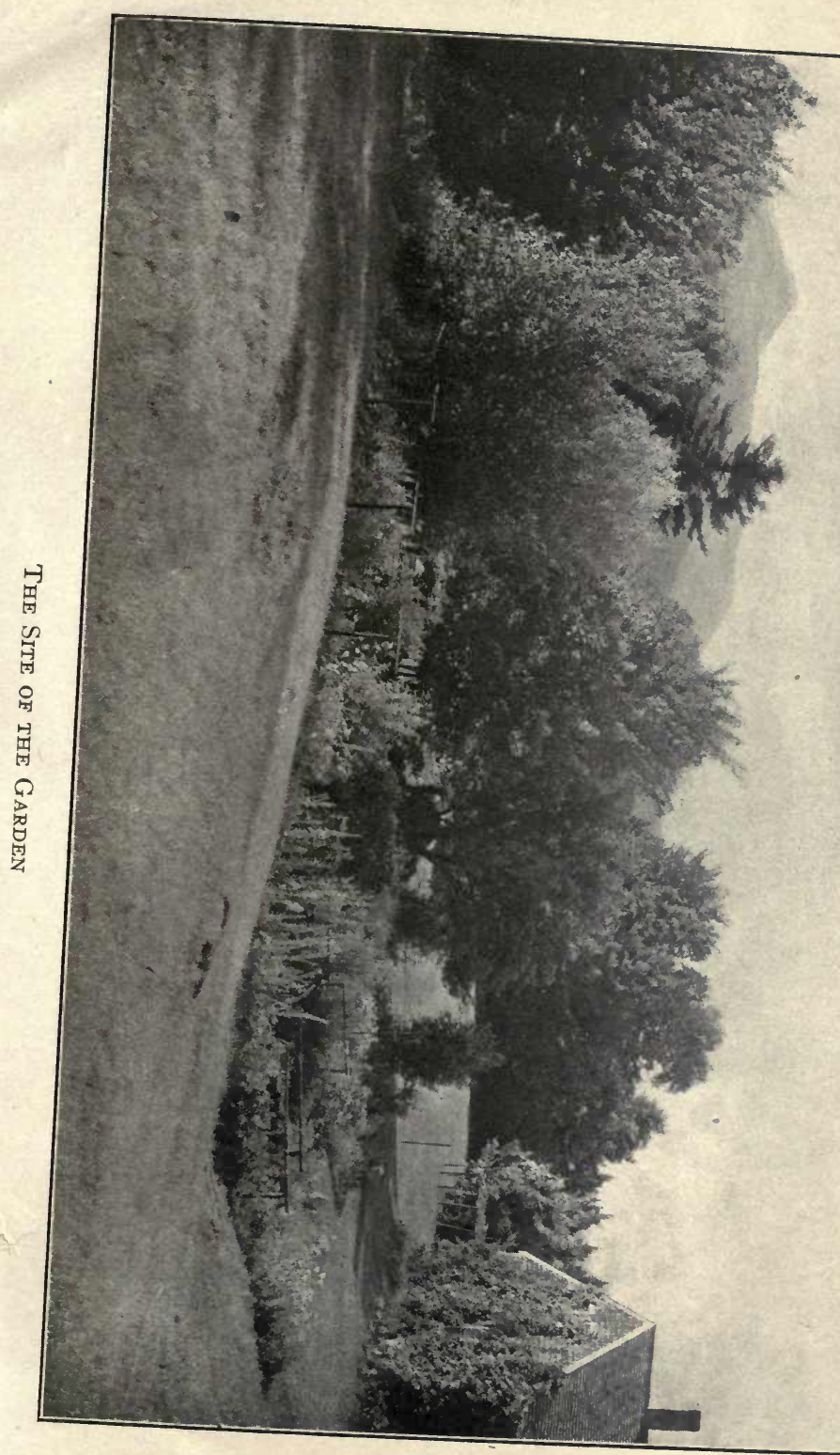





\section{American Sature series}

Group IV. Working with Nature

\section{HARDY PLANTS FOR COTTAGE GARDENS}

BY

HELEN R. ALBEE

ILLUSTRATED FROM PHOTOGRAPHS

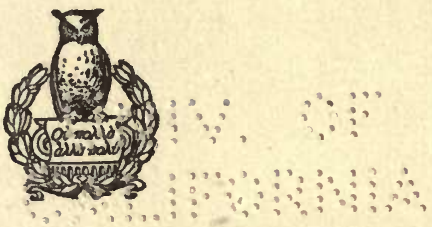

NEW YORK

HENRY HOLT AND COMPANY

Igro 


\section{CopXright, igio,}

BY

\section{HENRY HOLT AND COMPANY}
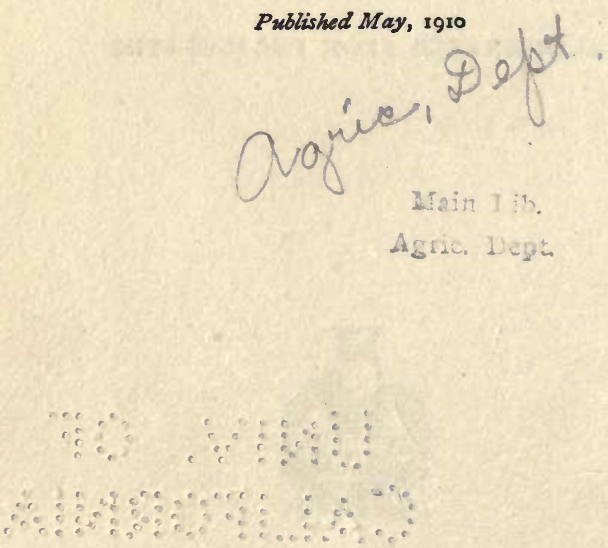


\section{CONTENTS}

IN IN THE BEGINNING • • • • • • • • • • • • • • • • I AN INCIPIENT GARDEN . . . . . . . . . . . . . . . II THE Garden Grows . . . . . . . . . . . . . . I8 My Ambition Grows . . . . . . . . . . . . . . 27 Within the Garden Walls . . . . . . . . . . . 40 Seeds . . . . . . . . . . . . . . . . . . . 49 A Descent into Particulars . . . . . . . . . . . . . 68 Propagation of Plants . . . . . . . . . . . . . . . 92 Vices of Plants . . . . . . . . . . . . . . . IO7

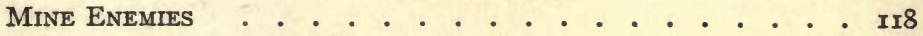
Photography of Flowers . . . . . . . . . . . . . I34 Some Gardeners I Have KnOWn . . . . . . . . . . . I45 A Dedication . . . . . . . . . . . . . . . . I59

Classmied Lists . . . . . . . . . . . . . . . . I6I White Flowers . . . . . . . . . . . . . I65 Blue Flowers . . . . . . . . . . . . . . . 2 I0 Yellow Flowers . . . . . . . . . . . . . 230 Pink Flowers . . . . . . . . . . . . . . . 247 Red Flowers . . . . . . . . . . . . . . 272 INDEX . . . . . . . . . . . . . . . 287

\section{0}





\section{ILLUSTRATIONS}

The Stte of the Garden . . . . . . . . . . . frontispiece Diagram of the Garden of Oblique Shadows. . . . . . . I The Well Curb . . . . . . . . . . . . . . . . 8 A DRy Bed In Early MAY . . . . . . . . . . . . . . 8 The DRY Bed IN JUlY . . . . . . . . . . . . . . . IO A Lilac Bush . . . . . . . . . . . . . . . . . 10 The Old Stone Wall and the Apple Tree* . . . . . . . I4 A Corner of the Stone Heap . . . . . . . . . . . . . i8 The Deeper You Dig, the More Rocks You Get Out . . . I8 Frame EDGINGS The Arbor Seat My Early Hollyhocks AN UNEXPECTED NoOK . The Product of Feminine Labor . . . . . . . . . . 29 A Chotce of Ways . . . . . . . . . . . . . . 30

A Garden Line Making for a Slope . . . . . . . . 30 A Double Terrace . . . . . . . . . . . . . . 32 A Blue and White Corner * . . . . . . . . . . . . . 34 A Cloud of Infant's Breath Gives Grace to the Garden . . 36 A Wave of Garden Heliotrope . . . . . . . . . . 36 The Garden Covored with Snow Presents a Smooth, Sloping,

UNBROKEN SURFACE . . . . . . . . . . . . 42 Snow Lies Late upon the Beds in Spring . . . . . . . 42 A Cornerstone of Happiness . . . . . . . . . . . . 44 A Big Stone and a Little Path . . . . . . . . . . . 44 Clematis Trained up as an Entrance Gate ... . . . . . . 46 White Physostegia Virginiana . . . . . . . . . . . ${ }_{4} 6$ A Tangle of Meadow-Rue, Wild Clematis and Hop Vine . . . 48 "That AWNING" . . . . . . . . . . . . . . . 48 Cheese Cloth Protection for Anndals . . . . . . . . 52 The Same Annual Bed in August . . . . . . . . . . 52 The New Nursery Bed Sheltered by a Wall and Tall PerenNials Planted Above IT . . . . . . . . . . 58

* Illustrations marked by an asterisk are from photographs by William Homes; all others are from photographs by the author. 
ShIrley Poppies . . . . . . . . . . . . . 58

WILd Carrot . . . . . . . . . . . . . . . 74

Japanese Clematis (Clematis paniculata) . . . . . . . 76

Virginia Creeper after Autumn Pruning . . . . . . . 76

A Terraced Driveway * . . . . . . . . . . . 78

Dianthus plumarius . . . . . . . . . . . . . 82

GoutweEd (Egopodium varigata) AS A Border Plant . . . . . 82

Low Border Plants Hide the Frame and Stone Edgings to the

BEDS . . . . . . . . . . . . . . . 84

AzURE Blue LARKSPUR . . . . . . . . . . . . . . 86

Lilac Pleony Poppies . . . . . . . . . . . . . . 86

Pink Canterbury Bells . . . . . . . . . . . . . . . 88

A September Rose, Mrs. John Laing . . . . . . . . .88

SYringa BUSH . . . . . . . . . . . . . . . . . 90

Bouncing Bet and Lilac Paony Poppies . . . . . . . . . 90

Value of Trees as a Background in Summer and a Windbreak

IN Winter* * . . . . . . . . . . . . . . . 92

The Landscape Toward the East as Seen from the Garden * 94 As SEen from My Window * . . . . . . . . . . . 96

A Heavy Blanket of Snow Falls Early and Disappears Late 98

A Bountiful Bed Full of Vigorous Peany Poppies . . . . 998

Golden Glow Against Gray Shingles . . . . . . . . I Io

Hydrangea paniculata. . . . . . . . . . . . . IIo

MEAdOW-RUE . . . . . . . . . . . . . . . 124

Hollyhocks Stripped of their Foliage because of RUST . . 124

A Hazy Day in October . . . . . . . . . . . . . . . I3 $_{3}$

The Dropping of Leaves Marks the Progress Nature Makes 138

A Curved Walk with Terraced Beds Cut Out of a Slope, Sug-

GESTEd By SHadows at Night . . . . . . . . . . $\mathrm{I}_{42}$

Portion of a Bed Set with Young Shrubs for Autumn Effects 142

Late September Annuals . . . . . . . . . . . . I48

White FoXgloves . . . . . . . . . . . . . . . . 148

White Flowers Recurring like a Chorus in a Continuous

MELODY

Wild White Daisies under Cultivation . . . . . . . I54

Tablet-"The Garden of Oblique Shadows" . . . . . . 160

Chrysanthemum Maximum . . . . . . . . . . . 186

Early Pink Cosmos Still Blooming in October . . . . . I86

ARctotis SOUth AFrican DAISY (Arctotis grandis) . . . . 200

Sweet Scabious and Dog-Fennel . . . . . . . . 200 

DIAGRAM

or

GARDEN OF OBLIQUE SHADOWS

TOP OF SLOPE

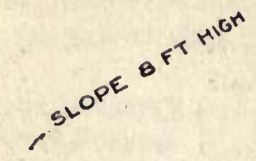

NURSERY BED

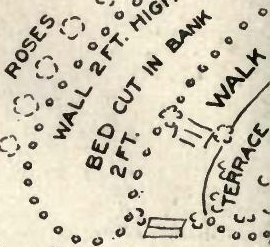

FALK

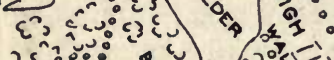

ए

e

$70^{2}=10$

2 FT. STONE WALL

BED 3FT. ABOVE LOW GROUND

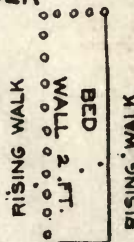

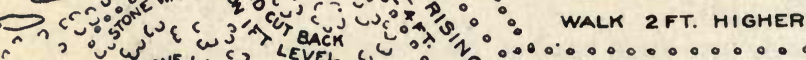

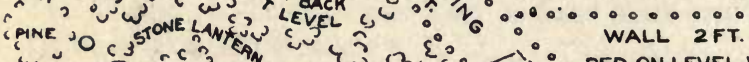

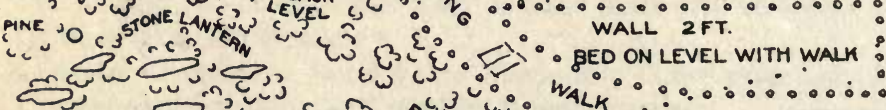

IFT. HIGH

POCK GARDEN

पूW GROUND

DOTTED LINES INDICATE RISING LAND

BANK ON EITHER SIDE 

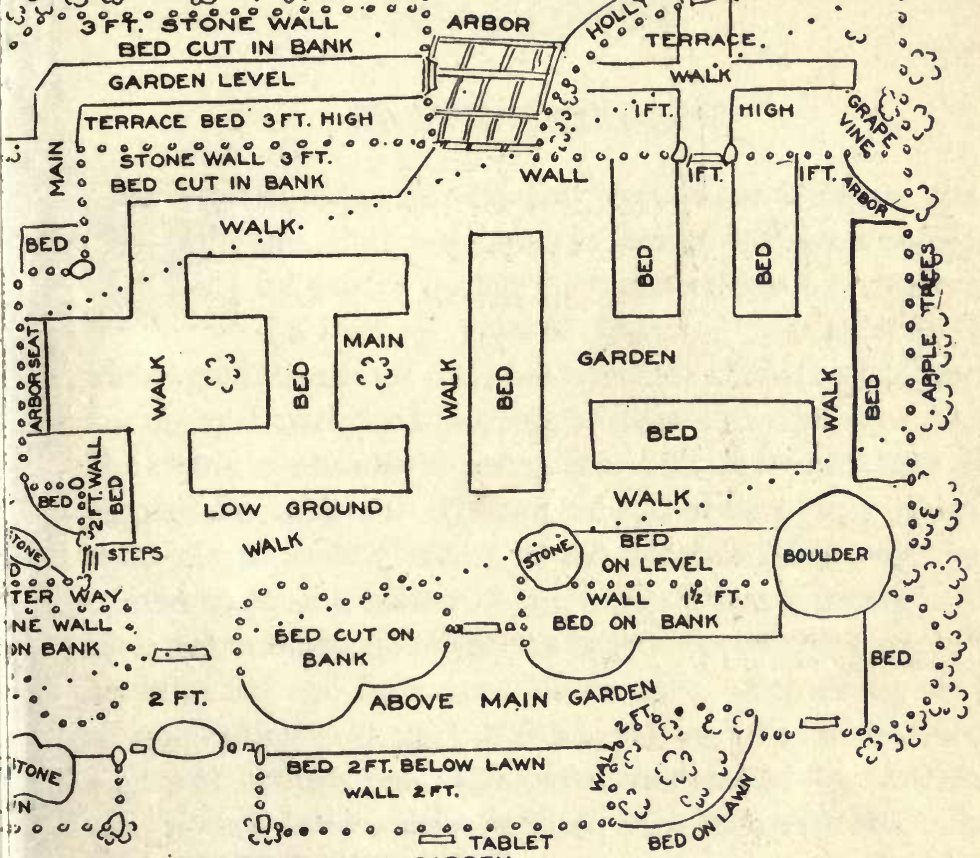

LAWN $4 F$ T. ABOVE MAIN GARDEN 


\section{HARDY PLANTS FOR COTTAGE GARDENS}

\section{IN THE BEGINNING}

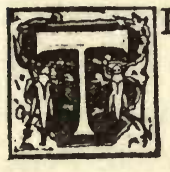

HE impression made by certain garden books upon the mind of a reader is that in America a successful garden springs from the soil much as Minerva did from the head of Jupiter. Opening wide his wicket gate the author discloses hundreds of rosebushes bending under a perfumed burden; he points to shrubs of giant height and multitudes of perennials, difficult to raise, that are perpetually in bloom. Though the author may touch blithely upon the possible disasters of the floral kingdom, they are treated more as a matter of tradition than as a present evil; his larkspurs show no blight, his hollyhocks are free from rust; his lilies fail not from mites or drought. Apparently all is smooth sailing from start to finish; yet we, who have dabbled a bit with Nature, read with mixed emotions as we recall seasons of despair over our own roses, lilies, larkspurs and hollyhocks; for these wayward inhabitants of our garden have had an unfortunate habit of contracting every known disease. Other unhappy memories of defeat and loss rise up and darken the page. Our humiliation is needless; for, in the flush of success, authors have thoughtlessly omitted any mention of mistakes.

The present volume is not an ambitious contribution to the subject of floriculture; it is a faithful record of the ignorance, repeated failures and disheartening losses that have attended 
my effort to assen ble in a limited area the choice varieties of hardy shrubs, perennials and annuals offered by our best nurserymen, and to arrange them so as to have a succession of bloom of pure color in each separate bed throughout the season. I am not so far removed from my mistakes as to have forgotten the way to final success. That my garden blooms and flourishes to-day is due wholly to indomitable perseverance and untiring energy; for I represented the average woman, who wants flowers but lacks knowledge and experience in their culture. The average woman seldom knows what she wants, and she has neither an unlimited purse nor a corps of trained assistants at her command. While she hopes to accomplish great things with the aid of her one man-of-all-work or perhaps none, she is bewildered by the array of scientific names in the catalogues, for the florists make no concessions to her ignorance by listing plants under their common names; so, after a brief and unsatisfactory survey of catalogues, she returns to her initial thought which has hovered about some familiar flowers, dear from association; or, perhaps, if of bolder spirit, something seen and admired in another's garden. Whatever the original impulse is, it results almost invariably in a few nasturtiums, marigolds, zinnias, or other easy, short cuts to a mass of color.

If successful with these indestructible plants, her enthusiasm grows and she reaches out cautiously toward larger operations; but with the best intentions at heart, there is much that an ardent purpose will not supply; it is not enough to know the botanical names of desirable plants-one must know their manner of growth, height, time of blooming, exact color, special requirements of soil and moisture, and a hundred et ceteras of vital importance. Such has been my experience and I know the bitterness of defeated hopes, and have seen summers culminate in failures due to my ignorance, 


\section{In the Beginning}

and realized that months must elapse before I could remedy the mistakes.

In fact my garden has been a natural growth of hardy constitution, else it could not have survived the shocks it has received. Planted in various latitudes, lying dormant years at a time, it has suffered every phase of misfortune and neglect, but has finally surmounted all difficulties and is now enjoying a beautiful resurrection.

It is impossible to state when or where the germ was first planted, but it must have germinated and have had a long tap root at an early age; for, when six years old, in a burst of enthusiasm, I declared one day, "When I grow up I mean to marry a gardener, then I shall have all the flowers I want, and I shall have morning glories running over the stovepipes." As our house was not rich in stovepipes-being heated by an unpoetic furnace-it was evident that my imagination had already begun to riot in unconventional freedom.

My florist propensities had scant opportunity in a city lot filled with a number of fruit trees, inconceivably big to young eyes. It is not a pleasure to recall my efforts to cultivate a narrow strip of ground that lay between a high brick wall and a six-foot board fence, unvisited by a ray of sunshine. I shall not linger upon those years when I tried to bring a bit of the woods into this north fern bed, where transplanted wild flowers scarcely survived a season. I used to walk up and down the narrow path looking wistfully for signs of my wild flowers which seldom came up. Yet this was a growing season for me; for unconsciously I learned the names and habits of the flora of southern Ohio, and my love of nature was expanding and thriving on starvation rations. Gradually I became acquainted with many cultivated flowers, known to me only through visits to greenhouses or in the gardens of neighbors having a southern exposure and no fruit trees. 
One thing I did not learn was, that you cannot trust to the tender mercy of Providence when planting; so for years and years I bought small packages of seeds, and in blind faith dug little holes in the ground, which I watered intermittently; and some of the holes came up-but most did not-and all was vanity. Nor do I think this experience of mine, futile and ignorant as it sounds, is rare among genuine lovers of flowers. They, as well as I, do not know how to go about it; and in consequence, we see our ambitious plans fruiting in puny reluctant plants that reflect our neglect as plainly as the protruding ribs of a starved horse proclaim the cruelty of its owner. Both are pitiful to see, and deep is my repentance over those past victims of misguided affection.

However, as I have said, through innumerable failures and guilty of a thousand floricides, I came to learn that a flower bed must be prepared, that seedlings must be protected from frost, sun and drought and too much water; that plants must be cared for and groomed daily, and that, if you do your part faithfully, your protégés will surpass in growth and bloom the most flattering promises of seed catalogues.

I shall never forget my first efforts to reform life-long errors. I had married and was living in the country with unlimited space and sunshine and ample leisure to gratify my love of flowers. During the first two summers I followed the old trick of tucking in a seed and bidding it God-speed-but nothing sped. Then it was that Adam, who chanced to be an illuminated edition of my early ideal-a gardener at heart, though not by profession-suggested that a flower bed should be prepared. I felt there was much hard-headed sense in his remark, yet inwardly resented it.

"I have prepared it," said I, with the bland innocence of a babe.

"How did you do it?" inquired he. 
"Oh," said I, "I dug it up, and made the earth light. What more do you have to do?" and I showed him where I had prodded the earth a little, perhaps three inches deep.

$\mathrm{He}$ did not answer, but smiled inscrutably. "I'll make the bed ready for you," he said; and then began such elaborate operations as I had never dreamed of.

It was around a huge boulder that the bed was to be made. First he took an axe-a very dull one, to be sure; but I began to see the varied and hitherto unsuspected uses of a whole row of axes which hung neatly upon the barn wall-and made a deep clean-cut line through the turf two feet distant from the boulder. Making cross cuts a foot apart, he lifted the squares of sod lightly with an implement called a spading fork, turned them over to beat the loose earth from the roots, which soil he assured me was too good to lose. Then he spaded the earth fifteen inches deep, picking out every stone, then brought a whole wheelbarrow load of well rotted manure, working it in thoroughly, and added a bucketful of wood ashes, mixing it with the soil.

I am ashamed to relate the amazement I felt at the great care he was taking. "Do you have to do this with all flower beds?" I asked with studied carelessness.

"If you want things to grow," answered he. Now if Adam had been any other man he would have seized the opportunity to instruct his wife on hermany dishonorable points of ignorance; but, because it was he, I was, allowed to chew the cud of reflection on past sins of omission and draw my own inferences from former failures.

When the bed was smoothed and raked, and the loose earth and stones removed from the grass, Adam stood off for the first time to view his work, which restraint I think shows masculine superiority. I have a fluttering way of stepping off at least ten times while doing anything, just to see how well it looks. 
I was very effusive in my praises; I realized what a valuable lesson I had learned in agriculture as well as in the neat workmanlike way a bed should be made.

The instruction was not lost. The next day I gathered all sorts of tools together, chose an axe from the unlabelled collection, and trundled them out on the lawn to make a bed for myself. Everything was stubborn from the insubordinate turf to the hard soil. Every time I put in my spading fork it struck against stones. It was very hard unaccustomed work, and I soon sat down to ponder the easy grace of the gardener's movements the day before. I worked a little more and then sat again, reflecting on the wisdom of the negro, who said, "De sun am so hot, de cotton am so dry, and dis yer nigger am so tired, I don' got a call ta preach."

At this moment Adam appeared, and everything went on velvet wheels. Faint from fatigue, I was thoroughly discouraged, and decided that if successful flower gardening involved such labor, I should never attempt to play with that graceful art. But my memory of fatigue is short-lived, and before many days I began another bed, and again faltered; and I noted that if I faltered at the critical moment when Adam hove in sight, I had an able assistant at my command. So by dint of a little work and the use of discretionary fatigue I got a tidy bit of arable land under cultivation that summer, and I learned to pluck at my tools quite handily. I had the usual commonplace assortment of flowers, tall and dwarf nasturtiums, the double and single African marigolds in lemon and orange colors; but they made a respectable showing.

Following the curve of the driveway, we had set out oldfashioned semi-double red Lancaster roses in a bed perhaps a hundred feet long, and I alternated the above-named annuals with the roses, so that there might be a succession of bloom after the roses had fallen. This also was successful, 


\section{In the Beginning}

and we might have gone on planting the common annuals and extending our nine beds to an indefinite number, had not the following year been one of great drought. I am not good at remembering figures, but the toil of that summer burnt in two numbers on my mind. For just thirty-five evenings Adam and I dragged fifty buckets of water from the well to irrigate our widely separated plantations. The rose bed, which was several hundred feet from the well, required nine buckets of water to give each struggler just a sip, on which we thought, considering the season and our heroic efforts, that out of common gratitude, the roses ought to have contrived to get along. But they did not even try. There is no coöperative spirit in flowers. They will not accommodate themselves to your necessity, and be thankful for half loaves when there is no bread. The only side-light of appreciation we got for our pains came from our old Irish cook, who remarked to me one day that "we made a pretty picture on the lawn," which was a great concession, considering she had to launder my draggled white frills and Adam's duck trousers. I tried to get what comfort I could from the æsthetic side of our never-ending labor, and when a trifle fagged, I would suggest to Adam, "that we group ourselves for Marcella's benefit."

Vainly did we empty the well on the parched earth; thrice did we plant some beds, nothing succeeded. At the end of the summer we came across the most tragical little growths. In clearing up a nasturtium bed, where aster seeds had also been planted, I discovered a single wee anomalous plant about three inches high, bearing a morsel of bloom less than half an inch across; and this rarity proved to be an aster. I also found morning glories with only two leaves, proudly bearing a miniature terminal flower on its four-inch vine. Poppies were mere threads of growth, with quarter inch flowers. Everything had peaked and pined. 
In consequence of this disastrous summer, I forebore further planting of annuals for two years, and allowed several beds to revert to grass, and filled the few we retained with shrubs and native perennial flowers that would take care of themselves. This ignominious compromise was bitter, for I did not realize that the value of those abandoned beds was not lost; that the discipline of heretofore unused muscles was a permanent possession, and that, in gradually hardening myself, outdoor exercise had become a pleasure and a necessity. A few flowers more or less were of no consequence compared with this definite gain. Only a single bed remains of that reconstructive era. It is one lying under the sitting room windows, with a hot dry southern exposure. Next to the house was planted a thick row of purple German iris which blooms in May. A discreet number of pink cinnamon roses are allowed to flourish at one end, and they bloom in June. In front of the iris is a row of Helen flower, Helenium autumnale superbum, which is nipped back when the plants are a foot high to induce a low bushy growth; and in front of this rich green background the yellow Rudbeckia alternated with white Chrysanthemum maximum make a gorgeous showing through July and August. By September these fade and are cut away and the Helen flower breaks into a mass of golden bloom, which is margined at the very edge of the bed by a low thick border of the native immortelles with gray cottony leaves and close heads of creamy white flowers. As a permanent background the cottage walls are completely covered with Virginia creeper, and when all else is gone, its flaming red foliage is more decorative than any flower. The only attention this bed requires is to dig in fresh compost in the spring, and an occasional division and resetting of the plants. The vine has to be pruned severely each autumn; but nothing has to be watered; and for this slight care 


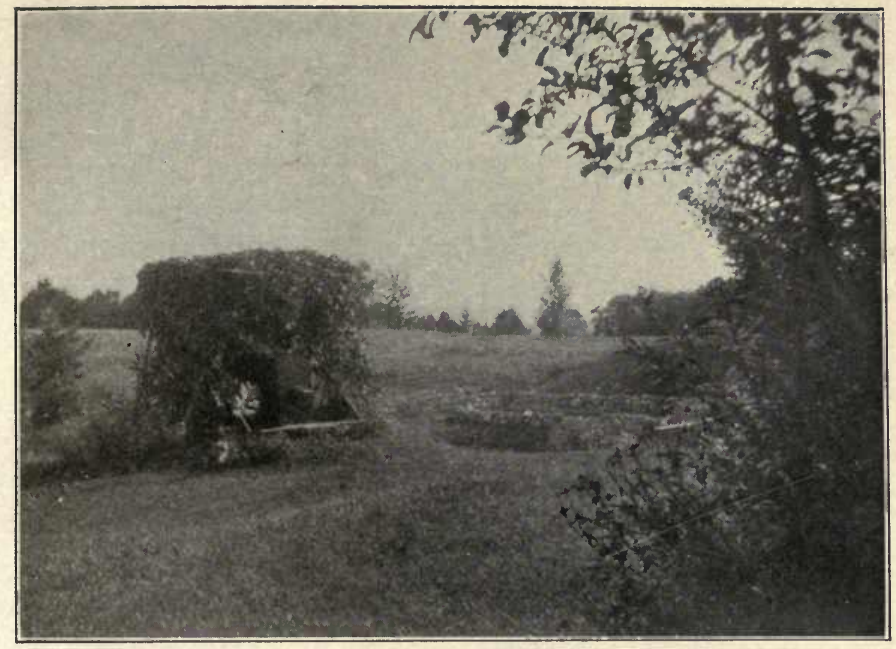

The Well Curb

[P. 7]

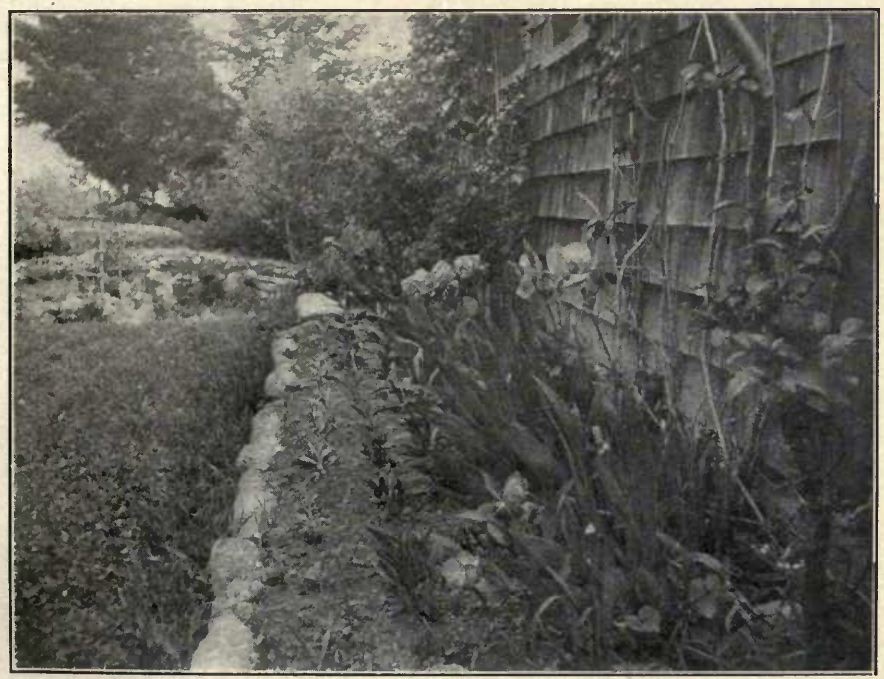

A Dry Bed in Early May

[P. 8] 


\section{In the Beginning}

we have a continual succession of brilliant color from May until October.

Later we set out another permanent bed equally accommodating, with white lilacs as a background, and filled it with hardy roses-rugosas, old-fashioned semi-double red roses, the pink cinnamon, the white and pink Scotch, and the common blush roses; and as a border to them were planted alternately sweet-william and purple iris. This gives a succession of bloom without a conflict of color, and beyond forking over the earth and dividing the plants as they increase, this bed takes care of itself; occasionally it is weeded and the grass edge must be cut out.

As a beginning in shrubbery we planted syringa, white and purple lilacs, snowball trees, Hydrangea paniculata, masses of cinnamon roses, and wild roses brought up from the sea coast, purple fringe, sumachs, young spruces and hemlocks, white locust, mountain laurel, shad bush and native rhododendron. By giving them deep mellow soil and a liberal mulching they need no attention in the way of water, unless the summer be exceptionally dry. Most of them spread from the root, and can either be allowed to grow in clumps, or divided and reset, to increase further. I like this way of enlarging one's stock; there is a patriarchal flavor in having young families grow up around the parent stock, in time to be set out as centers of other communities. By gradual separation and extension one can get beautiful masses without much labor or expense.

Meanwhile I had already begun to plant hollyhock seeds everywhere. I say begun, because it grew to be a habit, and when I had nothing else to do, I used to go out and drop a few seeds in a new spot. This was nothing more or less than atavism, for I had not entirely escaped my old desultory methods. Yet the results were good, owing to Adam's careful fertilizing, and before long I had quantities of young plants that were set 
out permanently to bloom the succeeding year; and they have continued to bloom ever since increasingly in geometric ratio. You cannot have too many hollyhocks, provided they are delicate pink and pure cardinal red in the single, semi-double and double varieties. Kind neighbors are only too glad to share the burden of caring for them, and an oversupply of any choice plant often leads to interesting exchanges. Before I had a real garden and a consequent enlargement of heart, I used to think the matter of exchange very small business. This doling out seeds or young plants and getting others in return was too much like dickering, and I frowned upon the whole proceeding. But there came a time when flowers bore a new aspect, and nothing now gives me greater pleasure than to have a friend present me with her favorite flower, which ever after is associated with her. The more things I have planted in this way, the dearer has my collection become; and to-day I go through my garden and tell over these offerings, linking them with affectionate thoughts of the givers, much as the pious nun tells off her beads to the various saints. More than this, when the gift has been bulbs or plants that require resetting, the bond is so strong that those who sent them seem to hover near and companion the hours devoted to planting the contributions of friendship.

But, as the too loquacious novelist of the last century used to say when he brought his froward pen to an abrupt pausethis is anticipating. 


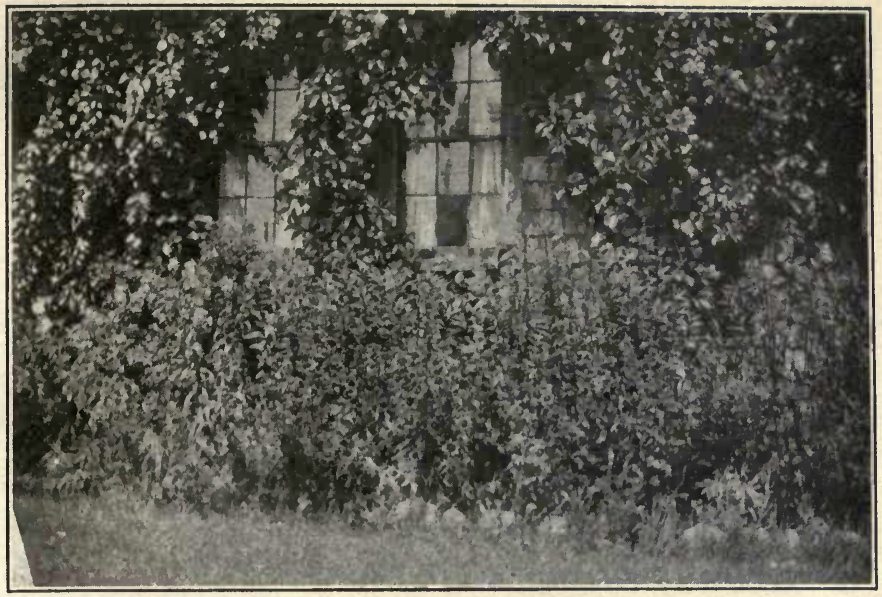

The Dry Bed in July

[P. 8]

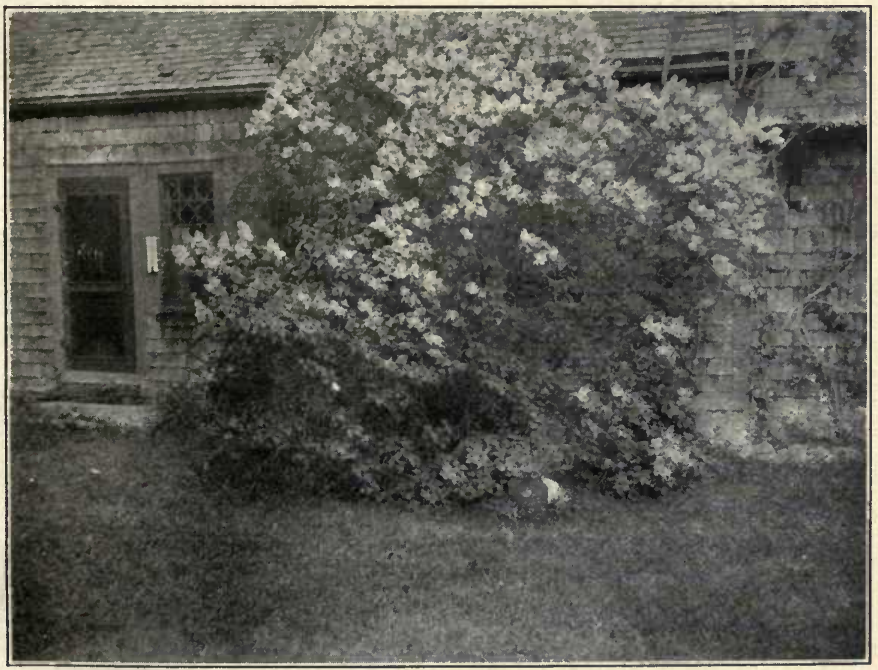

A Lilac Bush

[P. 9] 



\section{AN INCIPIENT GARDEN}

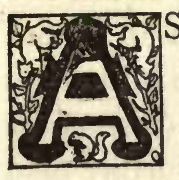

I have related, the indiscriminate spotting of the lawn with flower beds big, little, long, round and square continued during several seasons, and I look upon it as the Dark Ages, during which floriculture made no progress. I wearied of the narrow limitations imposed by a few shrubs. I hungered for flowers and color, though each new experience convinced me of the wisdom of confining myself to durable nasturtiums, marigolds, and ever more nasturtiums - they being the only flowers that survived the droughts that yearly doomed us. That single wizened aster decided me that asters were not for me, nor cosmos, poppies, cornflowers and many other hardridden favorites.

Then there came a pause in a peculiarly severe winter that housed us for months, that piled the snow almost to the tops of certain windows, a winter which cut one off from all past experiences and left him like a new-born babe, open to new influences. At first when the wind roared down the chimneys, and rattled our doors and windows, and made merry with drifting the snow still higher toward the eaves, I took refuge in the atlas. Thumbed were the pages bearing the maps of semi-tropical countries; worn were the margins where pink and yellow sun-kissed islands bask in turquoise seas. I was on intimate terms with a hundred sheltered nooks in many climes, and all open to a southern exposure. Adam confided to me that he hoped by another winter that we could go to the Equator where he meant to have a house right on the Line, 
with the front door opening to the north and the back door to the south of it.

It was at this juncture that several of those much-maligned seed catalogues came to Adam, who prudently buys his vegetable seeds during the month of February, before the spring rush comes. Idly turning over its pages, my eyes struck two familiar names-Ageratum and Agrostemma. In an instant I was carried back ten years, when, one summer, in Minnesota I undertook gardening on the alphabetical basis (just as the Peterkins were instructed in foods) and I got no further than the A's, so interesting was the initial letter of the alphabet. The A's always have the advantage, much as the first volumes of Grote's "History of Greece" show wear and fingermarks that entirely disappear when the twelfth volume is reached.

In that remote time I had read the A's with enthusiasm, and as none of the names was familiar, it is small wonder that my fancy was captivated with these words; "Ageratum-effective plants for bedding, covered with bloom throughout the season." Surely that was the plant for me! Hear also, "Agrostemma-Attractive, free-flowering perennials of easy culture and excellent for cutting." Attractive? It not only attracted, but caught me at first sight. I bought both, dug little graves for both, visited them at increasing intervals, as those do who are careless of their dead, and then quite forgot them. No, not quite; because for years after I used to speculate about their fate; had they come up? What did they look like? I had never found out. Now here was a chance for an intelligent settlement of that ten-year old question. I'd buy them, and watch. So I browsed on; not only the A's but every letter in the alphabet was rich in treasures. If the A's bloomed throughout the season, the B's were "an unrivaled strain saved from the best selected blooms of the finest hy- 


\section{An Incipient Garden}

brids;" the C's were characterized by "richness of color and profusion of flowers" - and so on with undiminished eloquence to $\mathrm{Z}$-Zinnia, where my intoxicated eyes caught "one of the finest plants ... commence to bloom in June and continue throughout the season ... require little care... any common garden soil ... prize strain ... unsurpassed." $\mathrm{Ah}$ ! here was a fulfilment of a life-long desire; here were quantities of lilies that toiled not, and nobody had to toil; no more fifty buckets of water at night; no more digging and manuring beds two feet deep; "any common soil" would do. Had I not the grower's word for it? and we had a hundred acres of just such soil needing zinnias to hide the poverty-stricken grass that grew in segregated clumps over our barren hill-top. What cared I for snow-drifts, for howling winds, and $20^{\circ}$ below zero weather? Airily I spent my days on the lawn (in my mind) gently plucking flowers that never grew less than two feet high and eight inches across. The sun shed only a soft genial warmth; the sky was always blue, except when it showered agreeably. I was in the gardener's Paradise, and had a gloriously happy time; and my lists grew.

One day, when looking out of the window, it occurred to me that, with so many prospective treasures, I ought to have a garden to plant them in. Surely a garden-not patches on the lawn; a garden where some day perhaps I could walk, and I resolved if that day ever came, I shouldn't go trailing long drabbly white garments about damp walks in the dreamy abstracted fashion of damsels such as artists have loved to paint; for my garden was going to be damp, perpetually damp, walks and all; it would have to be if it bore those eight-inch flowers. And thus did I go on planning the garden that Eve should make. Why not take the very spot before my eyes? Was it not sheltered on the north by a high stone wall and apple trees, that, at the proper moment, should form a pic- 


\section{4 \\ Hardy Plants for Cottage Gardens}

turesque background for-just what would be the correct foreground did not occur to me at that instant. Sub rosa let me confide that the foreground has been and continues to be a perplexing problem, for under the shade of the trees the tall pink hollyhocks, foxgloves and sweet williams planted there have a shifty method of drying up in a time of famine, though for two seasons they were beautiful, yet not quite coincident with apple blooms; so I have come to regard the old stone wall as a permanent background to the general garden, heightened by the green of the apple trees and the bed itself is little more than an experiment-station where I test the endurance of plants.

Further:-was there not a fine tangle of grape-vine that needed a reconstructing hand to weave it through the boughs for a natural arbor over a stone seat that could be built in the corner, and a dozen yards more of it used as a covering for the rustic fence to be made on the west side? Surely less charms than a stone wall, overhanging apple-trees, a grape-vine, a possible arbor and a stone seat-later found to be a great promoter of rheumatic joints, because it was so shady that it never got quite thawed out in summer-have decided more momentous questions than a garden site. In ten minutes I laid out more work than I accomplished in a whole year.

Immediately I set to work with a large sheet of paper in front of me for diagrams, my seed catalogues on the rightfor I had foreclosed and taken possession of all current and past issues of the seedsmen-seeds in packages piled up on my left, and doubly flanked on every side by seed lists-Corneliaand-her-jewels fashion. These same books, lists and packages became my intimate companions. The daily paper would be found under them; they strewed tables and chairs; they preëmpted couch and floor space. I arranged and rear- 


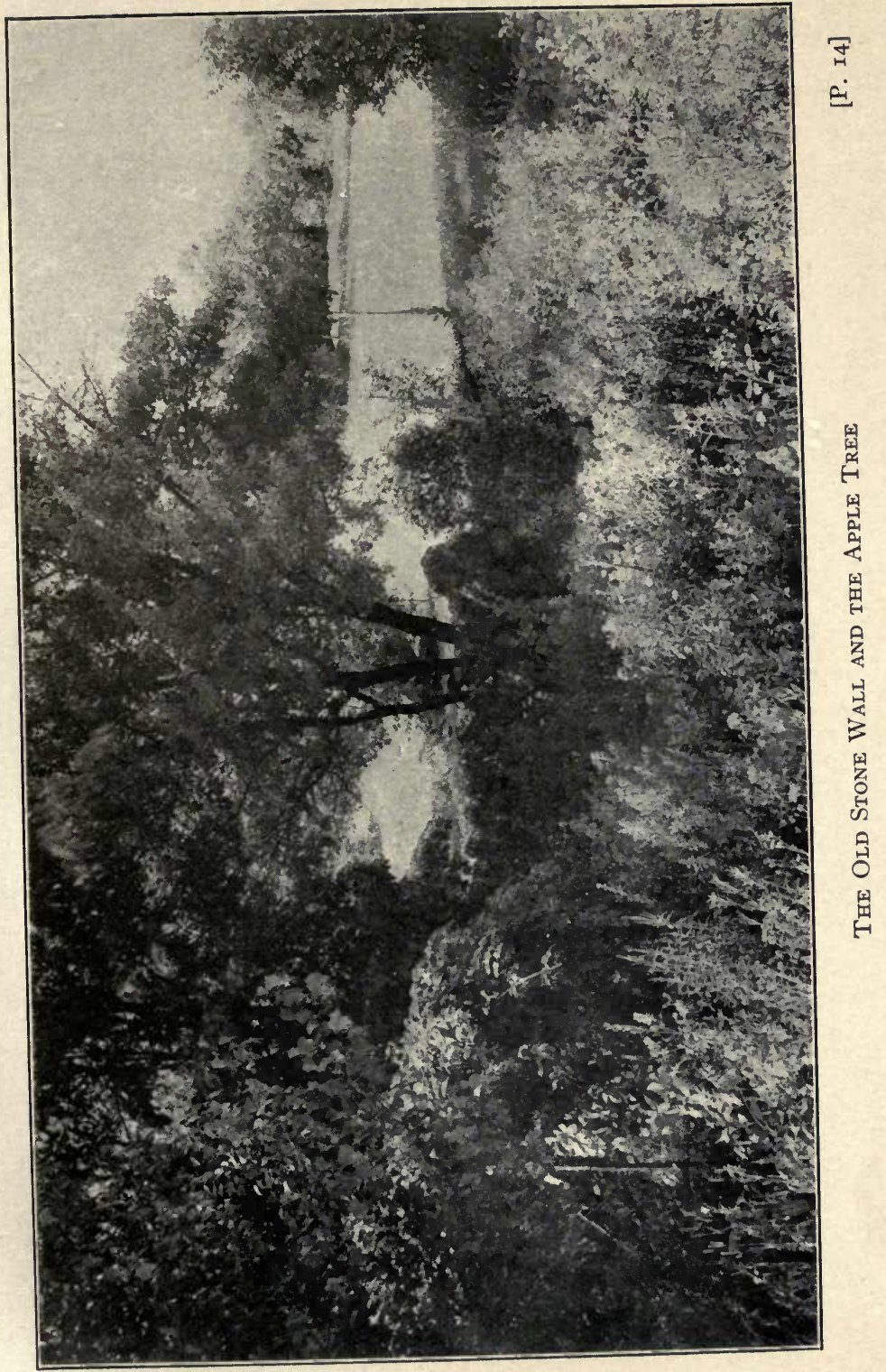



ranged the magical names upon diagrams until frequent erasures compelled fresh ones-and all the time I was learning a little about flowers.

Impatiently did I wait for the tardy coming of spring, and the subsidence of the snow was marked by Mount Ararat appearing in its usual place on a slope about fifty feet from the house. As the snow melted, I made a painful discovery. It was true that the spot I selected and diagramed at least twenty times had a protecting stone wall, also, apple-trees overhanging, also-a grape-vine-also it was not the smooth inviting hollow my fancy had pictured, but a dump heap for boulders and rocks, big and little, that had been unloaded there for years with a view to filling up the swale that lay between the two slopes, one of which fell away from the house, the other rising across this natural runway; also-countless wild blackberry and red raspberry bushes, hardhack and other tough shrubby growths that had become deep rooted among the rocks. This crescendo of difficulties lacked nothing to complete my discomfiture. When the snow lay five feet deep it was a smooth undulating stretch. How had I happened to forget these insuperable conditions? I grew lower in mind, but said nothing. One bright Sunday morning when the sun shone as all suns should shine on prospective gardens, I bade Adam go forth with me. I sat him down on the bank still soggy with the winter storms, and said, as collectedly as I could: "Well, what do you think of it?"

"Think," he repeated slowly, a way he has when he wants to gain time and is about to say something that he knows will be disagreeable to me.

"Yes," said I a trifle impatiently, recognizing how gently he was about to slay my pet plan, and anxious to have it over. "This is the spot I have chosen for the garden. What do you think of it?" 
"I don't think anything of it; it's impossible," said he. "Rocks-brambles, you can't make a garden out of them."

For a brief moment his denial shook my confidence; but a cherished hope is long-lived, and thrives amidst thorny obstacles.

"It is pretty discouraging," I urged, "but what of all my plans-my dreams-my charts? I can't give it up. Nowhere else is there a stone wall with a grape-vine and trees in happy propinquity."

Then he turned a full masculine gaze upon me. "You ought to have known there were rocks there and bushes; there are plenty of places, why choose the hardest possible spot on the farm?"

"Oh yes," pleaded I, "plenty of spots, but not garden spots. I don't want to go about digging any more holes in the ground at random. I want to decide on a place already selected by Nature as a favorable location, and build up where she has begun. The very size of these bushes proves the fertile conditions," I urged, laying desperate hold upon the most obvious impediment and bending it neatly to my argument. "This is the only suitable place on the entire farm. Besides, it is not only near the house and the well, but it has natural advantages and features," and I glibly enumerated them again, forgetting that for weeks I had talked of little else than of a certain stone wall, grape-vine and apple-tree.

He looked sceptically about him. "I've heard of them before, and if you like the idea of that grape-vine, and stone wall and apple-tree, why not enjoy them just as they are? why tangle them up with the garden question? My advice is, don't make yourself any unnecessary work; any place will do." Here he arose, and paused; "I'm sorry for your disappointment, but you must surely see for yourself that it is 


\section{An Incipient Garden}

wholly impossible. It's too damp to stay here any longer," and he strolled away.

Finding myself weakened under the force of his arguments, I chose another adviser-my pretty maid with golden brown hair and rose leaf cheeks, to whom I had daily confided my accumulating dreams.

"Mollie-come here-sit down," and down she sat obediently. "This is it," said I waving an authoritative hand in the direction of the tree and grape-vine, ignoring rocks and brambles. "This is IT. My good Adam says it is impossible; what do you think?"

She looked not at the difficulties, but like a true woman she spoke. "Do you want it?"

"I do," replied I fervently.

"Then I'd have it," quoth she.

And thus it came to pass that a certain well-beloved spot is bounded on the north by a stone wall and a background of trees, on the east by a rising slope upon which open my chamber windows, on the south by the full sunshine, and on the west by another rising slope beyond which stretch forest trees. Never was there a more favored nook, free from early and late frosts, moist from the depression made by the swale that runs between the banks, forming a natural waterway to carry off the winter snows, sheltered from the wind in every direction. ${ }^{1}$

1 See Frontispiece-The Site of the Garden. 


\section{THE GARDEN GROWS}

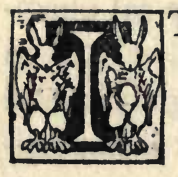

$T$ is one of the blessed compensations that we cannot recall pain once experienced, we cannot summon the fear that once paralyzed us. All our past is insulated by varying degrees of forgetfulness. Now, after eight years when I stand at the edge of my small world, it is difficult to recover the alternating moods of enthusiasm and despair, the high hopes of each new day and the utter fatigue and discouragement at night-when I attacked that stone heap. Be it remembered, however, that I had been housed most of the winter by five feet of snow on the level, that for months my feet had tingled to get out on the solid earth, and my hands, being normal hands, longed to pull and tug at something. Moreover, I was fired by a holy zeal; yet if this recital is to be wholly truthful, I must state, that, having gathered a crowbar, a hoe, a pickaxe, a grubbing hoe, a shovel, a sickle and a potato digger into a wheelbarrow, I paused with sinking heart when I wheeled my cargo to the stone heap. I felt the need of more tools!

I had decided to recover twenty-five feet square of the waste, and my original idea was to dig out the bushes from between the rocks, remove the larger rocks, levelling off the others, and then have several cartloads of good rich soil dumped on the twenty-five foot area, and mark out my beds.

My experience is that nothing affords such violent mental gymnastics as an original idea. It never works; yet one clings to it like a drowning man to a plank; and if you can conceive of the drowning man trying to nail a few more planks to his 


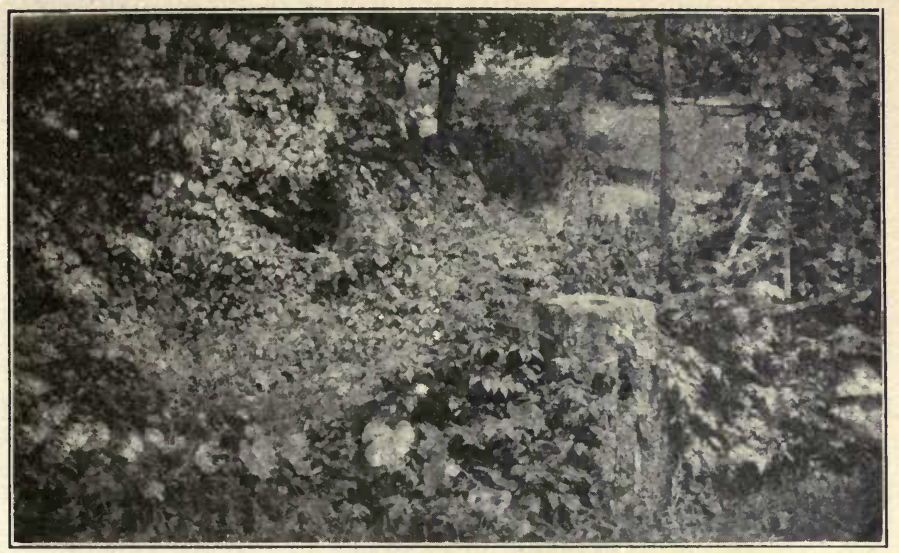

A Corner of the Stone Heap

[P. I5]

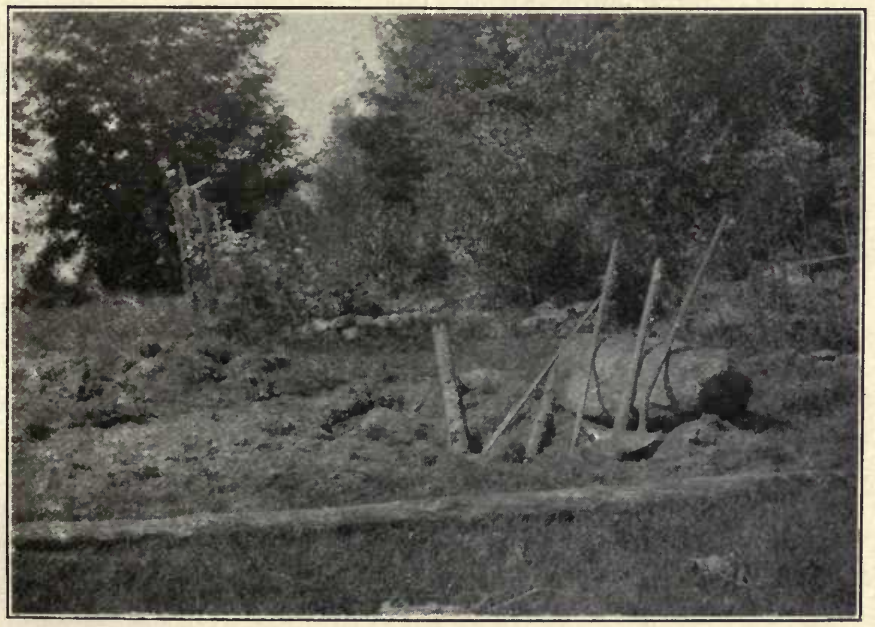

The Deeper You Dig, the More Rocks You Get Out [P. I9] 
slender hold on life, you have my position exactly. I hold on to an idea with a death grip, and by attaching to it all sorts of incongruous compromises, it materializes in a form never conceived; which proves that original ideas are vital organisms, and follow their own mode of development, and you meekly trail on behind. I used to think my failure with original ideas was due to an excess of imagination. I now believe it is due to gross ignorance of the laws that govern the mental world. This enterprise proved a shining example of the phœnix form such an idea takes from the ashes of one's plans.

For many years the rock heap had been the dumping ground for coarse rakings of manure and small stones from the flower beds, mulch from the vegetable garden, clippings of grass from the lawn and dead leaves. These had decayed and made a rich black compost. Hence, the tilling of a stone heap is a very different matter from tilling the average New Hampshire soil. In the former, the deeper you dig, and the more stones you get out, the more light rich earth you have; while in the ordinary soil the deeper you dig and the more rocks you get out, the bigger the hole left. I think I come close to the truth when I say our average land runs a bushel of rocks to a pint of earth; and as for the quality of the earth, the less said, the better it is for the reputation of New Hampshire farms. Let it be understood that I am generalizing from a single example, which is said to be the prerogative of genius. When conversation flags in our household, I can always radiate a genial heat by introducing casually the topic of the native soil. Adam rises to it like a fish to a fly, and one would think we were Government experts, the way we fling our statistics. In his loyalty he declares New Hampshire raises more corn to the acre than any State in the Union. This is met with scorn; the great Western States are cited; but Adam utterly disclaims the possibility of a yield of a hundred bushels 
to the acre, nor seventy, no, nor forty; perhaps twenty-five would represent the actual figures. Somehow this conversation, oft repeated with interesting variations, reminds me of Lot pleading with the Almighty for the salvation of Sodom, and the numerical results closely resemble each other. I like Adam's sincere defense of a lost cause; it is a strong guarantee of domestic fidelity, even if he does call me Miss Ipse Dixit before we get through. If it were not for the rocks and native soil and a yearly drought thrown in for good measure, a gardener could loaf most of the time in this region.

The first few days proved I was still an amateur. I would dig out a bush here, heave a rock there, shy little stones toward a deep unfilled hole in the corner until my hands were worn down to the quick; but of good honest systematic work there was none. I very much needed a boss; but Adam had evidently decided not to interfere with my education; and he also knew, that, when possessed with an idea, I am apt to grow a little heady. So he wisely absented himself, though I knew he was always within hailing distance in his own garden, and was only waiting to be summoned. The deep deposit of black soil found between the rocks was like striking a vein of metal, and I speedily decided that life was not long enough to dig over the entire area; that I had better abandon the plan of covering the stones with earth, that it was easier to lay out the beds at once and confine mining operations within their limits. From necessity I had to reinforce my deepening shafts by enclosing them with strong wooden frames, and this is how it happens that my beds are bounded by box (?) edgings-an ugly device, but cheaper than brick. Within these enclosures I dug down about eighteen inches and after the stones were removed, I had perhaps eight to ten inches of mellow black earth. The beds were then filled to the top of the board edgings with a mixture of the top soil of Adam's vegetable gar- 


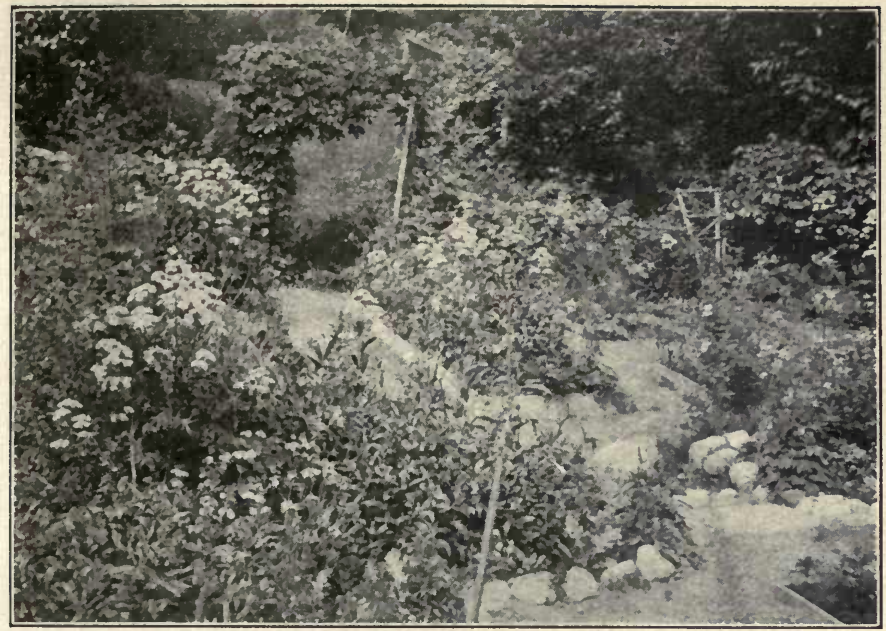

Frame Edgings

[P. 20]

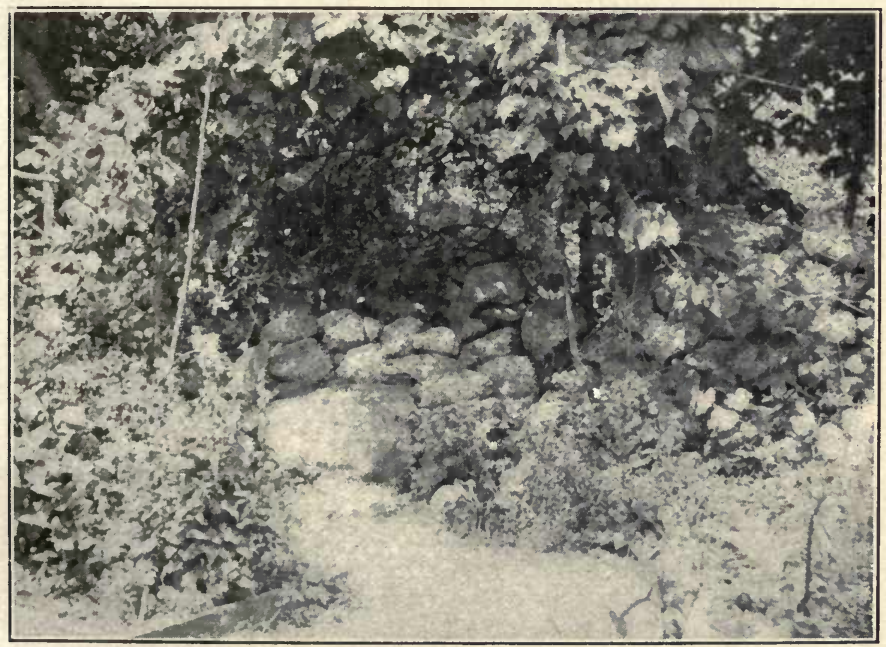

The Arbor Seat

[P. 2I] 
den-some of it being coaxed, and some quietly appropriated-wood ashes, leaf mold from the woods, sand and manure. I had a man place the larger boulders in the corner, where the long-talked-of seat was made, and the smaller ones I laid up in a low wall on two sides. This was another compromise with the original idea. I had intended to have the stones hauled away-just where was not clear, but somewhere. But this use of them as boundary walls proved a much easier solution; and from this first makeshift disposition of the stones came the later construction of the garden walls, which are not only one of the chief beauties of the garden but have proved to be of the greatest value to me. Of these walls I shall speak more at length later. A rustic fence on two sides was made from young spruces from our woods, the vine was woven through the boughs of trees into an arbor over the stone seat, and finally everything was in readiness for planting my seeds. Measured by the labor expended on bushes, boulders, the rustic fence and preparing the compost, the twenty-fivefoot garden was enormous; but when enclosed by walls on three sides, it shrank to the size of a postage-stamp. I consoled myself with the thought that everything is dwarfed when measured by Nature's yardstick. Her areas are so vast that the ground plans for the most spacious house become astonishingly small when staked out.

When I came to follow the diagrams made for sowing seeds, I saw that too many things had been crowded into a small space, and though the plans were followed in a way, I happened upon a much safer method of distribution, that I still use, which is to scatter the packages of seed over the allotted ground, and when the bed is thus apportioned, one can better judge how much space should be given to each variety.

I planted five and twenty varieties of seeds, but recall only a few of them, and these are remembered chiefly for their mis- 
conduct. The evil that we do lives after us. The early cosmos quoted as three feet high was given the whole length down the middle of a bed; but in my virgin soil it grew over five feet, and when a long rainy season occurred while it was in full flower, it leaned over and completely blocked one of my paths; and I let it do so, because I did not know any better. I never thought of stakes in those days. The pentstemon, a gift, grew lustily, and when September arrived with no visible bloom I thought it wise to look up its credentials, and found that while it was very desirable, it was a tender perennial. As I knew nothing of shielding delicate constitutions from our northern severities, its place knew it no more after that first summer of green promise. I had been attracted by the high praise given to the Nicotiana affinis, and I planted a whole paper of seeds, watered and watched them advance from their first seed leaves. Occasionally I questioned why the nicotiana appeared all over the plot, but thought it was due to the scattering of seeds by the birds, that sat daily on my rustic fence to fly down during my absence and nip off the heads of the blue annual larkspur. This was a vague inference about the cause of the decapitated heads that were found on the ground until the cosmos grew over the walk like the leaning tower of Pisa, and further access to the larkspur was cut off. So I went on in bland ignorance, and fingered the woolly leaves of my nicotiana, and by September I began to wonder why there was no bloom.

One day I had a visitor, a young woman of prompt and ready action, who had made a special study of botany. She looked patronizingly on my bit of cultivated rock heap with its fading beauty, while I apologetically set forth my plans for an extension another year. She suddenly made a dive and plucked out one of my nicotianas and tossed it aside.

"Why what are you doing?" cried I in dismay. 
"You don't want these weeds in your garden; why here's another-they are all over the place."

"Yes," said I proudly, "those are my nicotianas; they are doing well, but for some reason they won't bloom."

The Botany girl laughed. "Nicotiana! mullein!-and you have been tenderly growing mulleins all summer?" and she tore out another handful with deadly precision.

I respected her knowledge, for she had just received her degree, yet I was distressed and unconvinced. "Are you sure? do you know nicotiana?" I questioned, pointing to the label clearly bearing the name of the row.

"You had better ask if you know mullein," and she laughed again, and tweaked out the last vestige of my woolly plants.

She was right, and to this day, not quite certain of the difference, I grow a certain number of mulleins in the fond belief that they are nicotiana, in spite of the fact that the first mullein leaves, before the tiny inner ones begin to show, are slightly crenate or scalloped at the edges, while nicotiana has an entire edge and much smoother leaf; otherwise I still hold they resemble each other quite needlessly. The delightful fragrance of the latter and its beautiful flowers are somewhat offset by their being closed through the day, except in very dull weather, and the plant is infested by the potato-bug. I had an abundance of delicious wall flower, ten weeks stock and pansies. Everything flourished-plants, cutworms, grubs, moles, but of these I sing later. The hollyhock seeds planted along one side by the rustic fence made a famous growth. They sent down deep roots among the rocks below and bloomed vigorously the second year.

Each year yields a moment of pure joy. The first occurred when a friend stepped down into my small domain to view things. He sniffed delightedly.

"What is it that smells so good? It is delicious," and he 
stooped over the stock. "No, it is not that," and he smelt of the wallflower. "No, what is it? It recalls to me the delightful memories of childhood."

Now there is no more delicate compliment that a man can pay a woman than to tell her that something she has or does restores that happy time. I fairly bristled with pride.

He hovered an instant over the mignonette, sweet peas, white petunias and pansies, no-it was none of these, nor boy love nor sweet alyssum. Then he picked up a rosy-cheeked apple, one of the many that clutter up my walks each summer-a phase not included in my inventory of charms when deciding on the site of the garden. "Ah, this is a part of it," he exclaimed softly. Then he stood up and turning slowly around he tried to concentrate all his senses in his nose. The fragrance was penetrating and sweet. "It is the garden!" said he at last, and he was so pleased with the solution that I almost expected that he would tell me that I reminded him of his mother.

The next climax of satisfaction came during the second year of my campaign. I was making an extension, which meant that a slope rising both ways had to be dug out, and the earth redistributed. That is the most that men ever do: they never actually make anything. They dig out a bit here, and fill up there; they cart matter from one place to another, but they neither add to nor substract a jot from the original substance of creation.

I was in the act of redistributing, and I did not know that Adam had been watching the manful way I clove the bank with my pickaxe, and then tossed brimming shovelfuls of earth into the wheelbarrow, thoroughly enjoying the exercise of my strength.

"Haven't you an Irish ancestor somewhere in your family? You dig like a Paddy." 


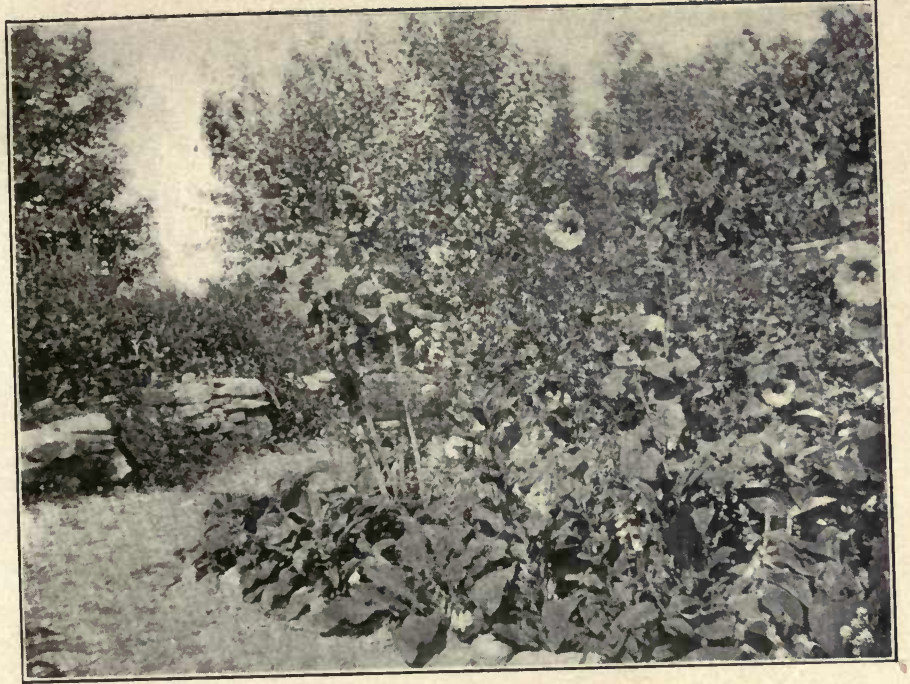

My EARLy Hollyhocks

[P. 23]

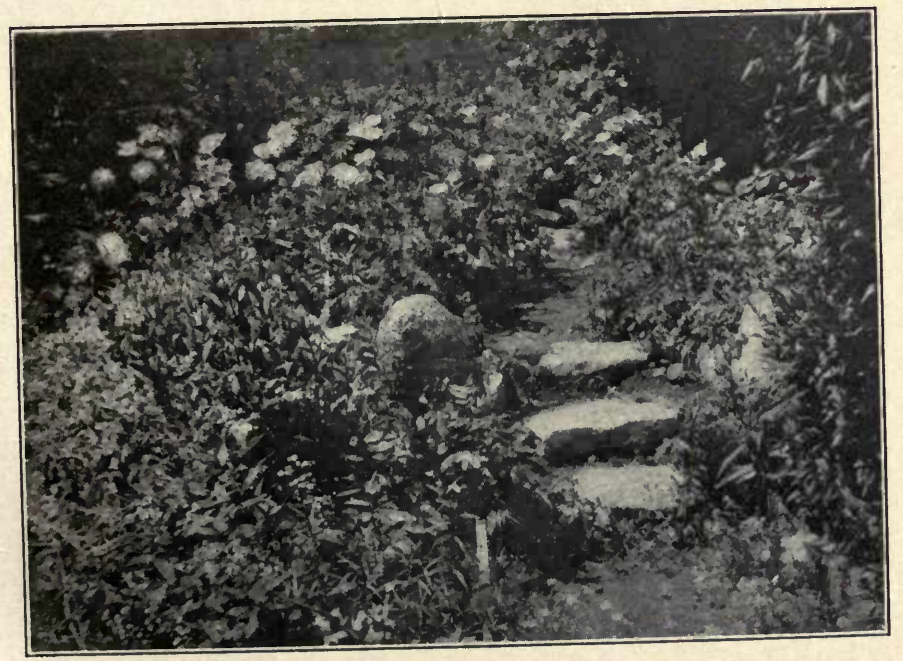

AN UneXpected NoOK

[P. 25] 

Never has praise from any lips so rejoiced my heart as this unexpected tribute.

The third moment came two years later when a very skilful amateur gardener made me an afternoon visit. We talked intelligibly without the need of an interpreter. She knew candytuft and Dianthus without being told; also spoke understandingly of the deeper mysteries of Physostegia, Stokesia, Boltonia, Euphorbia corrolata, things representing the higher education in a garden.

By and by she slipped away from my side, and while I was prattling on with an ordinary denizen of this lower world, she threaded her way through the paths from terrace to terrace.

"How delightful your garden is," said she on her return. "You can really walk in it, and how many charming, unexpected nooks and corners you have!"

Sweet is the praise of a friend. Had I not cherished in my heart for years this privilege of walking in my garden? not merely stepping down into it and out again, and seeing the whole at a glance as I did the first year, but take a leisurely stroll from bed to bed, from one elevation to another, and choose which way one should go. Her words touched the tenderest depth of my aspiration.

I was much impressed that first summer with the total lack of dignified reserve that exists in the floral world. The riotous way that self-respecting flowers, with centuries of cultivated ancestry behind them, hobnobbed over the rustic fence, was a scandal. The raspberry bushes, still left in the unclaimed territory, leaned over the wall and dallied with the cosmos. The climbing nasturtiums, which were supposed to make a decorous barrier between the sheep and goats, lost their reserve and got into many disgraceful entanglements with the tramps outside. The bindweed and wild buckwheat vines found ready admission to the select society of African 
marigolds and stock, and established the most intimate relations. Both inside and outside my walls was a spirit of jovial fellowship. But the most immoral thing in the garden was a hop vine, perfectly incapable of self-support, ready to attach itself to any object. I found it one day twining like a boa constrictor around a tall grass stalk. Such shameful dependence upon any frail support at hand will, ultimately and inevitably, lead hop vines, when they reach the human stage, to look to their wives for maintenance.

I fostered an unnecessary grief that first summer. I was so happy in the plenitude of bloom, that I was ready to order mourning in advance of the sad day when the frost should destroy the beauty. Gentle melancholy darkened many an August day with the anticipated sorrow. But Nature has a kind way of alleviating many of our griefs. Before the frosts came, almost all my annuals-I had little else that summerhad run their race and wore a frowsy, jaded look, and I was thankful when, at last, a sharp frost added the finishing stroke, so that, with a clear conscience, I could tear up the withered stalks and throw them over the wall to make a deeper compost among the rocks outside. The need of removing each plant as it faded had never occurred to me, for most of the garden faculties of my mind were still dormant. 


\section{MY AMBITION GROWS}

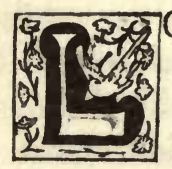

ONG before the first summer was over I felt the need of more room. The twenty-five-foot area was but a narrow chrysalis shell, and I determined to spread my wings another season. Then, too, I did not like the things that went on in that impenetrable jungle outside the walls. Almost any hour of the day one could hear strange noises within its depths, rustling sounds, fugitive glimpses of snakes, chipmunks and red squirrels. In October I cleared a new piece about twenty-five feet by forty of rocks and bushes, and looked upon the daily exercise as an outdoor game rather than work. I had learned to use my tools more intelligently; the shovel more often replaced my threadbare hands in removing earth; occasionally I remembered to put on gloves.

It has been my privilege recently to read how a lady conducts herself in a garden, and I now see how I have defied every convention in the matter of garden etiquette. The book must have been written at a time when damsels were addicted to tight lacing and swoons, for the author apologizes gracefully for the lady who wants to garden, and her advice is obviously to give courage to a feeble sisterhood.

"It must be confessed," writes my English authority, "that digging appears, at first sight, a very laborious employment, and one peculiarly unfitted to small and delicately formed hands and feet;" and then, after a careful explanation of the way mere man performs the operation, she continues; " $\mathbf{A}$ lady with a small light spade, may, by repeatedly digging over 
the same line, and taking out only a little earth at a time, succeed in doing with her own hands all the digging that can be required in a small garden, the soil of which, if it has been in long cultivation, can never be very hard or very difficult to penetrate; and she will not only have the satisfaction of seeing the garden created, as it were, by the labor of her own hands, but she will find her health and spirits wonderfully improved by the exercise, and by the reviving smell of the fresh earth." Was ever hard labor so delicately sugar-coated? with all my errors of judgment I never took a homeopathic view of the relation between earth and tools.

I feel like a hoyden when I recall my energetic efforts, the farm shovel, the pickax, the thirty-five-pound crowbar. I have no extenuating "as it weres" in my record. It is a clear and undeniable charge upon my past that I did actually create my garden from a stone heap-not from "land under long cultivation." I am a barbaric Amazon; but what can be expected of one with a probable Irish ancestor except a wild outbreak of rude strength in unguarded moments, when wrestling with virgin soil.

Further: the lady's proper weapon is a spade "smooth, sufficiently slender for a lady's hand to grasp, of close elastic wood," only "tolerably strong"-evidently no lady is expected to expend her precious strength, provided she has any, on garden operations- "one that shall penetrate the ground with the least possible trouble." Still further: "A lady should have a pair of stiff leathern gloves or gauntlets to protect her hands not only from the handle of her spade, but from stones, weeds, et ceter $a$ which she may turn over with the earth, and which ought to be picked out and thrown into a small light wheelbarrow which may be easily moved from place to place."

Surely this picture of sweetness and light quite shames me. This is the way true femininity conducts itself in the presence 
of rocks, soil and weeds; and as a guarantee that this is a real, and not a fancy sketch, the lady's hand, that makes but a pleasant mockery of toil, is pictured gently extended, clothed to the elbow with her stout leathern gauntlet-as I recall mine, they were mostly either in the barn or sunning themselves on a distant rock-and in her hand is something that looks like a composite growth of all the garden, thus proving that feminine labor lightly pursued is productive. And the Lady's wheelbarrow, duly portrayed on the next page, is the triggest, nattiest little toy ever offered for sale. Then the author tells you the

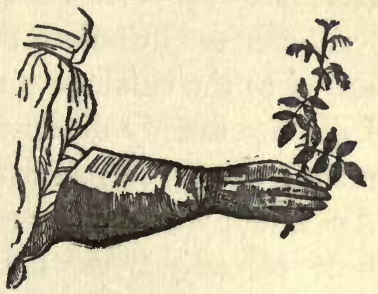
angle at which to thrust in your spade, how to use your strength, how to raise the earth on the spade-all of which she says "may be done with ease." She evidently measures the human chain by its weakest link, and after saying that "so few ladies are strong enough to throw earth from a heap," she tells how the feeble can make a profitable compromise, and achieve the same results by a strategic use of her tools. I do not know what would have happened if I had used these dainty super-refined methods. It took brawn and pluck and plenty of it to prepare my land. In vain do I scan my authority for some hints regarding how a lady should act when she strikes among the et ceteras a rock several feet across, or finds her garden line escaping from the "soil under long cultivation" and making straight for a slope that has not been tilled since the nebular period of our globe. What sort of a compromise shall she make with her shovel so that the increasing pile of earth, dug out of an ever rising and extending bank, shall deposit itself on the further side of a terrace wall; and is the lady's wall to be made by sundry stones 
evaporating from the general heap and wafting themselves into place? The voice of the silent past answers not, and I am forced to the conclusion that no lady would attempt such a project, or she, who does undertake it, cannot be of gentle rearing. These doubtful imputations do not trouble me much, even though the garden I possess is mine solely through the conquest of just such impossible conditions.

Winter set in before the work was done, and again I resorted to the catalogues and botanies as my chief literature. I did not exactly distrust the glowing accounts of the seedsmen: I wanted corroboration; and when I found the impartial Asa Gray, who seldom raises his scientific admiration to the heat of adjectives, quoting any plant as "handsome," "showy," or "cultivated in choice gardens," immediately that gem went on my list. Neglected was the atlas; warm sun-kissed islands had no attraction; the foot-rule, blank sheets of paper, spread out on a lapboard, a rapidly decreasing eraser, gave full occupation until January, when I sent off for fifty varieties of annual and perennial seeds. I prudently limited myself to those not costing more than ten cents per package. I bought also two hundred Neponset paper flower pots, that come in all sizes, and take the place of the more perishable earthen pots at one third their price. Each acts as a guardian angel to the seedling raised in it; for, in transplanting, the pot may be turned over a plant to shield it from the sun, and it also gives protection from any untoward frost that may descend at unpredicted moments. Under its benign shade a plant endures transplanting as comfortably beneath a hot July sun as if it were a cloudy May morning.

I had brought in a quantity of rich mellow soil-it should have had more sand in it, as rich earth often causes young seedlings to "damp off," that is, to drop over and die suddenly, when kept too moist-many little stones to put in the 


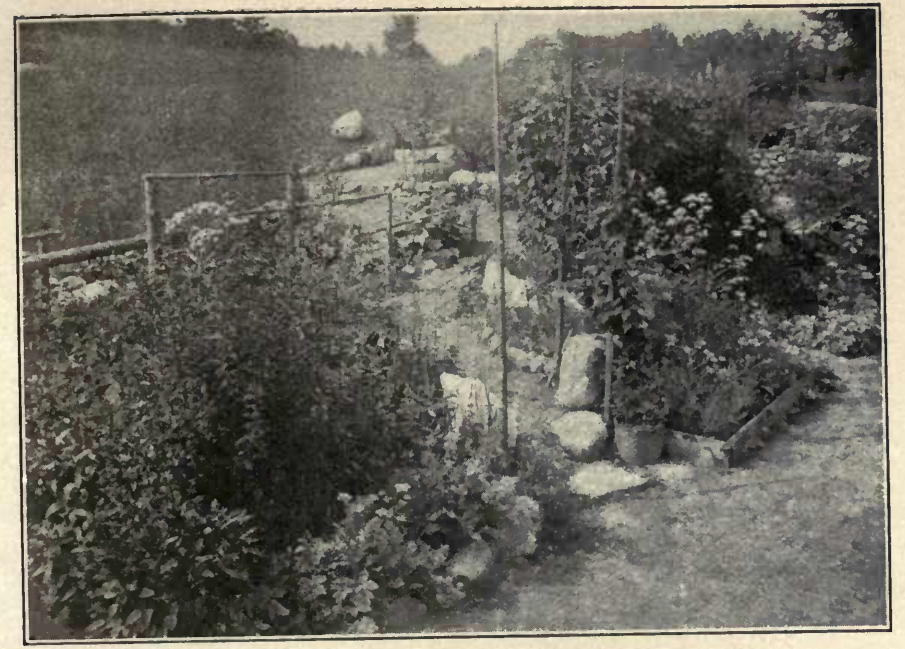

A Choice of Ways [P. 25]

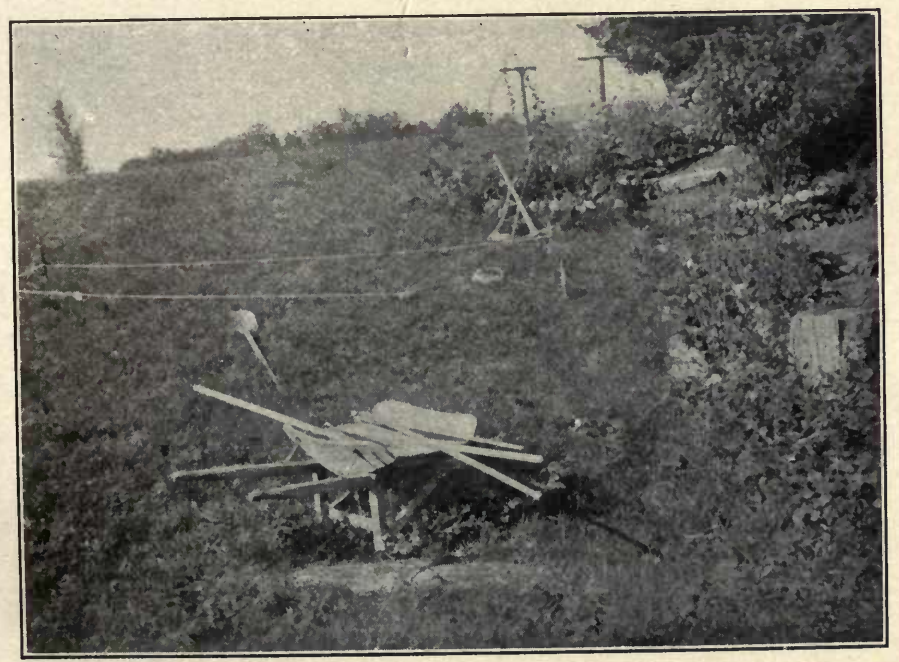

A Garden Line Making for a Slope

[P. 29] 

bottom of the pots for drainage, and one bright Sunday morning at the dark of the moon (to obey the almanac) I began the holy work of planting some of the seeds. Later I planted others at intervals of a week apart, writing the name and date of planting on each pot. Every sunny window and warm corner in the house was laid under contribution to my purposes. My forcing-house was a long mantle shelf over a wood stove, which was kept at temperate heat day and night. When the first seed leaves appeared, the pot containing the new-born was placed in the sun in a contrivance made by fitting a shallow frame into the lower casing of a window, with cleats nailed across the ends from six to nine inches apart, and narrow shelves four inches wide were set on the cleats. When three pairs of leaves appeared, each seedling was transplanted into a separate pot and placed in the cool shade on the top of a low bookcase which served as a cold frame. By the time the seedlings had recovered entirely they were ready for the fourth stage, which was to take them into a sunny chamber upstairs with a south exposure, but no fire, where an even temperature of about $60^{\circ}$ was maintained. As I had no appliances, I used anything at hand; and when a large table became too full, I took out the shallow drawers of an old-fashioned bureau and filled them with my pots, resting one end of a drawer on the window-sill, the other on the edge of the table, and in this way increased my area of possible sunshine three or four times. This last stage of hardening is imperative; for if seedlings are kept long in a warm living-room they grow spindling and very tender and are quite unprepared for the changeable weather and high winds of our Northern spring.

By. May I had several hundred plants, and the chamber had an attenuated smell of a real greenhouse. While this method of propagation gave me a good start, I have never tried it since. In the first place it is an enormous care, and 
very little is gained by an early start. I had to dig the little things up with my eyes during February and March; but when the vital force of spring really begins, nothing can resist it. It stirs the heart of the onion buried in the depth of the cellar, and the potato from the black depths of its barrel reaches out in response; and until this force operates, nothing speeds as it should. I found, too, that asters planted in February indoors were but a trifle larger toward the end of May than those grown from seed planted in the open the last of April; and further: when a most unexpected and unheard of frost befell us toward the end of May, the asters grown in the open were untouched, while the tender house-bred ones were killed almost without exception. I have worked out a better and much easier plan for growing annuals, which I will give in its proper place under Seeds.

While these green things were cheering my heart indoors, I made careful diagrams for the dimensions and arrangements of beds in the new section. The frost was not yet out of the ground when I began afresh on the work outside, and each morning before the sun got high enough to melt them, I found those curious and beautiful crystal growths made by the mois ture oozing out of wet soil in slender glittering filaments, each bearing, as a crown or blossom, a tiny patch of earth carried up from the place it sprang. A little corner was dug out of the rising slope so that the excavation was perhaps eighteen inches deep at the furthest extremity and tapered down to nothing as it reached the old garden. A stone wall was here laid three feet high before the ground began to rise, but tapered to eighteen inches where the bank was eighteen inches deep. This gave a uniform three-foot wall above the level of the new beds, which were dug out as before a foot or two deeper, enclosed with boards, and a thick layer of sods was spread evenly, which is said to prevent the heaving up of the earth in freez- 


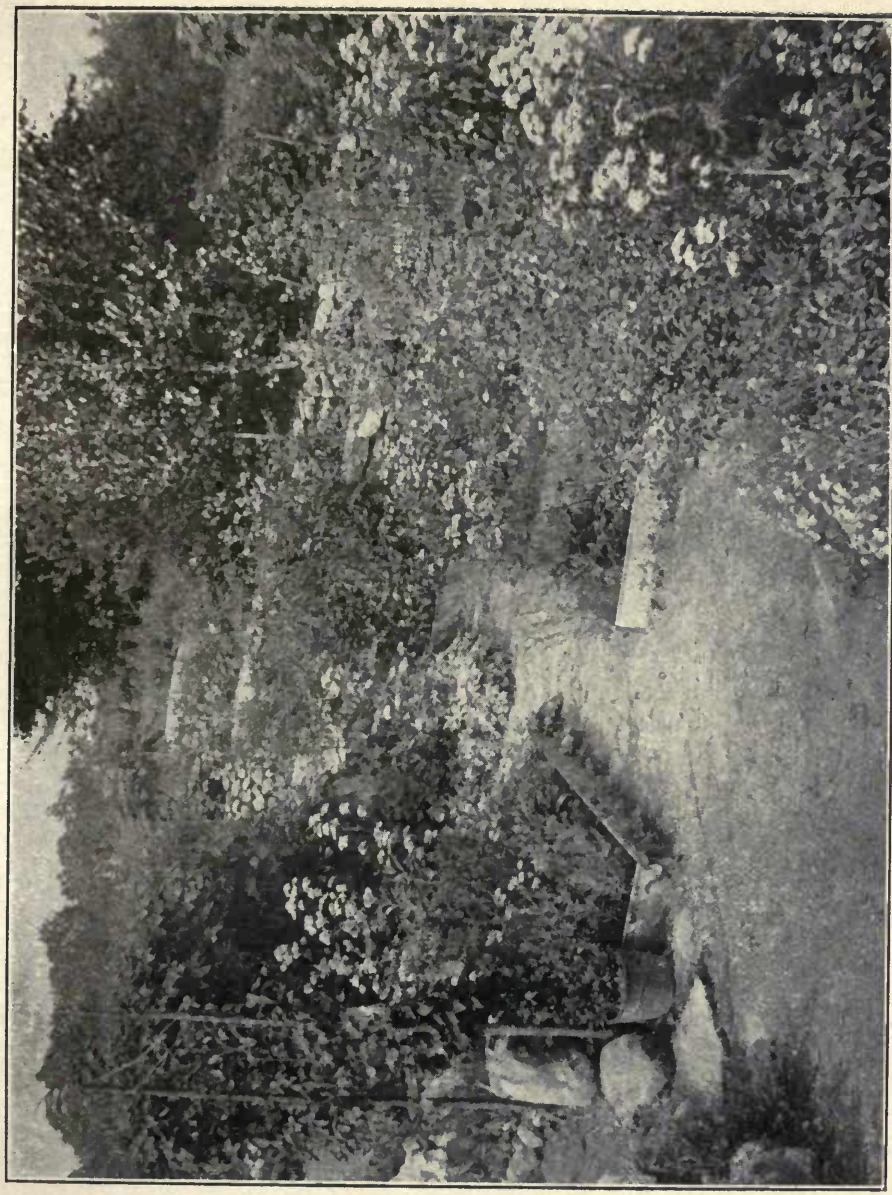

m

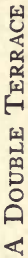


ing and thawing, and is also an admirable fertilizer, as it speedily decays. Then they were refilled with a compost as the first beds had been. To do this I had several cartloads of black muck, garden loam, sand, manure and wood ashes hauled onto the bank near the house and dumped separately, and a little at a time was hoed from each into a central pile, which a man wheeled to the beds. The old subsoil was thrown over the new walls, which bounded the extension on the west and south, and by filling up to the level of the top on the outside of the walls and back to the rising bank, a new elevation was established. I have now done this twice, and have thus secured a double terrace on the west side of the garden, from which side the main portion presents the appearance of a sunken garden, with the first terrace three feet and the second rising six or more feet above the original level. Effective as this arrangement is, it was conceived as a matter of pure utility, and a convenient means of disposing of the surplus earth in excavating the bank, and saved carting it off. It is a safe statement to make that where necessity is used as a guide, a certain kind of beauty inevitably follows. For this reason it is not well to imitate another's work, but to follow where your own conditions lead. I much regretted at first that I had no garden plans to study for a model; but, as I now see my own completed, I cannot imagine it as successful in any other form, owing to the peculiar conformation of the land. It has lent itself to my convenience in the gradual extensions from year to year; it offers every condition, from full exposure to the sun to complete shade, of dry and moist situations. Certain beds have been planted so as to maintain bloom the whole season through; others are arranged to keep up the appearance of bounty by maturing at a late day when many things are gone. Though made of units, the garden is composite in its structure. 
I shall not attempt an enumeration of the things I tried that second summer, for the general results of my eight years' experience are given in the Appendix; and it is a matter of no consequence what I began with, or when I attacked the delicate question of bulbs and lilies, when I planted shrubs, when I was fired with a desire for roses. Sufficient to say that each year I have followed some central thought; and if one has a catholic taste, it is inevitable that he will thirst for new possessions each year: but, do not add more than can be cared for properly; for even a plant should have the right of Christian burial.

With this addition sprang up the idea of maintaining pure color in my garden; so one bed was devoted to blue and white flowers, another to pink, another to pure red and another to yellow. Several were uncertain and mixed in color, experiment stations as it were, and one I called my Isolation Hospital, where unknown things were set out until their speech should bewray them.

The results of that second summer were so-so. Some things were glorious in their bloom; among them were the hollyhock, Lilium auratum, yellow day lily, Agrostemma coeli rosa, garden heliotrope (Valeriana officinalis) rose colored sweet-william, cornflower, Cosmos, the ever-faithful nasturtiums, marigolds and calendula. I found it very difficult to maintain my color scheme. Chance seeds of another color would get in and flourish so vigorously that I had not the heart to weed them out. The greatest struggle was and has been to get a succession of bloom in the blue beds. I know the height, the time of blooming, the manners and customs of innumerable blue flowers; I tear to pieces and reorganize year after year those blue beds, making combinations that I believe will surely be successful; and they would be, except for the fact that plants newly set sometimes sulk and will not 


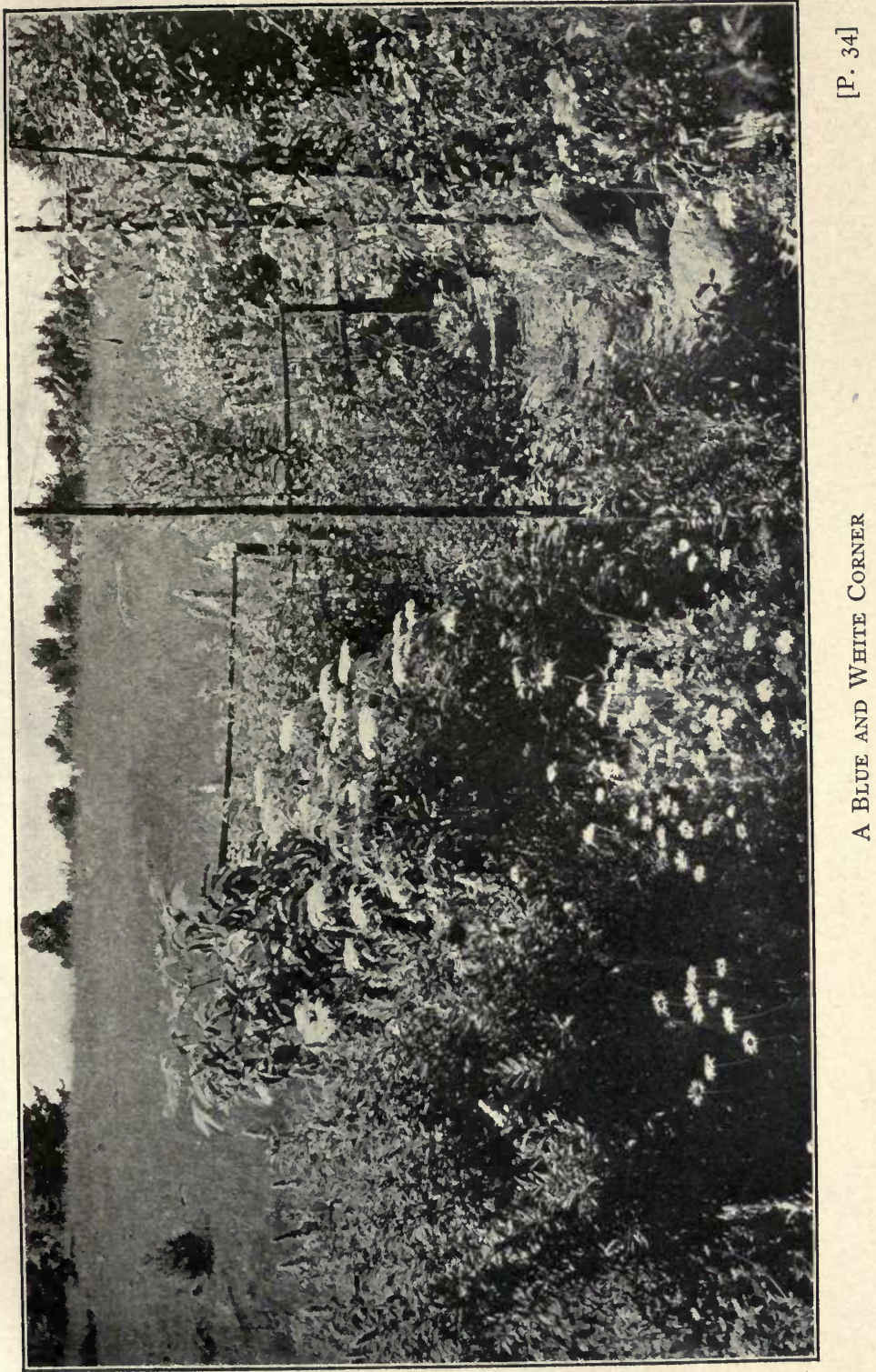


- 
bloom. Some take a year or two to get established after being transplanted; others, just as they are about to bloom, get some infantile disease like the blight of the larkspur, and all is up with them for that year. I pray and water those beds with my tears, but supplication is in vain. Theoretically my arrangement last summer was perfect; but what can one resort to when larkspurs fail, when the Japanese iris is all leaf (it used to have glorious crowns of bloom before it was transplanted), the Siberian iris multiplies, but otherwise balks, the two-year-old Pentstemon grandiflorus remains an obstinate little green clump, the Catananche and Wahlenbergia follow the Pentstemon's bad example, the Lobelia syphilitica is eaten down by a cutworm, and the blue and purple asters get caught between the upper and nether stone of the annual drought. What avails it that the lovely white Physostegia, Chrysanthemum maximum, meadow rue, infant's breath, wild carrot, achillea, garden heliotrope, Hesperis matronalis, perennial white phlox, all planted as accessories to give grace and airiness to the heavier blue tones, do their part bravely-the bed is distinctly white, not blue, save for early blue spring flowers gone by June, monkshood and campanula of July, the Veronica spicata of July and August, and the lilac Physostegia, Liatris and Michaelmas daisies of August and September. I love these plants, and want to get a definite color effect through them, and I do not want to compromise by substituting quantities of annuals; cornflower, nigella, anchusa, nemophila, annual larkspur, Phacelia, Eutoca viscida, just because they are a rich blue. To arrange blue perennials, so that they will present a succession of bloom from May to October in the same bed, is the high ideal I aim to reach, and I seem likely to give my remaining years to the study. Incidentally I find combinations that are beautiful such as white Physostegia Virginiana and Veronica spicata; German Iris and white col- 
umbine; white larkspur and Stokesia cyanea; deep blue columbine and the white Hesperis matronalis, also caraway; white Achillea Ptarmica $\mathrm{pl}$. $\mathrm{fl}$. and nigella or cornflower (if the latter does not grow too tall); purple Japanese Iris and $G y p$ sophila paniculata (Infant's breath); blue monkshood, elderberry and meadow rue; blue larkspur, meadow rue and white wild carrot; Michaelmas daisy and the tall white Cosmos; forget-me-not and perennial candytuft; blue lupines and garden heliotrope; Canterbury bells and feverfew; snowdrops and scilla; grape hyacinth and Arabis albida; but in arranging combinations you must not only have the bloom of plants coincident, but also an equality of height for each to act as a foil to the other; everything depends on the two blades of the scissors acting in conjunction.

The more beautiful a bed is at any given time, the more sure it is to show blanks at other times. Through a mistake of judgment I grouped one year an entire bed with blue spring flowers, and until the end of June the effect was all that could be desired, but during the remainder of the season it was nothing. Few flowers remain in bloom longer than three or four weeks and some last but a week or ten days; one must recognize that each is but a small passing contribution to the summer glory, and make provision for an understudy when a particular star retires from the floral stage. I now know my flowers so well that I can count on the precise time when they come and go, and I have tried the experiment of planting certain things at intervals over the garden, so that, for a week or two, when those plants are at the height of their bloom, a wave of that color is all over the beds instead of being massed in one place, to leave a great void when they go. Great care must be exercised if you place a little pink or blue in a yellow bed to end the engagement before the yellow plants rise in combat to the eye. It takes more knowledge to manage color this way, 


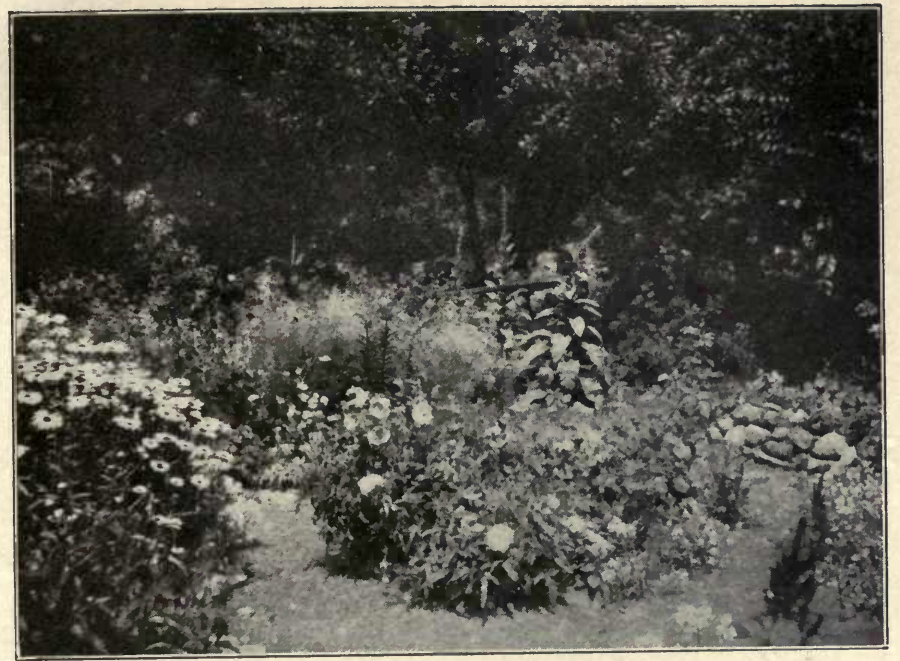

A Cloud of Infant's Breath Gives Grace to the Garden [P. 36]

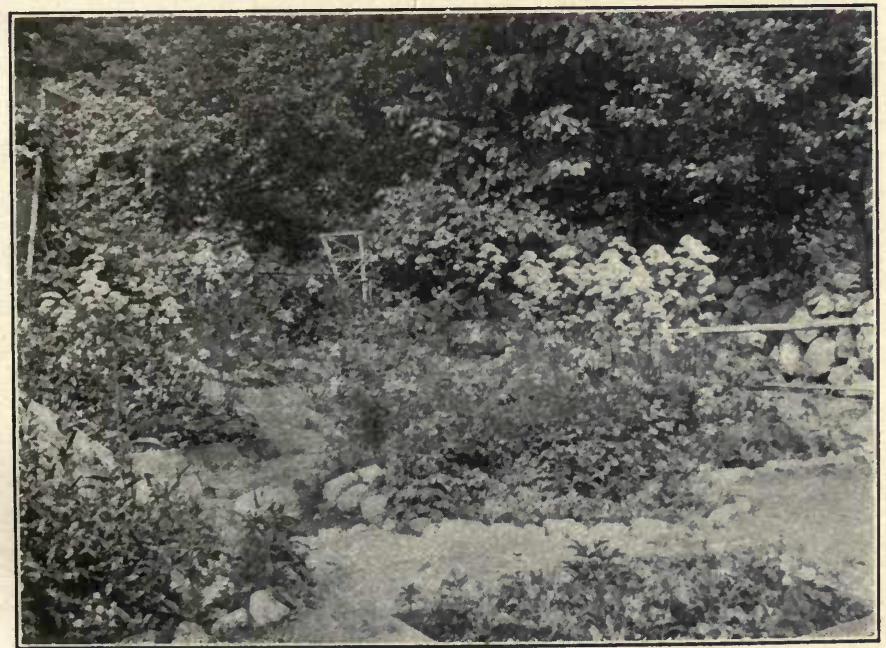

A Wave of Garden Heliotrope

[P. 37] 

but it is far more satisfactory. For example my yellow bed is not distinctly yellow until August when the Rudbeckias, Heleniums, Helianthus latifolius and Helianthus mollis and golden glow are all in bloom. During the earlier part of the season I can count on these plants being green, and I plant in that bed any color that I intended to emphasize over the general garden up to August. In early spring that bed shows blue hyacinths, later the rose pink Lychnis dioica rosea; later still the blue Campanula rapunculoides. During the interval between the last named, the creamy yellow day lily (Hemeroccalis flava) shines forth like stars against the north boundary wall beyond. In this way certain beds may be committed to definite colors, yet lend themselves to a larger color tone that may pervade the whole garden for a brief season. I mean to work along this line still further; but it must be remembered, that, to get a strong general effect, one should have from a dozen to thirty plants of showy bloom of any given variety. Instead of giving a single large space to columbines I distribute them according to color in every bed, and during their reign, the garden seems to be largely columbines. In the same way, I have used the Michaelmas daisy, hollyhock, campanulas, forget-me-not, perennial phlox, flava lily, polemonium, foxglove, Chrysanthemum maximum, perennial pea, infant's breath, lupines, iris, lychnis, sweet-william; also meadow rue, garden heliotrope, and clematis, which break into a white foam, the high-water mark of the whole summer, and then gently ebb into green obscurity. By choosing your dates with exactness, you may plant what you will in any bed, and still maintain pure color; but, to do it, you must know your plants intimately. For several years I have kept a careful record of the date of bloom of each plant. If conditions are normal, they appear each year promptly to a day; but sometimes the season is late, or a cold prolonged rain defers them 
a week, or a hot dry season forces them along, for all of which allowance must be made. These lists are of the greatest aid in arranging combinations.

A spirit of thankfulness is a good thing to cultivate at all times. I remember, several years ago, being not a little annoyed at finding a huge African marigold flourishing in a corner of one of my blue beds. I was inclined to pluck it out at once as an impertinence. Later, when a heavy shortage of blue flowers occurred in that vicinity, and my yellow bed went to pieces under a two months' drought beginning in July, I was grateful for my brave little marigold and only wished there were twenty like it in the same place. Yellow beds and pink ones can be counted on with much more certainty than blue ones, because both comprise many long and steadfast bloomers; and there is so much life in these colors that a little of them will brighten quite an area. A good way is constantly to try new combinations and trust not a little to chance. Some of my happiest effects are largely due to chance, directed by a consideration of the height of certain plants. When the question involves color, height, time of flowering, also length of bloom, it takes much shuffling to achieve what you want.

Every moment that could be spared from other duties was given to my flowers that second summer. I wearied poor Adam almost to extinction. I would talk over the wheel to any acquaintance we met on the road. From every one who came to see me was wrung the concession that things looked flourishing, and promised even better by another year.

It never occurs to an enthusiast that there may be an obverse side to his shield; that he may seem mildly mad when he is having a beautiful effervescent time with a hobby. We gradually come into all the truth that is for us, and it was in this wise that a flood of light was let in on my conduct. I was in 
the midst of an accidental conversation held in the middle of the road late in September that second year, when my instructor, a calm, middle-aged woman, but old and established in garden ways, suddenly broke in upon my fusilade with the query, "Have you had your garden long?"

"No," said I, "only two summers of garden and two winters of catalogues."

"I thought so," she replied enigmatically. I scented something wrong.

"What made you think so?" demanded I.

"Because you take it so hard," and mischief lurked under her innocent smile.

The blow staggered me for a moment, but I recovered, and answered jauntily: "The second summer is always hard on teething babes, and I am cutting a lot of wisdom teeth this year." 


\section{WITHIN MY GARDEN WALLS}

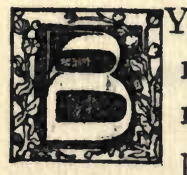

Y happy coincidence our two birthdays and the anniversary of our wedding day come before the middle of April, for each occasion offers the opportunity of presenting seeds and plants. The first time I tried this wholly disinterested act was when I made a birthday offering of rose bushes to Adam. I liked the thought of a living souvenir, which should yearly blossom in celebration of the day; but I now have the idea that his hopes may have been fixed elsewhere, for I not only had to explain the reason for my choice, but he never remembers they are his, and he takes no particular interest in their growth. Somehow his indifferent attitude reminds me of an illustration I once saw in which Algernon Sidney was bestowing a box of cigars upon his young wife Angelina, who in turn presented to him, as her gift, a pair of lace curtains. The artist caught Adam's expression exactly when I introduced him to the roses. Perhaps it is because of Adam's other-worldliness that he soars above things terrestrial. A gleam of genuine pleasure lights up his countenance when I give him a Greek book or new neckties-provided I do not make a fatal choice-but the smile and the gift are soon laid away, and it is like putting a child through the catechism to find out later from him what he actually received. In subsequent years I celebrated our anniversaries in a way pleasing to myself. One February I made myself a wedding gift of one hundred and fifty varieties of plants, shrubs and seeds. A few omissions were supplied in March on my own birthday. The next year my generous 
gift was repeated and highly appreciated-by myself. There is a yearly crop of new books on Greece, and I confine my souvenirs to Adam to them, for I notice that they elicit a broader and more permanent smile than does any thing else that I choose, and he never innocently asks me a few days later, "Who gave you that?" as he has been known to do about other tokens of affection which I have presented. I am always a bit embarrassed at his laying the burden of possession on me, when it happens to be my gift to him, prayerfully selected and done up in the whitest of tissue paper and the palest of blue ribbons, with a sweet little sentiment inside; but he never feels embarrassment over his mistake-he simply laughs and leaves me to ponder why my gifts make no permanent impression on his memory. Perhaps the male brain is not developed in appreciation, and we must not be too hard on mental or physical incapacities.

As I have not yet arrived at the age when birthdays no longer recur, I have gradually acquired large additions to my stock, and each year witnesses an extension of my territory. The garden has crept up both banks until it is now one hundred and twenty feet by sixty, and has almost reached the house on the east side. Wherever it has been possible I have given beds the protection of a stone wall from two to three feet high and the advantages of a wall are so great that I must dwell a moment on the subject, for it has a much wider application than merely to my own use. In choosing the site of a country house, one naturally selects an eminence, for the sake of outlook, drainage and other considerations. New England abounds in such sites, but these same eminences are full of rocks and ledges; the soil is usually poor compared with lowlying lands, and the question how to make things grow near the house on a hot, dry, stony hillside becomes a serious problem. For this reason my solution of this particular difficulty 
may be of value to many amateurs. A stone wall three feet high built southeast or south or west of a bed not only shades the roots of plants from the hot rays of the sun, but in the cool shadow of it, evaporation does not go on as in the open, and the soil of a dry exposed bed, when thus protected, is rendered damp and shaded for a good part of the day. Several hours of direct sunshine are good, but few plants can stand it all day. Also in winter these walls catch the snow and pile deep drifts that are a perfect protection to even tender perennials. Although a portion of the garden lies on a low level, the greater part of it is three and six and even eight feet above that level; yet, when covered with snow, it presents a smooth sloping unbroken surface under which all inequalities of height disappear. In the shadow of the walls the snow lies late upon the beds in the spring, which saves the plants from the alternate thawing and freezing that are so disastrous. In some instances these walls merely face the cutting of a bank that rises from two to three feet above a bed, and sometimes I have built them up from the ground in a double row of rocks. I note that plants in these shaded beds flourish amazingly and never suffer from drought no matter how prolonged it may be; this means an economy of labor in watering.

Aside from the utility I like the strong contrast of tender plant life against the stern granite. The Japanese have used stones as one of the chief adornments of their gardens, and while we cannot and need not imitate their use of them, we can make them serve in our own way. I have a broken jagged stone almost four feet high at the corner of one of my walls, that I always speak of as a corner-stone of happiness, so great is my pleasure in seeing it serve as a background in turn to rock columbine, harebells, meadow rue, Japanese iris, clematis, Physostegia and Michaelmas daisy.

Nothing could be more favorable to the growth of deep- 


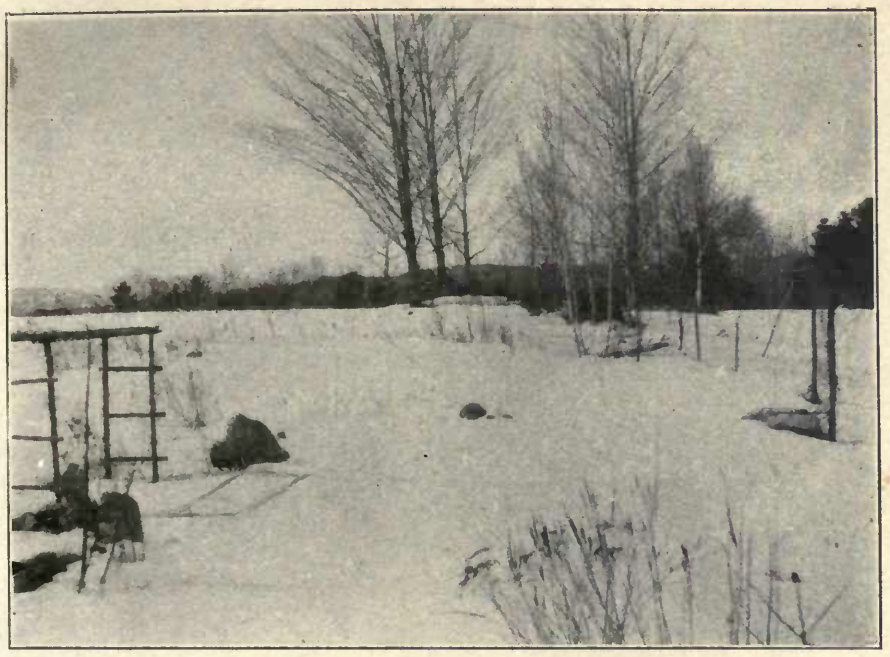

The Garden Covered with Snow Presents a Smooth, Sloping, UNBROKEN SURFACE [P. 42]

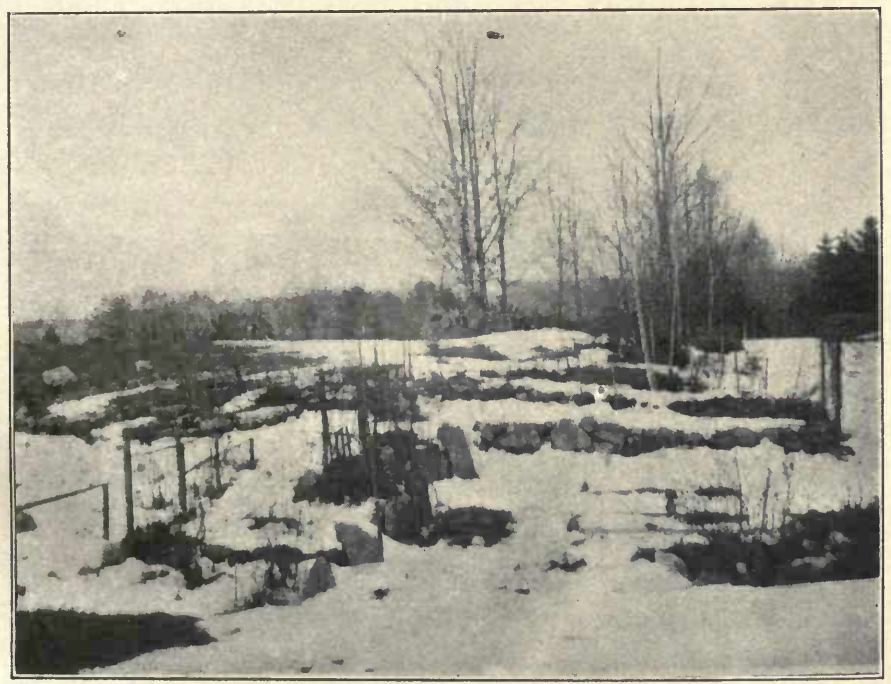

k

Snow Lies Late Upon the Beds in Spring [P. 42] 


\section{Within My Garden Walls}

rooted perennials than the cool wet rocks that underlie many of my beds. They afford a perfect drainage, yet retain the moisture to an astonishing degree. Even in a very dry season I often find the walks of the lower garden quite damp in the early morning. When once rooted among these rocks plants establish themselves amazingly. I once planted seeds of the hollyhock mallow (Malva alcea), and as they gave no evidence of growth the first year I forgot all about them. Late in the following year I discovered a new plant in bloom, which, when analyzed, proved to be the forgotten mallow. I was delighted-but not for long. The third year it grew like Jack's beanstalk, not the promised three feet, but five-and still on until eight feet high. I stood about helplessly witnessing this phenomenon, yet powerless to check it. It waxed still stronger the fourth year and covered a space of four and a half feet through, by eight feet high-imagine thirty-six cubic feet of mallow with its wretched little straggling bloom. I determined to evict it. I used first the gentle persuasion of a potato digger, the most homeopathic treatment I ever apply. It firmly resisted. Then I got the spading fork, but the mallow stood unshaken. Then I seized the pickax and crowbar and wrought fearful havoc, extracting the greater part of it, at least two bushels of roots that were a foot and a half long. A little of it was kept to set out in the dryest and most exposed portion of the garden, and it has meekly shrunk to a three-foot growth. This year I found a portion still remaining in its former place, lording it over a fine lot of pink Lilium speciosum and I peremptorily took off all the heads when only a foot high. I have decapitated it regularly once a month throughout the summer. It is now bigger than I am; a small portion has become equal to the whole, in defiance of mathematics. I mean to get it out if I have to sacrifice the pink lilies. 
The same thing happened with a blue lupine. It wouldn't budge until I applied pickax and crowbar. I tried the same forcible argument on a blue Veronica spicata that was given temporary shelter in a pink bed until the pink tenants got better established. So far the Veronica has won every round; its position is impregnable and I am alternately divided between my determination to use dynamite if necessary, or to capitulate with the Veronica and decide that a little bright blue is not criminal in a pink bed. As the season advances and the bloom is past, and it is incontinently shedding its unreachable seeds in every direction, I think I shall resort to explosives. Rocks are great institutions for permanent residents.

My various operations have included many compromises. I came across one stone that took two straining men and a stout work horse to slide it down into a deep hole, where it was covered up to remain until Judgment Day. Then I found others that all the king's horses and all the king's men couldn't stir, and they still maintain their positions by sheer force of character. One of these I walked around so much, trying to decide what could be done with it, that I wore a little path. The big stone and the little path looked so very Japanese that I came to accept it on those terms, and by dint of rough stone steps leading up to the little path, a clematis trained up as an entrance gate to it, and a rustic vine-covered fence beyond, I have a queer anomalous corner filled with a succession of blue flowers that quite delights my heart, for I can see it through a window as I sit at my desk every day. To-day the blue flowers are mostly gone with only the Liatris and Michaelmas daisies still to come: but by accident a native white aster by the rustic fence has shot up several stalks seven feet high, with a crown of bloom several feet across, and framing it about as a halo, I see pale pink, deep rose pink and cardinal red hollyhocks which grow in beds beyond it. It is needless to say that this 


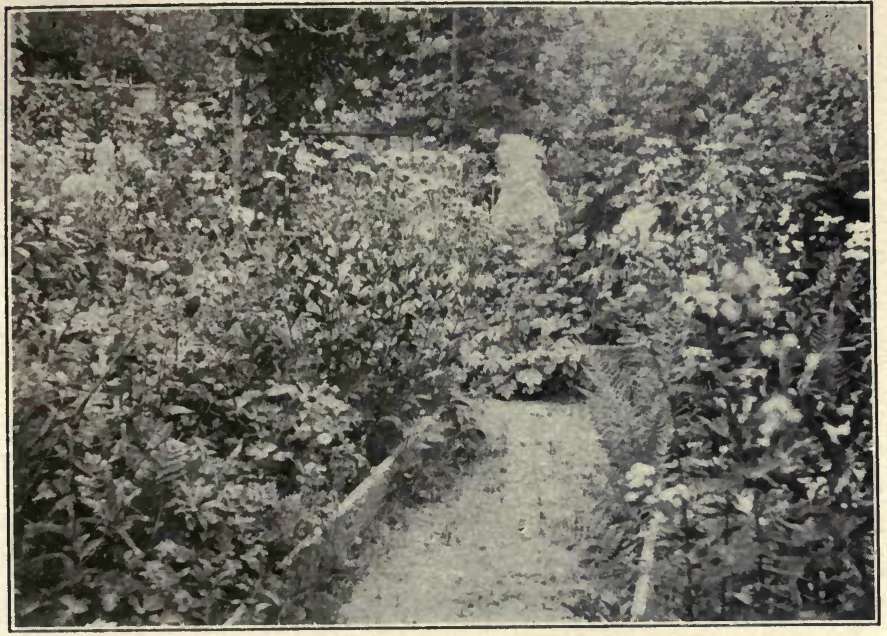
A Cornerstone of Happiness
[P. 42]

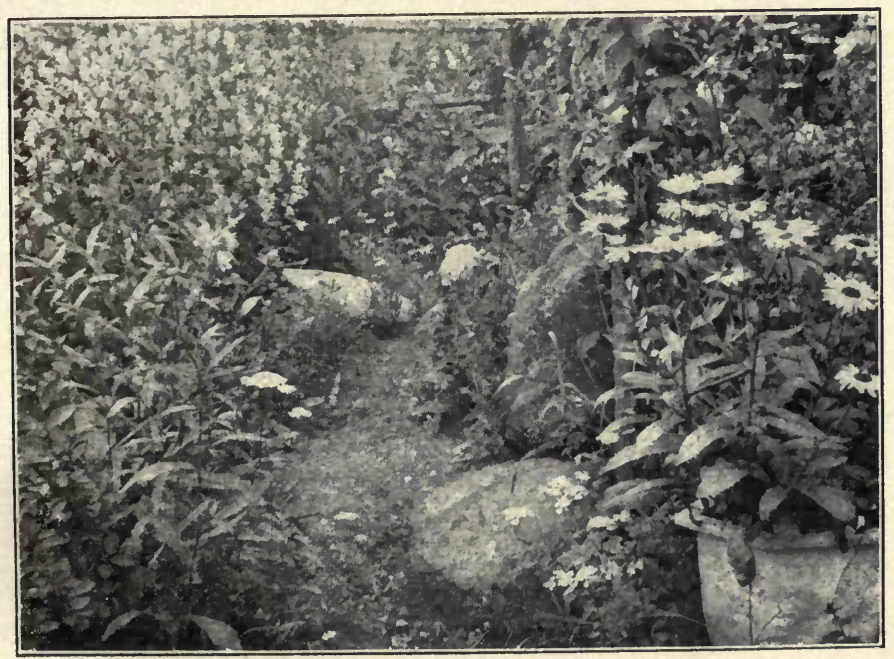

A Big Stone and a Litrle Path

[P. 44] 


\section{Within My Garden Walls}

chance combination will be carefully preserved another year, and repeated elsewhere-if an inspiration can ever be repeated.

A favorite point of view is a rustic seat that commands a larger part of the garden. In the beds facing it I have planted many of my favorite flowers, the deliciously-scented flava lily (Hemerocallis flava), Madonna lilies, Lilium auratum, blue and white lupines, blue and white larkspurs, Physostegia Virginiana alba, that resembles threaded pearls on its green stems; the beautiful white Achillea Ptarmica, pale shell pink and salmon pink columbines, infant's breath, lovely meadow rue, forget-me-nots, the fragrant garden heliotrope and Hesperis matronalis, and other delectable things. By the side of the seat grows a sweetbrier rose in the deep shadow of a stone wall, where it has made a growth of eight feet. Over the seat is a trellis upon which is trained a white clematis, Virginia creeper, fragrant yellow honeysuckle, and a hop vine; also the Allegheny vine modestly creeps up one side every year, and I always find deep purple and white morning glories looking into my face before the summer is over. Of all these I think the hop vine is the most fascinating in its graceful festoons of pale green hops.

There is only one trouble in my garden, there is always too much everywhere. I am soft-hearted and one thing after another gets a start, and they hail other companions, and before I know it a dozen things are crowding to the front. So long as they do not kill each other, I let them alone, for every plant has its day, and we need many days to fill the entire summer with bloom.

I have in another direction an arbor leading out of the main garden to an upper terraced wall. It is covered with hop vines and Virginia creeper growing at one corner, at a second is a Wistaria sinensis that makes a beautiful leafy column about 
its post each year, though it does not bloom-it is said to take seven years' residence in one spot for the wistaria to feel at home, - a grape-vine and Japanese wistaria are on the third side. It is a perfect bower of green and proved a curious stumbling-block to a strange urbanite, who found herself on our hill one morning. She wanted to get away, and I was anxious she should, as she came at a critical moment in my affairs, when, if she had been an intimate friend, I should have given her a good book, bidding her go sit under a green tree and be happy until I was free. Being a stranger, she was treated with more ceremony and less tolerance.

"Isn't there a path down to the high road?" she inquired. "There is," said I with ill-concealed satisfaction. "You go down through the garden, and on through the orchard beyond, and you will find a turnstile in the wall just as you reach the wood path."

She seemed a bit confused-perhaps she had once been lost in a wood and felt a natural caution. She wanted me to repeat the directions; I did so, but she still stood uncertain. "I am to go down through that path and under that"-she paused, extending a much bejewelled forefinger, her vocabulary, gathered on the city pave, had no equivalent for a luscious green arbor- "That, ah-that awning?" she interrogated.

"Yes, go under the awning," I repeated, "and out through the orchard-you can't miss the turnstile." What this last rural term meant to her mind I never learned. As no one was reported missing in the woods, I presume she must have found her way.

My walks are covered with sand, for it does not track into the house as the native soil would. Sand has another advantage; it serves as a seed bed for a multitude of self-sowing plants. When I want a forcible hollyhock, lupine, canterbury bell or columbine, or desire particularly strong annuals such 


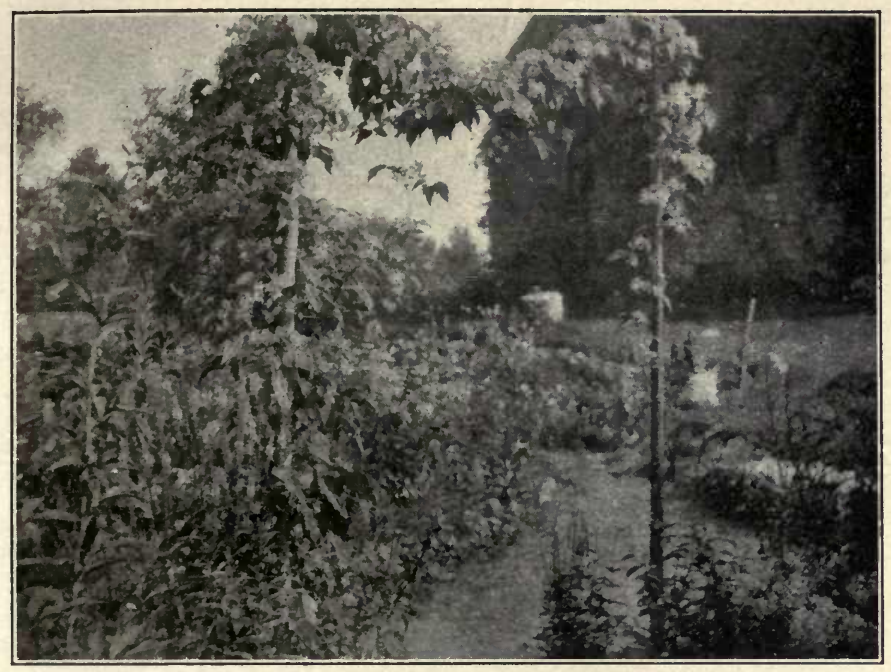

Clematis Trained up as an Entrance Gate [P. 44]

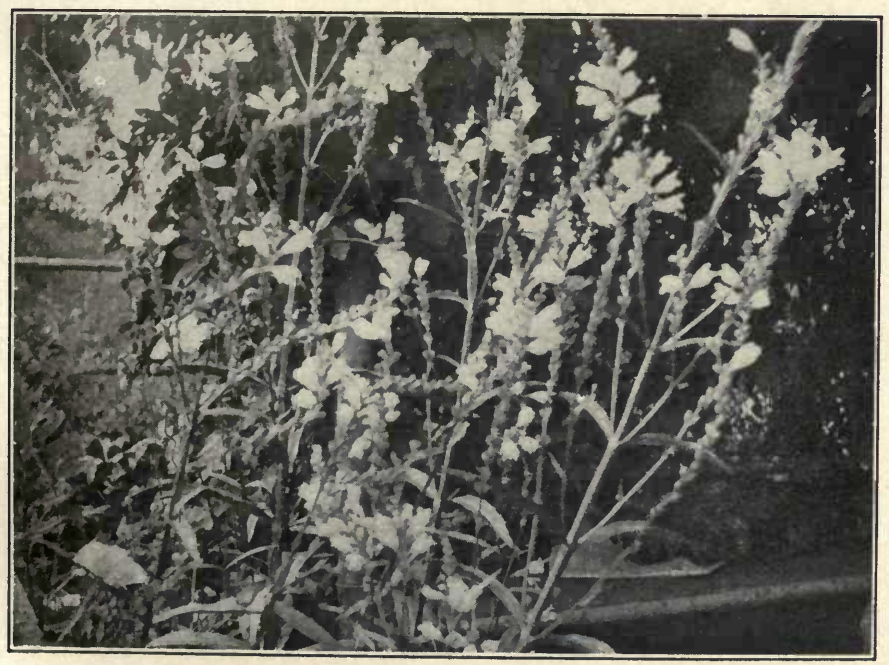

White Physostegia Virginiana

[P. 45] 
as candytuft, sweet alyssum, cornflower, Linaria marrocana, or catchfly, I do not plant the seed; I look about my walks until I find them and then transplant them. This is where I get my best specimens to fill the gaps made by cutting down early perennials after they have bloomed. I do not have to coddle these sturdy plants; they have stood the test of winter and a frosty spring. Any one who has watered seeds to young planthood has a genuine admiration for self-supporting walkgrown plants.

"But," exclaims the Tidy Woman, she who maintains an orderly top bureau drawer though the heavens fall, "how disorderly your garden must look all cluttered up that way."

"Indeed it does, Madam, at times; so much so that Adam files an injunction to restrain me from further neglect, and threatens to hoe the walks himself if it is not done by a certain day."

"My path is literally strewn with flowers," I protest to him sentimentally, and I remember various church weddings with little pages and flower girls strewing posies down the aisle; they were but a symbol, and this the real thing.

My words have no visible effect upon my neat Adam. He is a worthy man, but he has no eye for nice distinctions existing in seed leaves. He does not know at sight a new-born lupine or columbine or asperula or forget-me-not. He simply can't be trusted in my walks unless disarmed of hoe and shovel. Sometimes I am forced to accompany him:

"Ipse Dixit, I'll not wait another day; your walks are disgraceful," he announces suddenly; his determined voice has a long-suffering undertone that I respect.

I well know what this means, and leave any important domestic situation to act as body-guard-not to him, but to the intended victims.

He always wants to begin at the entrance, and work steadily 


\section{Hardy Plants for Cottage Gardens}

over every inch of ground on to the bitter end. "Now you may begin here," I say, setting his metes and bounds as if he were the ocean, "and work carefully down this way, keeping clear of every border at least a foot; they are full of things I can't spare; but don't touch this," suddenly spying some perennial advanced to the third pair of seed leaves, "nor this-oh, you must shy away from that," and I make magic rings of cleared ground with my own hoe about the endangered seedlings.

Adam has learned the fatal power of concentration, and hoes steadily on. His are not the sins of omission; he has a good heart and an imperturbable temper, yet he has the red hand of the slayer. Vainly do I make vast deserts of sand about little green oases I want spared. If I look up in the sky one minute, or wander ten feet from his side to escape the death-cry of his victims - the deed is done. Destruction, apologies and clean walks are synonyms for Adam's hoeing.

Of late years I undertake this delicate commission alone. My hoe has intermittent habits, I always have from four to six very hot irons in the fire, and the worse the walks look, the less I want to see them. But affairs work up to a climax, and I stand in not a little awe of Adam's salutary criticism. I prize his approbation and I am growing to like a clean, trim walk for its own sake, so I have learned to harden my heart and reap great harvests of flowering things that I would fain let stand. But when the painful task is over I feel the guilty contrition of a young girl I once knew, who used to beguile her lonely hours with rifle shooting, and, being a good shot, she would daily bring down a chipmunk or red squirrel, which she proceeded to bury with many tears in her own small garden plot. Her grief took a prudent form, for she planted each limp little body at the root of a shrub to serve as a fertilizer, and in consequence I always spoke of Margaret's garden as her animal orchard. 


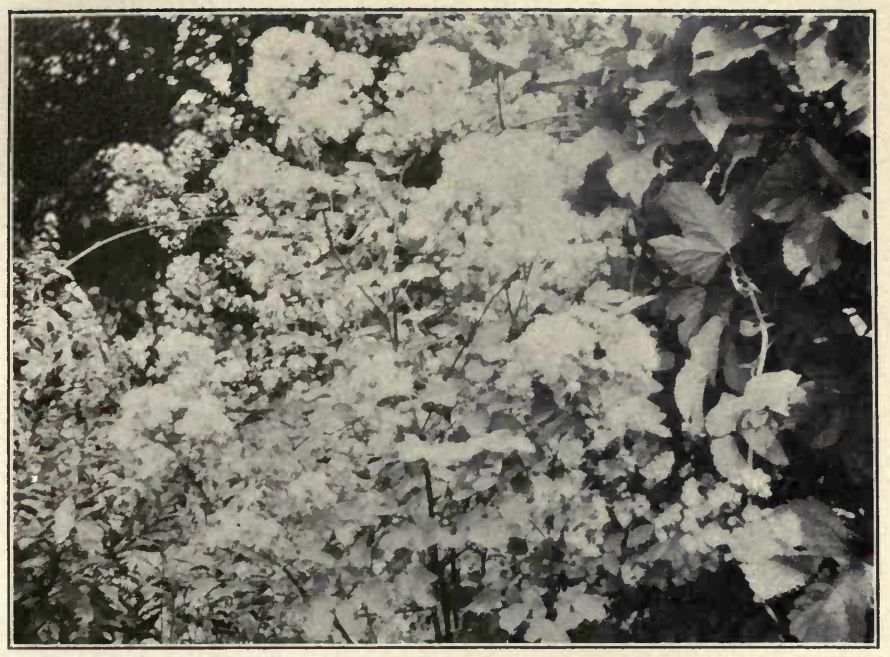

A Tangle of Meadow-Rue, Wild Clematis and Hop Vine [P. 45]

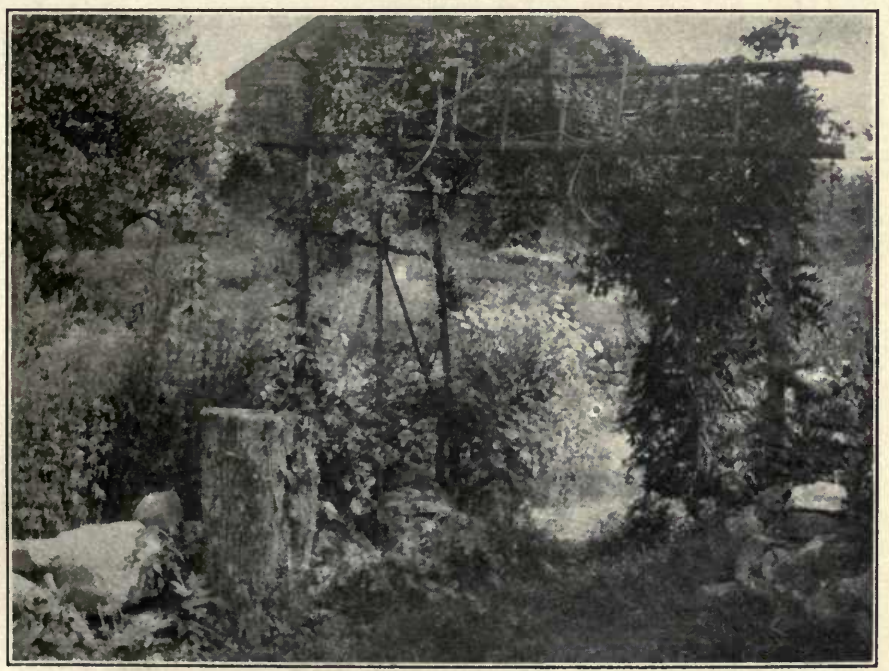

"That Awning"

[P. 46] 


\section{SEEDS}

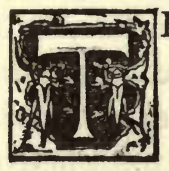

HE third winter we spent in Florida, and as we did not return home until the first of April, I had to resort to other methods than mantel-raised seedlings, which while interesting was not practical, and determined to raise my annuals in a hotbed. I love adventures and perils-if closely attended by escapes-and had been duly impressed with the manifold difficulties of Adam's hotbed for vegetables. I like the idea of playing guardian to a hundred tiny souls, fending them from frost, too much sun, too much heat, too little water, well knowing that, if like Homer, I nodded a moment, destruction would follow. As soon as the frost was sufficiently out of the ground to work-which means that the earth had thawed out to a depth of a foot or eighteen inches, and beneath that all was still solid ice-I dug out a small grave-like hole two and a half feet wide and four feet long, the dimensions agreeing with a discarded window casing, and its accompanying storm-window. I went down about two feet or more, the earth thawing as I dug, and then Adam was summoned to give further advice. He brought fresh manure and put it in to the depth of a foot or more, trampling it down hard with his big rubber boots, and then we fitted in the frame, tilting it toward the south so that the back edge was six inches above the ground and the front edge two. We carefully banked it around with turf, so that no cold could get in about the edges, and I got some finely pulverized loam from my compost heap, and covered the manure to the depth of about five inches. The glass was put on to remain a few days, 
until the heat made by the fresh manure had subsided. I found it hard to wait those few days, particularly when considerable snow fell, and my operations seemed to be deferred indefinitely.

The first day the sun shone forth, I decided to risk an encounter with Adam, and started out with a shovel, a broom, several boards, newspapers, my basket of seeds, markers and a pencil. It is true I wore a hood, heavy winter coat, arctic overshoes and leggings as if starting on a polar expedition. Adam spied me as I was loading my plunder in the wheelbarrow. "Where are you going, Ipse?"

" 'I'm going a-planting, sir, she said," " I sang out gaily.

I have learned that a bold front has great weight with Adam, and when about to do something that is sure to call forth a word of remonstrance, I assume the attitude of being predestined from the beginning of the world to perform just that identical act. I do not know whether it is Adam's respect for fore-ordination or my determination that carries the day-but I seldom lose.

"Ipse, you must not; the snow is six inches deep where you intend to work, and it is still winter," he pleaded.

"It depends on where you look," said I. "It is summer overhead, and spring is overdue at least two weeks by the calendar."

"You will gain nothing," continued he. "It is too early; wait until next week."

"Manana is not my policy, Adam," said I firmly, "don't oppose me. You know I always yield to your advice. These seeds ought to have been planted a month ago. What is the use of a hotbed if you wait until it is warm enough to plant anywhere outside? I'm going to shovel away the snow from the front of the frame, sweep the ground clean, lay down these 
boards, cover them with papers to sit on and it will be as warm and cozy a work as if I were knitting by the fire."

Adam never nags; he knows how far a prudent husband should go, and having gone the full distance, he waves a farewell hand as I pursue my arbitrary way. On this occasion he gallantly trundled the wheelbarrow down through the drifts that still lay two feet deep in the runway, and up to the hotbed that was steaming under the glass.

I filled my space with seeds of annuals, drawing shallow furrows through the earth, dropping in a few seeds sparingly, and smoothing the earth over them. One of the chief difficulties with amateurs is that they sow seed too thickly. Seeds look so small that it is hard to realize the space a single plant will cover. I knew a man once who sowed three packages of Shirley poppy-seed in a bed a foot wide and four feet long, and then asked if he ought not to have put in more! The rule is to plant seeds to the depth of three or four times their size, but, if very fine, seeds should be merely scattered on the surface and pressed in lightly. Some are too fine to strew properly and may be mixed with a little fine earth, and then scattered. After a row was sown I pressed down the earth until it made a slightly depressed line in order that the water might settle in these depressions and sink in gradually. Each row was carefully marked with its name upon small portions of a strawberry box that had been torn into inch strips.

I hovered about that hotbed like a bee about a honey pot, lifting the front edge a trifle each sunny day to let in the air, carefully replacing it at night. As the weather grew warmer the lid was raised still higher, so that the young plants should be gradually hardened. By the middle of May I had perhaps thirty varieties of annuals ready to set out, and felt the same triumph a physician would, who had brought a community through a cholera epidemic without losing a life. 
These were carefully transplanted, and each seedling was covered with a Neponset pot for three or four days. To transplant I use a mason's small pointing trowel, and by thrusting in the trowel three or four inches and drawing it forward, it makes a deep clean hole, or rather, a wide slit in the ground into which you can drop the roots of the plant to their full depth. If water is poured in at once before pushing back the earth, the ground is wet down to the very tip of the roots, which is not the case if the earth is put back first and watered afterwards. I believe that this method of soaking the earth at the very roots has been the reason why I seldom lose a plant when transplanted. Even young poppies survive when thus treated. Before lifting the seedlings it is well to water them thoroughly in order that as much earth as possible may cling to the roots. If the plants are too thick in the rows, you lose most of the soil when separating them; therefore sow seed sparingly in the row, and have more rows, if necessary. Leave a slight depression about each plant for the water to settle in, as was suggested for the seed rows.

There is this to be said, however, about transplanted seedlings: they require much more care for a time than if allowed to remain where the seed was sown; they must have daily watering; and, if scattered promiscuously over a garden, it means much labor; they must be shaded from the hot sun for a week or more, and they are never so large or vigorous, unless every condition is favorable. I have since found a much better way to treat annuals than to start them in either a hotbed or a cold frame. I now have beds devoted to them, on either side of the entrance to the garden, one three feet by seventeen, the other three feet by fourteen. These beds are part of a terrace that is two feet lower than the lawn about the house, and face the southwest. As soon as the earth is mellow, perhaps by the last week of April, I plant the seeds in the open 


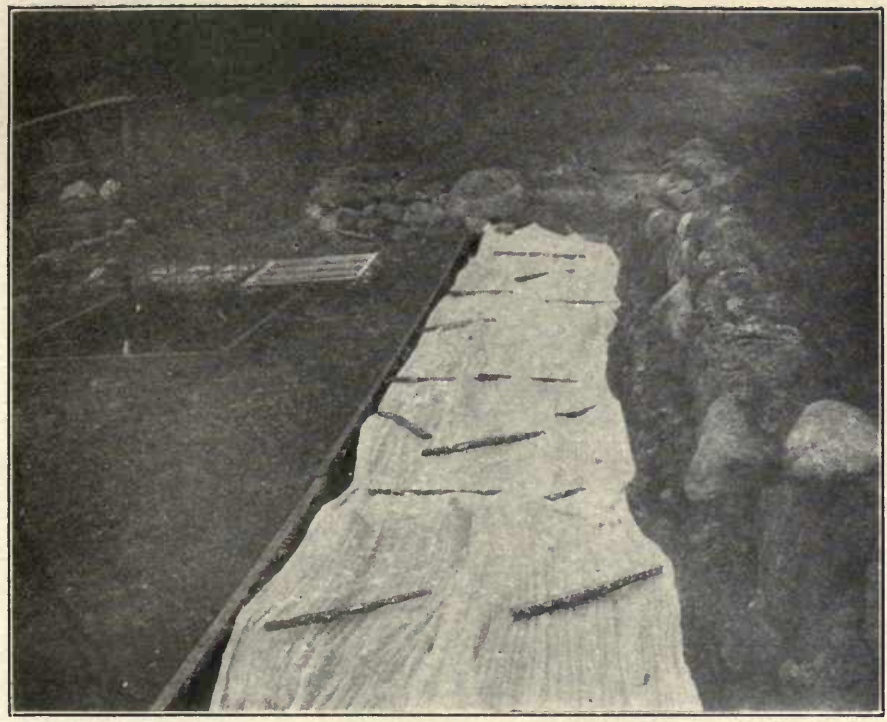

Cheese Cloth Protection for Annuals

[P. 52]

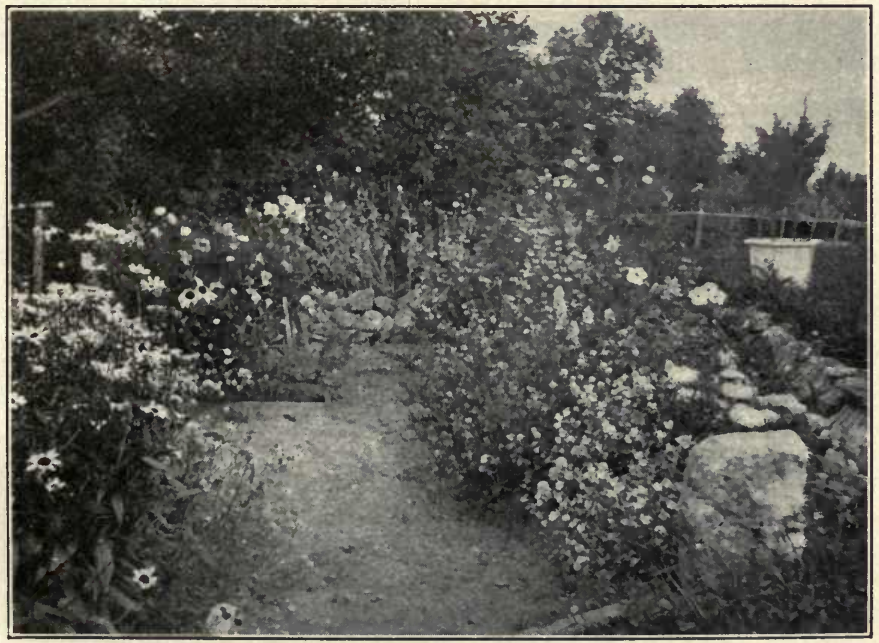

The Same Annual Bed in August

[P. 53] 
ground where the plants are to remain. One bed is for pink flowers shading into red, the other blue, and the tender varieties of each color are grouped together in a small space. If the weather is warm I let the beds alone, allowing the seeds to take their time to germinate, and I water them very little, which forces them to root deeper. If the weather turns cold or a frost is impending, and especially after the seeds have come up, I cover the beds temporarily with a double thickness of cheese cloth, and the more tender plants with the storm windows of the house. In this way I have brought my plants through killing frosts, and they have the advantage of hardy open-air growth, and deep roots that withstand prolonged droughts. Many annuals that are recommended to be started early in gentle heat, bloom under this treatment in July and the first week of August, which is as early as they are ever secured according to the catalogues. Seeds should be sown thinly, and even then they will probably require further thinning out, and may be transplanted elsewhere to cover vacancies made by the departure of early perennials. Transplant them early so that they may become established before hot weather. This method involves almost no care and very little watering; for one does not go over little tracts in many beds; and, placed at the entrance of the garden, the annuals make a conspicuous showing during the trying months of July and August. I get my plants so early that the seeds of the first heads of any variety have time to mature and drop, and thereby I secure a quantity of self-sown plants of the most vigorous growth the following spring. I shall never return to the troublous, difficult problem of a hotbed for annuals.

Nor do I find it any advantage for raising perennials in my latitude, while the disadvantages are many. After I got out my first consignment of annuals I was so happy in the success, that by the middle of June I planted the bed full of perennial 


\section{Hardy Plants for Cottage Gardens}

seeds. They came up promptly-that is some of them-ran their brief race and disappeared - at least, most of them did. I could not imagine what was the matter, and planted more seed. I watered the bed daily, tilted up the glass covered with a piece of burlap so as to shade the bed from the extreme heat of the noonday sun. I sat by its side fondly, but my attentions were largely in vain. Rows of green here to-day were gone tomorrow. "The days of man are as grass; the wind passeth over it, and it is gone, and the place thereof shall know it no more." Surely when David sang he must have known the sorrows of a hotbed. One day late in August I ran a hairpin down between the furrows to loosen the earth, and tumbled out a white grubworm, and for several days my one aim in life was to unearth grubs.

Now the white grub is the son of that frazzled, trampishlooking brown beetle that had hovered in numbers over my hotbed earlier in the season. I shall never forget my first adventure with one. I had a well-manured open bed in early May where I was planting seeds, and was not a little annoyed by these beetles buzzing around. I had tried to kill them, but they are crusty creatures, and my little stabs at them were ineffectual. Finally one lit on the ground, and to silence him until I got through, I dropped a Neponset pot over him. I could not have treated him with greater civility; for later, when I lifted the pot, he was not to be found. I was guileless in those days, easily puzzled over a thousand nameless causes and too obvious effects, and I wondered if he had burrowed out as a woodchuck does, or what had happened. I did not find out for a whole year, and when I learned their habits and saw them make a sudden dive into the ground, I pounced right after them with a stick; but I never went quick enough nor deep enough; for they burrow with incredible speed right down to the moist manure that is 
the basis of all hotbeds, and there lay their eggs. I won't describe the white grub, for it is a horror to think of with its thin, shiny, bluish-white skin, thick body, and unnecessary equipment of legs. When you see something from half an inch to two inches long that turns your very soul with revolt, it is the white grub, that never comes to the surface in bold fashion to stand tiptoe on the end of its little tail to eat a plant right through above ground as the manly brown cut-worm does. No, it wanders just below the surface, eats the roots and tender stalks of seedlings that can utter no sound-but just die. If you are new to the business you stand around futilely witnessing the infant mortality, and declaim against the acts of Providence. I was happy in capturing six victims in the hotbed though the rows were already decimated, and I knew that a whole year had been lost for many of the seeds planted. The following June, after my annuals were removed, I decided to dig over the hotbeds-I then had fourwhich had been prepared in the usual manner with manure and loam, except that they were planted late enough not to require glass, and to my amazement I found not six grubs, but literally hundreds. I immediately understood the cause of my former losses, and determined never again to use manure as an underpinning of a hotbed, for it is manure alone that attracts the brown May beetle. In recent years I have gone much further and do not use manure anywhere in the garden, unless it has been thoroughly mixed with other ingredients in a compost heap, and has stood a year or more, and is carefully forked over before applying to the beds. I have not found a single grubworm for four years and believe this is the only safeguard against them.

Having despatched the battalions, I planted perennial seeds again in faith, strengthened by a quantity of wood ashes mixed through the soil, as a protection against pests, using no 
bottom dressing, and had about seventy-five varieties under way - I thought. Many rows came up and my heart was glad; then a drought befell us, and grasshoppers were sore in the land, and katydids and crickets found my tender greens fresh and appetizing, and again I saw young life mowed down by the relentless sickle of Fate. I went out ten times a day to shoo the ravaging horde away. Then I covered the frames closely with cheese-cloth, only to find at any hour of the day a couple of dozen fat sleek crickets basking under the cool shade, eating at their leisure. So, droughty as it was, I transplanted everything that was large enough to risk, sowed more seeds in the bare rows, and played Providence to the remaining nurslings that were too tiny to be lifted. In the autumn the wind drifted the leaves into the cold frames and I left the nursery, well content to have so good a shelter provided.

The following spring I hurried home from the South, eager to see how the little things throve under their deep blanket of leaves. When I reached those beds I stood by veritable graves. I had decided not to cover them with sashes because of the heavy snows that pile up five and even six feet on the level, and I feared that the plants would suffocate and the sashes to my frames be ruined. And there were my sunken beds submerged under a foot of water that had melted from a recent snowfall, while the earth frozen solid under the blanket of leaves prevented it from sinking in. There were no funerals, though the dead from drowning were unnumbered. Another winter I tried covering the cold frames with boards, weighted down with stones to keep them in place; but I leave home too early in winter and return too late in the spring to give them proper attention. Everything was moldy or rotted, and I saved but little. I discovered in the spring, when the beds were thoroughly overhauled, why they had suffered so from drought the previous summer. Forest trees over 
thirty feet away had sent out fuzzy fibrous roots that had made a dozen laps up and down the mellow soil, and out of each small cold frame I took at least half a bushel of gluttonous roots that had robbed the earth of moisture. Having made repeated trials both of hotbeds and cold frames, from which I never got one third the plants I should have had, I decided to make an experiment of my own. Unless seedlings are grown in the open, they are apt to "damp off," a condition where too much heat or moisture weakens the growth, and without warning the stem decays and the little plant dies. I chose a sheltered spot half-way up a bank, remote from trees, facing the east in order to get shade from the afternoon sun and protection from the northwest winter wind, and here I prepared an ordinary bed, without bottom heat or manure, the soil being first a layer of grass sods turned root-side up, then a mixture a foot deep of loam, leaf mold, wood ashes and much sand, which is reserved for a seed-bed and nursery.

Now some people advise planting perennial seeds in August; but in northern latitudes many of these seeds take a month or more to germinate, and there is not sufficient time before winter sets in to make a stocky growth that will withstand extreme cold. Then, too, the vital forces are stronger in spring; there is greater probability of moisture than in August; and a seedling that has achieved six months of vigorous growth the first year is better prepared for its active duties the second. For these reasons I now plant seeds of perennials early in May, so that they may have the whole summer for growth. Seeds then may take their own time to germinate, a few days, weeks, or even a year, if necessary, without the need of disturbing the bed to rout out grubworms or invading roots. If at all crowded, when large enough, the seedlings are separated and reset in the other end of the bed; otherwise, they are allowed to remain where they are until they attain a blooming 
size. While this bed requires daily attention, the plants are cared for collectively with much less trouble than if, as little seedlings, they were reset in permanent positions all over the garden.

With this sheltered nursery bed I have not only carried young seedlings successfully through the winter, protected with only a light mulch of leaves, but some varieties, planted as seeds in May, have developed into strong blooming plants within three months, such as English daisy (Bellis perennis) and Callirrhoë. The deep well-drained soil is kept moist by the shadow of the stone wall facing the cutting in the bank; and, to give further shade, I have planted above it tall perennials that do not seed readily, such as azure and deep blue larkspur, white perennial phlox, pink hollyhocks. For spring bloom I have added the early pink lychnis (Lychnis dioica rosea), blue and white columbine, and white foxglove for June; but these must be watched and every seed vessel removed, as they sow their seeds far and wide.

I have also found it an advantage to construct an awning of cheese-cloth over my perennial seed-bed, high enough to admit air and a little sun, yet a protection from the direct noonday rays. Some advise that this be replaced later with an open lattice-covering made from laths, which would admit more sun. I have not found it advisable because of our long extreme droughts. With my utmost endeavor I can scarcely keep the bed sufficiently moist when a drought continues six to ten weeks, so that cheese-cloth is none too much shelter from the burning heat. Under this light canopy I have had self-sown foxgloves make a tuft of leaves twelve inches across the first season.

My great trouble is to preserve virgin soil anywhere. No matter at what season I construct a bed, nor from what source I collect my earth, lo! before the bed has cooled from the heat 


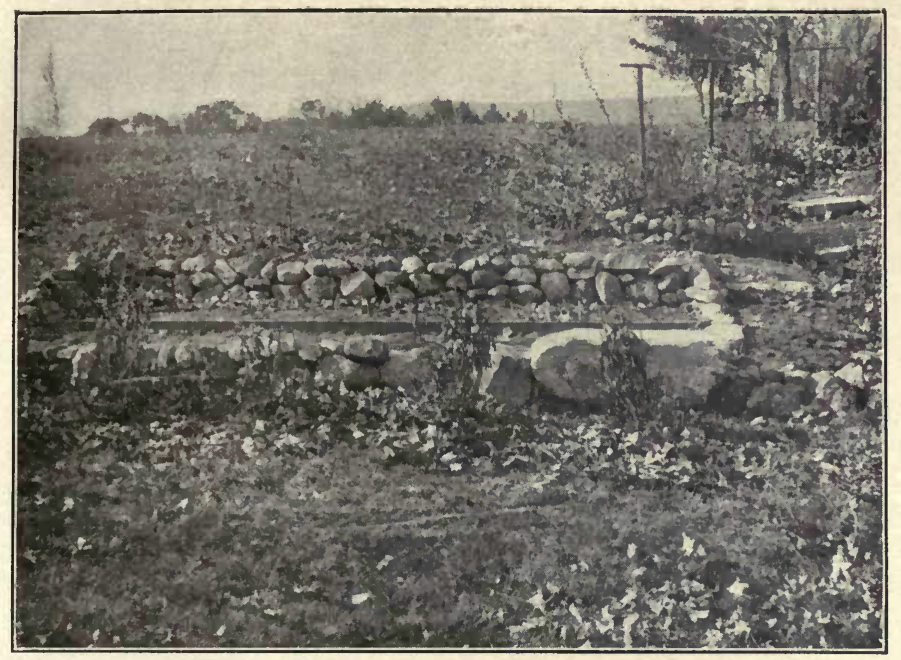

The New Nursery Bed Sheltered by a Wall and Tall PerenNials Planted above it

[P. 57]

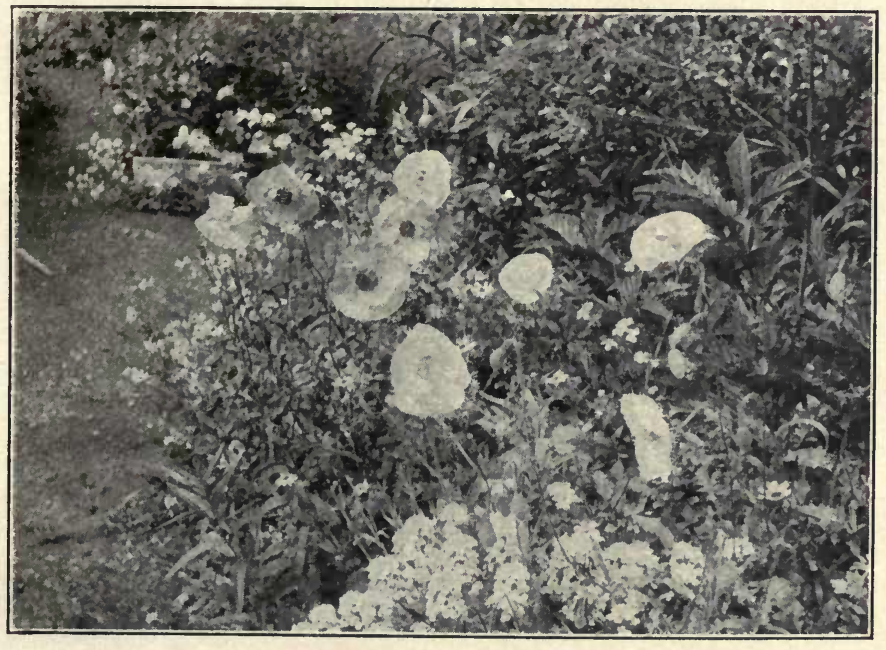

Shirley Poppies

[P. 6I] 
of my shovel all kinds of desirable but unsolicited tenants have moved in and make themselves very much at home. As my heart is grateful for any garden good, when unsought Anne Hathaway poppies, that are given the freedom of the vegetable garden rods away, offer themselves as stancher friends than shy pentstemons or reluctant Lobelia syphilitica, the fault is not wholly mine if a lusty poppy bed flourishes over the heads of these recalcitrants.

"Oh, but that is not gardening in the strict sense," you will say, severely.

"Of course not," I reply, "but it is flowers, and plenty of them, and if not of one kind, then another, by all means. I like surprises-some people call them disappointments; all depends upon how you look at them." The earth must be clothed, and every seed-bed is a living testimony to Sir Thomas Browne's commentary on that memorable third day of Creation: "Gardens were before gardeners, and but some hours after the earth." Equal suffrage dates from the moment, when, after the appearance of dry land, the earth busied itself bringing forth grass, herbs and trees, each yielding seed after its own kind.

I continue to experiment with twenty-five to fifty new varieties every year, just to see what they are, though I retain but few of the annuals as permanent residents. If, after three years' trial, I do not get results from a perennial seed, I buy a single plant of it, and propagate by division of the root, and also sow its first seed as soon as it matures, and again the next spring. I have tried to cover the peculiarities of seeds and their special requirements in the Appendix. Some are extremely difficult to grow under ordinary conditions. I have utterly failed to germinate Dictamnus, Lobelia syphilitica, Ethionema, Trollius, Romneya coultera, Adenophora and Ranunculus. These I have bought as plants. Some seeds 
require unusual conditions such as Gentiana crinata, the beautiful blue fringed gentian, that is not native to my vicinity. It is a biennial, and requires a moist sandy place for its seeds to germinate. I have experimented with it by a partly shaded brook, where it is damp, but not wet. I cleared places and covered them with sand upon which I have strewn the seed. So far I have failed to get any result, but I shall try it a few years longer before giving it up.

To return to seeds; they are as individual as the plants themselves. Some like the Eremurus, iris, rose, Dictamnus, Bocconia, Romneya, Incarvillea, Clematis Jackmanni, the flava lily, Hyacinthus candicans and perennial phlox take from six months to a year to germinate. A few have a hard husk which has to be filed to admit moisture, as the Japanese morning-glory; the Abronia is enclosed in a papery shell impervious to moisture which must be removed if it is to germinate promptly. Some must be planted with the eye down; some, like the Portulaca, cannot be sown until June; certain annuals are better to be sown in the autumn, and again in the spring to insure a long succession of bloom. Some are better to be kept from one to three years before planted. I subjoin a list of perennials and annuals that you may trust to sow their own seeds, and plants derived from self-sown seeds are much hardier than those raised in the usual way.

\section{SELF-SOWING PERENNIALS}

Agrostemma coronaria

Anchusa

Asperula hexaphylla

Candytuft, Per.

Canterbury bells

Centaurea montana

Cardinal flower
Chrysanthemum maximum

Clematis

Columbine

Daisy, Ox-eye

Daisy, Paris

Daisy, Yellow (Rudbeckia)

Feverfew 
Flava lily

Forget-me-not

Foxglove

Gypsophila paniculata

Hesperis matronalis

Hollyhock

Johnny-jump-up

Larkspur, Per.

Lobelia cardinalis

Lupinus polyphillus

Lychnis chalcedonica
L. coronaria
L. dioica rosea

Lychnis flos cuculi
L. viscaria

Lythrum salicaria

Malva sylvestris

Pansy

Perennial pea

Phlox, Per.

Rocket (Hesperis)

Sweet-william

Veronica

Violet

Wild carrot

\section{SELF-SOWING ANNUALS}

Agrostemma coli-rosa

Alyssum, Sweet

Amaranthus

Ambrosia Mexicana

Artemesia annua

Asperula carulea

Calendula

Calandrinia

Candytuft

Catchfly

Clarkia

Cleome pungens

Collomia

Coreopsis

Cornflower (Centaurea)

Cosmos

Dog-fennel or Mayweed

Eritrichium

Evening stock

- Fern, Sweet

\section{Gaillardia}

Godetia

Gypsophila elegans

Larkspur

Lineria marrocana

Morning-glory

Nasturtium

Nigella

Nicotiana

Nycterinia

Palifoxia

Petunia

Phacelia

Phlox Drummondii

Poppy, Shirley

Poppy, Pæony

Schizanthus

Silene pendula

Tridax

Viscaria carulea occulata

Whitlavia

It is interesting to note the differences of color in the seeds of plants. Take for example the aster: a white aster has a 
faintly tinted whitish seed, the pink is a trifle deeper, the red and purple are a deep brownish tone. The white foxglove seeds are white, the purplish red foxglove seeds are almost black. The poppy and morning-glory show the same difference. Many other plants follow this distinction, which it is well to remember if you buy a package of mixed seed; for you may pick out the seeds by their different tones, and plant them separately. I find the same differences exist in the stems of plants. White varieties are of a pale green-in asters, cosmos, columbine and stock; the pink varieties have a slightly reddish tone, often a mere streaking of color on the stem, while the red or deep blue or purple varieties have a deep red, mahogany or almost brown stem. If your eye is quick to discern differences, you can discover these peculiarities while a plant is still a young seedling.

There are many seeds that are offered only in mixed colors, yet $I$ have secured pure color from them by planting them in some corner, and then separating them in the following manner. Among the flowers that bloom first I choose one or more heads which show great perfection and note the exact color, tying the stem before the petals fall in order not to lose track of it. As the later seed-vessels form they are cut off so that the vitality of the plant may be given to further bloom, and to that single seed vessel. To maintain pure color, I had to devise some way by which I could distinguish the exact tone represented by the marked seed-vessels, as well as of these mixed seeds. First I tied the stems with colored strings, but they faded; then I fell upon the simple device of using black and white darning cotton as the least noticeable way to mark a stem. I cut off short lengths, not over three inches long, and tie them about the stem close to the seed-vessel according to the following code. A double tying of white cotton denotes a pure white variety, and so on. 
CODE FOR MARKING SEEDS

White . . . . . . double white tying

Light pink . . . . . . single white

Deep pink . . . . . . single white and single black

Red . . . . . . . . single black

Purple . . . . . . . double black

Lavender . . . . . . . double black and single white

Deep blue . . . . . . double black and double white

Light blue . . . . . . double black and triple white

Deep yellow . . . . . . . triple black

Pale yellow . . . . . . triple black and single white

When the seeds are perfectly ripe I gather them on a dry sunny day and fold each variety in a little square of white paper after the manner that an apothecary does up a powder, and either tie it about with a thread, or pin the ends over each other. There is no scattering of seed if done this way, as there so often is when put in small envelopes and carelessly sealed. Each packet is marked with the variety, and its exact color, as indicated by the tying code, and I get not only exceptionally strong seed, but I am absolutely sure of my color, provided the plant reproduces true to itself. Some annuals do not mature early enough to insure good seed, and these I buy yearly for new stock.

A word of advice may be permissible regarding the purchase of seeds and plants. It is a matter of economy to buy from the highest priced, most reputable firms. It costs time and labor to raise reliable seeds, and if they are offered, as some firms do, at three cents a package instead of five, you get only about one sixth the usual amount, and they are not always true to name, to say nothing of the disappointment and loss of time given to raising cheap mongrel varieties. Some plants bear so few seeds that they are necessarily scarce and 
high in price, and the higher the price of a package is, the more surely you are guaranteed in getting something rare and difficult to obtain, or an exceptionally fine selected strain. This is also true of plants. No firm can market strong healthy plants at retail for less than ten to fifteen cents apiece for the common varieties, and a correspondingly higher price for rare ones; and when a plant is offered for five cents, postage prepaid, it is so small that it is worth about two. Get a few plants each year from the best house you know, and you will have in time a collection that is worth while.

$I$ have in mind the futile experiment $I$ have made to secure Eremurus robustus, that is quoted from two to three dollars a plant. I could not afford to pay so much, and bought seed at twenty-five cents a package, and planted them with the greatest care. They take a whole year to germinate-which I did not know - and the second year I found six tiny triangular spears of green where Eremurus was marked. I was very happy until I discovered that the brown cutworm was also interested in my collection, and three of them had already met with an untimely end. I transplanted the remainder at once from the hotbed - this was before my emancipation from that snare-and put on a double patrol to guard them. A few days later two more had yielded up the ghost. I visited my one ewe lamb at least ten times a day, and it was growing in stature and wisdom until, about three weeks later, I got out one morning just after the tooth of the serpent had laid low the sole survivor. I could have wept, but did not; for I made such a savage chase for the destroyer that grief was lost in wrath. Here were two years lost, and I was just where I began. I bought more seed and planted again, waited another year for the seed to germinate, and the next, which was the third spring, found nineteen little threads of green up. I transplanted them and their place was carefully marked, for they 
die down in summer. The fourth spring they were again reduced in number to seven - then dwindled to four; and now after five years of prayerful watching I am still on the waiting list, for it will take at least four years more for them to mature to a blooming size: nine years of faithful love for an uncertainty is a sore test for a gardener. Considering that, when full-grown, the large, fleshy roots are very brittle and perishable, and must be packed with the utmost care to transport, it is evident that a mature Eremurus at three dollars is a bargain. The same thing is true in regard to roses, bulbs, or shrubs that seem costly; you are paying merely for carefully selected varieties plus the years of care you are saved in bringing stock to perfection; and the price is not exorbitant. In some ways there is great advantage in raising one's own plants; they are perfectly acclimated; they can be transplanted under the most favorable conditions, at your own convenience, and plants are saved the long exposure of their roots to the air during transportation. Aside from these conditions, it is really necessary for one who grows many plants to know the seed leaves, in order to distinguish flowers from weeds. There are few things exactly alike in this world, but it takes an experienced eye to know Hesperis matronalis from the common wild primrose at an early age, or Lychnis roseum superbum from sorrel, Gaura Lindheimeri from smartweed, Nicotiana affinis from mullein, many of the tiny bulb seedlings such as Hyacinthus candicans, Eremurus, Dianthus cruentus and iris from common grass, as well as to identify at once the little growths that spring up in the walks and over the garden. I not only know at a glance any bit of green an inch high of the many varieties I have raised from seed, but I can very shortly plant it in its proper color bed with definite certainty merely from the looks of the stem, leaf or manner of growth. I can tell at the third leaf whether a 
larkspur is blue, white or red; whether sweet-william is rose pink or red, a morning-glory is white, pink or purple, or a Lychnis is a pink or red variety, and so on.

It is interesting to note that seed leaves follow very simple typal forms as a rule, and only later in their life do plants develop their specialized character. Compound, pinnate, palmately cleft and deeply incised leaves often appear only as the third or fourth pair in a plant. On the other hand a plant that has been hybridized to take a more complex form often reverts, if neglected, to the simpler type of the original stock. This intimate knowledge of plant life is a source of the keenest pleasure as well as an admirable training in accuracy of observation. We enjoy things in proportion to the exact and comprehensive way we see them, and in growing seeds we are trained in a nice discernment. This knowledge of leaf forms is also valuable when plants appear in the spring, and it is necessary to divide perennials for resetting. One does not know his garden until a leaf tells as much as a flower, or a stem supplies the missing link. A basket of perennials was sent me from Connecticut, which represented several things I did not have. A few were labeled, others I identified by family resemblances. One plant puzzled me. Its leaf somewhat resembled Physostegia, but was broader and its manner of growth did not quite agree with either of my varieties; and when the buds formed, the compound panicles were fourgrooved while mine were round tapering spikes. One day when it was three feet high I unconsciously touched the stem and it felt square, which I had not observed with my eyes, and my instinct said at once-it is Physostegia, which it proved to be when it flowered. The feel of plants is as varied as their leaf or blossom. Succulent leaves, like the Sedum spectabile, feel cold and clammy, several degrees lower in temperature than a hollyhock leaf. Some thin smooth leaves are full of 
pores, receiving and discharging moisture, which keep them cool; while woolly pubescent leaves are much warmer. An Irishman once called the mullein a canton flannel ivy. Note the difference of temperature between the leaves of the Clematis paniculata, Lilium speciosum album and Physostegia as compared with those of the Lychnis coronaria, Anchusa Barrelieri, Helianthus mollis, and Rudbeckia. I do not know that it can be laid down down as a general rule, but it is certainly true of many plants, that those with rough, woolly leaves suffer more from heat and drought than those with smooth glossy ones.

Speaking of one sense supplementing another reminds me of my belief that the sense of sight is next-door neighbor to the sense of touch, and each sits on the other's doorstep at times to receive impressions. The green foliage of the tall late cosmos and the tender green depths of a locust-tree give me the same pleasurable sensation that I get when touching fur or a silky velvet. I have seen square flat heads on certain people that feel rough and harsh to the eye. 


\section{A DESCENT INTO PARTICULARS}

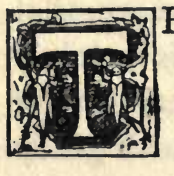

HIS chapter will be dull-dull and useful as work clothes and garden boots. It would be impossible to write such a chapter early in May, when all is joy and beauty, and the heart is light with the expectation of fulfilling at last the promises of former years. By the middle of September, one has grown calmer and can see that a slight gain has been made in definite knowledge; the purple light of spring has mellowed to russet and tawny shades; though the horizon of the unachieved has moved but a little further off, its rim is still supported by fair hopes. With the summer's successes and failures immediately before the eyes, one can grasp the situation more clearly, and generalize a multitude of apparently slightly related facts.

Gardening is not the mere growing of a few pretty flowers, nor sending a man out to dig and trim, or a maid to gather the bloom which the châtelaine arranges indoors while she talks volubly of my garden. Gardening is the gateway through which we approach another world than ours, a world governed by inflexible laws, a world made up of units as individual as human beings are; yet many bear close family resemblances by which we trace their ancestry back to a remote common stock; a world in which some of its members are rapacious and self-seeking, others-so sensitive and delicate that any unfavorable condition destroys them; some so prolific that, if unchecked, they would soon cover the globe; others bearing but a single child at long intervals; still others sterile and to be propagated only by cuttings or division of the root. 
The various talents and gifts observable in the human family have their equivalent in the way that certain plants emphasize portions of their organism. In the Venetian sumach, or smoke tree (Rhus cotimus) we see the culmination of the plant in the curious extension and division of the petioles of the flowers, which is often mistaken for its bloom. Volumnia, the goddess of petioles, must preside over its life. In $E u$ phorbia heterophylla and E. pulcherrima, known as Mexican Fire and poinsettia, the beauty lies in the scarlet bracts that surround the inconspicuous flowers; in the bittersweet, it is the scarlet aril surrounding the berry; in the Physalis Francheti, or Japanese lantern plant, it is the brilliant red fruiting calyx. In some plants the chief value is in the foliage, which may be richly colored, or soft gray, white, or woolly; some have beautiful seed pods like honesty (Lunaria biennis); some are prized solely for their fragrance, as mignonette, boy love, Ambrosia artemesiafolia, sweet fern, lemon verbena. Some are strange and grotesque in shape, as the Calceolaria and lady's-slipper.

There are many plants that offend my sensibilities, not only because of their manner of growth, odor, habits, but they seem to stand for something distinctly unpleasant or irritating. I look upon blotched, spotted and streaked flowers as offensive vulgarians; colored lilies represent bad taste and loud talking in the floral world. Some do not fulfill the promise of youth, as, for example, the common mullein. I know of nothing more alluring than a young mullein unbitten by ambition. Its low rosette of woolly gray leaves are all that one can desire, and if it were content to remain a modest tuft, and send up a straight leafless stalk not over two feet high, and open its spike of flowers at one time, the mullein would be incomparable. As it is, it reminds one of a person of simple worth who suddenly loses a sense of proportion and drags his unripe vir- 
tues into public view in an undue struggle to make himself seen and felt in his community. If I were making mulleins, I should guard their youth more carefully, and check the first intimation of headiness.

Some plants attract one from the beauty of their names. I confess this alone prompted me to buy Stephenandra flexuosa, Zea gracillima variegata, Euphorbia corrolata, Deutzia gracilis, Amaryllis, Asperula azurea setosa, Armeria formosa. Also poetic associations led me to appreciate Amaranthus, Lavender, Spikenard, Asphodel, Rue, Rosemary.

As a child I observed the invariable use of the correct botanical name of plants by florists and their assistants. A man might speak broken English and be apparently uneducated, but he never condescended to use the common name of a plant. There is an equal reluctance on the part of the general public to adopt the specific name; they accept any makeshift in preference, little realizing that any scientific study, if patiently pursued, shows beneath the dull terminology a vital principle that relates it with the living world. From this point of view, the dryest technical name becomes interesting and significant. They are not mere arbitrary names, but descriptive terms that help one to choose exact varieties: thus ruber, rubra, coccinea, cardinalis, fulgens, splendens denote red varieties; albus, alba, albida, nivea, niveus, blanda, candidum represent white; roseus, rosea are rose colored or pink; carulea, ccelestina, azurea, violacea are blue; aureum, aureus, flava, flavum, luteus, sulphurea, the yellow; maculata, spotted or streaked with white; argentea, silvery. Common garden varieties are indicated by hortensis, vulgaris, officinalis. Size is indicated by major or majus, tall; minus, nana, nanus, small. Moschata, fragrans, odorata, odorissima, suaveolens represent fragrant varieties. A climbing variety is scandens, while a creeping one is repens, reclinatum. Texture is denoted by 
tomentosa, mollis, pubescens, villosa, as downy varieties; hirsuta, hairy; rugosa, rough; spinosissima, thorny. A spring variety is verna, vernalis, or vernis; a summer is astivalis, an autumn as autumnalis. The opium poppy is Papaver somniferum, literally the sleep-bearing poppy. It takes but a slight knowledge of Latin to understand the terminology of the garden, and the Latin name is so much more liquid and agreeable in its vowel sounds than the English equivalent that I love the Latin name. As in the best catalogues plants are thus classified, it is really necessary for the amateur to familiarize himself with scientific names, which can be done by referring to a good botany, which gives both the common name and the Latin.

But we must not linger over this fascinating subject for there are many other matters that need a word. For example the fragrance of flowers is seldom given the prominence it should have. By exercising a little thought, fragrant plants may be placed at the entrance of a garden, near objects of interest, or about the seats. There are fragrant flowers for the whole season, and special attention should be given to secure fragrant varieties of any species. A sweet odor seems to be one of the compensations given to certain plants that otherwise are handicapped by size, obscure color, or little beauty. What should we care for mignonette, ambrosia, violet, lavender, fragrant evening stock if they had no perfume? Some plants possess every gift of fortune, such as roses, white lilies, lilac and fragrant peonies; but many of our favorites are loved for their perfume alone. I subjoin lists of the fragrant flowers in my garden classified under shrubs, perennials and annuals. By referring to the Appendix, their time of blooming may be determined. This list does not include roses. 


\section{FRAGRANT SHRUBS}

Boy love

Bush Honeysuckle

Chaste Tree (Vitex agnus-castus)

Cladastris tinctoria

Clethra alnifolia

Chionanthus Virginicus

Elaagnus canadensis

Lilac

\author{
Locust, Honey \\ Raspberry, Red-flowered \\ Sumach, Fragrant \\ Sweetbrier \\ Sweet-gale \\ Sweet-scented shrub \\ Syringa \\ Weigelia rosea
}

\section{FRAGRANT PERENNIAL VINES}

Clematis, Japanese

Honeysuckle, Belgian
Honeysuckle, Japanese

Polygonum multiflorum

\section{FRAGRANT PERENNIALS}

Alyssum saxatile

Arabis albida

Asperula odorata

Asphodel, Yellow

Bouncing Bet

Carnation, Hardy

Clematis heraclafolia, var. Davidiana

Clematis recta

Cyclamen Europaum

Dianthus Caryophyllus

D. plumarius

Dictamnus

Elder

Erysimum ochralucum

Feverfew

Forget-me-not (in evening)

Galtonia candicans

Galium boreale

G. Mollugo
Gysophila paniculata

Heliotrope, Garden

Hesperis matronalis

Hyacinth

Hyacinth, Musk

Jonquil

Lavender

Lilium auratum

Lily, Yellow Day

Lily, Japan Day (Funkia sub. cordata)

Lilium speciosum album

L. speciosum rubrum

Lily, St. Bruno's

Lily of the Valley

Lychnis splendens

L. vespertina

Mallow, Musk

Narcissus poeticus var. alba plena odorata 


\section{A Descent into Particulars}

Paonia, var. Marie Lemoine

$P$., var. humei carnea

Pansy

Phlox paniculata

$P$. divaricata
Primrose, Evening

Rosemary

Sweet-william

Valerian

Violet

FRAGRANT ANNUALS

Abronia

Alyssum

Ambrosia artemesiafolia

Bartonia

Bean, Flowering

Candytuft

Cleome pungens

Centaurea, var. Imperialis alba

Cephalipterum .

Datura

Eritrichium

Fragrant evening stock

Limnanthes

Lupinus mutabilis

L. arboreus

Mandevilla

Martynia

Mignonette
Moonflower

Nasturtium

Nicotiana

Nycterinia

Pansy

Petunia (White)

Scabious

Schizapetalon

Stevia serrata

Stock

Sweet Clover

Sweet Fern

Sweet Pea

Sweet Sultan

Verbena

Verbena, Lemon-scented

Wallflower

Another matter which does not always receive enough attention is the use of green in a garden. Green is the natural environment of a plant, but we have fallen into a pernicious habit of crowding together colored bedding plants so solidly in many of our public parks and boulevards, where flowers are supposed to have an educational value for the masses, that a protest should rise against this false idea of beauty. Properly insulated by green, one can use colors near each other that would clash if brought immediately together. Take for example a red bed: there are but few pure red flowers; they 


\section{4 \\ Hardy Plants for Cottage Gardens}

range from scarlet and orange scarlet into crimson and bluish tones of magenta and solferino. The result is fatal if these are mixed indiscriminately together; but, using the pure red as a central note, a border may gradually merge either into the yellow-reds or the purplish-reds, and if plenty of green is used to separate the plants, the effect is gorgeous. A proper admixture of light airy plants such as Gypsophila paniculata, Asperula hexaphylla, Gaura Lindheimeri, meadow rue, garden heliotrope, Stevia serrata, Galium boreale, wild carrot and caraway will add loveliness to brilliant reds.

A successful red bed, or one of any given color, is not the product of a season. One must begin by assembling the plants, and arrange them theoretically; but each year will witness removals and new combinations. It may be well to make a note, while plants are still in bloom, of any change to be made in the autumn; for, in the reconstructing days, details are apt to be overlooked and plans forgotten. Most perennials are benefited by occasional lifting, and the larger the plant, the more likely it is to require division after a few years. Of course shrubs are exceptions to this rule. If a number of plants of mixed unknown colors, say of phlox, are planted at once, they may be marked when they bloom by the color code I have indicated for marking seeds, and in the autumn can be redistributed according to their precise color.

A most careful study should be made of the character of plants, their relative size, height, and time of blooming; also the duration of bloom. Tall plants should be placed in the rear, and low ones toward the front of beds or borders; or the tall ones may be planted in the center of large areas. In removing a plant think twice before digging it up, and thrice before resetting it. Have the new location already prepared, with a bucket of water at hand, and soil adapted to the needs of the new occupant dug over and mellowed considerably 


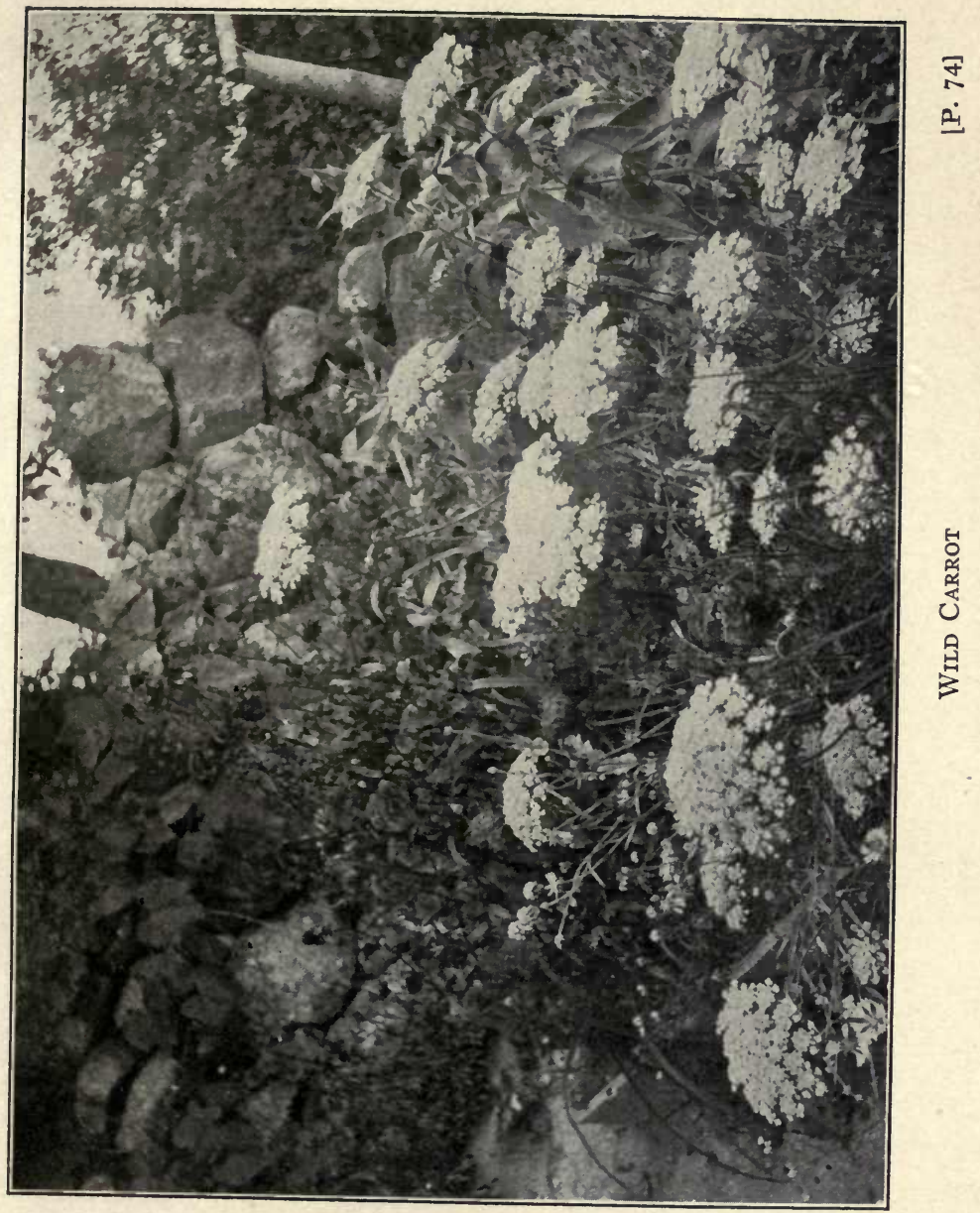



lower than the plant is to be set. In removing, loosen the ground all about a plant or shrub, and if it holds fast, run your hands down among the roots, and lift them gradually so as not to break them. Take up earth in a mass about the roots, if possible, and it is well to water the plant thoroughly before attempting to remove it, which prevents the earth from scattering from the roots. Make a puddle of water in the hole, set in the plant, and draw in the loose soil gradually, working it in carefully among the roots which should be spread out; pour on more water and fill up the hole, pressing down the earth with the hand, or very lightly with the foot. Do not trample hard, for the roots are often tender or brittle. Reset the plant as deep as it was before, taking care not to allow the earth to settle among the stalks in the crown. Make a slight depression about the plant so that, when watered, the moisture will collect and sink in gradually. By taking these precautions I have transplanted large specimens in full flower without the slightest injury. Firmly rooted plants or shrubs should be lifted after a heavy rain storm when the earth will be found to be loose and mellow to a great depth.

Ferns add interest to beds of any color. I do not know their exact botanical names, but I have taken perhaps six varieties of native ferns from the woods, and have disposed them in various beds with good effect. They may be taken up either in early spring, or, by cutting back, may be transplanted successfully in midsummer, if shaded for a few days and well watered. Contrary to the common belief, both ferns and cardinal flower may be given full sun and rather a dry location, provided the soil is rich. I once had a cardinal flower given me when in full bloom, and as there seemed little chance of saving the bloom I took no pains to shade it for a while; but it bore the change well, continued to blossom and the following year was greatly increased in height and vigor, 
notwithstanding it was placed in a dry bed in full sun. Later a seedling appeared in the hard-baked walk at the edge of a stone step, and owing to my negligent hoe, escaped infantile disaster. Through the severe droughts of the past three seasons, it has flourished and bloomed in the dry hard soil, in full sunshine, the stone over the root being its salvation. It is almost impossible to tell a cardinal flower from Veronica spicata when in the seedling state; the only difference being that the cardinal plant has a leaf of a darker green and less crenate at the edge. I mention this because the destruction of young Veronicas is one of my occupations: they lodge at all seasons in every unguarded place.

Another addition to the green of a garden is obtained from the first year's growth of the Allegheny vine (Adlumia cirrhosa). It is a biennial and does not run as a vine until the second year; but the first year it makes a low spreading growth of delicately divided leaves on long slender stems, much resembling the maidenhair fern, and it is quite as useful as that fern in the arrangement of cut flowers. I especially recommend the plant for this purpose, and as an equally beautiful vine the second year. It then dies; but as it is selfsowing it is permanent when once established. As it does not root deeply, the first year's growth may be used in a lily bed with the pink annual larkspur as a shade to the ground. In an iris bed a cover to the ground may be secured by growing pansies, either as seeds, which bloom in a few weeks, or setting out the full grown plants. Other plants that root but lightly are candytuft, sweet alyssum, Clarkia puchella, Scotch pinks and Helianthemum, and they may be grown in lily or rose beds. Gladioli are to be recommended for rose beds, as they require much the same conditions as roses, and do not shade the ground. I have tried Shirley poppies in a rose bed, and though they root lightly, they make such a rank growth 


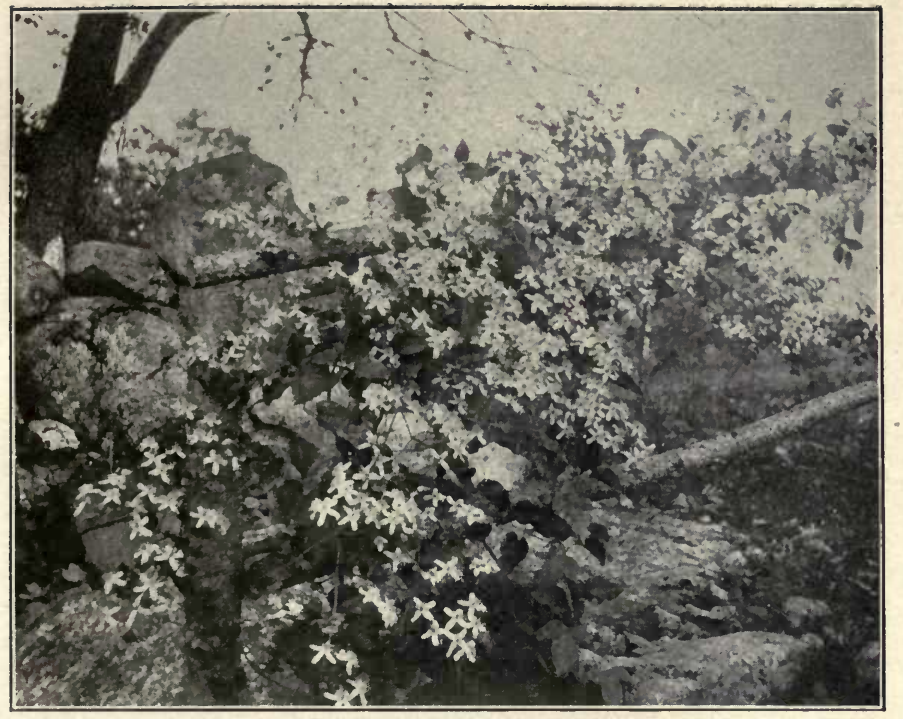

Japanese Clematis (Clematis paniculata)

[P. 72]

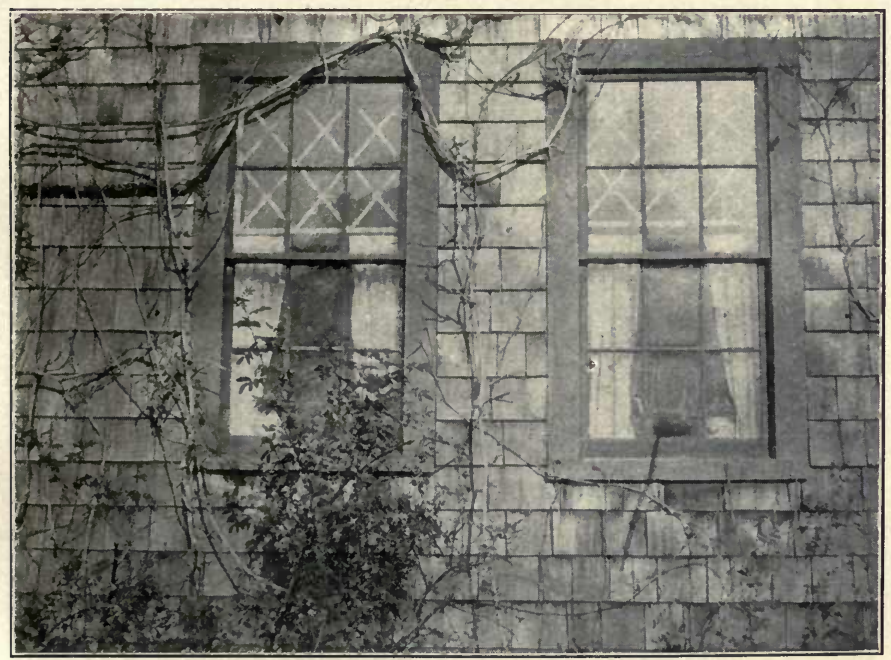

Virginia Creeper after Autumn Pruning

[P. 77] 
in rich soil that they choke the roses. Some people use perennial phlox among rose bushes so as to carry bloom into the autumn.

Another useful plant is the hop vine, which transplants easily, increases rapidly at the root when well established, and covers a wall, trellis or an arbor with graceful festoons bearing the pale green fruiting calyxes. Among other green vines the Virginia creeper stands out preëminently for use in a severe climate or exposed situation. It takes some time to get established, but once started, there is no limit to the growth. It needs some sun, plenty of fertilizing, as much or little water as you wish to give, but above everything severe pruning each autumn, and the result is wonderful. Our cottage is completely clothed with it, and I give an illustration of the way the vine looks after pruning in the autumn. It covers the screen at our front door without interfering with opening the door; and it is often amusing to see how puzzled people are about entering through a vine. We also contrived a way to use the creeper over a trellis built on a back piazza. Holes were cut in the floor near the house, the vines were drawn up through them and fastened to the wall and then trained over the trellis, to give shade to a table where we take our meals al fresco. The drip from the roof supplies the vines with sufficient moisture, and though they do not thrive as well on this north wall under such unusual conditions, they make a gradual growth each year.

There is needless prejudice against covering a shingled or frame cottage with Virginia creeper, because it is said to rot the walls. We have found this is not true. Sixteen years ago, when we took our old house, the frame was newly shingled, and where the vine is close and thick near the roof, the shingles are still new and fresh looking; elsewhere they have turned a silvery gray. The leaves, extending outward, act 
like countless watersheds, and oniy when they fall do the walls ever get wet. There are two varieties of Virginia creeper, one with light green, rather thin leaves, that turn a bright scarlet in the autumn, the other has heavier glossy dark green leaves that turn a dark maroon at the edge before frost comes, and bright crimson later. The second variety is the stronger and more beautiful of the two.

Adam devised an ingenious use of a dumpheap of rocks and débris, the accumulation of former generations, by having the stones piled as compactly as possible, and held in place by a retaining wall. When leveled, he earthed it over, and sowed it with grass seed, and the result is a broad terraced driveway across a swale. It is edged with oaks and maples that had found lodgment in the original heap, and having now attained enormous size, they complete one of the most picturesque features of our premises.

There are three plants that have no value for flowers that give a delicious perfume to a garden; one, a low herb, whose trade name is Ambrosia Mexicana, also Southernwood or boy love, because it seldom bears any flower (Artemesia Abrotanum), and sweet fern (Artemesia annua), which grows four feet high with delicately cut fern-like leaves, small greenish inconspicuous flowers, and green stems that turn red in autumn. The odor of it is both sweet and aromatic. It is also said that Kochia scoparia is very attractive as it turns a beautiful red in autumn. I bought it under the name of Belvidere (Kochia trichophila) which makes the same claim, and either I got a wrong variety, or something was amiss, for it was not beautiful at any season.

I have used sumach extensively about the house for the sake of the beautiful foliage both in summer and autumn: it turns a flaming red under the first frost. The creamy green flowers are borne in great panicles, which turn late in September to a 


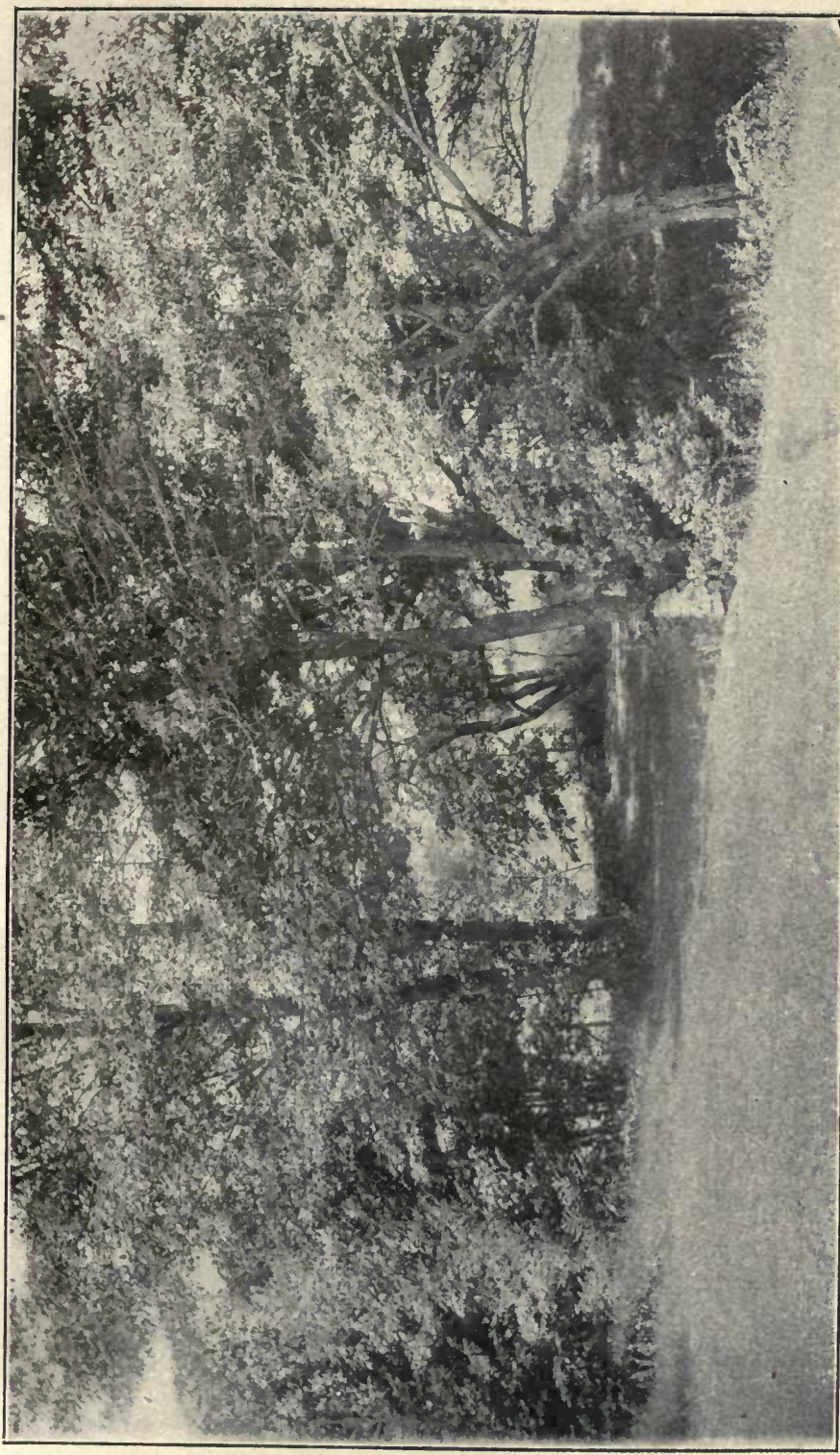


deep crimson. The rose-bug infests the sumach and sometimes strips the bloom to the naked stems. Care should be taken lest it spread from the root.

The tall cosmos makes a beautiful background for colored flowers and, though it is so tardy in coming into bloom that it seldom flowers in the North before the frosts come, its fluffy green fur is lovely to look upon if one can spare the room to grow it. A single plant often grows six to eight feet high and three feet in diameter. I have seen the tall cosmos lifted, when in full bloom, just before frost, and planted in tubs for house use. If transplanted carefully, it continues to bloom until Christmas, a truly wonderful sight.

I find the maidenhair tree (Salisburia adiantifolia, also sold as Ginkgo biloba) to be entirely hardy. It is from China and has interesting foliage that resembles the leaves of maidenhair fern, triangular and notched at the outer margin. The fruit is a drupe, and both the fleshy part and the nut are eaten in China. As the male and female flowers grow on separate trees, the Chinese plant the two close together so that they are practically one tree, producing male and female flowers. My specimen remains a low shrub, though in some portions of the United States it grows to the size of a large tree.

Brilliant autumn effects, that brighten a garden after a sharp frost has killed the flowers, are secured through the use of certain perennials and shrubs. Among the former I note that the foliage of meadow-rue turns a deep yellow; that of the Aster Novi-Belgii, which bears a heavy terminal cluster of rosy lilac flowers with bronze yellow centers, turns a rich purplish rose. Spirea tomentosa becomes orange, orange red and bronze; Kochia scoparia, a brilliant red; sundrops (Enothera fruiticosa, var. splendens) also become a velvety red, as does Lythrum salicaria.

Among shrubs that turn a fine color are Spirea prunifolia, 
reddish bronze; Spirea salicifolia, bright yellow green and reddish; Spirea superba, a rich reddish purple; Spirea Thunbergii, reddish yellow; Japanese barberry (Berberis Thunbergii), bronze, orange and crimson; Rhodora Canadensis, red; cinnamon rose, orange and orange red; sumach, deep red and orange red; Stephenandra flexuosa, bronze yellow; Ginkgo biloba, a clear yellow; cranberry tree (Viburnum opulus), brilliant red; Japanese snowball (Viburnum plicatum), red; hobblebush or wayfaring tree, a lovely old rose and claret color; crape myrtle, a bright scarlet. Among others that are attractive are Euonymous alata; Kerria Japonica; Itea Virginica, flowering dogwood (Cornus florida), shad bush or Juneberry, and Chionanthus Virginicus. Certain pear-trees turn a brilliant red or purplish color; and the Japanese peach becomes an old rose.

Aside from yielding a rich coloring in late autumn, there is a variety of hardy shrubs and trees that have colored foliage at all seasons, and these may be planted in groups of single species with bright green shrubs and evergreens, or in contrast with each other, or with reference to herbaceous perennials that bear showy masses of bloom. The following list will give some idea of the possible effects obtainable from a few of this desirable class.

BARBERRy. Purple-leaved (Berberis vulgaris, var. atropurpurea). A rich purple foliage that holds from spring to autumn; very attractive when planted with yellow-leaved shrubs. Give a sunny position.

BEECH. Purple-leaved (Fagus sylvatica, var. purpurea). Said to be the finest dark leaved tree in cultivation.

BURNING BUSH. Waahoo (Euonymous atropurpureus). 6-I4 $\mathrm{ft}$. Flowers dark purple, showy; leaves a bright green. The fruit is the chief attraction, becoming in autumn a bright scarlet, and borne in great abundance so as to cover the tree; hence the name.

ELDER. Golden (Sambucus nigra, var. aurea). A golden yellow 
color that does not fade. Give a sunny position, pinch back to induce a bushy growth.

Hazed. Purple (Corylus purpureus). 4-6 ft. In early spring the leaves are almost black, a little later become a dull purple, and so continue throughout the season. Thrives in dry or moist soil.

HOP HORNBEAM (Ostrya virginica). A small tree of slender form native to my district; flowers inconspicuous, followed by handsome fruit resembling the hop clusters, except longer and more slender, that hang in festoons. Leaves turn orange-brown in autumn.

Itea Virginica. $5^{-8} \mathrm{ft}$. Leaves turn from green to scarlet in midsummer, and continue so through the season. White flowers in June.

Lead Plant (Amorpha canescens). I-3 ft. Purple flowers in clustered spikes and whitish or lead-colored foliage.

PEAch. Blood-leaved (Prunus Persica). A variety with blood red leaves in spring, becoming purple in summer.

Silver BERRY. Silver Thorn (Elceagnus argentea, also known as E. Canadensis and E. parvifolia). 6-8 ft. Flowers yellow and fragrant in August, leaves silvery white, fruit edible, dry and mealy, but esteemed by many; throws up many suckers.

SMOKE TREe (Rhus cotinus). 4-8 ft. Towards autumn the rosy flower pedicels make a reddish mist over the entire bush and is mistaken for the bloom which comes earlier; foliage turns a rich red.

SPIREA. Golden [Physocarpus (or Spirea) opulifolius, var. aurea]. $5-7 \mathrm{ft}$. A yellow variety especially bright in spring; said to be one of the best shrubs in cultivation.

SPIREA. Purple-tipped (Spirea superba). A vigorous shrub, that, during the greater part of the year, is a rich ruddy tone, and during the summer when the foliage is less vivid, it bears many large flat heads of red blossoms, so that at all seasons it has a marked beauty.

Sumach. Fern-leaved (Rhus glabra, var. laciniata). 3-5 ft. Finely cut leaves on long stems. If grown with several stalks from a common root, the interlacing branches resemble a ball of fire in autumn when the leaves turn a brilliant red.

Any foliage or autumn effects are more striking if the entrance of the garden faces the west, and the afternoon sun shines through the leaves. In arranging a garden, study every point of view; visit it at its magic hour, and you will see won- 
ders that are not revealed to the common eye. I recall an episode that occurred in Florida which illustrates this point. In front of the house we took for the winter stood a liveoak tree that gave me peculiar pleasure as I walked home at sunset, and saw its delicate tracery of foliage against a rosetinted northwestern sky. I frequently chose that hour to return in order to enjoy the perfect beauty. I spoke of it so often, that the owner of the house asked me to show it to her. I walked her off to the place where it was loveliest, and then bade her turn around and look. "Why," exclaimed she, "it is beautiful, but I never saw it before, though I have lived here twenty years. Indeed I have been on the point of having that tree cut down, for it looked so ugly from my window."

An interesting feature of a garden is the use of a succession of low border plants as an edging. There is no one plant that will continue to bloom throughout the season, and instead of using a single variety, try planting three or four that will supplement each other. For example, one may use rock cress (Arabis alpina), which blooms early in May and alternated with this the forget-me-not (Myosotis alpestris), a hardy variety that blooms later in May, and the Scotch pink, Dianthus plumarius, that blooms in June, leaving spaces where sweet alyssum or candytuft may flower during the remainder of the summer. By this arrangement a flowering edge may be maintained throughout the season without lifting or setting out a plant. I have planted forget-me-not and Agopodium varigata just outside the board enclosures of my beds in the walks, and they completely hide these ugly but useful boundaries.

For border plants I recommend among blue and purple perennials; Scilla Siberica, Anemone pulsatilla, pansy and lady's delight for April; Aubretia deltoides, var. Eyeri, Myo 


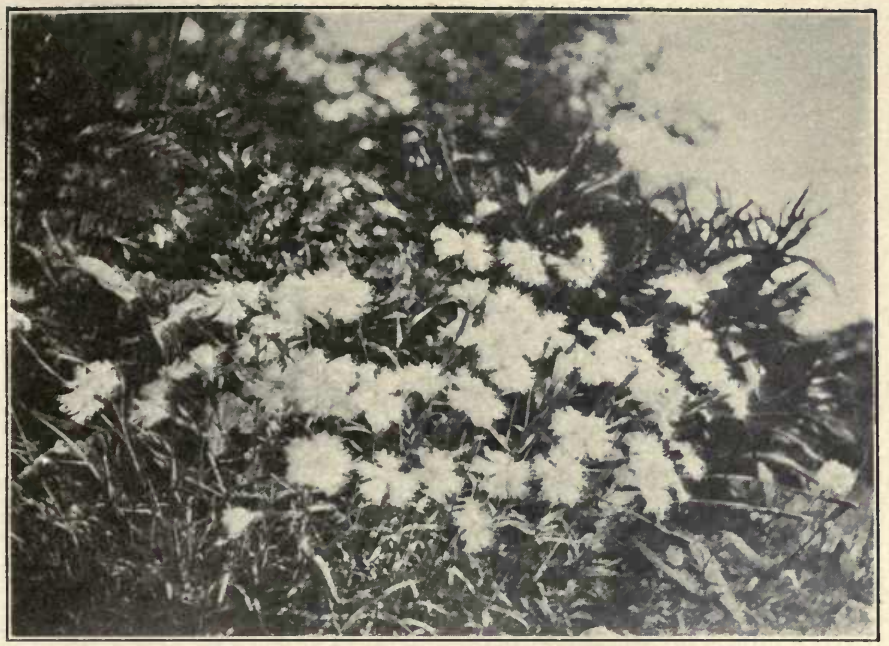

Dianthus plumarius

[P. 82]

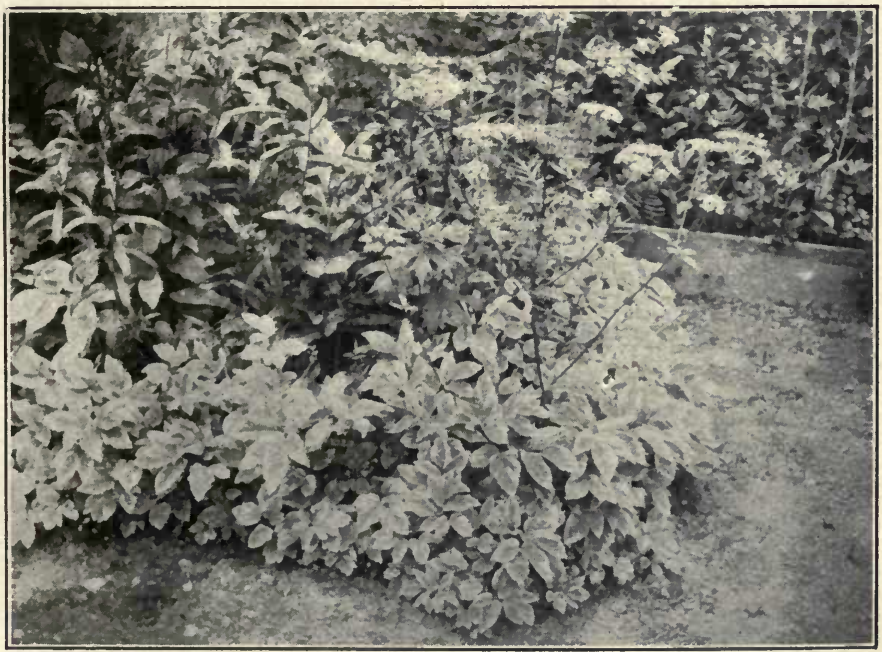

Goutweed (Agopodium varigata) AS A Border Plant [P. 82] 
sotis alpestris, var. Victoria, Jacob's ladder, creeping phlox (Phlox sublata atropurpurea), Russian violets for May and early June. Campanula turbinata for July. Of the blue annuals there are dwarf varieties of Ageratum, Linaria marroccana, pansy, Nigella, Nolana, Whitlavia, Phacelia, Nemophila for July; and for August most of these are still in bloom to which may be added verbena.

For a pink edging there are among perennials Scilla nutans, var. rosea for April; pink forget-me-not, creeping phlox (phlox sublata) for May. English daisy (Bellis perennis) for May on through the season. For June, Crucienella stylosa, maiden pink, Armeria plantaginea, Helianthemum, Japan pinks (if in their second year), Saponaria ocymoides, sweetwilliam, Tunica saxifraga, Verbena montana, which is not quite hardy with me. Of pink annuals for June are Clarkia, candytuft; for July, Ageratum, var. Lasseuxii, Abronia umbellata grandiflora, the exquisite peach-colored catchfly (Silene compacta, var. pl.fl.), branching larkspur (if sown the previous autumn, else it will not bloom until August or even September). Fenzlia (Gilia dianthoides rosea), Saponaria calibrica and verbena; for August Vinca rosea.

Among red perennials for an edging are Aubretia deltoides, var. Leichthinii, tulips and hyacinths for April and May. For June, Japan pinks, Saponaria ocymoides, var. splendens and sweet-william, for July, Callirhöe involucrata, coral bells (Heuchera sanguinea) and dwarf snapdragon. Red annuals for July as an edging are Adonis astivalis, mignonette (Reseda, var. excelsior), dwarf nasturtium, pinks, portulaca, Collomia coccinea and Verbena, var. Defiance.

Yellow perennials for an edge are crocus and pansy for April; Adonis vernalis, Alyssum saxatile, var. compacta, Erysimum puchellum and Iceland poppy for May; for June, Helianthemum alpestre; for July, sundrops (Enothera fruti- 
$84 \quad$ Hardy Plants for Cottage Gardens

cosa, var. splendens); yellow annuals there are for July: dwarf nasturtium, Abronia areneria, Oxyura chrysanthemoides, pansy, portulaca, and dwarf snapdragon. For August; Erysimum Perofskianum, Lasthenia Californica, Limnanthes Douglasii.

Of white border perennials are snowdrops and crocus for April; forget-me-not, lily of the valley, Phlox sublata, var. alba, Arabis albida, evergreen candytuft, white Iceland poppy and English daisy for May; Anemone sylvestris, Spirea filipen$d u l a$, var. pl. $f$. (which grows with me but a foot high), Tiarella cordifolia, Japanese and plumarius pinks, Galium boreale, thrift or sea-pink, sweet-william, goutweed (Egopodium varigata), Helianthemum mutabilis for June; and for July: dwarf white snapdragon. Of white June annuals suitable for edging are alyssum, candytuft, cynoglossum, nasturtium, Nemophila; for July: Abronia, Ageratum, Silene armeria, Collinsia bicolor, Eritrichium, Eucharidium, Mesembryanthemum, Nigella, Nycterinia, pansy, pinks, portulaca, Saponaria calibrica, var. alba, snapdragon (as an annual), Whitlavia. For August are Callindrinia speciosa alba, Leptosiphon, Gilia androseca and verbena.

The showiest flowers, and in many cases the longest bloomers, may be classified according to their color and time of beginning to bloom. The following lists are not exhaustive, merely a suggestion.

\section{BLUE PERENNIALS}

ApriL. Hyacinth, lungwort (Merlensia Virginica), scilla.

MAY. Lilac, columbine, German iris, wistaria.

JUNE. Canterbury bells, Spanish and English iris, Lupinus polyphyllus, pæony.

July. Campanula, Clematis Jackmanni, Japanese iris, larkspur, Physostegia Virginiana, monkshood, Stokesia cyanea, Veronica spicata, Platycodon. 


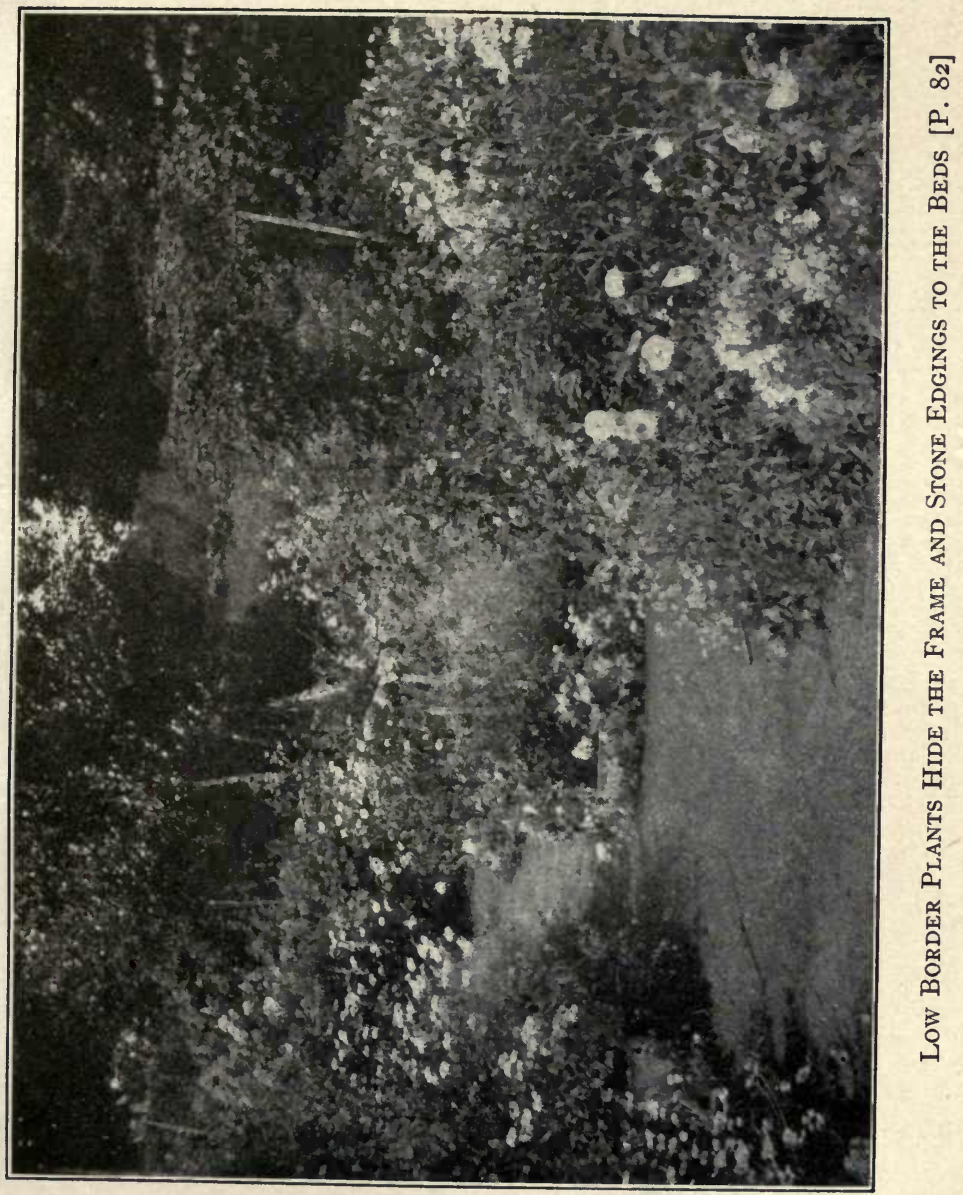




\section{A Descent into Particulars}

August. Perennial phlox, Erigeron glaucus, climbing monkshood (Aconitum reclinatum).

SePtember. Perennial asters, Boltonia latisquima.

\section{BLUE ANNUALS}

JUNE. Bachelor's button, dwarf convolvulus, Nolana.

July. Asters, lupines, pæony poppy (lilac).

August. Browallia, rocket, scabious.

\section{PINK PERENNIALS}

APRIL. Hyacinth.

MAY. Japanese flowering crab-apple, peach and plum, lilac, columbine, Eremurus robustus, Lychnis dioica rosea.

June. Roses, Diervilla, Incarvillea Delavayi, foxglove, lupine (Lupinus Douglasi), a cross between the annual and perennial varieties, Lychnis flos cuculi, oriental poppy, queen of the prairie, sweet-william.

JuLy. Mountain laurel, rhododendron, Canterbury bells, hollyhock, perennial pea.

August. Perennial phlox, gladiolus, canna, dahlia, lilies, hibiscus.

SePtEmber. Japanese anemone, asters, hybrid perpetual roses, stonecrop, chrysanthemum.

\section{PINK ANNUALS}

JUNE. Poppies, Clarkia.

July. Asters, Godetia, Lavatera, sweet pea.

August. Cosmos, larkspurs, scabious, Tridax bicolor rosea, salpiglossis.

September. Late cosmos.

\section{RED PERENNIALS}

APRIL and MAY. Tulips, Japan quince, red Japanese peach, columbine, scarlet lychnis, crown imperial.

JunE. Roses, weigelia, foxglove, lilies, pæony, oriental poppy, sweetwilliam, scarlet honeysuckle. 
JuLy. Spirea superba, bergamot, cardinal flower, geum, Lythrum salicaria, trumpet creeper.

August. Smoke bush, dahlia, gladiolus, hollyhock, phlox, tritoma. SEPTEMBER. Japanese lantern plant.

October. Chrysanthemum.

\section{RED ANNUALS}

June. Poppy, scarlet runner bean.

JuLy. Amaranthus, aster, cockscomb, nasturtium, phlox, zinnia. August. Salpiglossis, scabious.

\section{YELLOW PERENNIALS}

APRIL. Crocus, pansy (if in second year).

MAY. Forsythia, columbine, Iceland poppy, jonquil, tulip.

June. Roses, Doronicum Caucasicum, yellow day lily (Hemerocallis flava), lupine, pæony, Thermopsis Caroliniana.

July. Evening primrose, Gaillardia, Hunnemania, rudbeckia, Asclepias tuberosa.

August. Canna, dahlia, golden glow, hollyhock, Helen flower, perennial sunflowers.

September and October. Chrysanthemum.

\section{YELLOW ANNUALS}

JUNE. Calendula, nasturtium, Eschscholtzia.

JuLy. Summer chrysanthemum, marigold, snapdragon.

August. Sunflower and zinnia.

\section{WHITE PERENNIALS}

APrIL. Crocus and snowdrop.

MAY. Bridal wreath, Spirea Van Houttei, fringe-tree, pearl bush; flowering dogwood, deutzias, lilac, scarlet thorn, columbine, narcissus, German iris.

JUNE. Locust-tree, roses, snowball-tree, syringa, perennial candy. 


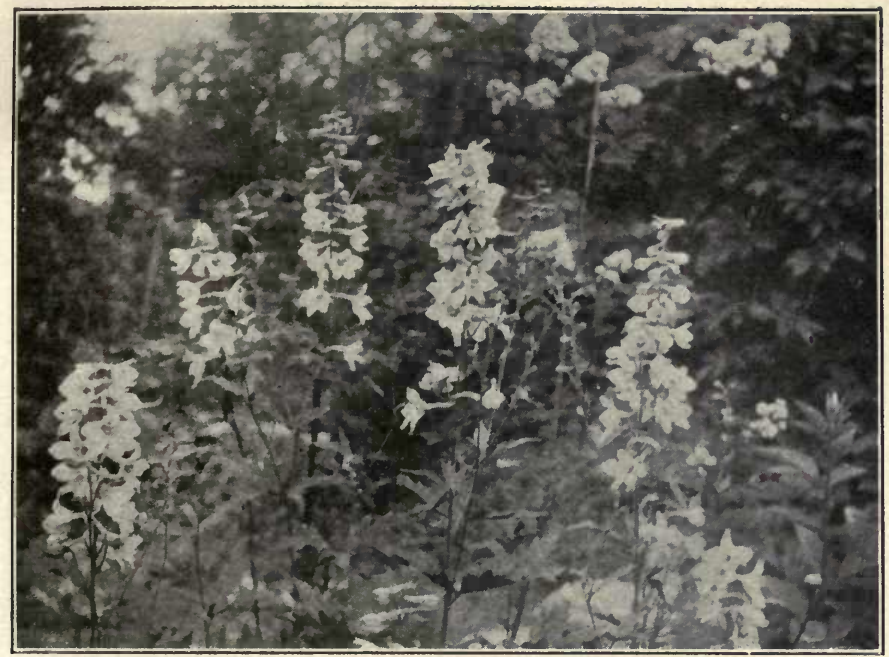

AzUre Blue Larkspur

[P. 85]

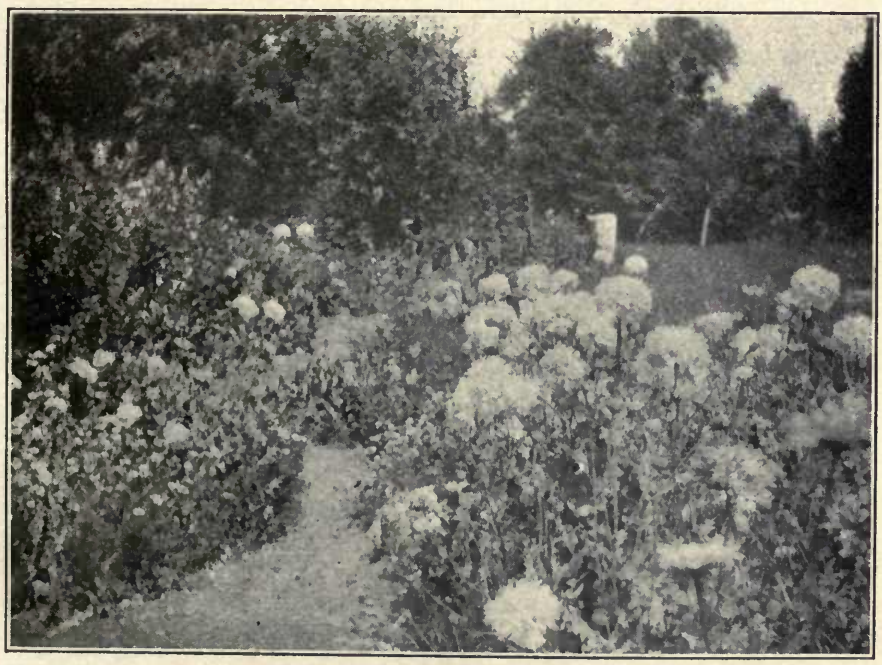


5 
tuft, Paris daisy, foxglove, garden heliotrope, lupinc, goatsbeard, meadow-rue, pxony, Hesperis matronalis.

JuLy. Elderberry, bellflower, wild clematis, Chrysanthemum maximum, C. latifolium, Japan day lily, Japanese iris, Madonna lily, platycodon, Spirea sorbifolia, yucca.

August. Hydrangea, hibiscus, hollyhock, auratum lily, Lilium speciosum album, perennial phlox.

SePtember. Japanese anemone, Clematis paniculata, Polygonum multiflorum.

OCTOBER. Chrysanthemums, Boltonia, asters.

\section{WHITE ANNUALS}

June. Poppy, malope.

JuLy. Arctotis, aster, cosmos, gaura, nicotiana, petunia, stock, sweet pea, snapdragon.

August. Scabious.

SEPTEMBER. Late cosmos.

I will enumerate a few of the combinations that I have found successful: Arabis albida with grape hyacinth or Phlox sublata; perennial candytuft and Lychnis dioica or Mertensia Virginica; Phlox divaricata and ferns; Jacob's ladder and white Iceland poppy of the second year's growth; German iris and blue lupines; white iris and Anchusa Barrelieri; coral bells and white daisies, annual gypsophila or caraway; Egopodium and forget-me-not; white foxglove and yellow day lily; harebell, dropwort and ferns; white foxglove and perennial blue larkspur; blue larkspur and meadow-rue; monkshood and meadow-rue; Asperula hexaphylla, Achillea and blue or pink cornflower; Gypsophila paniculata or Galium Mollugo and mallow (Malva sylvestris); campanulas and feverfew; elderberry, monkshood, tall blue larkspur and meadow-rue; oriental poppy and cinnamon fern; cornflower and candytuft; pink catchfly and annual gypsophila and candytuft; red Shirley 
poppy with a border of Egopodium and ferns; garden heliotrope and larkspur or monkshood; pink Shirley poppies and Paris daisy; bee balm and Galium Mollugo or Gypsophila paniculata; amaranthus and Chrysanthemum maximum and hydrangea; Veronica spicata and white Physostegia; lilac Physostegia and white larkspur; star flower (Triteleia laxa) and Coronilla varia; wild carrot and Rudbeckia or blue larkspur; pink mallow and Euphorbia corrolata; Chrysanthemum maximum and hollyhocks; bouncing Bet and lilac pæony poppy; nigella, candytuft and annual blue larkspur; pink branching annual larkspur and the first year's growth of Allegheny vine; perennial white phlox and hydrangea with golden glow or Helen flower; gaura and cardinal flower; amaranthus and early cosmos; pink or red scabious and pink or white early cosmos; gladiolus and perennial phlox or Japanese anemone; Stokesia cyanea and Achillea; Aster Novi-Belgii and blue or lavender Michaelmas daisy and white perennial phlox or white or blue Boltonia.

It may be objected that a too frequent use of white is made in the suggested combinations. I can only repeat what I say elsewhere, that white and green are the best possible foils for colored flowers, and are indispensable in a garden that expresses delicacy and grace.

There are many plants whose manner of growth does not lend them easily to general combinations, although the color may be harmonious; for example: the German iris throws out a heavy root stock in a circular way, which soon makes an unmanageable clump; and if divided, to keep it small, it takes a year, or more, according to the division, for it to bloom again. Also the Incarvillea Delavayi is surrounded by large radical leaves that are so admirably adapted as a background for its tall flower stalks that it needs no other plant as a foil. The same is true of Archangelica with its great acanthus leaves, 


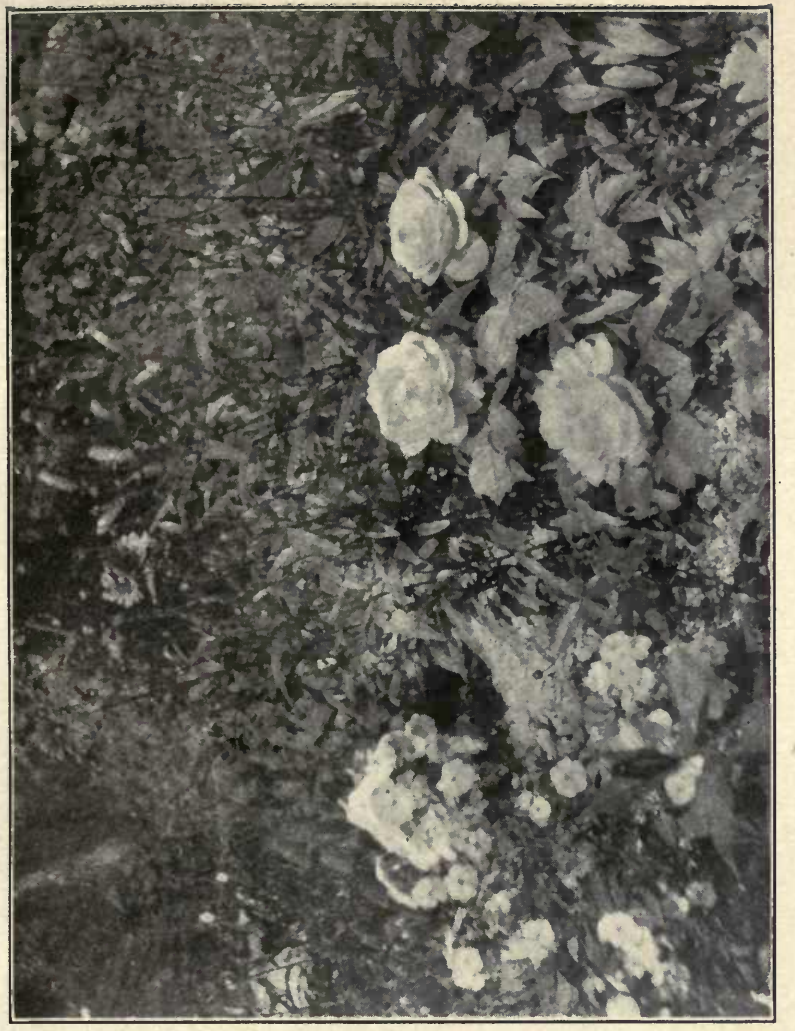

$\varpi$
$\infty$
$\dot{1}$

告

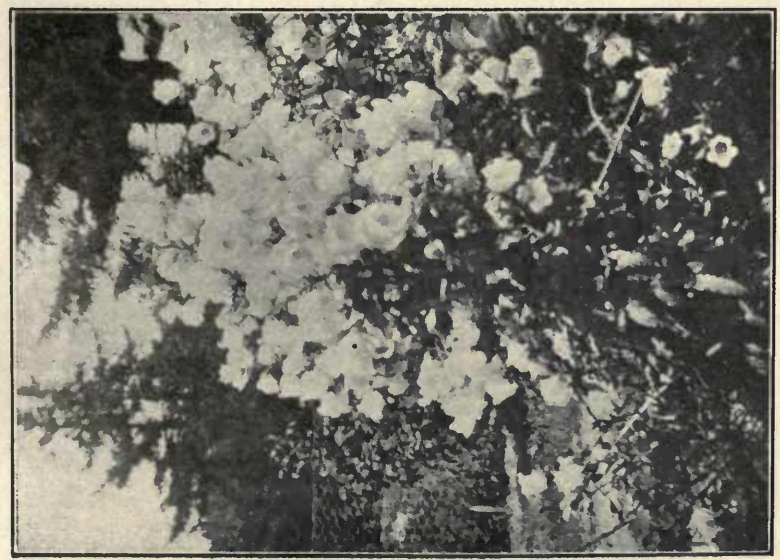

ڤ 
which, of course may be stripped off; yet they lend a peculiar distinction to the enormous white heads of bloom. In many instances it is better not to relate plants with others; make a group of them and let them stand for their own worth. Plants of slender delicate growth should not be placed in relation with those of sturdy form. Thus Triteleia laxa, which is lovely with Coronilla varia, would be put out of countenance if planted with Chrysanthemum maximum.

It is well to bear in mind the peculiarity of some plants that open only in the sunshine or at twilight, for such should not be given conspicuous position. Among those that open at nightfall are Nicotiana affinis, evening primrose, Nycterinia capensis, moonflower, fragrant evening stock, and Hesperis matronalis, which, though open all day, is only fragrant at dusk. Among the flowers that open only in sunshine are Anagallis, dwarf convolvulus, Nolana, sun-drop primrose, Callandrinia, Helianthemum, and Mesembryanthemum. Among those that close at night are some of the perennial asters, Lavatera, mallow, Malope, oriental poppy, Shirley poppy, certain pinks, some roses, Rhodanthe; while dog-fennel drops its petals as if in sleep, and the Arctotis grandis has such an intermittent way of opening and closing its flowers that I could not be certain whether it preferred sunny or cloudy weather.

I am often asked if my garden does not take all my time. It is now a hundred and twenty feet long and sixty feet deep, representing many yearly extensions and two nursery beds. I can say very decidedly that it does not. In the spring, when it is a luxury to dig and play in the sunshine, I sometimes give whole days to it; at other times, a few hours now and then are all that I can spare, and in the autumn an occasional day is devoted to clearing out and resetting; but I should say that the actual time given averages not more than half a day in a week. The reason the garden requires such little care is that the 


\section{Hardy Plants for Cottage Gardens}

ground has been thoroughly prepared, and the plants having been set with reference to their peculiar needs, provide for themselves. Annuals are grouped in a small area, and require very slight attention, if the heavens are propitious. My advice to an amateur is to let a garden follow a natural growth from small beginnings, and add to it only as you need elbow room. Half the pleasure in life is to grow and to make breaches in old horizons. If you begin too ambitiously, extensions may become a burden, and the more assistance you require, the less the personal joy. Occasionally I have a man for half a day to haul cart-loads of various soils to my dumping ground, or to gather stones for new walls; but this is the extent of my purchasing power, for I prefer to devote funds to buying choice varieties rather than to employ a man's labor. However this represents a personal idiosyncrasy of one who has learned to value the probable Irish ancestor, who has entailed upon me a wholesome love of work.

In choosing a site for a garden, let it have a southern exposure, or one to the southeast or southwest; get all possible shelter from the north, northeast and northwest winds and storms. If procurable in no other way, plant a hedge or wind break of trees a few yards from the garden, but not so close as to encroach on the soil. Some trees will run out their roots for yards in search of water or mellow earth. Choose a place with natural beauty and some irregularity. Use the defects as so many opportunities to bring out individual beauty. Unless your mind is constitutionally built on straight lines avoid long straight walks and borders. In marking out curved walks or beds, lay down a rope or hose to represent the proposed line, and study your curves from many points. A defect in curvature may not show from one place yet be obvious from another. Any undue flattening or bulging of a curve spoils its contour. Seek to have features of particular interest, to be 


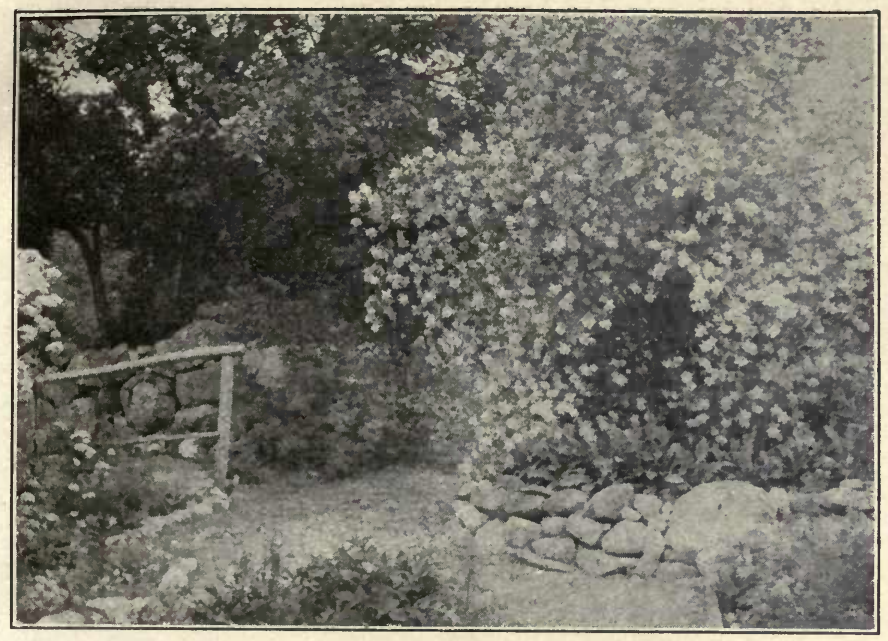

SYRINGA BUSH

[P. 86]

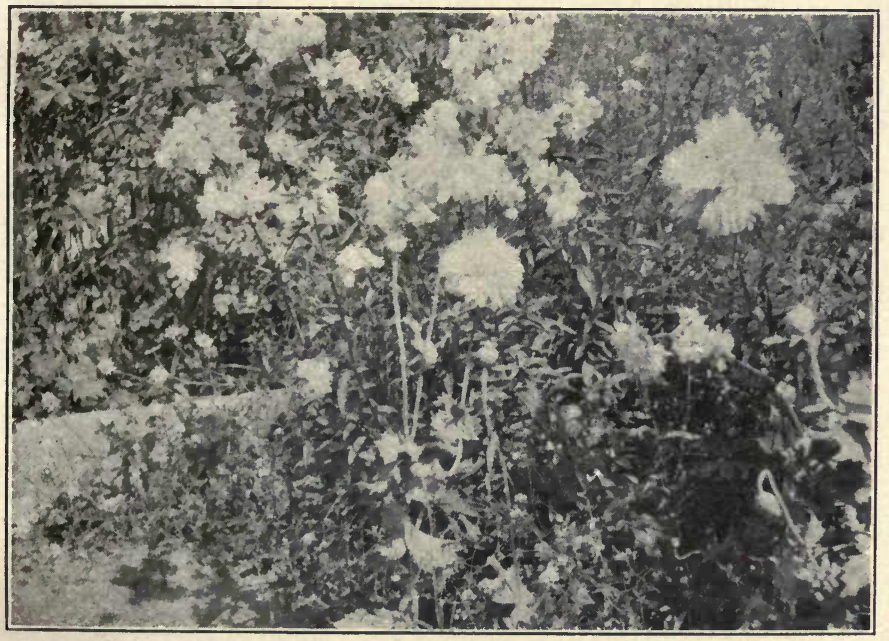

Bouncing Bet and Lilac Peony Poppies

[P. 88] 



\section{A Descent into Particulars}

seen at the end of a vista or where walks converge, or as a central idea. If, beyond the garden, a distant landscape is offered, study the possibility of having it framed in by branches of trees. A remarkable example of this is the manner the Japanese have pictured under innumerable phases their favorite mountain, Fugi-yama, always represented with a tree in the foreground, enhancing, but not concealing, the view.

Keep the garden closely related to the house, where it may be enjoyed from the windows or a piazza. If necessary cut a window down into a door leading out to it. Plant sweetscented honeysuckle and other fragrant things where the south wind, the prevailing quarter in the summer, may blow the fragrance through the house. 


\section{PROPAGATION OF PLANTS}

HE first requisite for the propagation and growth
of plants is a suitable soil. Most people take their
soil as they find it, adding much or little dressing
from the barnyard, or patent fertilizers, put in their plants, and abide by the results, which are, that certain things flourish well and others quietly disappear. This gentle disappearance, usually attributed to the weather, the nurseryman's stock, or pests, is the only protest a plant can utter against an unsuitable diet. It generally gives a month's warning that it is about to quit your service when it pines and droops, and whenever you see a plant grow pale and languid it is high time to consult authorities. I presume the best all-around soil is a rich sandy loam, for this is adapted to the majority of plants. By loam I mean the top soil of pasture or grass-lands, just under the grass for a few inches. It is full of fiber, and is the product of decayed vegetation, which has been incorporated in the earth beneath and has enriched it. It is generally brown or almost black, finely pulverized and rich in humus. It varies greatly, owing to the character of the soil beneath. In low wet lands it is black, heavy and sometimes a little sour, which last condition can be altered by spreading out a pile of it to the sun and air, and letting it freeze through a winter. In sandy districts it will be very light, and will need manuring, and, if procurable, a little clay and black muck well mixed with it, to give it body. In gravelly places it will need leaf mold, black muck and perhaps a little sand. A heavy loam resting on a clay subsoil is 


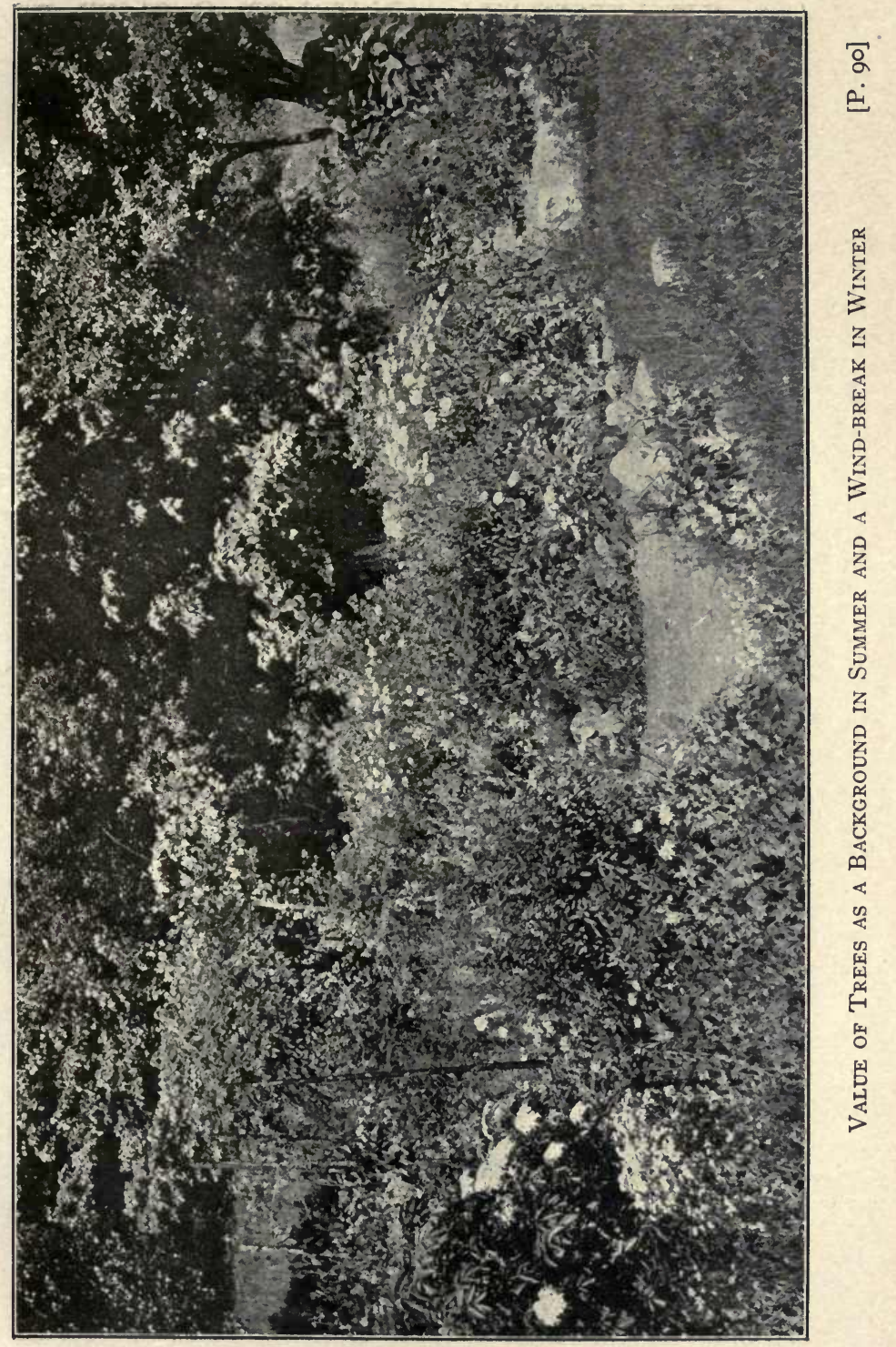


one of the best conditions, though it is harder to work; but it will need less fertilizing, will retain moisture and keep fertile longer than any other. This is a favorable condition for roses. The basis of all gardens should be loam, with a bottom layer of turf turned root side up, and other ingredients spread over the whole area; or, a still better way would be to make a rich general compost of one half loam mixed with leaf mold, sand, ashes, well rotted manure in moderate quantity. When this is well distributed, and dug in, special conditions may be created where they are needed. In setting out roses more manure and a little clay may be added directly to the soil where they are planted. For plants that thrive in sandy soil, a considerable quantity of sharp sand may be given. Others require leaf mold to excess, and this may be given. In short every plant, according to its need, may be provided with its own peculiar nutriment. It is also well to have a small pile of general compost to which has been added an equal amount of well rotted cow or horse manure, and let it stand a whole year or longer, stirring it from time to time until it is perfectly incorporated. After a year or two this may be used on lilies and gladioli, neither of which will survive if placed in direct contact with fresh manure, yet require a highly enriched soil. If you have a clay soil your difficulty will be greatly increased, for it hardens and cakes badly, and you must at any cost add a quantity of sharp sand to lighten it. Manuring will not do it, and sand is a necessity. I carefully save the coarse mulch and leaves removed from the garden in early spring, adding to them all the fresh refuse of plants, as they'are trimmed after flowering, and upon this pile I place a little manure and common loam. By autumn the bottom of it is resolved into a finely pulverized soil that makes an ideal fertilizer for plants when they are reset and prepared for winter. With a good general compost basis to which other ingredients, previously 
mentioned, have been added where required, one can raise every variety of plant suited to temperate regions. In the Appendix I have given the particular kind of soil recommended for the plants named, and it is worth while to give this subject serious consideration.

There are various methods of propagating plants-the commonest is from seed; yet I have shown in my chapter on Seeds, and also in the cultural conditions given in the Appendix, that it is not enough to plant a seed in good soil and water it. Certain seeds are more exacting than this, and it is well to give attention to the time of year when it is best to sow them; also the length of time they retain vitality. It is not prudent to plant perennial seeds in a cold northern climate as late as August or the first of September; for if they come up promptly the little seedlings will not grow large enough to establish themselves before winter. It is a waste of time and seed to try it. Either plant them later, so that they may lie dormant until spring, or wait until spring, unless you have a cold frame, and can give them attention through the winter. Seeds that take six months to germinate may be planted in September or October.

Further, the amateur may not realize it, but the price of seeds bears a close relation to his probable success with them. Five-cent packages will prove an excellent training-school for one, as they represent prolific sure seeders that will grow if you but throw them out of a window. The ten-cent ones will survive many ignorances; the fifteen-cent ones require specific knowledge, while the twenty-five and fifty-cent kinds are a pure gamble, being seeds of costly hybrid varieties that are apt to revert, or new acquisitions that may not be entirely acclimated to our difficult climatic conditions. Do not sow the whole package at once; seeds have been known not to come up, and a second and even third trial are often neces- 


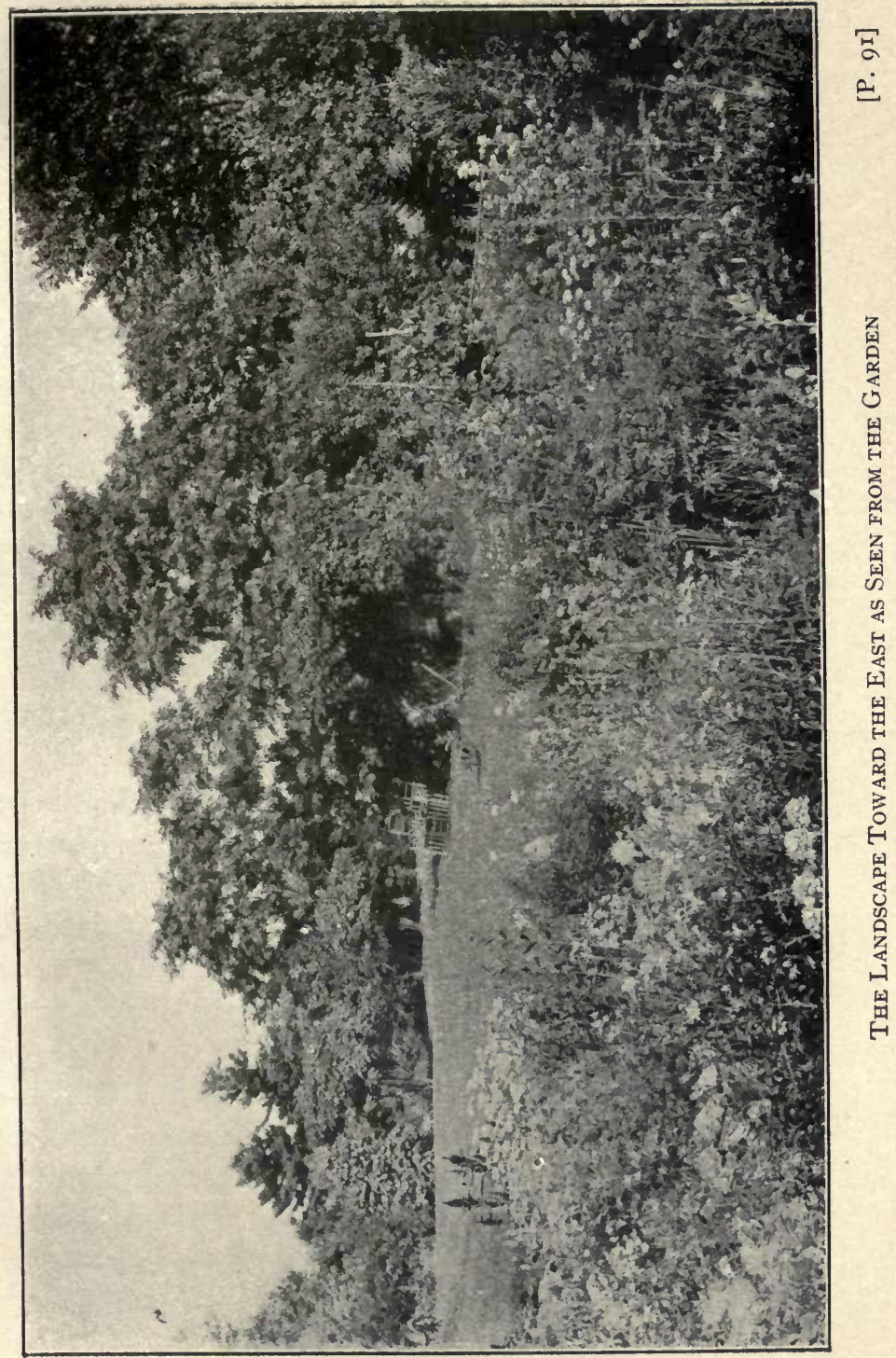



sary. If annuals, a succession of sowings insures a succession of bloom: but do not sow as I did once:-

I had not much space to give to poppies, and I was delighted with the idea of succession; so the seed was sown in little patches, perhaps eight inches apart, and the extra plants thinned out. When about four inches high I put more Shirley seed in the spaces so as to alternate with the growing plants. They also came up promptly, but the first planting became an impenetrable jungle through which no ray of sunlight penetrated. I was pleased, for I foresaw a prolonged thicket of bloom through the summer. By and by when the first growth showed signs of fading, I began a search for the successors, and faith! they needed a rescuer badly. Of all the anemic, attenuated growths I ever reared, they were the sickliest. In vain to admit them to sun and air then: they had reached a state of painful decline, and speedily faded from view. When you plant a succession of anything, choose a new spot each time, where the plants may have at least a fighting chance for life.

Remember, however, that when you undertake to raise perennials from seed, you should have the hope of living several years; else you may plant and leave it to men, who shall come after you, to gather the fruit thereof. Happy is the perennial seed that comes up in less than three or four months; happy is the perennial seedling that achieves a vigorous tuft of leaves the second year; thrice happy is the owner of the seedling that grows to a blooming clump the third year. If you have an incurable malady, either confine yourself to annuals, or buy full-grown perennials. Only those in whose veins the life currents pulse strongly, and have confidence in the future, can afford to play with perennial seeds, or plant young trees. I am willing to gamble with Fate, and yearly buy the tardy seed, and only resort to the purchase of 
plants when I have failed repeatedly to germinate certain seeds.

Do not think because you have a perennial garden that you can set out your plants once for all, and then retire on the half-pay list. It often takes more strenuous labor to get a plant out of the ground than it took to put it in. A perennial garden worthy of its name grows like Jack's bean-stalk and requires division, resetting and bestowal upon the poor twice a year: not every plant of course; but enough to keep up a continual exhuming and excavation.

There are various ways of dividing roots, and unless you know your plant well it is advisable to lift it bodily and hold an autopsy. Some plants, like the Armerias, make a single close tuft of leaves and the root cannot be divided safely. They must be propagated by seeds or cuttings. Others send out running shoots from the root, each in turn making a separate root growth of its own, such as the Michaelmas daisy, garden heliotrope, sweet-william, Physostegia, Bocconia subcordata, Achillea, Boltonia; these can be separated and reset. Others form huge clumps and must be divided by a spade; others form a clustered group of separate roots, which need only to be untwined and set out; the Verbascum for example. I have tried in the Appendix to cover this point of propagation by division of the root in its special application to different varieties.

Some plants require layering for their propagation, which is to bend a branch down to the ground, making a slight incision in the stem near a bud with a sharp knife, usually cutting in a slanting direction, pegging it down either with a hairpin or a small pronged twig so as to keep it in place, then covering this incision an inch or more deep with sandy loam. Keep well watered, and in the course of a few weeks, roots will form at this point, and in six months or a year the 


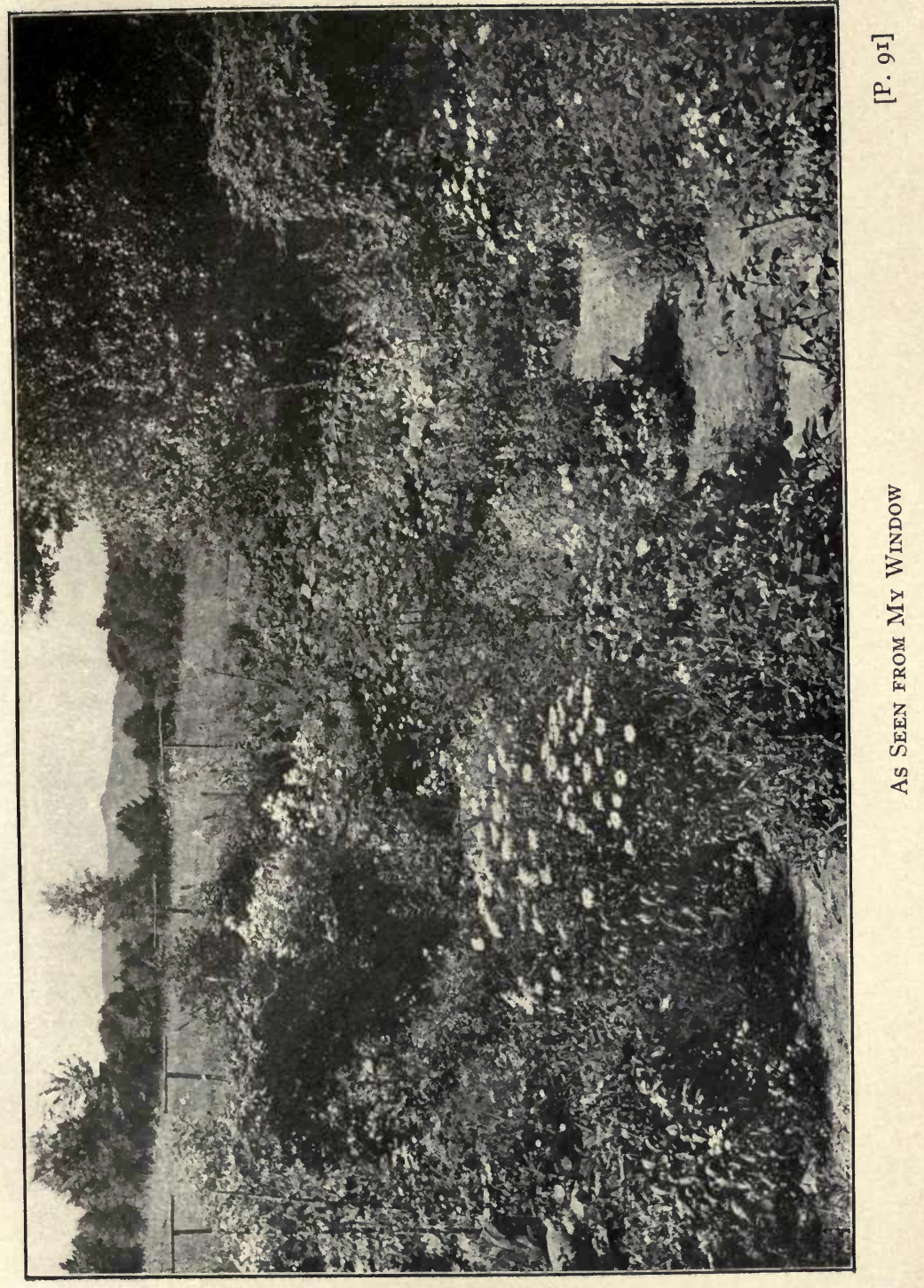


branch may be severed from the parent plant and reset. This is the usual way that Wistaria is increased; also the honeysuckle and many other plants which I enumerate later. Sometimes a branch cannot be bent down, and then the method used is different. A flower-pot or similar receptacle is cut in two lengthwise; the branch is run through the hole in the bottom and the two halves of the pot are then tied firmly together and filled with earth. The incision in the stem should come well below the surface of the earth in the pot, and the latter held securely in place by building a temporary support for it to rest on. This is a more difficult method, though frequently used by nurserymen. The clean cut partial incision in the stem promotes the formation of roots at that point, and the root formation may also be facilitated by scraping the bark lightly where the roots are to form.

Another method of propagation is by cuttings, which may be taken from the ripe old wood, the half ripened wood or new green shoots according to the plant. They are set in sand or sandy loam so as to cover two or three eyes or buds, allowing from two to six inches of the wood above ground; they are usually covered with a tumbler or glass jar for a season to prevent their becoming dry. If kept too moist they are inclined to rot; but if allowed to become dry, the delicate rootlets are killed at once. Cuttings should have little or no sun, for a time; and various devices have been worked out to promote their rooting well. One of the most practical suggestions is to take a box, and cut the sides so as to form a slanting top on which is fitted a glass frame. The box is filled with sand mixed with a little rich loam and the cuttings set with but one or two eyes above the earth. The glass cover retains the moisture, and may be lifted a little each day to admit air. Bottom heat, which may be derived from manure under the sandy soil, will facilitate growth if the 
weather is very cool. When the cuttings have rooted-and this takes considerable knowledge and experience to judge - the little plants may be reset in separate pots; these are plunged in a box filled with sand, which should be well watered so that the moisture may be absorbed by the earth in the little pots. It is a nice undertaking, requiring skill, watchfulness and good judgment, and the special requirements of various plants are too numerous to touch upon, so I give nothing but a general description of the method. This is an excellent way to root slips of roses, cut late in the autumn, and kept through the winter in damp sand in the cellar, or buried deep under a foot or more of earth in the garden where they will not freeze. They should be fresh and green when set in early spring.

Observe another point of importance: there is no one time when plants should be lifted, divided and reset. Some prefer to move the first of May; others like to be taken when dead asleep in a dormant condition, just before hard freezing weather sets in, or very early in the spring before growth begins. I have tried to indicate this in the appendix, as far as I could learn the choice of plants; but it is a matter for study and experiment.

There is another delicate question for the gardener to consider, and that is what sort of protection should be given to plants in winter-in short, the matter of mulching. I have known delightfully candid people who frankly asked what it was to mulch a plant. I like people who want to know things (provided they do not use that expression of surprise, "I want to know!"), who are willing to confess that we come into this life like a desk with pigeon-holed compartments - all empty - to be filled only as we experience loss, failure and disappointment, unless a fairy presides at birth and bestows that rare gift of being able to take advice. I 


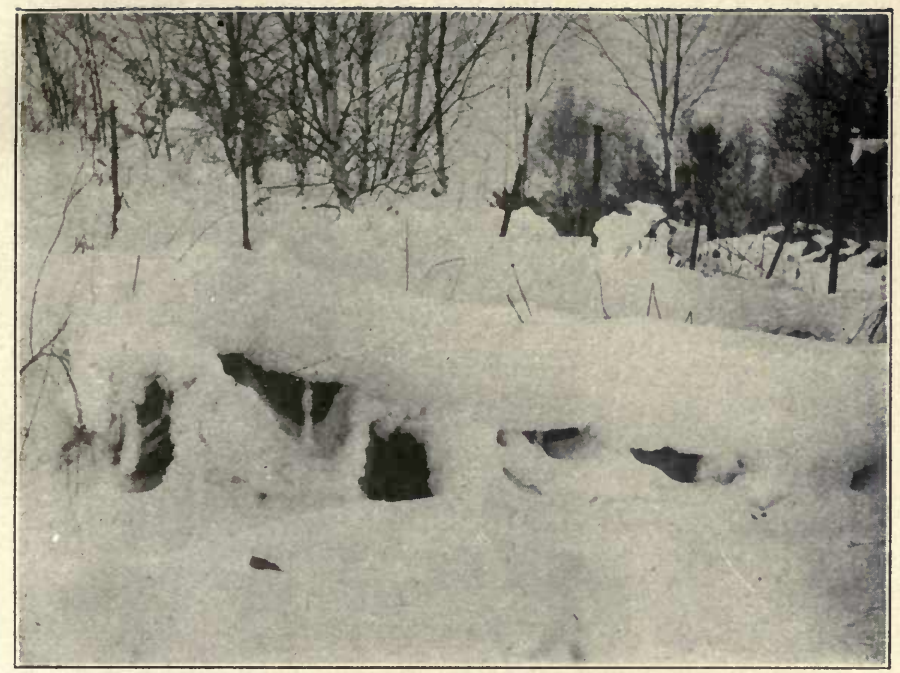

A Heavy Blanket of Snow Falls Early and Disappears

LATE

[P. 99]

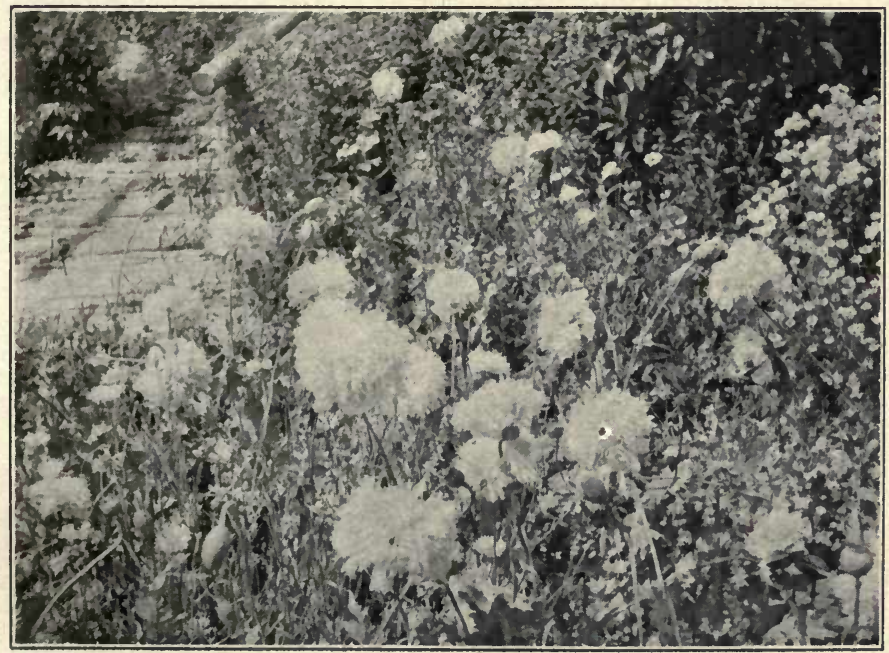

A Bountiful Bed full of Vigorous Paeony Poppies [P. 102] 

presume this reluctance to take another's experience is Nature's way of enforcing her truths upon each individual, for nothing is really ours until we have made personal proof of it.

To come back to those who timidly confess that the compartment of knowledge labeled "mulch" is empty. Mulch is half-rotten straw, hay or like substance with which plants are covered to prevent the alternate thawing and freezing of winter. It is also placed in summer about the roots of certain plants that suffer from drought, to keep the ground moist. In our severe winters only a slight mulch is needed; for a heavy blanket of snow, which falls early and disappears late takes its place, and when the ground once freezes, it remains frozen. Mulch is not so much to keep the ground from freezing as to prevent the alternate action of thaw and freeze, which not only throws the roots of plants out of the ground, but allows a plant to awake to life only to be nipped by the next freeze. Mulch prevents the sunlight from getting to the earth, and keeps it frozen until warm weather arrives.

Various things are used as mulch. Coarse manure, which gives the best protection from cold, also promotes an unseasonable growth, owing to its heat. It must be banked high over tea-roses and hybrid teas, also spread from six inches to a foot deep over some lilies; but for most plants I think it a very questionable thing to use, except in great moderation. One of the best mulches is coarse straw, hay or grass, provided it is free from weeds. It is light, porous and effectual. Another good mulch is leaves, provided they are not put on deeper than three to five inches. They mat down closely when wet, and will suffocate plants if too heavy.

Another mulch is pine boughs, or other evergreens. We have these in abundance and Adam finds them invaluable 
for covering the strawberry beds. One winter I used them in great quantities, covering every bed deep with them, after a heavy snow fall, and it proved the most disastrous winter in my experience. The field mice got in, made nests of the needles, subsisted on a mixed diet of resin from the pine, larkspur crowns, iris leaves, the bark of shrubs. The pine needles were gnawed off and strewn thick over the entire garden. I may be reasoning from a false premise, but I have laid my heavy losses that winter to the score of pine boughs, as it was the only winter I ever was troubled with mice, and the only time I ever used pine boughs to any extent.

Some plants are said to be benefited by a heavy mulch of coal ashes, such as hollyhocks, larkspurs; but I notice this advice proceeds from the vicinity of New York and New Jersey where the winters are more open and trying to plant life than they are in my region. In reviewing my various experiments, I find the best results came from allowing a thin layer of leaves to settle over the beds, as they were blown about in the autumn, adding them where too thinly spread, holding them in place by slender sticks or the stalks of tall perennials, and after the first snow fall, which serves as a blanket, I spread a very thin coating of strawy manure over the snow. This gives a three-ply covering, each very slight, but the protection is perfect as the snow does not melt under the manure until early April, unless it rains. In the winter of 1906-'07, the most severe on record, I did not lose a single plant under this treatment. It cannot be depended on save in regions where the snow lies deep all winter. However, it is not the actual cold that kills hardy things: it is the unseasonable warm day that prematurely starts growth; and anything that can prevent this, gives protection. In warmer latitudes than mine people have great trouble in raising young hollyhocks, perennial poppies and white larkspurs, 
because the little plants winter-kill. I have never lost a single one at this stage, even if they were growing astray in the walks, quite unprotected by mulch-but it is all due to the deep snow. In removing mulch in the spring, do it gradually, to avoid the results of heavy spring frosts at night.

It makes considerable difference where certain plants are set. The Montbretia is quoted as a tender bulb, which requires lifting and storing in the cellar during winter. I have carried mine through several winters successfully, when planted in the main lower garden, in a sheltered position, though I have lost others twice when they were planted on an elevated terrace within a foot of the outside stone wall. Give tender things a sheltered corner, and perhaps a pine bough or two, or better still place a barrel or box over them filling it with leaves. I attempted this treatment with a Cherokee rose brought from Florida, but I failed to place manure about the roots first, though the leaves were piled to the top of the box when I left in early winter; on my return they had melted down to four or five inches. The consequence was I lost all but a single shoot of my rose. I ought also to have put a cover on the box. I forgot to mulch it in any way the next winter, and lost it entirely, though I have carried Florida honeysuckle through three winters without much attention. As I look back I seem to have made every mistake possible to ignorance. But, given every possible mistake, one is bound to learn considerable as the years go by. Tender roses and shrubs should be tied up in straw, but I do not try to grow things that have to be coddled.

Under the propagation of plants comes the very essential question of how close plants should be set together. There are different opinions about this matter, and I have tried all sorts of ways, and find in a dry climate such as mine, that close planting is a necessity. For annuals of tall slender 
growth such as asters, cosmos, Gaura, Tridax, Phlox Drummondii, mallows and the annual larkspurs I allow but four or five inches between the plants. If a plant is bushy as $\mathrm{Ca}$ lendula, Lavatera, Shirley poppy, cornflower, saponaria, martynia, allowance must be made for a reasonable spread of foliage, and from six to eight inches will be ample. Where plants are close, they shade their own roots, their leaves prevent evaporation of moisture, and the sun does not dry out the ground. I like to see bountiful beds full of vigorous growth with no earth showing between.

The same treatment applies to perennials. Those of slender erect habit require but a few inches of space if the ground be rich; and even those of coarse spreading foliage like the Incarvillea, larkspurs, garden heliotrope, hollyhock, Helianthus and foxglove can be grown close to each other if the lower leaves are removed to make room for each other. If the overlapping foliage covers the ground too much, it prevents the rain from reaching the roots. A little experience will show how far a stripping of foliage may be carried.

Another value of close planting is that in beds where a succession of bloom is desired, the early plants are in full bloom while the later ones are still very small. By continually trimming out and cutting down plants after flowering, others coming later have a chance to spread their upper branches freely over the same area; and by preventing the seed-vessels from forming, the vitality goes into root growth. Once in a while stripping off the lower foliage is disastrous. For example, I once wanted more room in a pink bed, and cut off a number of lower leaves of the Ulmaria rubra venuista. To my dismay I saw later what destruction I had wrought; for out of these first leaves spring the tall stem that bears the beautiful peach-colored head of bloom, and unwittingly I had destroyed the blossoms for that year, save on a sin- 
gle stalk which I had left untouched. The loss was irreparable as the Ulmaria is one of the most beautiful of my plants.

Another mistake easy to make is to overlook the position of certain plants that are late in springing to life. One spring I watched vainly for my Incarvillea to come up, and not finding it, I thrust in a sharp little pointed trowel to remove a spirea growing near by, and, to my horror, I pierced the Incarvillea to its very heart. It was as cruel to me as if I had maimed a human being. I muttered many incantations over it, gave it massage and absent treatments, and prayed my guardian angel (I only know I have one in times of sore need) to heal the wound. The plant lived, but it is a cripple for life. The Dodecathon media, Mertensia Virginica and Liatris are also late in coming up, and these I mark with tall stakes so as not to mistake the places where they are planted.

Certain plants attain an unruly height and need special treatment. Among these are the golden glow, Helenium autumnale superbum, some of the perennial varieties of Helianthus, Boltonia and the perennial phlox. When these are less than a foot high, nip off the tips of the plant. They will then branch freely and grow perhaps four feet instead of six or seven. This retards the blooming a little and perhaps makes the flowers smaller, but there will be more of them. In treating phlox thus, a longer season of bloom may be secured by nipping some and allowing the others to grow. The unnipped ones will bloom perhaps two weeks earlier than those cut off.

After a bed is planted, do not think your responsibility is over for that season. Whenever you have a leisure hour, take a hand fork, a small implement with three flat tines, and stir the ground about the roots of plants. This is particularly needed if the season is dry, for it opens the ground to catch any slight rain that does fall-Adam calls them vague little 
showerettes-and the loose top soil not only absorbs moisture from the air and the night dews, but it acts as a mulch to the earth below. If you want to force any plant along, stir in a little ashes, manure or fertilizer, and then water well. The subject of water and watering is a serious problem with me. When the heavens are brazen, and the well is almost dry, and famine is sore in the land, my whole heart goes out to the sufferers. I then follow the advice of wise gardeners, and after stirring the soil well, I water as much area as I can thoroughly, and let that portion go for days while I relieve others. Particularly do I water those in full bloom, or those about to bloom. I also place a thick mulch of grass clippings about the roots of those plants that suffer from drought: gladiolus, tritoma, larkspur, hollyhock. I have found the earth moist under this mulch a week after it has had a good drenching. A valuable help is the waste water from the Monday wash tubs, provided no washing powders, borax or turpentine has been used in the laundry. Also the water from jars in the bed chambers may be given as a fertilizer to roses, vines and shrubbery. But the chief point is to keep the soil light and porous and every drop given has full value. When I go about the garden in a pitiful mood, singling out extreme cases as recipients for my restricted bounty, my heart yearns for those that lie just beyond the water limits. One year when the well went almost dry, the suffering was so extreme that I could not bear the sight of it, and I did not go near the garden for weeks. All the more cruel is it when a shower will carry over the garden for days, and a heavy rain suffices for two weeks.

One evening when plying my ineffectual watering-pot, I observed to Adam: "What generous agricultural methods Nature has! When she waters her charges she descends upon vast areas; she does not single out a township or even a State for her bounty, but she can cover half a continent.' In the 
same way when I painfully rake up my walks, I note the large way she sweeps a whole hillside with one touch of her winds. I love her magnificent operations. They are superb, inimitable, perfect!"

Adam was in a critical mood. "I think she is very imperfect," he responded. "She needs a man. Unaided she works in a blundering brutal way: she averages well: her cloudbursts and washouts and her parching droughts give us a fairly uniform average rainfall. Remember she wrecks and destroys as well as vivifies. She is a great extremist. She is far from perfect," - and he spoke as a man who had thrown down the gauntlet.

I, who am a blind and ardent worshipper of Nature, dropped down into the arena and picked up the glove. "How so?" I inquired, determined that he should make good his charge.

"Her great cosmic laws are not applicable to the individual. She is a wild untamable force. She does not strive for perfection. Where do you find a perfect plant, or even a perfect leaf? She begins well, but grows absent-minded about details," continued he, warming to the argument.

"How about the exquisite and perfect mechanisms revealed by the microscope? It opens a whole world of unapproachable beauty, harmony and symmetry," I questioned.

"That may be true," replied he, "but her vast forces on one hand and her minute details on the other reveal also the very painful gap that lies between. Given perfect atoms and perfect forces, we should have perfect creations, which we certainly don't have: something is wrong. Nature unaided blunders sadly. Nature plus man is Art; Nature plus man is Progress; Nature plus an able assistant produces a relative approach to perfection. For example: compare wild natural fruit with the Spitzenberg apple or the Albemarle pippin; the 
wild strawberry with the Belmont; or to come on to your own ground, compare the common wild rose with your fine garden roses-the Sharman-Crawford, the Mrs. John Laing."

"Mere hybrids-all of them," I defended. "Man destroys the balance utterly. He sacrifices everything to size and color. We think them beautiful, but are they? Man is blighting with his megalomania all fruits, increasingly beautiful to look upon, but with less and less flavor. How about the Ben Davis apple, the Keifer pear? Man's flowers have color, but no fragrance; size, but no fertility. A modern rose has no seed; it has to be budded to be reproduced. Man sacrifices all proportion to attain any given end, whether he breeds poultry, cattle, fruits or flowers; he weakens the vitality and makes them a prey to a thousand civilized pests. Do you call that perfection? But has not Nature herself provided the peculiar condition that man merely seizes upon to exaggerate? If you call it utility I grant it. Man has learned to take an accidental sport of Nature, and by artificial means to reproduce it. She furnishes both the sport and the man of wit to use it, but the moment he relaxes his vigilance Hybrid Perpetual roses revert to the manetti, the original stock upon which they were budded; the suckers below the graft of Spitzenberg apples revert to wild stock; highly civilized nations are becoming sterile."

Adam is as little convinced by my defense as I am by his arraignment. I find ample corroboration of his point of view on every hand. Every where I come close to the defeats and imperfect types that Nature casts aside as if they were broken experimental molds, not quite adapted to her use of them as final expressions or manifestations of Spirit; yet, when I close my eyes to the outward form and meditate on the purpose of creation, and Nature's ideals in her use of matter, I hear faith singing low in my heart, and I know that all is well. 


\section{VICES OF PLANTS}

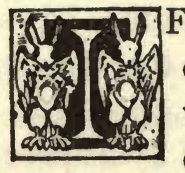

F criminologists would make an exhaustive study of plant life, they would find the sources from which many roots of evil spring. The human social fabric has a close analogy to the floral world, and much becomes clear when viewed in rudimentary forms. I do not know which way to refer the resemblance-that plants are so human in their character and expression, or human beings so plant-like. Perhaps the latter is the more logical to students of evolution. Plants have simple, elemental vices. They show rapacity, improvidence, caprice, selfishness, sloth, arrogant self-seeking and profligacy. It has been reserved for the human race to develop the meaner, petty vices-jealousy, anger, slander, envy, pride and ingratitude: of these an honest self-respecting plant is incapable.

For example, predatory wealth finds an equivalent in rapacious plants that make not only a vigorous central growth, but reach out on every side to establish branch offices where they install children and grandchildren with incredible speed; who absorb all the nutriment within many feet, and try to choke out those who dispute their territory. The progenitors of rascally railroad presidents, sinecure officials, commercial monopolists are descendants of the original sinners in the garden of Eden, the Michaelmas daisy, Achillea, perennial asters, garden heliotrope, Helianthus latifolius, Virginia creeper, Calystegia, bouncing Bet and hawkbit. Let but a single one of these prototypes of greedy financiers get a firm hold in your garden, and certain notorious oil monopolies are con- 
servative compared with it. The only thing to be done with either the floral or human type is to keep it moving. They best serve utility when not allowed to get thoroughly established. Both destroy a large portion of the social fabric when an effort is made to uproot them, for their ramifications are so complete that they underlie many innocent victims. I represent a generous distributor of this unlawful wealth. I bestow not millions-for plants have not evolved to that degree of debasement-but bushels of it on young struggling gardeners that need endowment, as I am determined to die poor in daisies, heliotrope and hawkbit. Whenever I hear of a new opportunity to play the generous benefactor, I unload my surplus-never quite able to impoverish myself, however. I attach no condition that an equal amount shall be raised by the recipient before the gift is forwarded. It is not that heliotrope, Calystegia and daisies are not good-nor dollars; it is merely a question how much of a burden of plants or dollars one can carry without inconvenience and impoverishment in other directions.

The pauper poor, with their irresponsibly prolific families, are but the human form of those improvident plants that shed their too fertile seed in every direction. If the population is restricted in either case to a reasonable limit, where society can provide for the children, they become excellent citizens. Otherwise they are flung out on the cruel world without suitable provision, and either the mortality is great-Nature's kind and universal way of disposing of a surplus-or both are forced to emigrate to find lodging for the ever increasing hordes. My orphanages, almshouses and foreign colonies are very shady unsanitary spots down by a brook, also the sides of the lane, where both diet and shelter are precarious, owing to the fact that that corner of the world is a regular slum district, already crowded with hungry trees and underbrush looking for work, 
and but scanty rations are accorded either to old residents or the new-comer. I try to play a Guardian of the Poor to these too-numerous waifs, and I know the difficulty of finding good Christian homes for the progeny of Lychnis dioica rosea, Veronica spicata, Digitalis purpurea, Aquilegia vulgaris, Rudbeckia, Chrysanthemum parthenium, Chrysanthemum maximum, all illustrious families found in every Florist's Blue Book. I try to build model tenements to accommodate the most promising of them in the annual construction of new beds, but I cannot keep pace with the teeming population, and for want of sufficient ground space, may have to devise hanging gardens eighteen stories high-garden-scrapers shall I call them? I should like to communicate with any one in possession of the original working plans of the hanging gardens of Babylon, for though they may be somewhat old-fashioned, yet they may furnish good ideas. I always prick up ears when Asa Gray mentions any plant as "cultivated in choice gardens," certainly a patent of floral nobility. I now believe a choice garden represents the aristocratic inner circle, the élite, a condition where the undesirable proletariat, the free seeders, are strictly excluded. Surely that is high society that has no poor relations, no unsought younger sons, no Botany Bay.

Some plants are valetudinarians, tender of constitution, with crochety appetities; and if the table prepared for them is not to their liking, they die of disapproval. Lilies are examples of this caprice. They like rich food, the richer the better, but it must be predigested, as it were. They require a heavily manured soil, further enriched with leaf mold; but it must be prepared a year or two in advance, and then they must be carefully insulated from it by a generous environment of sand. Their conduct reminds me of delicate ladies who pretend to nibble at the table, and gorge unseen from the pantry shelf. Would it be surprising, after eons of such cod- 


\section{IIO \\ Hardy Plants for Cottage Gardens}

dling, if lilies reappeared as capricious spoiled darlings of fortune? Even as lilies, they toil not, neither do they spin, and what can we expect, when, from the first, the moral education is neglected?

Certain plants are of singularly frail constitution, and though they may buffet the storms of life for a while they take cold easily, and all is over with them. I had a Spirea astilbe, that survived two winters, and was progressing to beautiful planthood. One spring night when Astilbe,

\section{"was in thought}

To brave its blossoms to the air,"

an unusual frost overtook it. At first I thought it but a severe cold, and that a little doctoring would restore health; but it grew steadily weaker, and by another winter "it was laid away," to use the pious euphemism for plain dying. The feverfew also has weak lungs and is sadly afflicted by a frosty spring night. It develops an irritating cough in the form of leaves that turn brown in a single night, which it perversely carries about with it long after it begins to flower, as if to remind you of your neglect.

It always interested me to note the cold-blooded attitude of political economists in the matter of the death of the individual, who had been reared to an age of self-support, and then thwarted the best interests of the commonwealth by carelessly dying. Their statistics make no mention of what that loss is to the father's heart, nor of the mother's tears: that death, or any death, before the individual earns enough to make full return for his keep, is so much needless loss to the State. If economists had their way, all persons at the age of four years would be compelled to give bond to live until fifty at least, or make a heavy restitution. I am compelled to take this same view of my plants, when, forgetful 


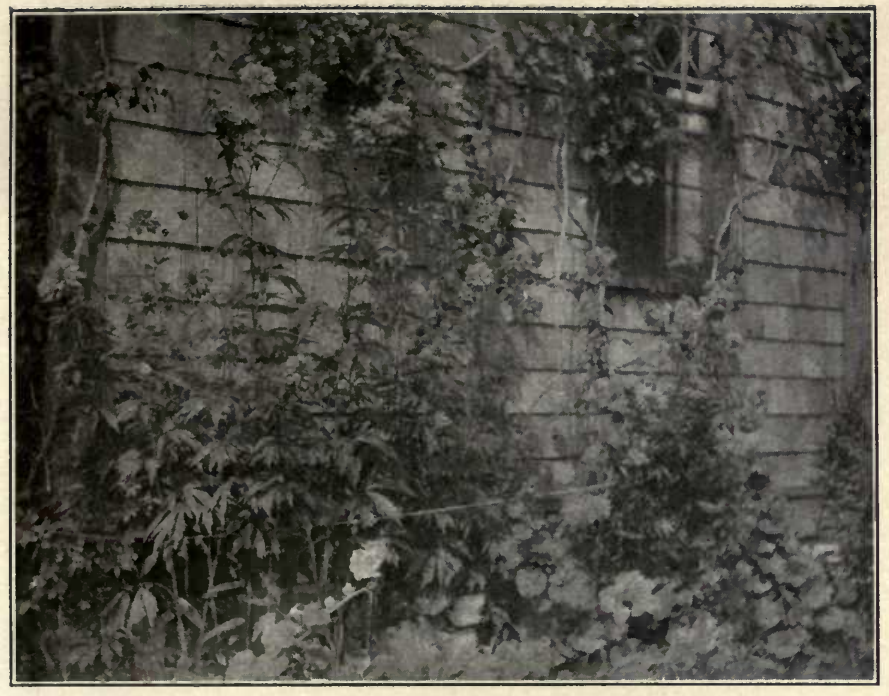

Golden Glow Against Gray Shingles [P. IO3]

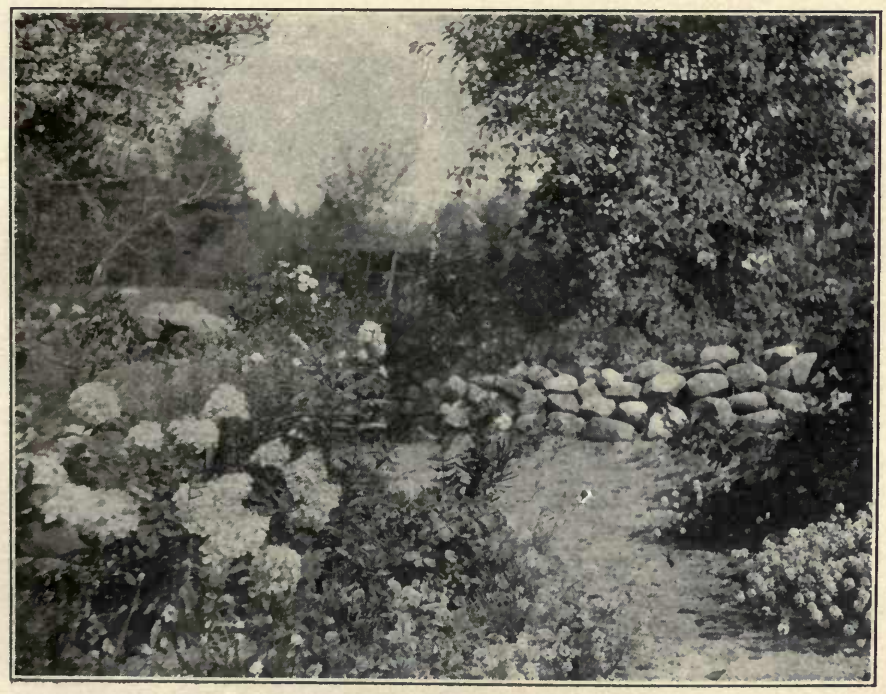




\section{.}

*. 
of the care given during infancy, the cost of transportation, plus the nurseryman's modest profit, a plant repudiates its debt to the past, and disappears from pure sloth. Of course it is easier to die than to live, sometimes. We all know, when beset with the thorns of life, how cool and inviting the ground is six feet down; but we are trained to the moral obligation to live, and live we do, in the face of fire, flood and disaster of every sort, if we are plucky and Atropos keeps her shears in her pocket. As a product of commercial enterprise plants have no right to shirk duty and go into bankruptcy; or worse, to disappear altogether. Do they commit suicide, or abscond, for they take every available asset with them? To what refuge do they flee? Yes, I know my remarks are growing pointed, and I mean to go still further and name as a chief offender the Lilium auratum, long recognized as a garden absconder, and lovely pale pink Pyrethrum bore it company. Among the idle loafers who ate and drank heartily at my table two summers ago and made no return were Lilium candidum - true they were planted in a place too wet and shady, but what of that?-Funkia subcordata, Hydrangea paniculata, only recently turned into a slothful vagabond, tritoma, Japanese iris, Stachys lantana, lusty looking Canterbury bells, two-year-old pentstemons and gerardias-all went out on a strike, and their labor had to be done by overworked annuals. Even a wee abortive blossom would have shown a good intention. True it was a cold summer, but sometimes one has to work to keep warm. Given a worm at its root-which is a plant's'heart-a lawful disease, the destroying hand of Fate in the form of drought, or ripe old age, it is right that a plant shall die-let it first discharge its debt of bloom to the race; but no word of extenuation can be said of the plant that sulks and won't work. For this cause came it into the world. 


\section{Hardy Plants for Cottage Gardens}

I have long pondered the question of when a plant actually dies. Surely not when its stalk is cut, for often the severed stalk holds its bloom and opens new buds for days after. Your arm makes no growth when it is cut off; so here is a new condition. Growth is the accompaniment of life and life is but a manifestation of the Spirit: but where does the Spirit reside? Both root and stalk may grow when the latter is severed, and single buds may be stripped from the stalk and later open into flower. At what point then does the residing Spirit wholly withdraw itself so that we may say, it is dead? Because I cannot answer this question, cut flowers become a painful responsibility to me. As long as there is a semblance of life in a single blossom, it is still a precious abode of divine energy, and the sad obsequy of throwing away cut flowers devolves upon Adam, who has a reasonable dislike of faded, offensive things. I want to be very sure that decomposition has set in, as that is our only proof of death, before I consign it to a final resting-place under a lilac bush: it is torture to see it cremated.

Once $I$ had to wait at a railroad station for a delayed train, and I studied the condition of life and death presented in the form of a lively locust-tree growing by the side of a telegraph pole. First I noticed the points of correspondence between the two, their contact with the soil, both were subject to the influence of the elements, both were alike in a woody tissue, in erect position, and equal in height. Ah, but the differences! One was stiff and inert, a rigid monument of an outlived past; the other lightly bent and swayed with every wind. Responding to its environment the tree sent forth its tender green leaves in friendly greeting to sun and rain, while to the pole the elements were consuming enemies slowly gnawing with relentless tooth. One represented growth, progress and reproduction, every fiber was instinct 
with life; the other was the consummation of death in all its grim nude ugliness. Was a dim sense of brotherhood possible between these two widely separated creations? Can the wildest imagination of a tree ever foresee itself builded into floors, timbers, into temples, or ships, or railroad ties? Is the lumber pile ignominy, or the destiny coveted of trees; and do they feel thwarted in their life work when they merely fulfil the life purpose, and are not used in constructive ways? Men are not happy merely to live; they must express themselves in one way or another. Is it a disgrace in a forest to fall from old age? Are there vague stirrings of aim and ambition in the heart of trees? What is their secret feeling toward storms, the winter cold and winds? The train came too soon for me to answer the questions that arose, but I felt it had been good to have sat for an hour, trying to interpret their silent council.

I have wandered far afield, and must return to depict vice as I find it. Some plants have low instincts and attract to themselves bad associates. If you are in the detective service and want to track the rosebug, visit the seemingly respectable garden heliotrope, any of the Spireas, the Asperula hexaphylla, and you will find him feasting at the table of your favorites like a bon vivant. If you want to entrap the green aphis send an investigating committee unawares to the tips of your choicest roses or gaura;-if you would arrest the potato-bug, set a spy on the nicotiana. I like not this company, and shall not further enumerate the blacklegs of the garden, for you will find them duly pictured in the Rogue's Gallery under the title of Mine Enemies. I merely mention the fact that some plants are leading a double life, and consort with very questionable companions.

Then there are plants with bad habits. Whether they eat too much, or drink too much, or it is due to some other 


\section{II4 Hardy Plants for Cottage Gardens}

indiscretion, they are an easy prey to disease. Else why should a larkspur of healthy parentage suddenly fall ill with a bilious attack of blight? Why should certain roses and the Michaelmas daisy suddenly break out with an eruption of mildew, as disfiguring a disease as smallpox? Why should robust hollyhocks fall like an apoplectic patient under the rust? Why should white larkspurs develop a cancerous condition in their young crowns, which learned practitioners call "the rot"? I advise an abstemious diet for the young; for one has no right to be a promoter of disease and become a peril to society.

The prototype of the social climber is the vine that clutches at anything higher than itself for a support, and uses everything but as a stepping-stone to further its advancement in the world. Doubtless we have all come the way of the vine through our remote past, for I have seen several varieties of forest trees, lying on the ground, denuded of their bark, and the twining propensities had not yet been outlived, for the grain of the fiber of the trunk still distinctly showed the spiral tendency. We are further advanced from the tree than the tree is from the vine, and it is high time that the race left this ignoble heritage of the past behind. Any one who has seen a vine strangle the life that helps it to mount higher, and then cut its acquaintance to gain another foothold, loyal to none, hurtful to all in its wolfish aggressions, must have an intense scorn for the social climber, who uses the same cruel methods, destroying a friend who has once served; whose only passion is to push a claim of rapacious arrogance at any cost.

Compared with this type I love the one I am about to describe-beggars. I discover beggary running far back of human annals; for in the weeds of the garden I see the foreshadowing of the outstretched palm, the avoidance of re- 
sponsibility, the shameless effrontery of the lazzaroni. Any squalid corner will do for a weed-a crevice in a stone, a cranny in a wall, while they flaunt themselves unblushingly in good soil. They are sun-loving brothers, running rampant if unchecked, yet thankful for the slightest foothold, willing to share even an inch of ground with any flower-their gratitude lifts them above the vicious outcast. My feeling toward the weed is indifference rather than dislike, for I grow so many flowers in a limited space, that the weed has but small chance. Sorrel is the most persistent mendicant, yet it is never defiant; then I have an occasional plantain, here and there an isolated grass stalk, and perhaps a morsel of chickweed and smartweed, and occasionally a sporadic case of purslane. While they respect the flower beds, they do hold mass-meetings in my walks, and every representative becomes a walking delegate, and they march in processions ten abreast until Adam steps in to quell the riot.

I ought to have a very kindly spirit toward weeds since they have given me many a happy hour, for weeding is my pleasant excuse to linger in the garden. I have even a mild sense of wrong when I root out here and there plants, commonly called weeds, simply because they bear no beautiful blossom, and I speedily pass from this unpleasant task to the removing of withered leaves or seed vessels from my plants, cutting back those that have bloomed, to make room for others waiting their chance to occupy the middle of the stage; then I turn to one needing a stake, or another that is worthy of being pulled forward into prominence, and I arrange and rearrange them as one does cut flowers. I linger long and lovingly over this grooming process, much as the fond mother detains impatient little Mary to pat and caress her bow of ribbon after it is once tied. A touch here, a removal there, another weed destroyed, a moment of leisure in which I pause to catch the glory of 
earth and sky-how the morning has sped away without a thought or care of fleeting hours and neglected duties! What a glorious waste of time weeding is! I only truly live when unconscious of existence.

I have come to know my weakness, and unless prepared to give up my whole morning, I go no farther than the doorstep; and even here I dare not linger long, so great is the enticement. It is this affectionate attention that tells in a garden. Any brief neglect shows itself in decay and disorder, especially if the season be too wet or too dry. One must not only care for the living, but provide for the dead, and the friendly persistent weeds ever draw me forth and spur me on to duty.

To my mind the worst offenders are the wantons that crossfertilize with anything. From their choicest selected stock will spring mongrel types of the most aggravating colors. Among this debased class I name the sweet-william, columbine, the hollyhock, the pæony poppy (sometimes). I well recall the care and two years' nurture I gave the seeds of a very beautiful cardinal red sweet-william. The third year it had reached the blooming period, and had been set out everywhere to replace a deep rose pink variety. To my disgust, the new plants proved every coloring known in sweet-william's calendar save pure red. Some wore prison stripes, some had red eyes, some were "straked and pied"; since then sweet willie has played me every sort of trick until I learned to snare him by taking a single plant that is particularly beautiful, and propagating by division of the root. I have even failed in this, for a plant singled out for its beauty, should be cut back the moment it breaks into bloom so as to throw its whole life into the root; and twice I have lost a very lovely tone of warm old rose, because I loved the bloom too well to cut it off, and the plant exhausted itself in flowering and died. One has to practice much self-denial in gardening. 


\section{Vices of Plants}

While I believe plants have their likes and dislikes-I can't imagine the hothouse heliotrope having a regard for a tigerlily-and some prefer to die rather than endure uncongenial society, I see no evidence that plants show the least germ of morality. They have not yet arrived at any nice discrimination between plant and plant as we see it between man and man. Perhaps this is why the garden is so smiling and contented. I find no trace of servility, malice, no bitterness of speech. Happy is that state of existence where vice and virtue are still but future, unrecognized possibilities. 


\section{MINE ENEMIES}

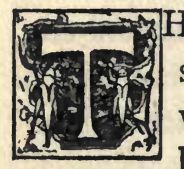

superiority that "our enemies are those with whom we have failed." I was inclined to question this large way of throwing the blame upon the innocent sufferer, but the garden sustains the New Philosophy; for surely my garden pests are but so many examples of my negligence, ignorance or tender heart.

When I first began gardening I should have put the tender heart first on the list, for my early life was molded by a priggish anecdote about a boy who needlessly put his foot upon an ant. There was no question left in the mind of the reader that the boy might have been absorbed in boyish projects and did not see the ant. No generous extenuation was allowed; the foot went on the ant with deadly precision, and the wickedness of that act will be handed down to the seventh generation. I feel that the little boy should now be absolved, in view of full expiation of his crime through having served as a moral lesson to countless young minds, who, in the aggregate, have walked tens of thousands of miles out of their path to give right of way to ants, caterpillars and spiders.

I recall my shrinking desire to let my first instalment of white grubs live, and how I deposited six of them in a capacious bushel basket awaiting my stout-hearted executioner, Adam, and how four of them crawled out through the holes before the man's hand appeared. But necessity and Adam's tardy coming have hardened me, and I have gone through progressive stages of ferocity, from throwing them over the 


\section{Mine Enemies}

stone wall, to covering the bier of my victim with green leaves, until now-in the words of the beloved Nelson-the garden expects every woman to do her duty and she does it. Three things denote the experienced gardener: ability to pluck a handful of squirming rose-bugs without qualms and despatch them neatly in a kerosene bath; with a sharp trowel in hand to play at cross-purposes with grubs and cutworms and to win the game; to stand unflinchingly while all sorts of bees, wasps, hornets, green, yellow, striped and red-headed flies gambol about one's head and face. These are the tests that prove the veteran of many summers. Any one cherishing qualms and fears, revulsions and nerves, may chatter glibly about botanical names and cultural directions; but if she cannot stand the fire of exigency that meets her at every turn, she will never fight the good fight involved in successful gardening.

But where shall I begin the enumeration, I, who love the heavenly blue and black velvet coat of the web-worm, who gaze with undisguised admiration on the iridescent metallic beetles, the coppery green armor of the dogbane beetle, the humming-bird moth with its bird-like whiz and movement, on silken butterflies, from the tiny white bride-like ones that hover over the filament stems of the Asperula, to the great yellow and black that hatch all sorts of unmentionable broods? It is hard to believe that these are real enemies-but they are. We must forget our natural history if we would enjoy the fluttering butterflies, balancing themselves on the edge of a flower. If these lovely creatures would only sip sweets perpetually and emancipate themselves from domestic duties, we should greet them cordially. Butterflies have but two lawful functions - to act as a poetic supplement to a fragrant flower, and to serve as a text on immortality.

The first pest of the season is the little stiff whitish worm, less than an inch long, found under the leaves used as mulch 
in early spring. I am told by an entomologist that they are the larvæ of some small Bibio lies, and are not particularly injurious, as they feed upon dead leaves and decaying vegetation. I am glad they have carrion tastes, for it disturbed me not a little to find whole nests of these vermin every spring, a sort of vanguard of the hordes that I have to combat later. As they have no criminal record, I'll dismiss them for worse offenders.

In dry seasons the most destructive worm is the brownish gray, sometimes bluish lead-colored cutworm, varying from half an inch to an inch and a half long. Whenever you see a young plant cut off just above the ground, and withering in the sun, you may know it is the work of the cutworm. Take any weapon you can find - a hairpin, if no other is at handand stir the earth slightly within a few inches of the plant, and you will find the worm just below the surface of the earth. It never goes deep, nor far. Do not throw it over the wall, but kill it on the spot. Sweet peas, sweet alyssum, gypsophila and coreopsis are its favorite diet among annuals; among perennials, young larkspurs, lychnis, lupines, lily of the valley, gladiolus, and pansy; and it dotes on a two-year-old Eremurus. Before planting a bed, or before anything is up in it, the advice is to spread a poisoned bait made of one part of Paris green to fifty parts of dry bran, placed in tiny piles over the ground in the afternoon and evening. Also to dip fresh young clover, pigweed, mullein or peppergrass in a solution of one part of Paris green to one hundred parts of water. As cutworms eat at night, it is also recommended to go out with a lantern and gather the harvest. I never could understand why a burglar's outfit of lantern and weapons were necessary, when the good honest sun will find the culprit eating almost any hour of the day and when not eating, snoozing in torpid idleness near his table. The cutworm never indulges in a con* 
stitutional after a full meal. So I take any convenient dewy morn for my operations, as I have to battle with them intermittently from early spring until other pests arrive to divide my attention.

The white grubworm is, in a way, worse than the brown cutworm, for it works below ground, eats the roots of plants, and cuts through the stem so near the roots that a plant seldom recovers from its tooth. It is a wholly unnecessary by-product of a garden, provided one takes the precaution never to use fresh manure directly in the beds. Prepare a compost heap where loads of sand, leaf mold, loam and well-rotted manure are deposited and worked over from time to time. When a year old, add this mixture as a fertilizer and you will have no grubs. During my first two years of gardening I made the mistake of using fresh horse-dressing, and the white grubs were everywhere. Since I have established a compost heap, the grubs have entirely disappeared. They have to be dug out and despatched, unless you are fortunate or unfortunate enough to have moles also, which follow a worm as the day the night.

If animals could only be taught how to use a garden properly all would be well with my world: but dogs do not stand at the edge and wag their tails in mute admiration of its beauty; cats will not avert their eyes from birds and concentrate on mice and moles; and moles will not pick their way guardedly between rows of plants and shoo their prey in welldefined runways. Hence, dogs, cats and moles are anathema, and I will have none of them.

"Ah, very nice," exclaims the gentle reader, "we do not like moles either, but what can you do to drive them away?" Before I answer that question, let me relate my early experiences with the mole.

My garden was constructed from a stone heap, and a stone 
heap is the natural abode of the mole, who soon found a rich harvest in the fare $I$ had unwittingly spread for it. While a discreet number of moles may be desirable, when it comes to daily tunneling under tender annuals, so that their roots are lifted high in air, where the hot sun makes short work of their young life, I prefer grubs to moles. At first I watched these loose elevations of the earth quite helplessly, then I went out four or five times a day to crowd down the earth, a process almost as destructive as the hot sun had been-and then I decided that between the mole and the grub, that would nip one plant and pay swift penalty, the odds were in favor of the grub, and I signed the death-warrant of the mole.

With subtlety and craft I began to study the mole. I took a comfortable chair into the garden and sat guard for the better part of several days. I found it to be a true rustic, breakfasting before six, dining about eleven, and supping at five. One could almost set the clock by its regular habits. It is curious how gazing steadily at anything semi-hypnotizes one, and how easily the imagination is aroused. I watched the ground until things wavered, but one day it was more than a waver-but was it? no-yes, yes, there was an unmistakable crepitation of the loose brown earth, and the long-sought villain was stealthily moving beneath it. But what was the good of that knowledge? I had nothing at hand to capture it, and though I tiptoed lightly away, and secured a weapon I watched in vain that day for any further upheaving of the earth. Next day at eleven I occupied a reserved seat in the front row, ready for the performance to begin. My chosen aid was a potato-digger, which looks like a hay fork of five tines curved at right angles. Again things wavered, and I trembled with excitement. I had supposedly laid aside my tigerhood thousands of years ago, but at the sight of that uncertain moving earth the old ferocity leaped to the front. I quivered as 
I have seen cats quiver just as they are about to pounce upon their prey, and I stood, potato-digger in hand, eager, but hesitating; for the movement was under some young wall flowers, and I could not sacrifice them. I waited until it reached the asters, and with a swift animal pounce I drove the digger deep into the earth and as quickly threw earth, astersand mole out upon the walk. Ignorant of its blindness in the bright sunlight I feared lest it should run away, and unequal to despatching it, my mind reverted to my faithful killer, Adam-but where he was, heaven only knew. It was a wild moment and wildly did I behave. For the first and only time in my life I gave my lungs free rein and how I yelled! It was blood curdling. Flung to the winds were those thousands of years of increasing self-control, of gentle aspiration, of calmness and I only hoped that the winds would carry them to the ears of the absent Adam. Thinking the garden was afire, or some deadly disaster had overtaken me, he and my maid came rushing to the rescue; and shamed was I, positively abased, to confess the occasion of the ferocious clamor.

While the prisoner was hurried away I determined to catch more moles-but differently. My ambition now was not so much a capture, but to exercise some self-restraint, and only when I should be able to catch one, clapping it into a flowerpot, cover it calmly with another, and walk composedly to Adam, wherever he was, and say sweetly and quietly - "take it"-I should know that I had mastered self. So I watched, flanked on one side by flower-pots, on the other by the useful digger; but I had to catch four before I could quite conquer my mad desire to shout for help.

When my beds were filled with perennials I had to give up my clawing operations; and now I find that common moth balls dropped in each hole or runway are quite sufficient to drive moles away. 


\section{I24 Hardy Plants for Cottage Gardens}

I am told that in the great cosmogony toads are invaluable to the gardener. I wish they had neater habits, and would squat on the walks, instead of wallowing out great holes under valued possessions. If we must have toads, let them be small and trig of figure, young and ever active. I have a hoary old grandfather with a spread of six inches from tip to tail, that clucks like a hen.

Another trial is the mouse that gnaws the bark of shrubs, girdles young trees, and eats the rootstocks of iris, and nibbles young perennials. Sometimes it may be caught in a trap, sometimes it is poisoned, but the surest way to protect trees and shrubs is to tie about them strips of tarred paper from six to ten inches high. If a heavy mulch is applied to the garden before the ground freezes, both mice and moles will seek winter shelter in the mellow soil, which may be prevented by late mulching after a hard freeze.

When the cutworm has been ordinarily numerous, there is no respite in the war waged against it, but a new campaign begins from the tenth to the fifteenth of June against a small tan-colored beetle called the rose-bug. And why rose-bug? By courtesy alone should it thus be called. For years it has ravaged the panicles of our sumachs, stripping the creamy green blossoms down to the bare stems. There is where I failed. I should have pursued it long ago; but, as I have only recently squandered myself on choice roses, I am just awakening to the fact that the rose-bug is a desperate evil. Authorities agree that hand picking alone conquers.

Some days before the new roses were in bloom, I discovered that a certain fern was suddenly blighted-it was the rose-bug at work. As I had never measured the strength and number of this foe, I merely began - a stampede; but one can't do that long; so I got a large tin tobacco-box (how useful Adam's manners and customs are to me) and mixing a little kerosene 


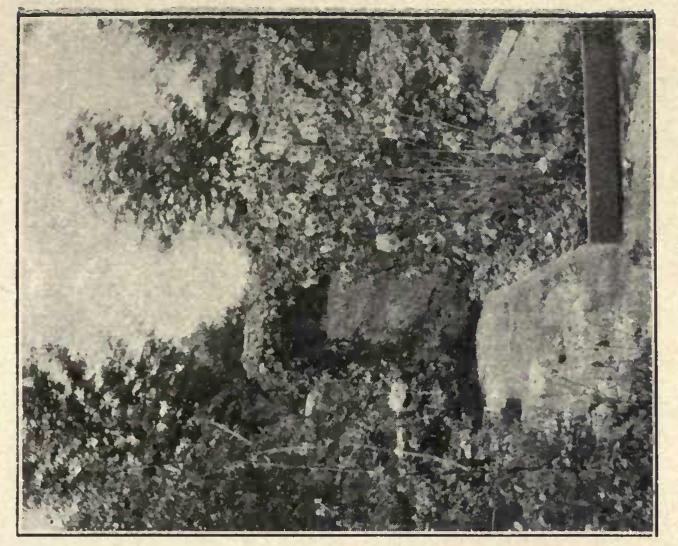

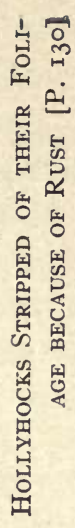

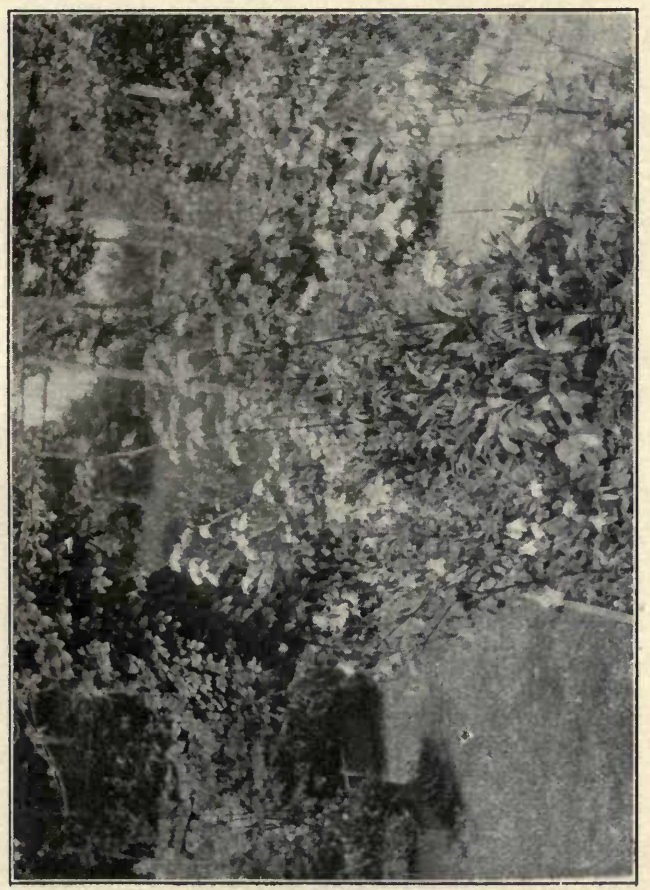

竝

里 

with water, I entered the detective service. Many times a day I went out, and found the garden heliotrope and Spirea salicifolia swarming; also the beetles were strolling up and down the stems of the Asperula hexaphylla, and gnawing great bites out of the Chrysanthemum maximum. They do not attack the half wild red Lancaster and cinnamon roses, and I thought I had cleared the garden of them before the choicer roses appeared, when I discovered new relays on the goutweed, mallow, meadow-rue, and hundreds of them on a Virginia creeper. Not that the rose-bug likes Virginia creeper; but, as an enemy, he finds a vine over my favorite seat a vulnerable point to attack. Everywhere save in the heart of roses, where we are bidden to search for the evil one, do we find it. Rosebug, forsooth! It is no such dainty epicure as that; it should be called Omnivorous Bug, for it samples everything, even yourself if you stay any length of time. But you don't, for another pestiferous creature drives you frantic and you escape indoors. I do not know its name, but it looks like a triangular fly with a small head and broad spreading transparent wings with dark spots, and it circles around your head and lights on your arm or back and bites as no gentle rose-bug ever thought of biting. There is something malignant about this noisy fly, and it is seldom that you can get a full view of it. I have had them pursue me over a hundred feet and even fly in at the screen door after me.

To return to the rose-bug: it flourishes a month or more, when the males die and the females descend into the earth to lay their eggs, come to the surface and die. The eggs hatch in twenty days, and the young larvæ begin to feed upon tender roots. In October they descend below the reach of frost where they remain until spring, gradually come to the surface, and in May are transformed into pupæ and in June become beetles. Two remedies besides hand-picking into kero- 
sene are recommended: spraying with arsenate of lead-five pounds to fifty gallons of water; or Paris green at the rate of one pound to two hundred gallons of water. The latter solution injures the foliage. Since Paris green is a remedy, I do not see why one cannot use it as we do for the potato-bug, which is half a teaspoonful of it sifted in a quart of flour and dusted over plants when they are wet. This proportion is not injurious to foliage. The rose-bug is a gentle creature, and clings to a leaf until you get a fair hold on it, which makes capture an easy thing.

Another rose pest is a small green worm that works on the under side of the leaf and leaves behind a brown skeleton fiber. Spraying helps a little, but it is better to stir into the ground a little air-slaked lime in early spring. One half of a rose bed where this was tried was quite free from the pest; the other half where no lime was used was eaten almost bare. Sprinkling the under side of leaves with one tablespoonful of white hellebore to a pailful of boiling water is recommended.

I was quite worn out by the time they departed, for their season was unusually long that first year of discovery, when to my distress I found the wild clematis vines almost denuded of leaves, also the Anemone Pennsylvanica was in tatters, and the new invader was a dark lead-colored bug almost an inch long, resembling a lightning-bug on the back, but with a huge gray abdominal expanse. It has a very small pin head which it carries in a spirited, cocky fashion, and drops at a touch. Later it infested the Japanese clematis, and proved a voracious devastator. I couldn't hand pick this loathsome insect, but scraped it off into my kerosene box.

Before this pest disappeared I found another and larger creature at work-my trials that particular summer grew like an inverted triangle, and if winter had not come to my relief, our garden pests would have increased to the size of a cat. 
The new horror was the oil beetle, a bright blue metallic insect without visible wings, fully two inches long, with a ridiculously small waist, and an enormous distension of body tapering to a point. This also infested the Anemone Pennsylvanica, now in complete rags and tatters, the wild clematis, Japanese clematis, and occasionally the larkspur. Drowning in kerosene is the only fit death for this disgusting vulture.

I despatched about forty thousand of these despicable enemies, had my usual bout with the potato-bug which devours the Nicotiana affinis, and thought to breathe something beside the nauseating fumes of kerosene, when I discovered the aster beetle at work, not so much on the China asters as on the Michaelmas daisies. It is a jet black beetle, less than an inch long, and must be hand picked, or more correctly speaking-hand-scraped into kerosene. I am sure these enemies have been with me in previous seasons, but either in less number, or the scales had just fallen from my eyes. We had unusual rains that year and in consequence more bugs. Drought may be my chief blessing after all.

With the establishment of a white woody variety of late aster, came a horde of yellow wasps, which were despatched by scraping them into a glass of soapy water, either early in the morning, or late at night when they were a trifle stiff with the cold.

The green louse that infests the tender tips of roses, also the Gaura and pinks can be controlled by spraying with a strong solution of Ivory soap-suds; or add to hot soap-suds two tablespoonfuls of kerosene to four gallons of water; mix thoroughly with a sprayer and then spray two or three times at intervals of two weeks. This is a weak kerosene emulsion and may be used for white worms, rose beetles and aster beetles, but is better for sucking insects. A solution of one pound of whale oil soap to eight gallons of water will also 


\section{Hardy Plants for Cottage Gardens}

keep in check sucking insects. I kept my roses in healthy condition all summer merely by spraying them with strong Ivory soap-suds at intervals of a week or ten days. I found no rosebugs on any rose except Madame Plantier, and not more than a dozen on that.

Contrary to the accepted opinion, I consider bees an enemy in a garden - an enemy to beauty; and bumble bees are rougher in their habits than honey bees. I have felt an angry protest, when observing the wanton destruction of a poppy bed made by the bumble bee, as it tumbles about among the stamens and loosens the petals so that they drop within a few hours. I have also observed when both bumble bees and honey bees are numerous, that the bumble bees vacate the poppies and give precedence to honey bees, betaking themselves to the hollyhocks instead, where they load up with pollen unmolested. There is something about hollyhock pollen that fuddles a bumble bee completely, and at early twilight, when all respectable bumble bees should be sitting by their firesides relating the day's adventures to the young, a tall hollyhock resembles a thirteen-story apartment house without its shielding walls to hide the occupants, and every flower has become a bed-chamber where one or more bumble bees, helplessly intoxicated and unable to go home, find shelter for the night. Nor do they always sleep off the effect by morning, for I have found them at nine o'clock still torpid and unable to move.

There are many minor pests more or less destructive in the form of flies that puncture the leaves of the aster, Chrysanthemum maximum, and tender leaved plants, leaving round dark dots; also those that pierce a stem to lay their eggs, causing a white spittle-like foam to ooze from the spot. Then there are special diseases of plants so numerous as to require technical study to meet them wisely. For example, the larkspur 
is subject to the crown rot in early spring, and the remedy is to cover them with ashes as a fall mulch; also to sprinkle airslaked lime about the foot, and over the crown. The larkspur blight is now under advisement, and no remedy is yet assured, so I was told by the Plant Industry Department at Washington; though I shall relate my own experiment later, which has been quite successful for two summers. It assumes the form of a shriveling of the buds just as they are about to appear, leaving abortive stems only. The only thing recommended so far by the Department is to cut out and destroy all infected plants, and spray with copper fungicides, using the following Government formula for Bordeaux mixture: Copper sulphate, three pounds; fresh stone lime, six pounds; water, fifty gallons. It is much better to use it freshly mixed, and as a small garden will not need so large a quantity at one time, each of the above ingredients may be dissolved separately in twenty-five gallons of water to be kept as a stock mixture. If the water evaporates, add water to make up the loss, and combine them as required, stirring thoroughly. Or, it may be made freshly each time in the exact quantity needed, using the above formula, by dissolving separately at the rate of one ounce of copper sulphate and two ounces of fresh stone lime each in a half gallon of water. Stir well when dissolving and when mixed together. In slaking lime add but a little water at a time to the lime, as it generates great heat, stirring until all lumps are slaked. Slaked lime should be kept covered with water until it is used.

The hollyhock rust has proved quite as deadly and unmanageable as the larkspur blight, when once established. As I have grown my larkspurs and hollyhocks from seeds, and I am a mile or more from any extensive garden that might have infection, the appearance of blight and rust was unexpected. It is said that rust, like mildew, attacks weak plants, but my 
experience is to the contrary, for I have never seen such vigorous plants as my hollyhocks were when the rust first appeared. Each plant was from three to four feet in circumference, and each sent up from four to six stalks six feet high or more. I was advised to use a weak solution of permanganate of potassium, enough to tinge the water, if the plants were young; or a weak solution of Bordeaux mixture, if the disease was advanced. I used the latter, as the yellow spots had crept up to the top leaves and the lower ones had all fallen leaving my hollyhocks as naked as a plucked fowl. The result was immediate death-I trust a painless one.

Reasoning from the advice that a frequent spraying with Ivory soap-suds was an excellent general insecticide for roses, I proceeded to apply the suggestion in a new way to hollyhocks and larkspurs. I made a thick foaming suds, adding, as an antiseptic, a half teaspoonful of baking soda to two or three quarts of water. Taking a handful of the foam, I began at the root of a plant and ran my hand upwards so as to cover with foam the under sides of the leaves as well as the top, the stems, and even the buds, if they were forming. This treatment was begun in early May, and four or five applications were made at intervals of a week. For the first time in many years the hollyhocks were free from rust, though on several plants, that did not get an early treatment, it appeared toward the middle of the summer in a mild form; and on others, that, intentionally I did not treat at all, the rust ran its usual destructive course. This method was wholly successful with larkspurs, and was rewarded with a full crop of bloom, the first in years. This simple remedy costs nothing, does not disfigure the plants, and from my two years' experiment I believe that these two diseases can be kept under control, if the applications are begun early, and continued for a month 
or more. Do not wait until the rust appears before you begin treatment, but start with the first growth of leaves. Meantime I advise a renewal of the stock by raising a yearly crop of seedlings and replacing old plants with strong young ones from time to time.

Then there is mildew that attacks roses, Michaelmas daisy, larkspur and other plants. It is due to continued wet weather, sour soil or unfavorable situation. Various remedies are offered. As a preventive, apply once a month Bordeaux mixture diluted to half strength, using the formula: sulphate of copper, six pounds; lime, four pounds; water, ninety gallons. This renders the foliage unsightly, and a milder preventive is often used: sulphide of potassium, one half ounce; water one gallon; apply once a week if the weather is wet and washes off the mixture. Another remedy is one tablespoonful of sulphur and wood-soot, made into a paste with water. Add boiling water, perhaps one or two quarts, and when cool, sprinkle plants or bushes. For mildew that has actually appeared, powder the plants and the ground beneath with flowers of sulphur; also stir into the soil a little slaked lime.

The Clematis Jackmanni has an artless way of disappearing without a word of farewell-mine did before I learned the probable cause and remedy. The bark on the stem of the Clematis is very brittle, and easily scraped when packed for transportation, and when this has occurred, the wounded place becomes an easy entrance to the eel worm that burrows in and destroys the vine. It travels at the surface of the earth, and if the wound is near the ground it has access. The remedy is to cut the stem off to the very root when planting, hill up sand about the plant, and cover the crown at least an inch with soil.

My Physostegia sometimes suffers from a blight that turns the plant yellow, and rots the stem off at the root and it dies. 


\section{Hardy Plants for Cottage Gardens}

I do not know the cause, but think it must be due to a sour condition of soil kept too shaded and moist. They are planted all over the garden, and in sunny locations the plants are healthy; elsewhere they are not. I mean to try a little lime in the earth as a remedy.

The cause of the auratum lily disappearing is said to be a white mite that infests the scales. In foreign countries where they are raised, the conditions are such that this is kept in check, while it flourishes in America. A well drained sunny situation, a rich soil with plenty of leaf mold in it, but no fresh manure, the bulb well insulated by a handful of sand directly about it when planted, give the auratum at least a favorable environment.

The Lilium Candidum is also subject to disease, and, as a corrective, the bulbs should be powdered with sulphur before planting. There are other specific diseases too numerous to mention; apparently they are the appointed way that plants pass out of this world, like the aster blight, due to the blue aphis that attacks the tender roots, for which the specific is wood ashes in the soil at the root; the carnation blight due to a little worm that finds lodgment in the stem and has to be burrowed out. Then there are plants that root near the surface of the ground, and while they die if kept too wet, they are also killed if the roots dry out or the hot sun strikes the collar of the plant.

Many of these peculiar requirements and conditions I have tried to enumerate under their proper heads in the Appendix; yet the treatment of plants can no more be generalized than the treatment of children can. There are inherent capacities and aptitudes that seem to demand certain environment, yet at times plants adapt themselves in a marvelous way to quite contrary ones. Evidently the great life energy is reaching out as eagerly to produce ever higher types through plant forms 


\section{Mine Enemies}

as it does through human beings, and there seems to be a universal desire on all planes of existence to escape the type form and achieve an individual expression. But it is only through a healthy vehicle that it can come to pass. Interesting sports in the garden proceed from healthy growths. If we desire to assist Nature's effort to produce through a strong normal type an individual variation, it can only be done by first eliminating disease and destructive agencies from the garden, and then affording every favoring condition. 


\section{PHOTOGRAPHY OF FLOWERS}

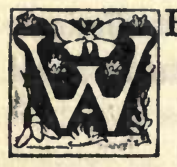

HEN Adam presented me with a camera, possessing the various attachments designed to bewilder simple woman, together with a dozen rolls of films, I was as much overwhelmed with the new dignity thrust upon me as if I had been an obscure Western politician summoned to take a Cabinet position. I had not gone through the snap-shot-pocket-kodak kindergarten; I was innocent of the least knowledge of the wiles and tricks a modern camera can play one, and here I was like a twoyear-old given a parlor clock to play with.

I was taken in hand by a professional photographer, who explained to me the functions and readings of the diaphram, the way to set for distance, who also interpreted the mysterious phylactery over the eye of the lens, T. B. I-25, I-50, I-I00-all of which instruction I asked him to let me repeat parrot-fashion after him, and when he declared my answers to the catechism were correct, he closed the camera, assuring me it was loaded-a terrifying word to one whose life-long horror has been a gun-and I reluctantly departed, saying that he would probably see me again shortly. I lingered on the doorstep of his piazza wondering if I could not invite him up to the cottage to spend a week, so hazy already was my impression of what had been said, and so unprepared had I been for the interview. Adam had intended to surprise me with his gift, and the effect was greater then he hoped-I was truly dazed. As we drove home with the camera, I admired the case, reported every word of my instructions, 
and offered to show the delighted Adam the esoteric mysteries within, and then I found I had failed to ask how to open the little beast. I was much chagrined, for it was a somewhat important item, and we were three miles from the source of wisdom. In the course of a few days I made the journey again, returned and felt myself ready for action.

I confess to no interest in genealogy, but I am sure if any one took the pains to investigate my lineage, it would be found that I was a near relative of Elizabeth Eliza Peterkin, whose extraordinary density was the delight of my youth. I could now open and close the camera, and my next desire was "to behold this world so wide" through the finder, preparatory to taking pictures. I found the finder, but nothing else, for I steadfastly held the open camera with the bellows end towards me, and, direct it as I would, I saw nothing but the back of the camera in the glass. I had sense enough to know that something was wrong, and that the fault was mine, though that was small consolation when I contemplated another three-mile drive for instruction.

I was given the same advice offered to Elizabeth Eliza, who was found by the Lady from Philadelphia sitting on a high stool, playing on the piano through the open parlor window. Elizabeth Eliza explained that the expressmen had carelessly set up the piano in the parlor with the keyboard next to the wall, and though she could reach over a big square piano and play at arm's length for a while, she could not do it long. So she had almost decided to give up her music, when it occurred to her to place a high stool outside the open window where she could reach through and play quite easily.

"My dear Eliza," exclaimed the Lady from Philadelphia, "Why don't you turn the piano around?"

"I never thought to do that," replied Eliza. 


\section{Hardy Plants for Cottage Gardens}

Said my instructor, with a twinkle of mirth in his eye, "You have been standing in front of your camera instead of behind it; turn it around, my child, and look."

The child turned it, and was deeply mortified at her utter stupidity; but she laughed to cover her confusion and said: "This reminds me of an episode that occurred at a baby show I once attended in the South. All the negro babies under a year old of the district had been sent in to compete for a prize and as they arrived they were duly ticketed with a large number pinned on the dress. Just before the opening hour, an assistant came in haste to the manager and said anxiously, 'We have lost No. 9. Have you seen it? And we have two No. 6's; we are getting all mixed up.'

"' 'No,' replied the manager, 'it was there a few minutes ago, for I marked the baby myself-it was a girl.'

"Then followed a hasty search, and a sudden exclamation of satisfaction from the manager, who called out, 'Here's No. 9; some one has set her wrong side up so she looks like a 6." "

More than a week had now slipped away, I had mastered two minor points, but had not ventured to take a picture, and I have to laugh at myself now as I recall my maiden effort. The camera had been bought to gratify my desire to photograph flowers, but no one had told me, that, of all objects under the canopy of heaven; flowers are the most difficult, and require technical instruction. I was unaware that four o'clock in the afternoon in a shady place is not quite the condition to set an exposure at I-25 of a second with a 64 diaphragm. The object chosen was a lovely confusion of blue lupines and yellow day lilies, and I spent half an hour in setting up the camera, and measured the distance at least three times, anxiously inspecting the various contrivances to be set. My cheeks grew hot and my hand unsteady while I tried to pluck up courage to squeeze the bulb. It sounds 
easy to do, but for a novice whose previous education has not included a course in squeezing bulbs it is a difficult science.

Your hand seems a thousand miles from the directing brain, and the communicating command to squeeze loiters on the threshold of the spinal cord, proceeds leisurely to the shoulder, and down to the hand as if out for a holiday. Meantime the hand waits for the word and wonders if the cable is cut. I gave a nervous, tremulous, continuous grip, and then fearing that I had not done it properly, I gave another, and the deed was doubly done. It had been an agitating hour, and while I longed to make instant use of the newly gained knowledge that double squeezes are an evidence of a perturbed mind, I felt I had had enough excitement for that day and was satisfied to close the camera and walk into the house, assured that I had fulfilled every condition, and that my initial attempt was undoubtedly successful, if somewhat flurried.

I was truly distressed when the first roll of developed films was placed in my hands - they were worthless; and more than this, the lupines had gone by, as well as the various other things I had taken, so they were lost to me for a whole year. The second roll was edifying, but not useful. Then in a sapient moment, I decided to keep an exact record of my mistakes, confident that, in the course of time, I should cover the entire range of possible errors, and it would be a pleasure to know what not to do, for I was not in the least disheartened. So I ruled out a little memorandum book thus:

\begin{tabular}{|c|c|c|c|c|c|c|c|c|}
\hline Date & No. Set & Time & Diaphragm & Distance & Subject & Hour & Weather & Results \\
\hline
\end{tabular}

and I have kept a careful report of every exposure taken. As I look over the column marked Results, I am surprised at 


\section{Hardy Plants for Cottage Gardens}

the fertility of my blundering mind, and to see what a variety of things can go wrong, and yet never repeat the same mistake. They run thus: Lost-time exposure left open, losing two films-under-exposed-lost through duplicating on last exposure-rolled film too far-snapped the shutter attachment by accident-focus bad - forgot to set any of the attachments-over-exposed.

By and by the tide turned and the results began a different theme-good-fair-very good-excellent-best of all.

After three years of faithful practice I can set forth a few words of advice-not as a finished exponent of this art, but as an earnest student who has learned somewhat of the fundamental principles. One is that crisp details add beauty to a flower photograph, and these demand a long exposure and small diaphragm. No. 32 of the F. system is excellent, even a 64 , if the sun is very bright, or thin white clouds flying, which give a high degree of the actinic rays. I find with a 32 diaphragm, a bulb (B) exposure of I-3 to I second, or more, according to conditions, give good results. By conditions, I mean the degree of light, and hour of day, whether in full sun or in shade, whether light or dark objects, at a distance of three feet or a distant view. From nine to ten o'clock in the morning during the summer months, the shadows are long and the atmospheric quality is tender and diffused; but the light is not strong and the exposure may be a second, which is beyond what is required at high noon. Also from three to four o'clock in the afternoon, the shadows are deep and rich in tone though the light is only fairly strong. A hazy day is also good, even a dull day, though it will be lacking in shadow, and the time of exposure must be increased accordingly. An excellent guide in the matter of timing exposures is found in the Wager Exposure Scale, manufactured in Baltimore, Md., by the John $\mathrm{H}$. 


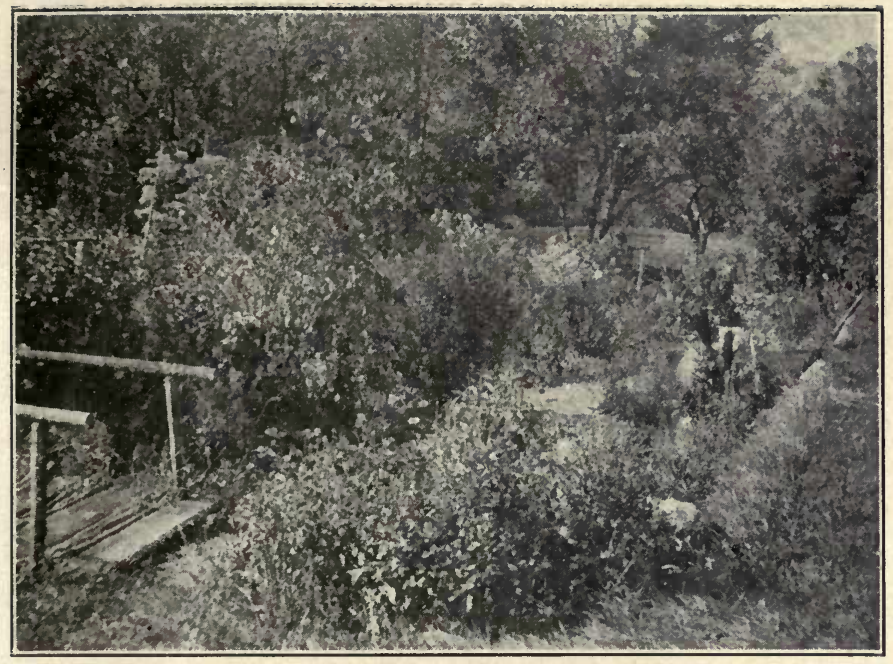

A Hazy Day in OCtober

[P. I38]

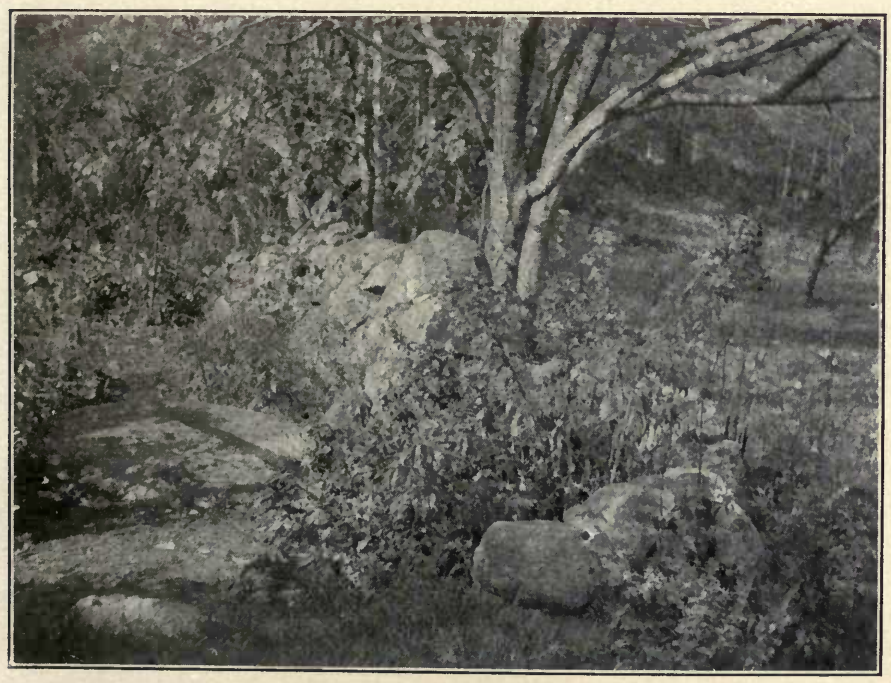

The Dropping of Leaves Marks the Progress Nature MAKES

[P. I40] 

Herrick Co. It makes allowance for every condition-the month of the year, hour of day, long, short or average distances, light or dark objects, also for clear sun, bright, hazy and dull weather and varying speed of plates. I have found it reliable and comprehensive.

In the matter of plates or films I learn from an experienced authority that the most rapid are necessary for flower photography, and that a color filter helps to preserve values, but extra timing is necessary with a color filter. I learn also that the conditions of flower photography are peculiar, in that to bring out the sharp details of a red blossom requires from four to six times as long an exposure as a white one; green details require two or three times; yellow but little longer, unless of deep orange tone; blue, unless of a deep purplish tone, about the same as white.

An excellent way to acquire a practical knowledge of your camera is to take the same object under different conditions of time, size of diaphragm, sun, shade, and distance, making a careful record of each exposure, and note which gives the best results. A helpful article on "Photographing Trees and Flowers" appeared in "The Photo-Miniature," No. I3, Vol. II., to which I refer the student. The subject is too large and technical for me to attempt any definite instruction. I only know enough to avoid the common, egregious, needless mistakes. Ten years hence when I have squandered my entire patrimony on films, plates, cameras and tripods, I may have an authoritative word to say. To-day I am but an index finger pointing to a delightful amenity of life.

One does not realize the constant flux and flow in nature until he has tried to photograph out of doors. There is but a single day in the life of many plants when they represent perfection of growth and bloom. If, on that particular day, you forget the engagement, or the rain falls, or the wind is 
high, or other duties interfere, the chance is lost. Sometimes the conditions seem perfect, and the tripod is set in place, when a slight wind springs up, and the delicately poised flowers wag their heads in response, and you wait, bulb in hand-and wait-and wait-sometimes half an hour for a moment of calm. It comes usually after a sharp blow, and you must be alert to take advantage of it. If you lose patience, and let it go, you are likely to lose the subject altogether; for a plant is not the same on any two days, and its climax of beauty is short-lived.

In the early spring we can easily follow the swift changes in the opening leaves and rapid growth; also in the autumn the daily variations of coloring and the dropping of leaves mark the progress Nature makes. We are apt to think that she rests, or gently matures during the interval. With camera in hand we grow sensitive to the infinite gradations of lighta passing cloud alters the whole aspect-of the magical changes wrought through the passing hours, where shadows shift momentarily; of the fluid character of the air, seldom in quiescence; of daily transition from leaf to bud, from bud to flower and flower to fruit. Contrary to actual experience, perfect beauty always impresses me with confidence in its permanence. An apple-tree in full flower, a maple-tree in autumn dress convince me that they are dependable stage properties; that, as lovely accessories, they must endure, they are guaranteed for life: and I am ever perplexed to see the petals fall and the beauty fade.

Once only in my life have I known perfect repose in Nature. It was a January day in a North Carolina pine barren, and I had wandered away from my companions, and sat on a fallen $\log$ to observe things. The stillness and hush were indescribable; not a leaf rustled, not a bird, cricket or insect could be seen or heard, no living creature stirred in the underbrush, 
no cloud floated across the sky. The landscape with its white sandy road, losing itself in a weird blackened forest of halfcharred turpentine pines, clothed knee high with flaming red underbrush of scrub oak, was as lifeless as a painted canvas, and I became sceptical of my own reality. The longer I sat the more fantastic and improbable did the trees and sky and my own existence seem. It was with an effort that I shook off the illusion, and dropped back into a living active world, where every leaf must act its part, if it be no more than to twinkle and coquet with the wind, where birds must flutter by and sing, and clouds float, and distant hammers and voices ring, and dogs and poultry utter their cry to keep men sane and normal. We must have action and sound, else Nature oppresses us as a bad dream of the night where nothing moves, nor is anything brought to pass.

Only when we try our apprentice hand in the faulty use of such a force as light in photography, instead of dense matter, do we realize how subtile, how powerful any force is, how inviolable are the results. We may blunder and patch up a mistake with matter; but a mistaken application of force is irremediable and destructive. Any thoughtful experiment leads us to the threshold of almost unimaginable speculations about the conditions when, as disembodied spirits, ages hence, we shall be liberated forever from the limitations of matter, and sometime be entrusted with the use of these sublimated agents-forces-not destructively and experimentally, but constructively. How shall we build, when we employ thought instead of brick and stone? What shall our gardens be, when we use the life principle instead of plants? What shall we communicate, when we send forth musical vibratory color instead of dense thought or still grosser words?

When we study a garden for its photographic possibilities, we see a thousand things before unobserved, and in new rela- 


\section{Hardy Plants for Cottage Gardens}

tions. We grow sensitive to the artistic effect of unusual combinations; we study with a view to rearrangement; mere color grows less emphatic and beauty of form, symmetry, variety and distribution more. We note the quality of shadow as well as light; we observe the ensemble as well as particulars; we see more in perspective. We visit an object to observe how it looks at different hours of the day, and at night. We note the modifications made by the different atmospheric conditions. Some of my most delightful suggestions have come through studying the garden under the moonlight, when a wholly unfamiliar aspect is presented, and the deep shadows supplement reality.

My latest extension along the slope was a problem for a whole year, during which, I worked out many diagrams, but none of them pleased me. Last August I chanced to look into the garden when the moon was full, and across a certain walk tall perennials and shrubs cast shadows, that looked like steps rising in a series of threes, curving toward and lost beneath a distant arbor. Here was a clear solution of my question, which was to construct a walk at the base of the slope and running parallel with it for thirty feet, and then let it rise in a curve to the top. To accomplish it, I had only to cut the bank on either side of the rising curve down to the level of three long terraced beds that already existed, and merely needed to be extended to meet the walk; and then by facing the cuttings with stone walls, I could secure the moist and shaded conditions that were so much needed for certain shrubs and tall perennials that had to be moved from their present exposed position because they suffered from drought. These were planted on the right, the taller ones next to the walls and shading the smaller ones, while on the left of the rising walk, where the slope was cut down perhaps five feet and leveled towards the front, was an unlimited space for masses of the low Lancaster 


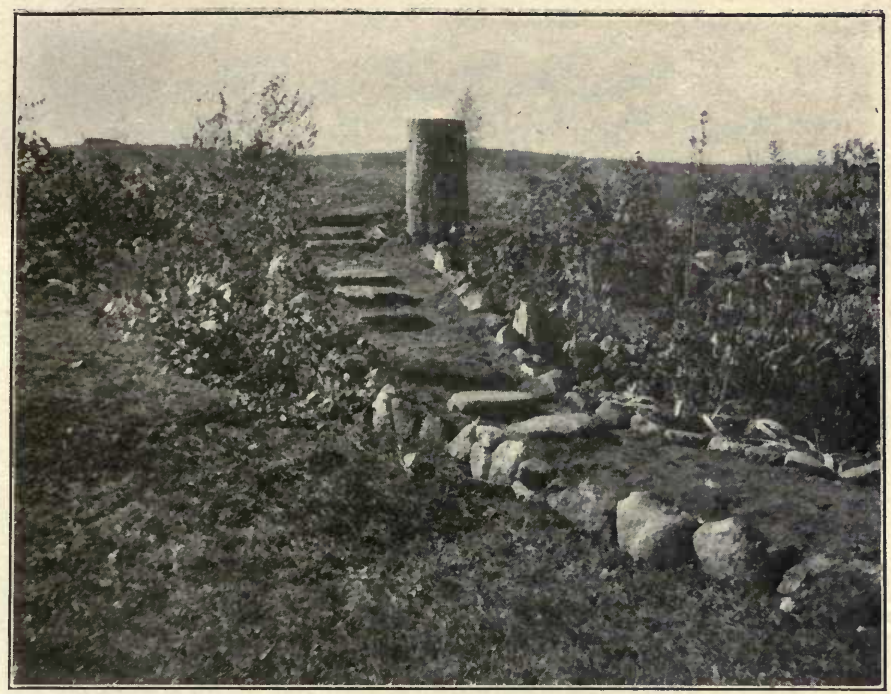

A Curved Walk with Terraced Beds Cut Out of a Slope, Suggested by Shadows at Night

[P. I42]

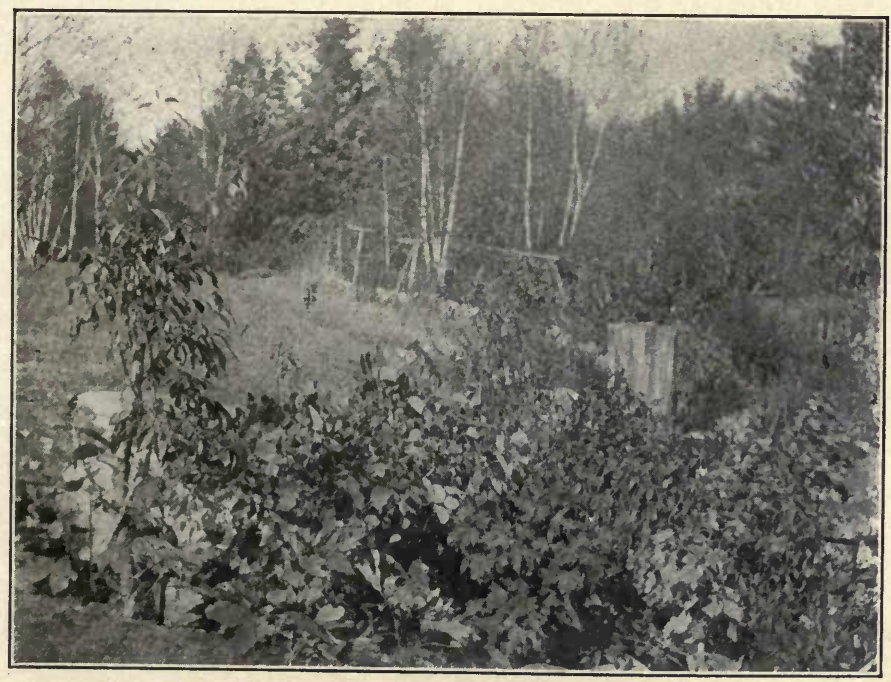

Portion of a Bed Set with Young Shrubs for Autumn EFfects

[P. 143] 

roses, hybrid perpetuals and my annual overflow of perennials arranged in front of a long undulating background of shrubs that I am gradually assembling for autumn effects. The photograph shows but a small portion of it in a new raw state, just as it was planted in late autumn. All about the stump are planted wild clematis and tall ferns, and in the corner of the first bed below the stump is a white variety of Clematis Jackmanni. The upper right-hand bed, which is a perfect Sahara, is set with Rudbeckia and Helianthus latifolius, both able to withstand any drought. The next just below was a former nursery bed, and is reset with columbines, blue lupines and meadow-rue, deep blue larkspur, white foxgloves, hollyhocks, perennial phlox and late asters. The third and lowest bed is planted with Lychnis dioica rosea, Paris daisy, Chrysanthemum maximum, white larkspur, golden glow, Helianthus, Helen flower and perennial phlox, with red Shirley poppies for a brilliant midsummer effect. And this is the fruit of a moonlight vision.

How varied the night effects are, seen under a crescent, or full, or waning moon, with clear soft blue-gray sky, or flying scud of cloud! How penetrating and tangible is the black darkness that blots out everything! I shall never forget an experience one starless night when a wild gale was blowing, and a storm impended. I went out to gather a ripe poppyhead that I had been saving and feared would be lost, and my feet were guided by instinct, as it was pitch black. There was something ghoulish in the clutching wind; the thick darkness was choking and malevolent. A spirit of evil was abroad and filled me with terror. I actually fled before it, and ran breathless into the house.

Instead of taking random pictures of any chance thing, I urge lovers of flowers to make a study of them by means of the camera. One may prefer to arrange cut flowers as a subject; 


\section{I44 Hardy Plants for Cottage Gardens}

another, single growing plants; some may choose garden effects at different seasons; some wild flowers; some perhaps will take a single family and secure photographs of its different varieties and species. It is vastly more interesting to use this art intelligently, and with definite purpose, than to gather a meaningless collection of prints. Aside from the interest and pleasure it gives, it has an esthetic, educational value to the earnest student. 


\section{SOME GARDENERS I HAVE KNOWN}

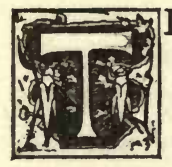

HERE are as many motives in growing flowers as there are reasons that take people into the country. A genuine passion for nature is seldom the root of either. Frequently it is mere obedience to convention. The "best people" are observed to do and to have certain things, and thus it is recognized as the proper thing to have orchards, well-kept grounds, a stable, a kennel and a garden, and worshippers of convention buy them as they do groceries, hire others to care for them, visit them rarely, and have no personal relation with any one of them. If an entertainment is to be given, the gardeners wheel in their products, and the maids, or some poor relative, arrange them; and a bushel or two left over gives no pang to the mistress; the surplus is a gratifying proof of the prodigal yield of the estate.

"God Almightie first planted a Garden. And indeed, it is the Purest of Humane pleasures. It is the Greatest Refreshment to the Spirits of Man; without which, Buildings and Pallaces are but Groose Handy-works; And a Man shall ever see, that when Ages grow to Civility and Elegancie, Men come to Build Stately, sooner than to Garden Finely," says Bacon.

Then there are those who have a barbaric love of colormasses of it-and whether their flowers are in the ground, or crowded into fat round bowls, they present solid sheets of color. As far as esthetic effects go they might as well spread yards of Turkey red calico or large flowered prints upon the ground. But this is their taste, and thus do they express it. 


\section{I46 Hardy Plants for Cottage Gardens}

Nothing is more interesting, than to observe the key-note of any given garden, and nothing is more significant as an interpretation of the owner's taste. There may be hundreds of varieties and many colors, yet at a distance all are blended into some particular composite tone which dominates, and too often it is a vicious purplish red, better known as solferino, or magenta.

For some inexplicable reason, most garden effects remind me of an old book of household wisdom belonging to my grandmother. In it were recipes for cookies, pastry and puddings; homely remedies for croup, typhoid fever and rickets; infallible cures for spavin, thrush and sprung knees, and useful hints about the care of young calves; instruction in domestic economy and the management of servants - a veritable repository of human knowledge. But the versatility of the writer did not end here. Being something more than a mere housewife and free dispensary, she prudently shut the door upon the material domain by inserting two blank pages as an insulator, and then launched upon the difficult questions of esthetics. She gave carefully prepared and authoritative recipes for painting skies, water, moonlight, fountains, trees. These were rescued from the blundering instincts of artists, and once for all chromatics was placed within the easy reach of the multitude. For years I used to hover over this compendium like a bee about a honey pot, and then look wistfully at a southwestern sky, when it presented a certain ineffable tone that was neither blue, nor gray, nor yellow, and wondered whether it was composed of gamboge, Venetian red, ultramarine blue, Naples yellow, or what, heightened by whiteall the recipes generously allowed for "heightening," whatever that might mean. I never reached any decision on this question; for, to my deep regret, a southwestern sky was not mentioned in the Book of Wisdom; so I finally concluded that 
the sky I loved best must be like the Italian sky, indescribable; else it certainly would have been prescribed. If the author were alive to-day to add an appendix, one item would certainly run thus: Average Garden-Take ten square feet of mixed petunias, preferably blotched and mottled, two feet by four of yellow and red zinnias, an eighth of an acre of yellow marigolds, an equal area of scarlet geraniums, a yard of balsams. Blend indiscriminately. Shade with purple asters, magenta balsams and variegated coleus. Heighten with sunflowers, cannas, castor bean and solferino dahlias.

Again there are those who feel a proprietary right in everything they touch, and such people grow flowers to cut. They have no more scruple in going out with a large basket and sharp relentless shears to devastate the beauty of their beds than they would to cut into a yard of cotton cloth. That is what flowers are for, and merciless is the hand of the butcher. To them they are useful commodities like butter, soap and tea. Glorious stalks of lilium auratum are not sacred (the more glorious the better, just as high-priced unsalted butter is preferable) nor great spikes of larkspur, nor campanulas, nor hibiscus, nor lilium speciosum. Never mind if the whole year's fruition is centered in a single head of splendid bloom, and half the buds are still unopened, off goes that head as lightly as if it were a nasturtium. No matter if, when cut, it lives but a day in water; it has served-for it was grown to cut! There are of course instances where you may eat your cake and keep it in a garden; but for the most part perennials allow themselves a limited amount of bloom, and you cannot have it on the stalk and on the mantelpiece at the same time.

Then there are certain spendthrift natures that grow flowers to give away. They have a passion for generosity. They will call in little Jennie from her play to give away the dress on her back; they will dispose of the last new book before the 


\section{I48 Hardy Plants for Cottage Gardens}

family has had time to read it. Jellies and pickles never ripen on their cellar shelves, for they are sent as a glad tribute to neighbors. They will dig up anything, and strip their most precious possession to give to any passer-by, who seldom troubles himself to carry it as far as the gate. When such a one meets a person gluttonous of things, sad is the havoc wrought. For example: in the early days when I was studying not only flowers, but the habits of mortals let loose among them, this conversation took place. Said a Gluttonous One: "My daughter and I were calling upon Mrs. - - who has a beautiful garden, and she told us that we could help ourselves to anything we liked; and my daughter gathered white foxgloves - the greatest quantity - as many as she could hold in her two hands," and she related the atrocity with all the relish of a cannibal who had just eaten a missionary. I immediately called her attention to a certain view of the mountains and gently but firmly led her a safe distance from the garden.

Incidentally let me confide that this same mountain view is my trump-card. Some people-strangers in our part of the world-have come to look upon us as public property, and not a few have even been known to visit us as they would a boulder or a glen. Their arrival is not always coincident with my convenience. They may come at the critical moment when the dressing for my truly delicious mustard pickles is thickening; when, at my ablutions, my ear alone catches the sound of the knocker, and I have no way of communicating either their coming or my helpless condition to Adam in the garden, or my maid who may be hanging out the clothes. They come at dewy morn when I am transplanting; they come when we are at dinner-a matter not half so tragical as arriving just as dinner, for three only, is ready to be served. They come in rain, and when the thermometer stands 


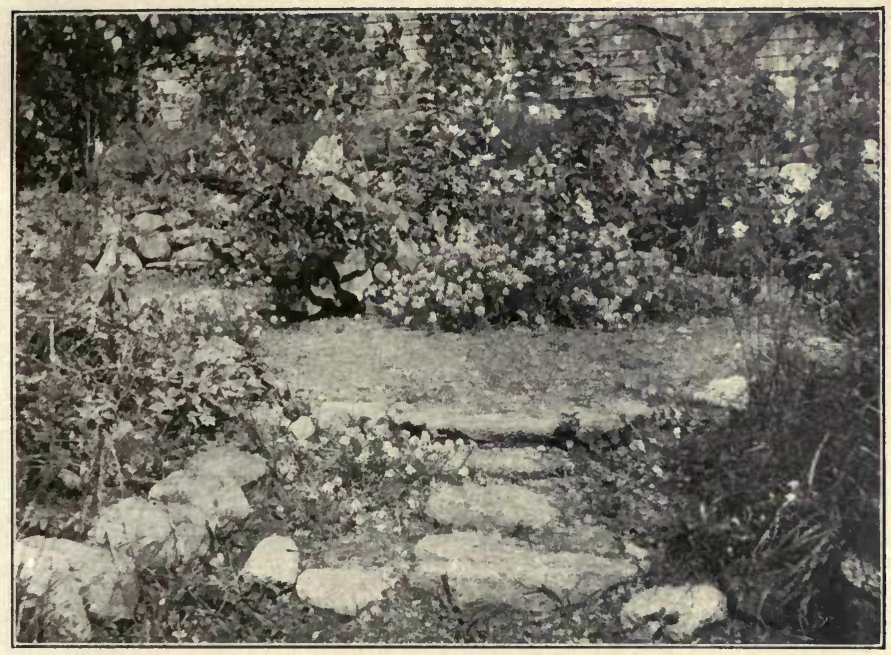

Late September Annuals

[P. I44]

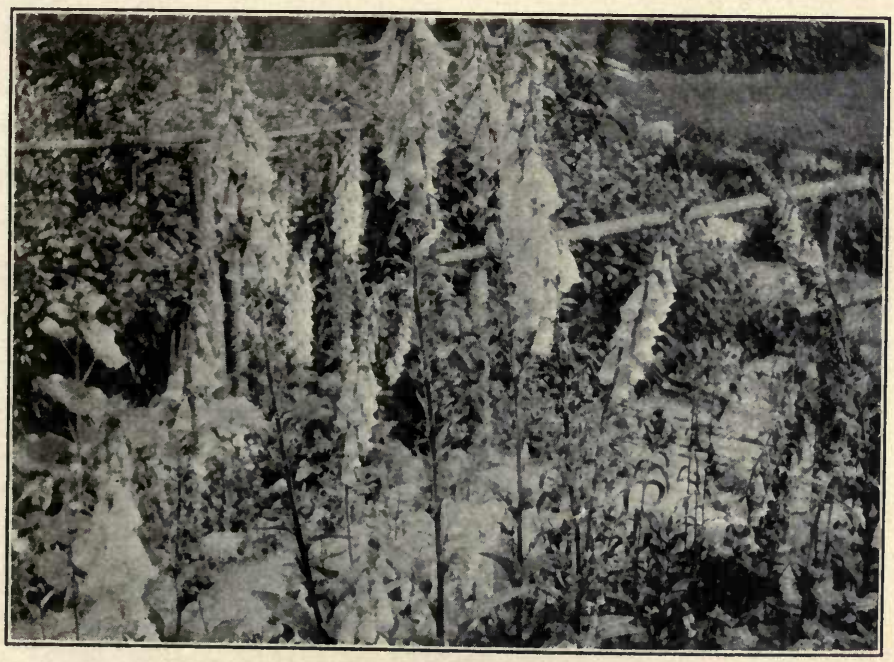

White Foxgloves

[P. I48] 

at $95^{\circ}$ and the entire family is in dishabille. No wonder I have had to resort at times to defenses against strangers, and this is my decoy, used particularly when my guests wear clean white gloves and natty little silk coats, and carry a lorgnette. Recognizing enemies of my convenience-they generally come in squads-I welcome them with great hospitality, not, however, asking them to sit down. I make a pretense of showing some new thing of interest about the room, and suddenly say,- "Let me show you something in the garden," holding them in leash at the edge, then wheel toward the aforesaid mountain view always conveniently at hand, wait until the adjectives are expended, then turn back to the lawn. There is nothing left to do; their carriage is obviously waiting for them, and they are encouraged to mount their chariot; they are down the lane before they realize that they have inadvertently stepped upon my inclined plane which gently bows an intruder down and out without hurting the feelings of anybody. Pray do not make the mistake in thinking that this device is used often. It is only when circumstances force the worm to turn, and never after three o'clock in the afternoon.

I have drifted from my subject, and return to the conservative gardener, who lives by tradition. She, it is, who preserves a remnant of her grandmother's garden, who has a natural antipathy toward all innovations as pernicious. She is an archive of the past. Her lettuce is always eaten with sugar and vinegar, never with a French dressing. Her culinary heavens rest upon the two pillars of baked beans and brown bread Saturday night, and Indian pudding in the middle of the week. No one ever need stumble over her furniture in the dark; for, from time immemorial, the chairs have been placed just so. Yet dear and sweet and true is she in all her aspectsif a little rigid; for it is she who has retained for us the old- 


\section{Hardy Plants for Cottage Gardens}

fashioned favorites, the almost forgotten things with aromatic odors. She it is who has giant bushes of cabbage-roses, blush-roses, moss-roses, the deliciously scented white-rose. In her garden flourishes the heliotrope, carefully removed to a south window through the winter. Wallflowers are there, and fragrant evening stock, clove-pinks, and lavender, boy love and sweet-fern. Her little bed of annuals represents touch-me-nots and snapdragons, and zinnias and gillyflowers, and she raises a puzzled eyebrow when you call them Impatiens balsamina, Antirrhinum majus and Matthiola annua.

While these are worthy exponents of the noble art of gardening - and may their tribe increase, for we can never have enough flowers in this sordid world-I find myself at variance with their principles. I am but a beggarly creature to the lordly owners of ten thousand flowers of any single variety; I am wholly lacking in esthetic appreciation of cut flowers to her who crams every fireplace, table and mantle shelf with her posies; I am a stingy miser to the openhanded, and an indiscriminate vagabond in the floral world to the conservative grower of a few favorites. I scarcely know how to defend my position against so many opponents, and I dare not hope to make good my cause; yet this is where I stand.

Once fairly launched on the catalogues, I had a consuming desire to make the personal acquaintance of every kind of hardy annual and perennial that I could obtain. Not that I wanted to continue raising them all, but I could not know them unless I grew them. Nor could I hope to accomplish my task in a single summer; I had the remainder of my life to pursue this fascinating question. Though $I$ have bought from fifty to a hundred new varieties each year, I have the prospect of going on indefinitely. In short, my chief purpose 
has been to maintain a sort of experimental garden where I might learn flowers, study them from their first seed leaves, watch their manner of growth, and rejoice in their first bloom. How eagerly I have awaited this event, this manifestation of the seen from the unseen, ignorant of the precise form it would take. It has been as marvellous to me as if I had stood at the elbow of Deity when the first forms were spoken into life, and my eyes had been the first to see the results. I cannot fashion a flower, but I can grow them, and thus repeat the miracle of creation. So I plant my seeds, obey the laws, and at my bidding a world of loveliness springs into existence. To me life is life, and all life divine; and I have no more desire to strip a plant ruthlessly of its beauty, than I have to pluck an arm from a child, or to disfigure its face. The whole development of a plant is sacred to me, and it has a right to fulfill its life just as I have mine; and when this is accomplished, and its bloom is passing, I remove all but one perfect seed-vessel, which is carefully labeled and preserved for future use; for in this way the plant is saved from a needless exhaustion of its vitality. Flowers are protected in my garden, and by making the conditions favorable for plant forms to grow to perfection, I feel that I coöperate with the vast cosmic law, that is guiding every manifestation of the Spirit through varied and progressive material forms: in my small way, I can thus aid and further the great cause of evolution of that, which is ready, at this particular moment of its existence, to take the special form of plant life in my garden. Does not this place in the reverent gardener's hand a divine commission? This may seem a fine-spun theory to the orthodox, but it gives a joyous impulse to the watering-pot!

Encyclopedias of horticulture become intensely interesting when we grasp that they are the genealogical records and biographies of various manifestations of Spirit on a lower 


\section{Hardy Plants for Cottage Gardens}

plane, where each entity has its own name, its family history and its native country. They record a world-wide compulsory emigration, and not infrequently the unwilling colonist has died of homesickness; others adapt themselves to strange conditions only after generations-but they are never again the same creatures. Not having evolved to the stage of locomotion, the achievements of plant life are circumscribed to the number, size, color and arrangement of leaf and flower. Some have developed the talent of fragrance; some have the genius of beautiful flower and fruit. Each one strives to manifest the perfect type, though few reach perfection. The family is represented in youth and age, the young offsets or shoots springing up about the parent stock. Some have a desire for travel and fling their seeds out upon the winds. Some families show great inequalities of development, having branches that have not progressed beyond the tiny herb, while other members have aspired to the higher forms of shrubs.

The orthodox have claimed that the earth and the fruits thereof were made for man. But I came to a truer knowledge one summer when, picking wild strawberries, I caught a glimpse of this truth: that each manifestation in the plant or animal world exists primarily for its own private evolutionary purposes; but that since both men and strawberries are derived from the same source, and equally obey the cosmic law that no creation liveth or dieth unto itself, there is that fine adaptation to each other, that fits the lower to serve the higher, without making that service the ultimate end of its existence. Its utility is merely a by-product of its life. It is the germinal form of a larger phase, which we call coöperative brotherhood, that vibrates through the whole universe.

I have become so sensitive to the Spirit in my plants, that at times when the garden is at its height, I am overwhelmed with its fulness of life, and am often filled with a deep mel- 
ancholy as I walk among my children-little creatures that have taken form at my bidding; for I am burdened with the heavy responsibility of having called so many into existence, and there are seasons when I cannot provide properly for their meat and drink, and on every side I feel their mute claims upon me, their foster parent. We feel a pitiful sympathy for the limitations of our dumb four-footed brothers, who yet speak eloquently through their eyes; but what of the unuttered gratitude or sorrows of our garden friends, who find no adequate expression to reach the careless heart of him who is pledged to love and cherish them? Their dumb silence touches me almost more deeply in their joy on a June morning than does their bitter pain under an August drought.

Spencer says the quality of life is determined by the degree of response to environment. If this be true, what is the quality of life that points a grown-up finger helplessly at the ordinary maple, oak or elm, our daily companions in either city or country, and says, "What tree is that?" that glances casually at the commonest flowers, poppies, morning-glories-even a nasturtium - and asks in good faith, "What is that?" Surely such a response to environment needs quickening, and I give as the chief reason for my garden efforts that $I$ wanted to know something definite of the floral world; I wanted to respond intelligently to this beautiful phase of human environment. A single specimen is sufficient to study and cherish. It is enough for me to have a single Ulmaria filipendula, with its extending family, and watch with keen interest for the precise date when it breaks each year into soft foamy white bloom. No stray visitor in the garden knows of my modest Ulmaria, nor of my one exquisite Triteleia laxa, now multiplied twentyfold, with its fragile thread-like stems and starry blossoms, nor the corner where the Houstonia grows, 


\section{I54 Hardy Plants for Cottage Gardens}

nor a hundred other dainty tidbits that are their own excuse for being. But I can close my eyes when a thousand miles away from them and make an exact diagram of each bed with its loved tenants. I often think that to inherit a garden, would be much like coming into possession of another's life at middle age. One would not know what to expect. What complications would arise! How little would be understood!

My next reason is that a garden gratifies my love of color and form. I do not care for it so much as a mass, although it is very beautiful with its successive waves of pink, blue and white-the white recurring at intervals like a chorus in the midst of a continuous melody; I love to descend to particulars, to get down close to a plant, study its manner of growth, the form and texture of leaf and petal and their markings, observe the perfect harmony of color and number as presented in stem, leaf, calyx, corolla and stamens. The stamens of some flowers are indescribably beautiful. I have sat and watched the soft gray green stamens and white filaments of a grayish lavender poppy until they seemed the most perfect example of beauty in all the world. I know one sensitive soul, who said to me once with brimming eyes, as we stood looking at a pale pink gladiolus with its lavender anthers, "It is so beautiful, it hurts." What could be more lovely than the carmine stems of the Stephenandra flexuosa, or the mahogany stems of the Gaura; or the red-tipped foliage of the Spirea superba; or the heart of a Lancaster rose or an oriental poppy; or the lyre-shaped markings in the throat of the martynia; or the bearded throat of the iris or Pogonia? Emerson says: "I do not so much marvel at the beauty of the world, as at the necessity of beauty."

A third and very cogent reason for my garden is to distribute the roots and seeds about the country side. With few exceptions perennials increase so rapidly either from the root 


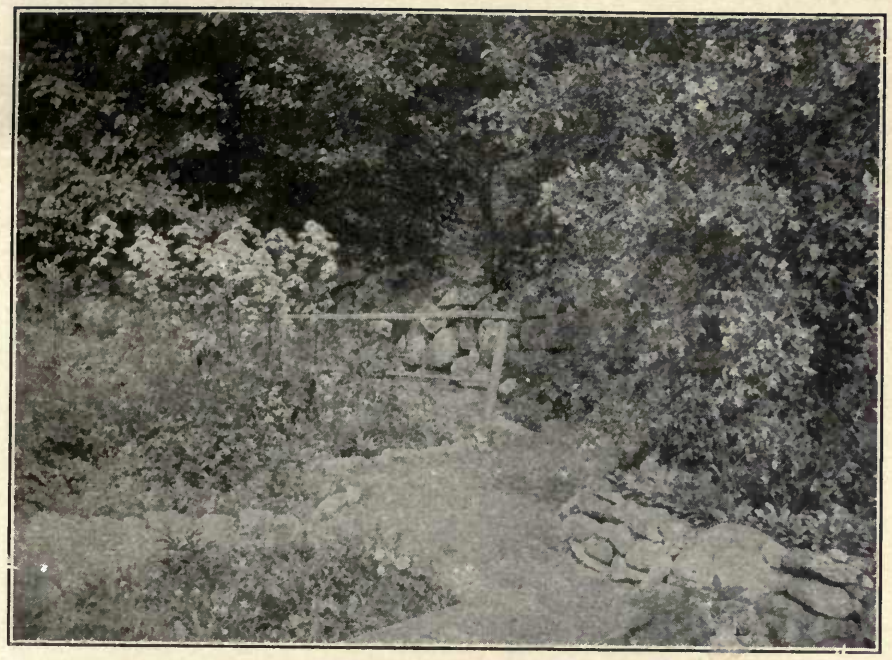

White Flowers Recurring like a Chorus in a Continuous Melody

[P. I54]

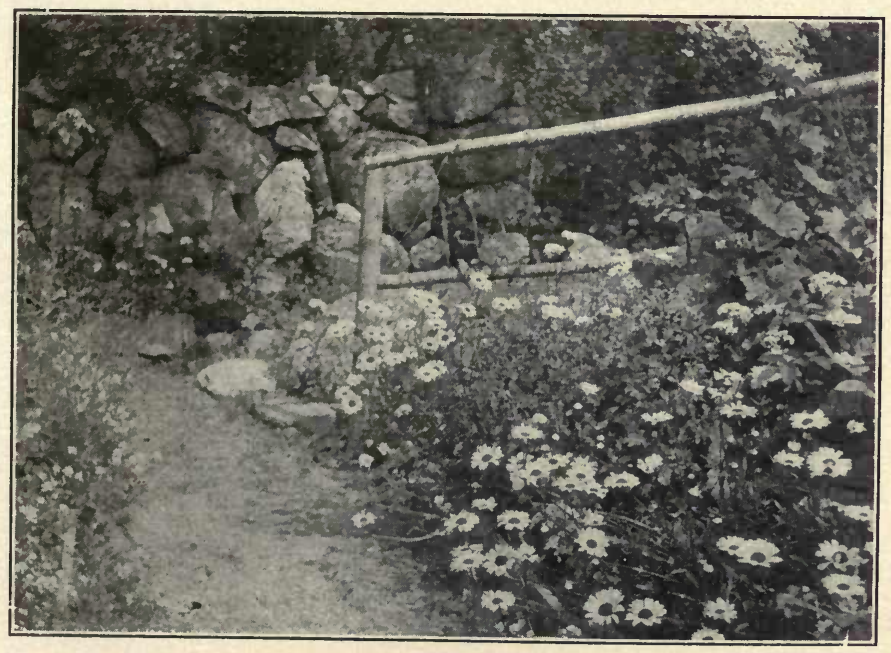

Wild White DaIsies under Cultivation

[P. I79] 

or through self-sown seeds, that one must divide his stock yearly to preserve any sort of balance. It takes time to secure the first increase, particularly if one buys only a single plant of any one variety; but in the course of three or four years his loaves are so multiplied that he can give away a basketful. If I have a choice recipe, a rare plant, a good book, I must share them; and I hope the time may come when my best and choicest plants shall be the common property of the entire region. When I give any treasure it is always with the injunction-"You must pass it along when it begins to multiply." If all gardens were thus distributed, we should not need to organize village-improvement societies; a generous rivalry would spring up that would leave no dooryard ungraced.

Eager as I am to distribute roots and seeds, I never offer cut flowers to my visitors, and this withholding of what to me is too precious for an indiscriminate sacrifice, is often severely judged; yet I find all true flower lovers feel the same about this point.

My home is the rendezvous of many interesting people, who summer in our region within a radius of fifteen miles, and often it would seem as if we were holding a reception. Pray what would my garden look like if each visitor went away with her two hands as full as they could hold? As it is, Mary's eyes are not always blue, nor her hair in curl. My apologies for bare green spots and bloomless sections are profuse; for, like other gardeners, my aim is to have the whole garden in perfect flower all the time. I wish my midsummer visitors were clairvoyant, and could see in my aura the loveliness of May and June. In August when poor Mary's eyes no longer shine, I have to groom the garden and rake the walks more assiduously than ever to make a presentable appearance, much as a middle-aged belle depends more and more upon 


\section{Hardy Plants for Cottage Gardens}

her steamed complexion, heightened by rouge and cosmetics, adopts a restricted diet, massage and Delsarte to preserve her fast-waning beauty. When locks grow thin, they can at least be parted neatly; and a careful removal of faded and dead growths keeps a September garden trim and neat.

One more reason for my garden, if any further be needed, is that it affords the most delightful and wholesome exercise imaginable. True, one is not beautiful in big, stout boots, in short skirt and too often collarless waist. Freckles and sunburn and roughened hands are not the usual weapons of coquetry. What matter these disqualifications when you have plotted a whole week for a free day in the garden? I have risen at half past five o'clock to get a good start; I have worked in the hot sun until I was forced to retreat for a few minutes under a tree to cool off; I have paused from sheer fatigue midway to the garden with a wheelbarrow of stones for a wall to a new terrace, and questioned if that present moment yielded the pure joy I had been anticipating for a whole week. I have rested shovel in hand while digging into a bank, to wipe my weeping brow just as a street laborer does, and recovering breath, asked myself why I was eager to do such work? To none of my questions have I ever found an answer, save that it was for the joy of the doing, and for the results that justify the hard work. Without these preparatory labors the garden could not have existed. From the very start I decided that I should have nothing done that I could not do myself; this was to be my one plaything, devised for my individual pleasure and exercise, and when it became too ambitious for my hands to tend, I'd give it up.

All I know of these specially appointed days is that they are too short, too few; the hours do not exist. I have clumped into the house at six at night-having taken only a reluctant period of rest at noon during a hasty dinner-so tired and 
stiff that I could hardly move-but so happy, so content, so full of the events of the day that I could hardly wait till the morrow to resume the work. This does not explain the fascination; I merely know that it exists and continues unabated year after year. After eight years I am still of the mind to have no stone walls that I cannot lay myself-and I have grown as fastidious about the selection and placing of my stones as a lapidary who works in mosaic-I shall have no new beds that I cannot prepare. At this moment I have just completed new extensions, a mood that takes me each autumn. And what lessons have come to me through this so-called drudgery! Who shall measure the impetus to horticulture every amateur gives, when insuperable obstacles are surmounted, and proof is made that a truly beautiful garden is possible where conditions were supposed to be impossible? It was only through the toilsome erection of overshadowing stone walls and careful digging out, refilling and fertilizing the beds, that our barren dry hill-top was capable of growing anything. Every step of this preparation was necessary to secure the perfect bloom. In short the garden as it now stands is the fine flowering of the varied manual effort that prepared it. I sought still further to see if the analogy would hold true beyond matter, and I saw that the beautiful glimpses of truth that had illumined so many of my working hours were a more etherialized flower and fruit of labor; that in my intimate personal contact with matter I had learned that it is but a symbol of spirit: matter had become the interpreter of higher things. Labor was the nexus which had linked matter with spirit, and through it, gradually, the many problems that confront my awakening soul are becoming plain and intelligible. Now when I address the elemental forms of rock and soil or the more spiritualized form of plant life, or my own inner consciousness, they all speak the same language, and proclaim 


\section{Hardy Plants for Cottage Gardens}

the same truths. I feel unified and in harmony with the world about me; I am one of the working forces of Nature. So the real flower of the garden is ever extending onward and upward as a revelation of spiritual insight. It is more to me than pulpits and books; it answers all questions; it purifies my beliefs and confirms my visions. 


\section{A DEDICATION}

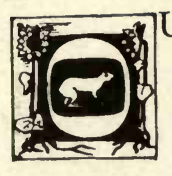

UR labor is but a manifestation of our thought, and in its performance we may swink and toil under the burden, or we may use matter joyously as a plastic means to an end.

No one should have a garden which grows nothing but flowers, and yields no other recompense to the gardener except successful plants. Over, beyond and above must hover the spirit of poetry, of wonder, of mystery; otherwise there comes a day of disillusion when you awaken to the weariness, anxiety and watchfulness, and begin to measure the reward. You need a larger insight, something that connects your efforts with the universal in nature, the ideal, the soul of things. Into this you may lift the garden, and at once drop the tired body and soiled hands, and the whole material aspect of labor.

For six summers I had watched the sun and rain weave a garment of flowers over the bare earth, and knowing that each creation of Nature differs from aught else in the universe, I sought to find wherein lay the essential difference between my garden and all others. By day and night I observed the play of color, the quantity and direction of light, the atmospheric effects; and it becomes a vastly interesting study to see how a familiar object behaves itself from day to day, how it accepts its environment, and adjusts itself to heat and cold, to sun and cloud. Each day the expectant eye catches a fresh glimpse of an infinite variety.

In time I discerned the soul of my garden, which manifested itself in its long subtile shadows. It was as if Nature 


\section{I60 Hardy Plants for Cottage Gardens}

had forbidden any but the soft gray shadows to enter; they, who love to magnify and duplicate beautiful things, alone were allowed to walk softly among the trees and flowers at dawn and twilight; and through the long moon-lit nights they molded with deft fingers images of all they saw. But never was a direct shadow permitted to enter. In recognition of this mysterious beauty, a tablet has been erected bearing the name of the garden in Japanese characters

\section{THE GARDEN OF OBLIQUE SHADOWS}

SHA YEI YEN

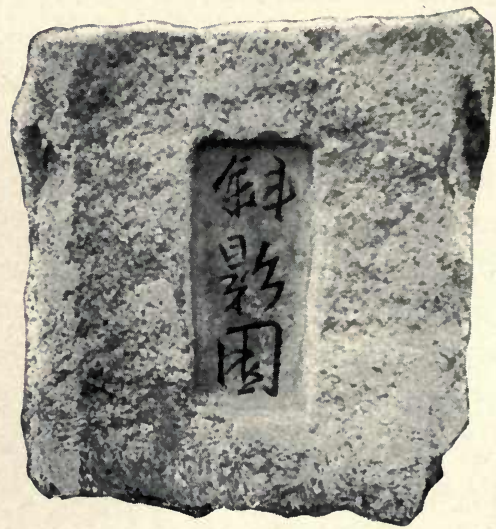


CLASSIFIED LISTS 


\section{A WORD TO THE READER}

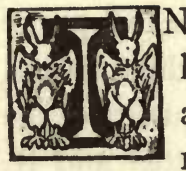

$\mathrm{N}$ the following classification I do not offer an exhaustive list of hardy trees, shrubs, perennials or annuals. Many are omitted that are choice, but not quite hardy beyond the latitude of New York City; also very expensive varieties are not included among shrubs. I name those that I have actually grown, or am now experimenting with. The nomenclature has been derived from Nicholson's "Illustrated Dictionary of Gardening," Asa Gray's "Field, Forest and Garden," R. G. Leavitt's "Outlines of Botany," and Mrs. Loudon's "Gardening for Ladies."

In making color divisions, I have given "White Flowers" the first place, because the majority of plants have one or more white varieties. The cultural directions for those grouped under "White Flowers" will not be repeated in other lists, even though their names may appear, duly recorded as special varieties, under other color lists. Should a plant have no worthy white variety and appear for the first time under "Blue" or other color, the cultural directions will accompany its first mention, to which the reader will be referred for the culture of subsequent varieties, that may occur in later color lists; and so on throughout the whole Appendix.

I have arranged this very simple, though seemingly complex, classification, which catalogues each plant separately throughout the different lists just as far as it has representatives of pure color, in order to give amateurs every oppor- 
tunity to choose not only their favorite flowers, but the exact variety that represents the color they may desire.

It should be borne in mind that the date of blooming given in these lists is for a place lying a little north of $43^{\circ}$ latitude, which has a season a few days later than that of Boston, and two weeks later than New York, and a month later than Washington, D. C.

Without wishing to discriminate against others, who may be equally reliable, I take pleasure in commending several firms that exercise especial care in regard to the quality of the stock they send out: for seeds, Schlegel \& Fottler and R. and J. Farquhar, both of Boston; and for shrubs and plants I recommend, to New England purchasers, Fred'k H. Horsford, of Charlotte, Vt.; and to those of southern latitudes, Wilkinson Elliott, of Pittsburgh, Pa., and Bobbink \& Atkins, of Rutherford, N. J. 


\title{
WHITE FLOWERS
}

\author{
APRIL \\ WHITE SHRUBS-None
}

\section{APRIL \\ WHITE PERENNIALS}

CRocus (C. vernis, var. Mont Blanc). 4 in. Single erect lily-shaped flowers; leaves striped with white. Each year the old corm or bulb dies out and new ones are formed. When the foliage dies after the plant flowers the bulbs may be lifted, divided and reset, allowing room to spread. If lifted before ripe, replant at once in another place to ripen. They do best in a sandy loam and leaf mold, mixed with a few small stones to insure drainage. For lilac, violet and yellow varieties see Blue and Yellow Per. for April.

Pansy or HearT's-EASe (Viola tricolor). 6-12 in. Many hybridized varieties in white. A universal favorite that is seldom grown to perfection by amateurs. For early flowering in April and May, sow seeds the previous summer, and keep the young plants over winter either in a cold frame, or transplant where they are to remain and cover lightly with coarse hay as a winter mulch. For summer bloom, sow seed as soon as the ground is mellow. Pansies require a sandy but rich soil, moisture and partial shade. All seed-vessels must be picked off, and if inclined to grow straggly, prune the plant to make a close growth. Do not expect too much of them in midsummer, for they flower best in spring and autumn, and suffer from heat and drought. Plant deeply to keep roots cool. For other varieties see Blue and Yellow Per. for April.

SNOWDROP (Galanthus nivalis). 5 in. Single nodding white flowers borne on slender stems. The bulbs should remain in the ground as they dry out when lifted and lose their vitality. Single and double 
varieties. Give a rich light soil, and they will thrive under the drip of trees. They are increased by offsets. It may be planted with Scilla Sibirica which blooms at the same time.

\section{MAY}

\section{WHITE SHRUBS}

Azalea Molis. 3-4 ft. A very handsome shrub that I cannot recommend as hardy, as it winter-killed the first winter.

Flowering Almond (Prumus Japonica). $4 \mathrm{ft}$. A low hardy shrub generally, but erroneously, known as Prunus nana, with handsome white or pink double flowers in clusters of twos or threes borne along stalks $2-4 \mathrm{ft}$. high. It is propagated by suckers and thrives in any good garden soil. Prune after flowering. It requires no winter protection. It is effective planted with a background of evergreens. See Pink Shrubs, May.

BrIDAL Wreath (Spirea prunifolia, var. flore pleno). $5^{-6} \mathrm{ft}$. A slender hardy shrub bearing a profusion of double white blossoms along the upper portion of its branches. All Spireas flourish best in rich moist soil, and spread by suckers at the root; can be increased by cutting through the extending roots, and after they establish themselves independently, replant them. In common with other Spireas the foliage turns a beautiful red in autumn, and looks well when planted near the white Boltonia asteroides which blossoms late in the autumn.

Deutzia. Slender (D. gracilis). I-2 ft. A low bushy shrub with panicles of snow-white flowers that resemble miniature snowdrops. A beautiful variety, but not quite hardy and should have slight protection in winter. Give a light rich soil.

Deutzia (D. Lemoinei). 2-3 ft. A later hybrid form, having a stouter growth than $D$. gracilis, larger pure white flowers, reddish yellow stamens. Late May or early June.

Fringe. White (Chionanthus Virginicus). Io ft. A hardy shrub with long clusters of fragrant fringe-like white flowers and large leaves that appear very late in the spring, and for this reason should be placed in the rear of other shrubbery. They turn a rich yellow in autumn. Does best in sandy moist loam and sheltered position. It can be increased by layering or seeds, and it may be grafted or budded on the common ash. 
LeUCOTHÖ̈ CATESBar. $4 \mathrm{ft}$. An almost evergreen shrub, leaves on long stems; handsome pure white flowers though their odor is unpleasant to some. Give a rich moist soil, sun and sheltered position.

LILAC. White (Syringa vulgaris, var. alba grandiflora). 6-1o ft. A hardy shrub of more graceful and slender growth than the common purple variety. It also bears smaller more open clusters of snow-white fragrant flowers. By keeping the roots heavily mulched with manure it throws out an abundance of suckers, which may be separated from the parent bush; propagated also by layering the branches. Should have a sheltered position, for it is sometimes blighted, when about to flower, by late spring frosts. After blooming cut off seed-vessels, else the buds for the next year will not form well and the bloom will be reduced.

PEARL BUSH (Exochorda grandiflora, sometimes called Spirea grandiflora). A beautiful shrub, often growing to a small tree with large white flowers growing in axillary clusters; has a rather naked, straggling growth and should be pruned to a compact form or planted in the rear of other shrubs; propagated by seeds, suckers and layering. Give culture similar to Spireas. Blooms late in May or early June.

Plum. Purple-leaved (Prunus Pissardi). A small tree with inconspicuous white blossoms, but prized for its bark and foliage. In the spring, the bark on the new growths is deep purple, and the bursting leaves are a violet crimson. Later they take a darker hue which they hold all summer without fading. Without a rival as an ornamental tree, though its fruit is inferior.

Shad Bush, Juneberry (Amelanchier Canadensis). 4-12 ft. A hardy bush or low tree with foliage of tender reddish green in spring, and of rich hue in autumn. The large and open-petalled white flowers are borne in long drooping racemes. In the wild state the growth is rather straggling, but it can be grafted on the hawthorn or quince and make a finer effect. It requires rich loam, and is propagated by layers or cuttings.

Snowdrop Tree, Silver Bell (Halesia tetraptera). 4-18 ft. A handsome shrub or small tree wild along streams from Virginia, South, but planted for ornament North. Bears showy drooping flowers from the axils of fallen leaves of the previous year; should have a sheltered position in deep sandy moist soil; propagated by cuttings in spring and autumn. Not quite hardy far North if exposed.

SpIREA ARGUTA. $3 \mathrm{ft}$. A variety closely related to $S$. Thunbergii. 
Slender branches, flowers pearly white, enveloping the entire bush. One of the best early shrubs. For culture of all Spireas see Bridal Wreath.

SPIREA PRUNIFOLIA, see Bridal Wreath.

SPIREA ThUNBErgir. 2-3 ft. A dwarf compact shrub with slender graceful branches, blooms very early with snow-white flowers in long open sprays. A beautiful variety.

SPIREa VaN HoutTeI, an improved form of $S$. trilobata. 3-5 ft. A spreading bush with long drooping branches, that are literally covered with flat clusters of white flowers; blooms several weeks later than $S$. Thunbergii, and is especially recommended.

St. Peter's Wreath, Italian May (Spirea hypericifolia). 3-6 ft. A hardy shrub with long drooping branches, small white flowers in small flat heads. For culture see Bridal Wreath.

THoRN. Scarlet-fruited (Cratagus coccinea). 3-6 ft. A hardy shrub or small tree, very ornamental because of its handsome foliage, flowers and scarlet fruit. The white flowers are borne in numerous clusters. It requires a dry sunny situation, and is propagated by seeds that sometimes lie for two years without germinating. One of our most beautiful native shrubs, but rather difficult to transplant.

\section{MAY}

\section{WHITE PERENNIALS}

ARABIS ALBIDA, see Rock Cress.

ASPERULA ODORATA, see Sweet Woodruff.

Asphodel (Asphodelus albus). $2 \mathrm{ft}$. Lily-like leaves form a tuft at base from which rise tall spikes of clustered white flowers; should have deep sandy loam. They increase rapidly by suckers which should be divided and reset in the spring. For yellow variety see Yellow Per. for May.

CANDyturt. Evergreen (Iberis sempervirens). I ft. A choice perennial bearing the greatest profusion of snow-white flowers in flat heads almost three inches across; thrives in any good soil and sunny exposure. Sow seed in spring and set out in September. Increased also by cuttings and division of root; is self-sowing. It is beautiful when grown with Lychnis dioica, Mertensia Virginica, Phlox sublata, or grape hyacinth. 
Columbine (Aquilegia chrysantha, var. alba). $2-3 \mathrm{ft}$. The columbine is one of the most desirable of our hardy perennials and comes in every color and variety of combinations. The divided foliage makes a bushy growth from which spring many tall stalks bearing erect or drooping flowers that take the form of a cluster of spurred cups. They do best in a rich sandy loam. They are much sought by bees that cross-fertilize the varieties. The way to perpetuate a strain is either to divide the root, or to cover the plant with fine muslin during the flowering season, so that insects cannot get access to the flowers. Sow the seeds when they are ripe, and transplant the seedlings where they are to remain, giving each a space of 9 in. each way. Self-sowing; and though the self-sown plants are particularly vigorous, they are not true to color. From seeds derived from a pale lavender columbine I grew every tone of pink and red, the palest rose, deeper rose salmon, shell pink, old rose and old red. It is in this way that new varieties are secured.

ENGLish Daisx (Bellis perennis, var. Snowball). 4 in. A hardy border plant making a tuft of leaves bearing numerous quilled white or white and pink flowers. It thrives best in rich well-manured loam in a cool shady situation. An English authority recommends taking up and dividing plants two or three times a season. They bear transplanting even in full flower if taken up with a portion of soil attached. Propagate from seed; if sown in early spring it blooms the first year late in July.

FORGET-ME-NOT (Myosotis alpestris, var. albus). I ft. A very hardy variety of Forget-me-not in white, sky blue and pink, which makes a close tuft of leaves from which spring many loose spikes of small blossoms with a yellow eye. One of the most valuable of early perennials either for bedding or as a border plant. It may be planted among hyacinths or tulips, which will be out of bloom by the time the Forget-menot is budding. Alternated with Agopodium varigata, the blue variety of Myosotis makes a lovely border. Give a rich soil and sunny position; when once established it reproduces itself freely from self-sown seed. Plants derived from seed sown in early spring are especially strong and prolific in bloom the second year. See Blue and Pink Per. May.

HyacintH (Hyacinthus orientalis, var. La Grandesse). I ft. An early spring bulb with thick lily-like leaves and a close large spike of waxy fragrant flowers. Plant in October an equal depth of three or four inches in light rich soil in sunny location. Give a light mulch 
through the winter. After blooming in the spring cut off the flower stalks and allow the plant to ripen. When the leaves turn yellow, lift and dry slowly and store in a dry cool place to be replanted in autumn. Mature bulbs deteriorate in time, so in order to keep up stock, remove small offsets when the bulbs are taken up, and plant in a nursery bed to the depth of two or three inches; they will flower the third year. To increase a rare variety the Dutch make one or two cross-cuts half way through a strong bulb after taking it up, and the next year it makes but little growth, but forms a quantity of small bulbs. These are separated and planted in nursery beds where they mature the third year. For other varieties see Blue, Yellow, Pink and Red Per. May.

HyacintH. Roman (Hyacinthus orientalis, var. albulus), $\mathrm{I} \mathrm{ft}$., is the parent of the Roman Hyacinth. It is more slender and delicate in growth than the common Hyacinth, but its culture is the same.

ICELANd Poppy (Papaver nudicaule). I-2 ft. A hardy plant with ornamental cut leaves forming a low tuft from which rise slender erect stalks bearing single and double white flowers. Give a good garden loam and sunny position. They are not very permanent and though they are self-sowing to a degree, it is well to sow a little seed each year to furnish new seedlings. Vigorous plants should flower for several months, and to promote bloom keep the seed-vessels picked closely. A light covering during winter is desirable. For other variety see Yellow Per. May.

IrIs. German (I. Germanica, var. Silver King and Florentina). $2 \mathrm{ft}$. A hardy perennial with sword-shaped leaves, large showy silvery white flowers from $4^{-6}$ in. across, and thick rootstocks that tend to increase at the surface of the ground. For this reason the roots must not be covered, as they rot readily, and do best in a well drained soil. They are propagated by breaking the rootstocks into sections and replanting in September, but it takes a year or two to get established, and they bloom with more certainty if left undisturbed for three or four years. See Blue and Yellow Per. May.

Lily of THe Valley (Convallaria majalis). 6 in. A familiar favorite, with two broad lily leaves, and single stalks of small sweet-scented globular flowers. Should have light moist soil, enriched with leaf mould. There is an erroneous impression that this plant needs shade, and it is too frequently given a cheerless north exposure, or a neglected corner of a garden. As it grows shabby after blooming it should not have a prominent position, but give it a warm shelter and considerable 
sun. Divide the clumps every few years in the early autumn, for the running rootstocks crowd each other and it does not flower so well. Plant the crowns or root buds so that their points are just below the surface, giving them room to spread. These root buds bear only leaves the first year, small flowers the second and are in full perfection the third year. Top-dress with manure in autumn.

Narcissus, Poet's, Pheasant's Eye (N. poeticus). I8 in. A hardy bulbous plant with narrow lily leaves and broad showy fragrant white flowers slightly nodding. Does well in any good soil, and is increased by offsets, and should remain undisturbed unless the roots become crowded. The foliage should be allowed to wither naturally as in the case of Hyacinths, Tulips, Lily of the Valley, for new bulbs do not form well when the leaves are cut off as soon as the flower has faded. If this is persisted in, it finally kills the plant. Divide clumps in July or August; if done later it checks the new growth. Top-dress when the foliage is removed.

NARcissus. Double ( $N$. poeticus, var. alba plena odorata). A double variety of the above.

NARCISSUS ( $N$. poeticus ornatus). An improved variety of poeticus, that is larger and blooms earlier.

PHLox. Creeping (Phlox sublata, var. alba). 6 in. A low creeping border plant making a dense mat of prostrate branches, which bear quantities of flowers an inch across. By shaking loose soil amongst the plants in summer, the trailing branches will take root and can be divided and reset in autumn. Give a sunny sheltered situation as it sometimes winter-kills in severe open winters in the North, and it should have a light mulch. For pink variety see Pink Per. May.

Poppy. Iceland, see Iceland Poppy.

Rock Cress (Arabis albida). $6-9$ in. One of the earliest border perennials which continues to flower from early May until autumn; bears fragrant white flowers in terminal racemes; gray woolly leaves sparingly toothed; thrives in dry shady location or in full sun; is propagated by division of the root, seed or cuttingș.

Rock Cress. Alpine (Arabis alpina). 6 in. A smaller and later variety making a close busy growth, plant downy, leaves sharply toothed.

SaxurRage. Early (Saxifraga Virginiensis). 9 in. A low-growing native plant making a flat tuft of leaves from which spring close heads of white flowers borne on naked stems. It should be more often culti- 
vated, and can be used as a border plant with blue Forget-me-not. Propagate by division and seed.

SweEt Woodruff (Asperula odorata), 6-8 in. Bears snowy white terminal clusters of delicate flowers, stems four-sided, leaves in a whorl; scentless when fresh, but when dried has an agreeable perfume; is used to spread among clothes to keep insects from them. Give a moist shaded location; spreads rapidly; divide roots, also propagate by seed.

TulIP (Tulipa gesneriana, var. L. Immaculee and Pottebakker). I ft. A hardy bulbous plant with broad leaves and erect lily-shaped flowers; requires a sunny sheltered position; plant six inches apart in October or early November to the depth of three to four inches with a little sand about the bulb to prevent rotting. After blooming, allow leaves to turn brown before lifting; dry slowly out of the sun and store in bags or drawers where the air can circulate. If the garden space is needed at once, take up the bulbs and plant at once in another situation where they can ripen; then store. Can be propagated by seeds or offsets; either is a slow process. Seeds sown in February in a cold frame, and protected the first winter, may be planted out the following spring, and will bloom in four or five years. The first year they are usually self-colored, but afterward assert their own coloring and markings. New varieties are obtained this way. The small offsets must be removed when the mature plants are taken up, and may be set out in a little nursery where they will mature in a year or two. The Tulip comes in almost every coloring; for other varieties, see Tulip under other lists.

\section{JUNE}

\section{WHITE SHRUBS}

ARROWwOOD (Viburnum dentatum). See Snowball.

Dogwood. Flowering (Cormus florida). 8-12 ft. A small tree with wide-spread branches, flowering at the end; and what is mistaken for the blossom, is a whorl of four large leaves of creamy white surrounding the true flowers that are inconspicuous; fruit bright scarlet; foliage turns crimson and purple in autumn. Slow growing; give a rich soil and moist situation.

Hobblebush, Wayfaring Bush (Viburnum lantanoides). 3-5 ft. A native shrub with handsome large leaves and broad flat heads of sterile flowers encircled with showy white flowers; berry turns a bril- 
liant red in early autumn, and the foliage becomes a rich old rose hue. Notwithstanding these features the bush itself is not handsome, because of its long naked straggling branches, and should be planted among other shrubbery such as Spireas, Flowering Almond or Stephenandra flexuosa which are of similar height. It is hard to transplant, unless taken young, though it can be propagated by bending down its branches, pegging securely; these take root easily and can be severed; hence its jopular name. Give a rich moist soil and shade.

ITEA VIRGINICA. $5^{-8} \mathrm{ft}$. Flowers in terminal clusters; leaves turn in midsummer from green to scarlet crimson and retain the shade until autumn. It should have a prominent place among white summer perennials. Give a sheltered position and protection in winter, for some report that it is not quite hardy.

LABRADOR TEA (Ledum latifolium). 2-4 ft. A low evergreen shrub with glossy elliptical leaves revolute at the edges, covered on the under side with a soft cottony lining which becomes rusty. Flowers, in large terminal clusters, are very handsome; the whole plant has a strong aromatic fragrance. This shrub should be more often cultivated. Sparingly found in New England.

Locust-Tree, False ACacia (Robinia pseudacacia). Io-30 ft. One of our most ornamental trees with pinnate leaves and great drooping clusters of fragrant white flowers. If given severe pruning for several years, while still a low shrub, it will induce a thicker growth, and prevent it running up to a tall tree with naked trunk and bare lower branches. It has a bad habit of spreading from the root and may easily become a pest. It is used also as a stock upon which may be grafted the Rose Acacia (Robinia hispida) a very beautiful rose-colored variety of low growth.

Mountain Ash, European (Sorbus Americana). $30 \mathrm{ft}$. Pinnate leaves, white flowers followed by clusters of handsome red berries. Very hardy.

Roses, General Culture of. Roses should be given a well-drained, warm, sunny location protected from winds. The bed should be dug out from two to three feet, and if the soil is wet, should have at least six inches of loose stones or broken brick at the bottom for drainage. Fill the beds to the depth of a foot with well-rotted coarse dressing, cow manure and grass sods turned upside down; over this should be several inches of rich light loam. Upon this loam set the roses, carefully spreading out the roots, and then fill the beds to within two inches of the top 
with a rich compost of loam, manure, leaf mold and a little sand. Add clay to the soil for Hybrid Perpetuals. In planting budded roses set the budded parts two or three inches below the surface of the ground, to prevent throwing out suckers; press the soil well in about the roots, leaving a slight depression about the root so that when watered the moisture may be all absorbed. For winter protection, draw the earth well up about the roots (for Teas it may be a foot or eighteen inches deep); peg down any long branches; cover with a foot or two of coarse grass or hay, and over this a few inches of coarse manure-green manure will answer, and a part of it may be dug in in the spring. Very hardy varieties do not need so heavy a mulch, only a little manure at the roots and a few inches of dry leaves and a bough or two to keep them in place. It is well to wrap the stalks from six to twelve inches high with tarred paper, just before the manure is placed about the roots, as a preventive against mice which work close to the ground. When in bud give frequent weak solutions of liquid manure, and continue through the flowering season. This may be made by securing a stout burlap bag to a barrel hoop, and placing in it a half bushel of manure and suspending it in a barrel partly filled with water; or sheep manure in the proportion of a pound to five gallons of water, and when used, as much more water may again be added. In setting out, prune from one third to one half, cutting just above a bud on the outside of the cane, and cut off smoothly all broken or bruised roots. At no time prune too severely, as it induces vigorous leafy shoots, but no flowers. Pruning a collection of mixed roses is a serious matter, and needs much study and knowledge of particular varieties. Some may be cut within six inches of the ground; others, like the dwarf Hybrid Perpetuals, should be slightly pruned in the spring, and cut back at least one half after the blooming season is over; others, like the Teas and Hybrid Teas, can bear only a gentle pruning, little more than cutting away dead or weak wood when the dormant buds begin to swell; otherwise one may mistake live wood for dead. Roses may be planted either in the autumn, some say rather early, others advise November; or they may be set out in early spring while still dormant. They should be taken up every four or five years and reset in a new place, or in newly enriched soil. To propagate roses take cuttings six inches long late in October or November-after the wood has ripened and the leaves have fallen. Tie them in bundles and store for the winter in boxes of damp sand set in a cold frame or cellar where they will be protected from frost. Or the cuttings may be buried 
out of doors in sand, putting them eighteen inches deep, and giving them further protection from the frost by a thick mulch of leaves or manure. In spring as soon as the ground can be worked, plant the cuttings in trenches leaving only one bud above ground. In making cuttings, cut just under a bud, which enables them to root more easily. For further directions see Propagation of Plants.

I have found a strong solution of Ivory soap an excellent general spray for roses. For mildew, it is recommended to spray with $\mathrm{I} \mathrm{oz}$. of sulphur to one gallon of water. For lice, spray with Kerosene Emulsion made as follows: dissolve $\frac{1}{2} \mathrm{lb}$. hard soap in I gal. boiling water, adding away from the fire, 2 gals. kerosene, and churn it well with a hand pump. Dilute twenty times for lice, soft-bodied bugs or caterpillars and four times for scale. For other pests and treatment see chapter, Mine Enemies.

Rose, Captain Christy (Rosa Indica, var. Tea). A vigorous-growing white rose, delicately tinted with rose, very large and full flower, good foliage; an early and late bloomer. In the coldest winters a little protection should be given.

Rose, Margaret Dickson (Rosa Indica, var. Hybrid Perpetual). White with a pale flesh-colored center; petals large and of firm texture; vigorous of growth, but will run to wood if pruned too severely.

Rose, Frau Karl Druschki (probably a hybrid Perpetual). Regarded as the finest white rose grown; is too vigorous in growth for small rose beds, as it often attains five feet the first year. Blooms snowwhite, fragrant, buds frequently three to four inches long; flowers at intervals throughout the season; requires full sun as it has a tendency to mildew in damp weather.

Rose, Mabel Morrison (Rosa Indica, var. Hybrid Perpetual). A pure white, sometimes edged with pink, very large in size and hardy.

Rose, Madame Plantier (Rosa Indica, var. Bourbon). A perfectly hardy pure-white rose, blooming but once, but in the greatest profusion; spreads slightly from the root, and the suckers may be severed and in the course of a few months be lifted and reset.

AN UNKNOWN VARIETY, $4 \mathrm{ft}$., that came originally from Virginia, makes a strong bushy growth, leaves roughish, a free bloomer in June only, but lasting a month or more. Heavy clusters of large white roses shading into a delicate pinkish-yellow heart; spreads from the root. A desirable and entirely hardy variety free from all disease, though relished by the rose beetle. 
Rose, White (Rosa alba). An old-fashioned white rose tinted with blush pink, very fragrant, with smooth leaves, perfectly hardy, spreads from the root and may be thus propagated; rather subject to disease; blooms but once in June.

Rose, Scotch (Rosa spinosissima). A slender low-growing, very spiny variety, with small shell-shaped creamy flowers, some shading to a blush pink; spreads from the root and is propagated by suckers; is perfectly hardy, free from disease, slightly fragrant; blooms but a short season.

Rose, Wichuriana, var. Manda's Triumph. A trailing hardy rose, with small, double white, very fragrant blooms. Useful for covering banks, stone walls or trellises; requires but little pruning if used thus.

SNowball Tree, Guelder Rose (Viburnum opulis, var. sterilis). 8-10 ft. A cultivated variety from Europe of the High Bush Cranberry (a native of low swampy ground), with large heads of a snowwhite sterile flowers becoming globular; hence its name. Fruit bright red in the original variety, and used as a substitute for cranberries. Transplant in October or November as it has few fibrous roots, and is apt to be killed before it is established if the spring season be a dry one. It should have a moist, even a wet location, if possible, for even when well grown it suffers from drought. Propagate by layering or cuttings of half ripened shoots inserted in sandy soil. Mulch in summer.

SNowBall, Japanese (Viburnum tomentosum also known as $V$. plicatum). Shrub of medium size, and dense heads of sterile flowers whiter and more delicate than the common Snowball.

SNowbali ( $V$. dentatum, Arrowwood). 5-10 ft. A variety with bright blue berries.

SPIREA, Golden (Physocarpus [or Spirea] opulifolia var. aurea). 5-7 ft. Double white flowers, bright yellow leaves; desirable as a foliage plant to be used with red or purple varieties.

Stephenandra Flexuosa. $4 \mathrm{ft}$. A hardy shrub with glossy deepcut leaves, stems that are crimson in spring and autumn, and clusters of small white flowers that cover the whole bush in the blooming season. Foliage is a beautiful reddish green in spring and autumn; a most desirable shrub that needs no protection. Give a good loam and a partial shade on roots.

Styrax JAPOnica, also known as $S$. serrata. 10-20 ft. A very choice shrub growing to be a tree. By nature, it assumes a single stem with low branches; but, by pruning, it branches freely, and the small and 
numerous twigs are covered with pure-white flowers an inch across, having yellow stamens. Leaves small and light green. Related to the Snowdrop-Tree, Halesia, but surpasses it. Seeds hang in round balls resembling coffee. Handsome at all seasons, although the bloom is of but short duration. Perfectly hardy.

Sumach, Fern-leaved (Rhus glabra, var. laciniata). 3-5 ft. A low variety with finely cut foliage on long stems, whitish flowers. The chief beauty is the brilliant crimson hue of the leaves in autumn, when it is compared to a ball of fire. It is best grown in the form of a low bush with several stalks springing from a common root. Prune tips to get a spreading top. Dry sunny situation.

SumacH, Smooth (Rhus glabra). Whitish-green blossoms in large branching heads; compound leaves, becoming a rich crimson in autumn; fruit is made up of velvety berries arranged in cone-shaped spikes. The whole appearance is very showy. It suckers badly, taking possession of entire fields, and is hard to uproot. Grows in dry sterile situations; excellent to plant about the base of trees.

Syringa, Mock Orange (Philadelphus coronarius). 8-12 ft. A hardy shrub making a large bush with many branching stems, large white fragrant flowers. As it flowers on the wood of the previous year, prune after blooming, thus encouraging new growths for the following year; propagated by seeds, cuttings, layering or division of the root.

Weigelia (Diervilla florida, var. candida). $5^{-8} \mathrm{ft}$. A commonly cultivated shrub with cream-white funnel-shaped flowers; will grow in any soil, sending up many suckers, by which it may be increased. For pink and red varieties see Pink and Red Shrubs, June.

Wrthe RoD or Tree (Viburnum cassinoides). 8-12 ft. Flowers yellowish-white in crowded heads; fruit a rich deep blue, ripening in September. Prune to a bushy form; spreads from the root; prefers wet low ground. Mulch in summer if planted in a dry location.

\section{JUNE}

\section{WHITE PERENNIAL HERBS}

Achillea, Sneezewort (A. Ptarmica $f$. pl., var. The Pearl). $2 \mathrm{ft}$. One of the best perennials grown, making a low bushy plant, bearing many loose heads of white flowers. It increases rapidly, and when out 
of flower, cut to the ground to promote growth. Divide in the spring; also propagated by seeds and cuttings.

Anemone. Pennsylvania (A. Pennsylvanica). I ft. A low herb with radical deeply cut leaves from which spring, later, stems that bear large snow-white flowers. Very attractive as a cut flower; spreads badly at the root. Give a moist light loam mixed with leaf mold and a shaded location, with plenty of room to spread. Is attacked by many insects, especially the oil beetle. Propagate by division of root.

ARCHANGEllica (Angelica archangelica, var. officinalis). $4 \mathrm{ft}$. A bushy herb with large, showy leaves, and huge flat heads of bright white flowers; does best in moist rich soil; good to plant among shrubbery. It does not spread.

Asperula ( $A$. hexaphylla). $2 \mathrm{ft}$. A hardy perennial with smooth erect stems and needle-like leaves arranged in whorls of six; very small numerous white flowers borne in airy loose clusters. It resembles Infant's Breath. Give any good soil, in moist shaded location; if in dry sunny place, it makes a stunted growth, and dies down early; propagate by division or seed. Self-sowing.

Bedstraw. Northern (Galium boreale). I ft. A native plant that, under cultivation, makes an ideal low bushy border plant, spreading at the root gradually and easily divided. It has a square stem, slender elliptical leaves arranged in a whorl of four, delicate fragrant white flowers borne in showy terminal branching panicles. If cut back continues to bloom all summer. In its wild state it is tall and straggling and not useful. Give full sun, a deep rich moist soil and frequent division.

Caraway. Garden (Carum Carui). $2 \mathrm{ft}$. A delicate herb with finely divided leaves and lace-like flat heads of tiny white flowers. While it is usually grown in the herb garden for its seeds it gives lightness and grace to colored flowers. Give a moist rich soil.

Clematis. Erect or Upright (C. recta). $2 \mathrm{ft}$. An herbaceous erect form of Clematis, with large clusters of fragrant white flowers and small heart-shaped pinnate leaves. Give a rich moist soil and partly shaded position. Propagate by seeds and cuttings. Mine winter-killed.

DaIsy. Paris (Chrysanthemum frutescens). $3 \mathrm{ft}$. A variety coming in late May just after and closely resembling the common daisy in flower, but a little larger, and literally covering with bloom the plant, which makes a bush two feet across. In spring it throws out many horizontal herby branches from white fibrous roots, that can easily be 
divided; perfectly hardy and self-sowing. I have a curious plant of this variety which is inclined to sport and produces two flowers joined in one at the end of a stalk, each facing a different way. One of my best perennials in point of bloom and vigor. Give a rich deep soil and full sun.

Darsy. Wild White, or Whiteweed (Chrysanthemum leucanthemum vulgare). $2 \mathrm{ft}$. A much despised weed which makes a beautiful garden plant under cultivation. In rich moist soil it makes a more bushy growth, and bears quantities of large white flowers on tall stems. Daisyshaped flowers add much to the grace of the garden, and as these come earlier than the Chrysanthemum maximum and Shasta Daisy, they supply the early type of this plant. Do not let it go to seed, but propagate by division of root.

Dodecatheon, Shooting Star, American Cowsuip (D. Meadia) I ft. A curious growth with a low tuft of leaves from which spring a simple flower-stalk a foot high, bearing handsome white nodding flowers with reflexed corolla; also a pink variety. It requires a rich moist soil; dies down in midsummer; increase by seed and division of root. See Pink Per. June.

DROPWORT (Spirea filipendula, var. $f l$. pl.). I ft. Known also as Ulmaria filipendula. A most lovable plant of delicate beauty, with finely divided fern-like leaves forming a tuft, from which spring a number of stalks bearing loose clusters of small white flowers, a close rosette in shape. It requires rich, moist soil and spreads slowly from the root.

Foam Flower, False Mitrewort (Tiarella cordifolia). I ft." A low running herb with a short raceme of white flowers. Good for naturalization in damp shaded situations. Spreads gradually from the root.

FoxGlove (Digitalis purpurea, var. alba). $4 \mathrm{ft}$. A handsome hardy biennial, and, if favorably established, it is a perennial. The leaves form a broad spreading tuft from which spring somewhat branching flower-stalks four feet high bearing declined large white finger-shaped flowers. If the flower-stalk is cut down after blooming the plant will bloom again in September. It is self-sowing and the strongest plants are thus obtained, do not try to divide; the results are not good. Give a rich moist soil either in sun or partial shade; is often planted under trees. Also purplish red and pink varieties, see Blue Per. and Pink Per.

Galega, Goat's RoE (G. officinalis, var. alba). $3 \mathrm{ft}$. An erect perennial with bluish-green leaves and clusters of white pea-shaped 
flowers. It makes a bushy growth, and needs room. Give it a sunny location in a rich soil, and let grow undisturbed. Propagated by seed and division of strong plants reset in deep rich soil. Also a blue var.; see Blue Per.

Galium boreale, see Bedstraw, Northern.

Galrum Morlugo, see Bedstraw, White. White Per. July.

Galtonia, Summer Hyacinth (Hyacinthus candicans). $3 \mathrm{ft}$. A very beautiful bulbous plant bearing racemes of large fragrant drooping white flowers. It needs protection in winter. Can be raised from seed, but it is better to propagate by offsets. Requires moist rich leaf mold. Very late in June or early July.

Garden Heliotrope (Valeriana officinalis). $5 \mathrm{ft}$. An attractive herb with large cut pinnate leaves and broad flat heads of small lilacwhite flowers that are deliciously fragrant; the root also has a pleasant aromatic odor. It can easily become a pest because of its vigorous running rootstocks. If kept under control it is one of our most desirable perennials; flourishes best in rich moist soil in either sun or partial shade. Is infested by the rose-bug.

GOAT'S BEARD (Spirea Aruncus, var. astilboides). A handsome herb with cut foliage and compound panicles of yellowish-white flowers. Used also as a house plant in winter. Needs rich soil. It cannot be depended on, as it will survive severe winters with a little protection, but a late spring frost will sometimes kill it. Give a sheltered position on this account.

GouTweed (Agopodium podograria, var. varigata). $2 \mathrm{ft}$. A low running herb with beautiful soft gray-green and cream colored foliage and flat heads of lace-like white flowers borne on stems two feet high. When combined with blue Forget-me-not it makes a handsome border plant; or it may be used effectively with scarlet poppies. It spreads at the root so badly, however, that it is a great pest, and difficult to weed out when once established. Thrives best in rich soil and partial shade.

Helianthemum, Rockrose or Sun Rose (H. mutabile). 6 in. A dwarf evergreen plant with whitish flowers that fall after the first day; opening only in the sunshine. Propagated by seed; good after once established; may be used as a border plant. Sandy loam, protect in winter.

IRIS. English (I. xiphioides, var. Mont Blanc; I. Angelica of gardeners). 2 ft. A bulbous-rooted Iris later than the German variety, and a little earlier than the Spanish varieties. All bulbous-rooted irises 
should be lifted every two or three years, as the new bulbs are formed directly under the old bulb, and in the course of time descend so low as to be out of reach of the air and are lost. They should be reset in September in light rich soil and sunny location. For other varieties see Blue Per. and Yellow Per.

IRIS. Spanish (I. Xiphium, var. Blanche Fleur; I. vulgaris of gardeners). $2 \mathrm{ft}$. A still later variety than the English Iris. The outer petals or falls are not like those of the usual Iris, but are long and strap-like, bearing heart-shaped petals at the end, which gives a curious orchid appearance. This is also bulbous, and the culture is the same as for the English variety. For yellow and blue var. see Yellow Per. and Blue Per. June.

LUPINE (Lupinus polyphyllus, var. albus). 3-4 ft. One of our handsomest perennials with palmate leaves borne on long stems and very dense racemes (often ten to fifteen) of white pea-shaped flowers. Seed pods are covered with silvery down. Requires rich soil, sun and moisture. Dig in fertilizer each spring. Propagated by division of the root and by seeds; is self-sowing. When once established makes a magnificent growth. See Blue Per. for blue var.

Lupinus Douglasi. $3 \mathrm{ft}$. A new hybrid variety, which is a cross between the annual and perennial varieties, blooming the first year if started early; spikes of bloom a foot long in white, pink and blue.

MEADow-RuE. Several varieties are native to New Hampshire, but all are desirable plants under cultivation. The Tall Meadow-Rue (Thalictrum polygonum) grows from 4-7 ft. with beautiful compound foliage resembling the Columbine, and terminal loose clusters of yellowish-white flowers; also Thalictrum cornuti, $4 \mathrm{ft}$. and $T$. adiantifolium, $2 \mathrm{ft}$. This latter variety is an excellent substitute for Maidenhair fern which it much resembles in foliage. $T$. flavium has pyramidal clusters of yellowish-white flowers and fern-like foliage that makes an excellent substitute for ferns in arranging cut flowers. After blooming cut to the ground as the leaves grow shabby; they all require rich moist soil, and partial shade, at least upon the roots.

MusK Maliow (Malva moschata, var. alba). $2 \mathrm{ft}$. A hardy herb with leaves cut into linear divisions and broad white or rose-colored scented flowers. Grows in any good soil; propagated by seeds or division. Also pink var.; see Pink Per.

Peony (Pceonia officinalis alba, var. Marie Lemoine). $2 \mathrm{ft}$. I name but one variety of white peony of the many that are offered. A well 
known hardy plant making a bushy growth, and bears huge double flowers. Peonies come in almost every color and many are sweetscented, and there are many single varieties. Requires a rich deep soil, and should be mulched and well watered in summer when the growth is made. A gross feeder; dig in cow manure about the roots. Should remain undisturbed, but can be propagated by division of strong plants in August or September, or by seeds. New varieties are obtained by crossing, and can be done by an amateur, if time and patience are given to the matter.

Carnation or Clove-Pink (Dianthus caryophyllus). I ft. While this variety is most frequently seen in pots as a house plant it will bloom in the open in four months from sowing the seed. A very full double variety with a fragrant clove scent. It makes a tall brittle growth, and if size of bloom is desired the plant should be disbudded and only a single flower be allowed to bloom. Give a deep rich soil of mixed loam, sand, cow manure or leaf mold. The buds are apt to burst on one side, which may be obviated by gently dividing the calyx with a pin as soon as the buds are swelled. Propagated by layering, for which, cut a strong shoot half through in a slanting direction at a joint, and bury an inch or two deep, fastening down with a pronged twig, or hairpin. Moderate water and shade should be given until the shoot roots; also propagated by cuttings in sand under glass, and by seed. Not hardy except varieties Vienna and Grenadin in white and scarlet. The Marguerite Carnation will bloom in the open from July until frost if sown in the spring. They are half hardy, and in sheltered situations if well mulched with coarse straw and pine boughs survive the winter.

Pink. Japanese (Dianthus Heddewigii, var. albus $f . p l$. .). $2 \mathrm{ft}$. A double white biennial variety of a beautiful but scentless pink that blooms late the first season, and is covered with bloom the second year. It is hardy with a slight protection in winter. Give a rich moist soil, a sunny sheltered position.

PINk. Hardy Garden, or Common (Dianthus plumarius, var. Cyclops). I ft. A single flowered variety of the old Scotch Pink, making a tuft of grass-like leaves; bears quantities of small sweet-scented whitish flowers with fringed petals. Propagated by seeds and cuttings, and sometimes by division of root. I do not succeed with this last method. There is also a double variety, and pink and white varieties of double Dianthus plumarius. A beautiful border may be made by alternating the Garden Pink with Forget-me-not. 
Rocker. Sweet (Hesperis matronalis). 2-3 ft. A hardy plant with coarse pointed leaves and loose racemes of white and lilac flowers very sweet-scented at nightfall with an odor like Clove-Pink. Does best in sandy, rich moist soil. Propagate single varieties by seed, the double variety by division of root. If taken up as soon as the flowering season is done, and transplanted into rich light soil, it will attain an extraordinary size, and flower splendidly the next season. Also a lilac variety.

Romneya Coulteri. In California a shrub 6-8 ft. high, but in the East it is nearly herbaceous. A very handsome addition to the garden, blooming freely from early summer to autumn, with delicately scented white flowers from 4-6 in. across, having a central boss of golden stamens. It needs a sunny sheltered position and very rich soil. I have been unable to raise it from seed and know but one nurseryman who offers it. In a moderate climate it is certainly worth trying; it has been known to be hardy as far north as Scotland.

SwEET-William (Dianthus barbatus). $2 \mathrm{ft}$. A hardy garden favorite that grows in a great variety of colorings. The flowers form a flattopped cluster, borne in great profusion. If cut back as soon as flowering is over, new blooms will appear. While they can be raised easily from seed, they rarely come true to color, owing to the cross-fertilization by insects. Propagation of a certain variety may be secured by division of the root or by covering a plant with fine gauze during the flowering time. If by division, cut off the blooms as soon as the color is learned, lift the plant and reset in very rich light soil where it will throw out a heavy growth from the root, which may be carefully divided either in spring or autumn and reset. Whole borders may be secured from a few plants in two or three years. There are beautiful pale pink and brilliant pure red varieties that are much more attractive than those with markings and eyes of another color. See Pink and Red Per. June.

Thrift, SeA-Pink (Armeria cephalotes Formosa, var. alba). I ft. A white variety with a low tuft of narrow leaves and an erect red stalk bearing a close head of handsome flowers. It is difficult to divide the root, and it is better to propagate by seed. There is a lovely pink variety. Still another variety, $A$. maratima also called $A$. vulgaris is increased rapidly by division, and as the seed comes up quite regularly it is often used by either method as an edging instead of Box. See Armeria, Pink, Per. June.

UlMARIA FILIPENDULA, see Dropwort.

Valerian. Spurred, Jupiter's Beard (Centranthus albus). 2 ft. 
A pleasing herb with smooth leaves and several stalks from the root bearing small terminal clusters of white, pink and coral red flowers resembling Honeysuckle. Thrives in any good soil; propagated by seed or by careful division of the root. It does not spread.

\section{JULY}

\section{WHITE SHRUBS}

Boy Love, Otd MAN or Southernwood (Artemesia Abrotanum). 3-5 ft. A woody stemmed shrubby plant with finely divided, grayish aromatic foliage. Seldom flowers, but when it does the bloom is in whitish-yellow panicles. Cultivated for its aromatic perfume. Easily propagated by cuttings; any good soil.

DoGwood. Panicled (Cornus paniculata). $5-7 \mathrm{ft}$. A late variety that takes a bushy form, with whitish leaves and loose clusters of white involucres in July and August; bark ash-colored; berries white. See Dogwood, White Shrubs, June.

ElderberRy (Sambucus Canadensis). 4-6 ft. A vigorous shrub with woody stems only toward the base; bears large flat showy heads of small white flowers followed by small purplish fruit. Give it rich soil and it soon makes a large clump.

Sweet Gale (Myrica gale). 3-4 ft. Cut-leaved fragrant foliage and greenish-brown flowers. Give a moist sandy loam.

Sweet Pepper Bush, White Alder (Clethra alnifolia). A native shrub, from 3-6 ft., cultivated for its deliciously fragrant white flowers. Does best in moist rich soil and partial shade.

\section{JULY}

\section{WHITE PERENNIALS}

Adam's Needle, Bear Grass, Silk Grass, Yucca (Yucca filamentosa). I-2 ft. A hardy variety of a subtropical plant with swordshaped leaves edged with thread-like filaments, and bears a branching terminal cluster of cream white bell-shaped flowers. Prefers a deep sandy soil, and is propagated by suckers. It is well to give it protection in winter. Excellent against a background of shrubbery.

BABY'S BREATH. This name is applied to several plants, one Gyp- 
sophila paniculata 2-3 ft. A dense spreading bush with tiny white flowers in light open panicles and delicate foliage; resists drought and grows in fairly dry soil. Propagated by seed, division and cuttings. See also Bedstraw, White. White Per., July.

Bedstraw. White (Galium Mollugo). 3-5 ft. This plant is erroneously called Gypsophila for which it is frequently mistaken, and also Baby's Breath. It makes a bushy growth, increasing rapidly at the root, has a square stem, elliptical leaves arranged in whorls of 6-8 and open clusters of tiny white flowers faintly scented. It does best by frequent division; also propagated by seed and cuttings. Give a deep rich moist soil and full sun.

BELLFLOWER. Campanula. This genus represents some of our most valuable and showy plants. While most of them are blue, there are many white varieties such as C. turbinata alba, 6 in. I ft.; C. persicifolia alba, $\mathrm{I}-3$ ft.; C. Mariesi grandiflora and C. Mariesi compacta nana. These have large showy flowers. There is also another, C. rapunculoides, a showy blue variety that spreads badly, has smaller nodding flowers, with many stalks springing from the root, drooping bell-shaped flowers borne in the axils of the upper leaves; if cut will bloom through the season. All can be propagated easily by seed or division of the root, and do well in any good soil. For blue varieties see Bellflower, Blue Per., June.

Bocconia, Japanese Plume Poppy (B. cordata). $4^{-6} \mathrm{ft}$. A handsome perennial herb with ornamental fig-leaved foliage and terminal clusters of yellowish-white flowers. It is excellent to plant in an angle or corner where it is sheltered from the north and east winds. Cutting off the suckers in summer will benefit the old plant and increase the stock. Give a rich soil. Handsome when massed against shrubbery.

Canterbury Bell (Campanula medium). $3 \mathrm{ft}$. A biennial form of Campanula, bearing a quantity of bell-shaped flowers two or three inches long; very desirable. If the seed-vessels are picked off as they form, it will bloom almost the whole season. It is self-sowing and the strongest plants are thus obtained, transplanting them in the autumn for the following year.

Clematis (C. Jackmanni, var. Henryi). A climbing perennial of great beauty. It dies to the ground every autumn but makes a heavy growth each spring; flowers from 2-4 in. across. Does well in any rich light soil and sunny exposure. Propagated by seeds and cuttings. For further cultural directions, see page I3I. 
Clematis, Wild, see Traveler's Joy.

Chrysanthemum maximum. $3 \mathrm{ft}$. This plant makes a magnificent bushy growth, bearing flowers about three times as large as the common white daisy. It blooms for many weeks if the seed-vessels are not allowed to form. Grows in any good soil in full sun. Propagated easily from self-sown seed or division of the root.

Chrysanthemum latifolium. $3 \mathrm{ft}$. A variety coming perhaps two weeks later than C. maximum; is, if anything, a better plant with broader leaves, larger flowers and more prolonged bloom.

I had still another variety that had a sort of frilled row of petals notched at the outer edge that was more desirable than either of the other two, and seemed to be a sort of $C$. latifolium, or derived from a stray seed of the Shasta daisy.

DAIsy. Great Oxeye (Chrysanthemum uliginosum). $2-4 \mathrm{ft}$. A graceful variety with slender bending stalks, bearing loose terminal clusters of white flowers, leaves sharply toothed, sessile. Propagate by seeds and division.

Euphorbia, Flowering SpUrge (E. corollata). $2 \frac{1}{2} \mathrm{ft}$. A very satisfactory plant bearing a broad open cyme of snow-white leafy appendages that are taken for flower petals, borne on long branching stems. Desirable for cutting or graceful addition to a red or pink bed. Give a rich loam and partial shade. Propagated by division of strong plants, but does best when well established.

Feverfew, Pellitory (Chrysanthemum parthenium $f$. pl.). $2 \mathrm{ft}$. A plant having a strong aromatic smell, making a bushy growth and bearing numerous clusters of white rayed flowers with yellowish centers. This, like all other white rayed flowers, adds variety and grace to beds of a single color. Propagated by self-sown seed. While hardy through severe winters, the young growth is tender under late spring frosts. Does well in any good soil and any location. If pruned low makes a good edging.

Foxglove. Woolly (Digitalis lantana). $2 \mathrm{ft}$. A biennial form of Foxglove of no great beauty; rather coarse leafy plant with curious brownish-white spotted flowers an inch long on terminal racemes. Not especially desirable. Moist light soil, partial shade. Propagate by seed and division.

Fraxinella, Gas Plant (Dictamnus fraxinella, var. albus). $2 \mathrm{ft}$. An aromatic herb bearing showy flowers in long terminal racemes. When bruised has a balsam smell or like lemon peel; emits a volatile fragrance 


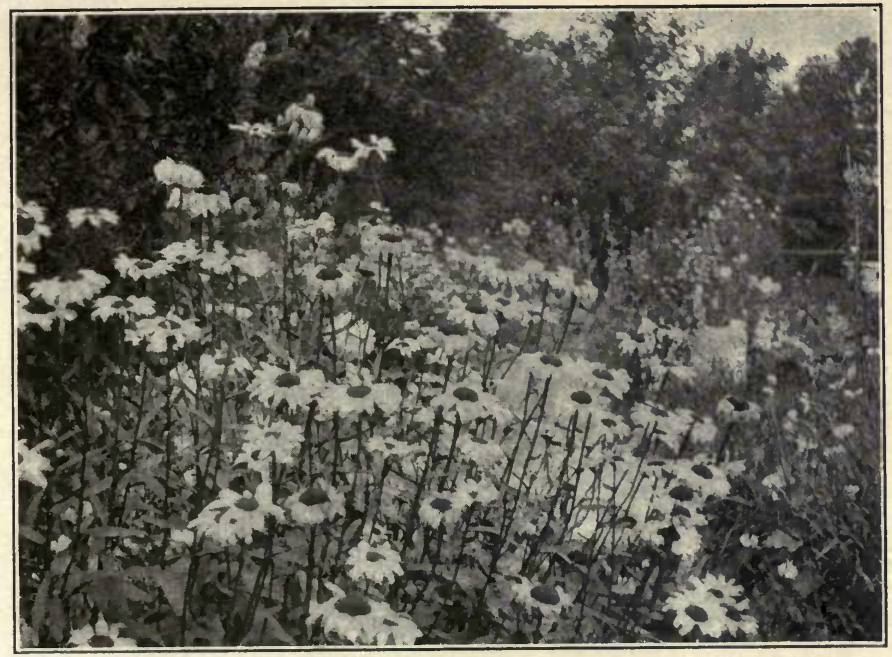

Chrysanthemum Maximum

[P. I86]

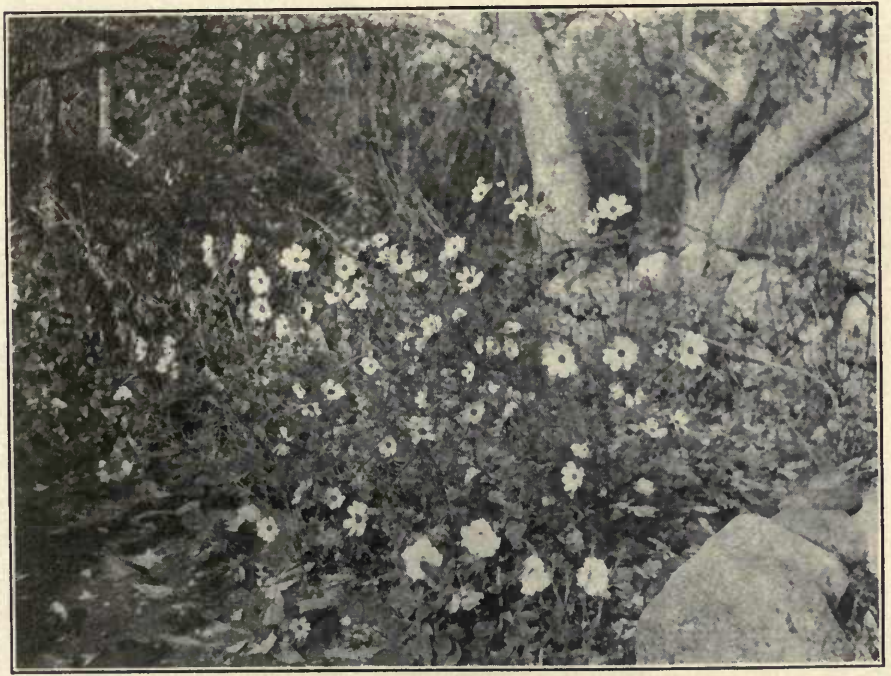

Early Pink Cosmos Still Blooming in October [P. 267] 
on hot close nights, which is so strong that it can be lighted with a match; hence its name. Does best in a dry situation, but not under trees. Do not crowd or disturb; give a rich heavy soil. Propagate by division of the root and by seeds sown as soon as ripe. Also a rose variety.

Galium Mollugo, see Bedstraw, White.

GaUra, Butterfly Flower ( $G$. Lindheimeri). 2-4 ft. While this plant is usually offered as an annual, I have found it a hardy perennial when protected with the usual mulch. It has but few leaves obscurely spotted like smartweed, and bears a continued succession of handsome white orchid-like flowers on tall branched mahogany-colored stems, which wave gracefully above other plants like hovering butterflies. As an annual it grows $2 \mathrm{ft}$. high; but as a perennial it is from $3-5 \mathrm{ft}$. Does well in rich dry soil and full sun. Propagated by seed. I especially recommend this flower which is too little known.

Gypsophila paniculata, see Baby's Breath; also Galium Mollugo.

Gypsophila Steveni, also known as G. glauca. $2 \mathrm{ft}$. A variety with long recurved opposite leaves, the whole plant covered with a gray bloom; tiny gray-white flowers on fine wire-like stems, petals reflexed, altogether presenting a curious metallic appearance. Very useful to support more delicate cut flowers. Propagated by seed and by division of the root that spreads slightly by deep suckers. Has a rather prostrate habit, and needs a support. See Baby's Breath, G. paniculata; also an annual variety of delicate beauty; see White An. for June.

IRIS. Japanese (I. lavigata, var. Moonlight. Also known as $I$. Kampferi). $2 \mathrm{ft}$. The Japanese Iris blooms after the other varieties are gone and surpasses them in beauty, size and variety of coloring and marking; the flowers of some of the garden varieties measure from 6-ro in. across; are broad and flat; the leaves are more delicate in form than the usual Iris, and can be used more decoratively. It does best in rich moist but not wet, soil, and partly shaded situation. As it takes several years to get well established it should be allowed to remain when once planted. It increases by running rootstocks extending in a circle, making handsome clumps. It can be also raised from seed (thus new varieties are obtained) but it takes a whole year for the seed to germinate, and five or six years before strong blooming plants are developed. Moonlight is a beautiful white variety with yellow center. For other Var. see Yel. Blue and Pink Per.

LARKSPUR. White (Delphinium grandiflorum, var. album). $3 \mathrm{ft}$. This Larkspur is one of the loveliest of all hardy perennials, but because 
seedlings often winter-kill further south is rarely offered in either seed catalogues or by nurserymen and then at a fancy price. It forms a good-sized clump, with finely divided leaves, and many spikes of glistening white flowers with green spot on the under side of each petal and black stamens. It is propagated easily from seed and is self-sowing if the soil is kept mellow. I raise most of mine from self-sown plants that spring up in my walks; strong roots may also be divided. While it is perfectly hardy it is well to give a mulch of coarse grass in winter. It grows best in deep rich moist soil, but also thrives in dry sunny situations if well watered in a dry season. If the flower-stalks are cut to the ground after blooming, new growths will spring up a second and even third time. It needs staking because of its brittle growth. All Larkspurs should be planted with the crown a little above the soil, as they are inclined to rot. Coal ashes over the crowns are said to prevent slugs. For other varieties see Blue, Yel. and Red Per.

LychNIs. - White, White Ragged Robin (L. vespertina, fl. pl.). 2 ft. A double day-blooming variety, which is a perennial, also a single biennial variety known as Evening-blooming L. Both are fragrant, and bloom in loose terminal panicles. Thrive in any good soil and are propagated by seed.

Madonna Lily (Lilium candidum). $2-3 \mathrm{ft}$. One of the most beautiful of fragrant white lilies, its name derived from the fact that painters represent the Virgin carrying these lilies. When well established leave it alone, but if it must be transplanted, do it in August after the flower stems die down. It should have a stiff rich loam, no manure next the bulb and full sun; it fails if given a moist shaded location. Propagated by offsets.

Mallow. Musk (Malva moschata). I-2 ft. A showy bushy plant with large white or pink flowers 2 in. across, borne in clusters; leaves heart-shaped below, the upper ones in 5-cleft divisions. Blooms all summer. Give any good soil, sun and moisture, if the season is dry, as drought shortens the bloom. The pink variety is particularly beautiful. Both have a faint musky fragrance. Propagate by seed and division. See Pink Per., July.

Milla multiflora, see Star Flower.

Monkshood (Aconitum Nepallus, var. albus). $3 \mathrm{ft}$. The Monkshood in its various colors of white, blue and yellow is one of our stateliest plants with its handsome foliage, much divided, and many tall loose spikes of hood-shaped flowers. If left undisturbed makes a fine clump; 
does well in full sun or under the shade of trees. Propagated by seed or division of the root; but great care should be exercised, for the root is deadly poison and dangerous to cattle if left about. Do not plant it in a kitchen garden as it much resembles horseradish roots.

Obedient Plant (Physostegia Virginiana, var. alba). 3-4 ft. Against a green background this plant makes a most beautiful effect with its clustered white blooms borne on tall branching stems. It spreads from the root and can easily be raised from seed. Mine are in a location where the roots are well shaded in a moist situation, but the tops are in full sun. Too much praise cannot be given this plant in either the white or lilac varieties; see Blue Per., July.

PEA. Perennial (Lathyrus latifolius, var. alba). 4-6 ft. This is another perennial making a magnificent growth, yet it is but little known in this country, though much prized in England. A single root when well established will send up from six to fifteen stems completely covered with clusters of flowers and buds, larger than the Sweet Pea, but scentless. It should be left undisturbed; nor is it easy to lift an established plant, owing to the enormously long roots that go down a foot or two in the soil. Keep the seed-vessels from forming, give water if the season is dry and it will bloom until frost; flourishes in any good soil in any location. If planted at the base of early blooming shrubs or those with naked stems it will cover the bush with bloom. Propagate by seed, which is self-sowing or by careful division of the root. Give a mulch if in an exposed position. There are pink, pink and white, also red varieties. See Pink and Red Per.

Platycodon. Wahlenbergia (P. grandiflorum, var. album). $2 \mathrm{ft}$. A low spreading variety of Campanula with showy terminal flowers rather flat and wheel-shaped; also blue varieties. Divide in spring, give a rich well-drained loam. For further culture see Campanula.

Potentilla $(P . a l b a) .2 \mathrm{ft}$. A low ornamental plant with grayishgreen leaves and white flowers borne in loose cymes. Increased by division of seed; thrives in any good soil. Also red and yellow varieties.

Star Flower (Triteleia laxa, var. alba). Trade name Milla multiflora. $2 \mathrm{ft}$. A delicately beautiful plant rarely offered, with narrow lily leaves and loose airy clusters of pure-white star-shaped flowers borne on tall branching thread-like stems, the flowers numbering from 8-20 on a single stalk. Cover lightly in the winter, give a sheltered position. Mine has full sun on the plant, but shade on the roots from a southern 
wall. Spreads slowly by offsets. Let remain when once established. A lovely plant but rare.

SNAPDRAGON (Antirrhinum majus, var. Queen Victoria). $3 \mathrm{ft}$. While this plant is frequently grown as an annual, blooming in August if the seed is sown in April, it is also a hardy perennial, and survives our severe winter with a little mulch. It bears full racemes of showylipped flowers and is highly ornamental. Seeds are inclined to sport, also the same plant does not always produce the same color of flowers a second year. The only way to reproduce a true variety is by cuttings. Thrives best in a light well-manured soil in full sun. In England it is grown on tops of walls, but our climate is too dry.

SPURGE. Flowering, see Euphorbia corollata.

THOROUGHWORT, BONESET (Eupatorium perfoliatum). $3 \mathrm{ft}$. A stout native plant that bears great flat heads of finely-fringed flowers. Under cultivation it becomes a handsome plant for shrubbery effects. Does best in rich moist soil; seeds itself.

Traveler's Joy, Virgin's Bower, Wild Clematis (Clematis Virginiana). $8-25 \mathrm{ft}$. A most beautiful native vine that does well under cultivation. Bears quantities of white flowers followed by fluffy white seed-vessels. Thrives best in partly shaded locations with moist rich soil. Self-sowing. Do not cut to the ground, as the old stems are often alive in the spring several feet up from the ground, though they may look dead.

Triteleia laxa, see Star Flower.

WILD CARrot (Daucus carota). $2 \mathrm{ft}$. A troublesome weed of the most delicate beauty, with fern-like foliage, and lacy heads of minute white flowers, followed by curious seed-vessels that look like a green bird's nest. Commonly called Queen Anne Lace. If the seed-vessels are not allowed to scatter, this plant can easily be kept within bounds. It is a biennial, and self-sowing. Very attractive planted with blue Larkspur, Rudbeckia, Stokesia, Bergamot, or any showy flowers that bloom through August.

YuccA, see Adam's Needle. 


\section{AUGUST}

\section{WHITE SHRUBS}

Angelica Tree, Hercules Club (Aralia spinosa). 6-20 ft. A low shrub or tree with a stout trunk covered with sharp prickles. A secondary growth springs up about the stem making a group of smaller ones on every side. These can be removed if a tree form is desired. When young, in autumn, the large stems, having served as branches, fall off as well as the leaves, and it appears to be more dead than alive. In spring it quickly reclothes itself, sending out compound leaves two feet long and half as broad. These form a cluster at the top of stem that are two feet long in a twice or thrice pinnate arrangement. The flowers are white in compound panicles and these great heads with their clusters of flowers and huge leaves look like a tropical palm in blossom. Give a shaded and sheltered position, as the top is too heavy to stand high winds. A rapid grower, especially in a moist situation.

DIMORPHANTHUS MANDSCHURICUS, a hardy variety of Aralia Chinensis. 3-5 ft. A handsome shrub with horizontal branches, leaves spiny, finely divided, arranged tri-pinnately, giving a fine tropical foliage effect. Flowers white, in many-stemmed broad terminal clusters. Hardy if given a dry porous soil and sunny, sheltered spot.

HydrangeA ( $H$. paniculata, var. grandiflora). $4^{-6} \mathrm{ft}$. This is one of the showiest of August flowers, and perfectly hardy. It bears great elongated clusters of white blossoms, the fewer the clusters allowed, the larger the size. It needs a deep rich soil and plenty of water. Although pruning may also be done early in the spring, it is advisable to cut almost to the ground in late autumn, then new shoots arise in considerable numbers, and each will bear a cluster during the season; otherwise the old wood grows tall and becomes bare. This variety does not turn pink and blue as does $H$. hortensis, which is a tender greenhouse variety. The color of the latter is very capricious, being secured in many ways, yet none is to be depended upon always. Alum water, sheep's dung, different soils, common salt, and steel filings at times produce the much desired blue tinge, yet not invariably successful. Propagated by division of root and cuttings taken in August or spring from the tops of the strongest shoots not bearing flowers.

SPIREA SORBIfolia, known also as Sorbaria sorbifolia. 3-6 ft. Large white flowers in panicles. It may freeze to the ground, but the new 
spring growth is more vigorous in foliage and bloom than when produced on the old wood of the previous year. Plant with Blue Spirea.

\section{AUGUST}

\section{WHITE PERENNIALS}

Canna (C. Ehemanni, var. Alsace). While the Canna is not a hardy perennial, the root may be saved from year to year by storing over winter in boxes or pots of earth. It is useful in securing subtropical effects in a garden, but I do not grow it. Propagated by division of the root, if care is taken that each portion has a root bud attached. Divide in spring; place pieces in 4-in. pots and set out in late May or June. It can also be raised from seed, but as its roots when young are brittle, the seed should be sown in single pots so as not to disturb the roots. Give a rich deep soil, a sheltered position with sun and plenty of water. Canna needs coddling to bring it to perfection, and for this reason has no place in a hardy garden.

Funkia, JAPAN DAy Lily (F. subcordata). $2 \mathrm{ft}$. An ornamental tuberous-rooted lily making a large clump, bearing many stalks with long white funnel-shaped fragrant flowers. Propagate by cutting roots through with a sharp spade in early spring. None but strong roots should be divided; it takes a long time to get established. Give partial shade, deep rich soil and moisture.

Gentran. White (Gentiana alba). $2 \mathrm{ft}$. A native perennial variety that can be naturalized in low wet places or grown in a damp corner of the garden. It bears terminal clusters of yellowish-white flowers. Propagated by division of root, or seed sown as soon as ripe. Rich wet soil is best for it.

Gladiolus (G. Childsii, var. albus). $3 \mathrm{ft}$. The Gladiolus is not hardy, yet it can be cultivated with so little trouble and is so gorgeous a plant that no garden should be without a few of some color. Leaves are erect and sword-shaped, from which spring stalks bearing from 6-20 lily-shaped flowers often several inches across. It is propagated by offsets or seed. Prepare the bed in the late autumn, dressing it deeply with well-rotted cow manure; apply none in a fresh state when planting. Plant at intervals from May Ist for six weeks to secure a succession of bloom. Excellent when set among shrubbery or in rose- 
beds. Set bulbs $3^{-4}$ in. deep, in full sun, and stake before flowering. It needs mulch about the roots if the season is dry, and plentiful watering. After flowering, cut off the seed-vessels, and lift when the tops are withered, after frosts come. Dry in a cool shed out of the sun and store in a dry, warm place through the winter. For other var. see Yel., Pink and Red Per.

Hibiscus, Marsh Maliow (H. moscheutus, var. Crimson Eye). 4-6 ft. A tall plant bearing white flowers often $4^{-6}$ in. across, with a center of rich deep red. It does best in a rich moist soil. Propagated by seed and division of the root. A new variety has been made by hybridizing which claims to be a great improvement on the usual type. Also pink var.; see Pink Per., August.

HоLцуноск (Althea rosea, var. alba). 5-8 ft. One of our finest hardy plants, a biennial in some places, with me a perennial. It forms a thick clump of large leaves from which rise stout stalks bearing enormous wheel-shaped flowers of many colors. The erect growth makes a good background for lower bushy perennials, or they can be grown in broad rows without other plants, or as the foreground of a high hedge or shrubbery. Seeds should be sown in early spring and the young plants removed to a permanent position in August or September. I allow mine to seed themselves, and thus obtain strong plants, each year finding enough to reset in early spring, where they get well established by another season. Top-dress with manure when about to flower; give plenty of water and full sun. If plants are weak, allow only one stalk to a plant and stake early. If in a locality where they winterkill, cut back to within 6 in. after flowering, lift the plants and winter in a cold frame. Some recommend a mulch a foot deep of coal ashes as a winter protection. Of late, hollyhocks have been affected with the rust, an orange-colored fungus growth that appears on the lower leaves first, and spreads upward, in time destroying the entire foliage, and injuring the bloom. If discovered early, we are advised to spray with a weak solution of permanganate of potassium; if advanced, spray with a weak solution of Bordeaux mixture, neither of which helped my plants. Try my special remedy, page ${ }_{3} 30$. Remove all infected leaves and burn them carefully, and change the bed; or one can save the seed and let hollyhocks go for a year or two, and try afresh. It is said that the single varieties are less affected than the double ones. Give a deep rich soil, underdrained with stones if possible. May be also propagated by division of strong roots. 
ImMORTELle or PeARly Everlasting (Anaphalis margaritacea). $2 \mathrm{ft}$. A common weed with slender leaves that are cottony on both sides, making a soft gray-green effect. Flowers retain the pearly white scales of their involucre, and grow in large branching terminal clusters. Under cultivation this plant is very attractive, especially as a border to a dry bed where nothing else will grow; try it. If the top is pinched off when the plant is only a few inches high, it will increase the bloom. Propagated by suckers.

LrIy. Auratum or Golden-banded (Lilium auratum). 3-4 ft. The most splendid and heavy-scented of all white lilies, bearing flowers often 8 in. across with reflexed petals spotted with maroon or carmine, a yellow stripe down the center, and conspicuous maroon anthers. This lily is very capricious, and seldom finds a favorable home. Give a deep rich well-drained soil, plenty of moisture; some say full sun, others partial shade. Under all these conditions it frequently decreases in vigor until it bears but a few small blooms. It is said that this decline is due to the presence of a small white mite that infests the scales, and flourishes more vigorously in American gardens than in its native habitat. The main point is to keep the plant strong and healthy. Some advise removing every year or two, and propagation is generally secured by buying freshly-imported bulbs. In setting them out in late autumn, it is well to surround each bulb with a little sand to prevent rotting; plant from $5^{-6}$ in. deep. Never allow any manure directly at the root of this or any other lily. This lily, if freshly imported, usually arrives too late for fall planting unless the ground is prepared in advance and covered deeply with mulch to prevent freezing. It may then be uncovered and the lilies set and well mulched for the winter. Otherwise, set the bulbs in early spring as soon as the ground is ready.

LILx. Plantain, see Funkia.

LILX (Lilium speciosum album). $3 \mathrm{ft}$. This is the most delightful of all lilies for its waxy texture, delicate fragrance and beautiful form which is similar to the Lilium auratum, but smaller. It is pure white with purplish spots on the reflexed petals, and from 3-10 flowers appear on a stalk. Its requirements are similar to those of $L$. auratum. It needs partial shade, but not under overhanging trees. Of late it has been subject to a blight, which causes it to disappear. Plant in autumn. It blooms until late frosts.

Mallow. Swamp, see Hibiscus. 
Mountain Fleece, see Polygonum.

Mountain Feather FleEce (Stenanthium robustum). 5-8 ft. A very beautiful hardy perennial with long lily leaves and panicles of feathery, drooping white flowers often 2-3 ft. long. As the flowers ripen they turn to shades of pink and purple. Requires a deep, rich, moist soil; propagate by seeds or offsets.

PHLox. Perennial (Phlox paniculata, var. F. G. Von Lassburg). $4 \mathrm{ft}$. Though there are many white varieties, this is said to be the best white Phlox under cultivation, bearing great heads of pure white flowers. It requires a deep, rich soil, sun and much water during the flowering season, also a top-dressing of manure during summer. If the tops are pinched off when plants are about a foot high, they will make a lower more bushy growth, and the flowers will be more numerous, though smaller. They will also be a little later in blooming. By pinching off only a portion of the plants, or the outside stalks, it will retard the bloom of certain ones and thus prolong the season of bloom. Propagated by seed or division of the root in spring or autumn. The latter method is the surest way to perpetuate any given strain. It can also be increased by cutting a strong root in pieces and treating it as you would seeds; also cuttings taken from roots of old plants grow easily, and cuttings from shoots that will not bloom that season are used. Seed, if sown early in heat, then hardened and planted out in May, will bloom the first season; by this latter method new varieties are secured, as they cross easily. White Phlox is particularly beautiful planted with Golden Glow, Helianthus or Stokesia Cartesia. Also many shades of pink, red, lilac and blue; see other lists.

Polygonum. Mountain Fleece ( $P$. amplexicaule). 2-3 ft. Has a strong, woody rootstock, flowers creamy-white in one or two racemes from 2-6 in. long. Give partial shade and any good soil; inclined to spring up over the garden. Propagate by division; needs a little protection in severe winters. Blooms very late in August or early September. Also a deep red variety.

SNAKEROOT. White (Eupatorium ageratoides). $3 \mathrm{ft}$. A native plant in some portions of the North and Middle West, but very desirable under cultivation. It is of erect, leafy growth with thin green leaves and large heads of finely-divided white flowers. Give a rich moist soil; propagated by division of root. 


\section{SEPTEMBER}

\section{WHITE SHRUBS}

Althea, Shrubby. Rose of Sharon. 6-I2 ft. Sometimes seen in white, but pink and purple and red are more common colors. See Rose Mallow, Pink Shrubs, Sept.

Pagoda Tree or Japanese Sophora (S. Japonica). Io-20 ft. A tree with graceful bluish-green compound foliage, long terminal clusters of creamy-white flowers resembling the Acacia. Very graceful tree. Give a deep rich soil in a sunny sheltered position. It is not hardy far north.

Polygonum multiflorum. A hardy vine with slender, woody, reddish stems in the form of numerous branches from the root, bearing loose clusters of fragrant white flowers. Give a rich loam and full sun, and mulch through a dry season. Root tuberous; protect in winter.

\section{SEPTEMBER}

\section{WHITE PERENNIALS}

ANEMone. Japanese (Anemone Japonica, var. Whirlwind). $2-4 \mathrm{ft}$. One of the best autumn plants. Large white flowers, yellow centers; handsome leaves, growing mostly in a clump at the base. Give a rich moist situation; excellent under trees in partial shade. Leave undisturbed and protect in winter. Propagate by seed and division. Also a pink variety, see Pink Per., Sept.

AsTer. White ( $A$. paniculatus?). $\quad 4^{-8} \mathrm{ft}$. A native Aster that makes an extraordinary growth under cultivation. It gradually increases at the root, throwing up several erect, leafy stalks, with thin, pointed, entire leaves. The top is much branched and bears flat clusters of white-rayed flowers with yellow centers. The blossoming top often measures more than two feet across. Planted with pink or red Hollyhocks, this Aster makes a magnificent show. Give a rich moist soil and full sun. Propagate by seed or division.

Aster. Perennial. $3-4 \mathrm{ft}$. I have been unable to identify the name of this charming variety, as it was sent to me from Massachusetts, where it is native. It makes a low branching shrubby growth, with 
siny awl-shaped leaves, and numerous snow-white flowers, borne all along the branching stems making compound panicles eighteen inches across. As it blooms until the heavy frosts and is a mass of feathery white flowers, it makes a valuable addition to the autumn garden. Give a rich moist situation. Propagate by division of root, which spreads extensively.

Boltonta (B. asteroides). $5^{-7} \mathrm{ft}$. A plant resembling the Aster, of erect, hardy growth, bearing numerous heads of white flowers with yellow centers. Also blue and pink varieties. Propagate by seed and division of the root. It spreads badly, but can be planted among shrubbery. It blooms until late frosts. See Blue and Pink Per. Sept.

Clematis. Japanese (C. paniculata). 6-20 ft. The most desirable of all vines, making a vigorous growth of glossy green foliage, and covered through the autumn with loose feathery clusters of fragrant white flowers. Needs a deep rich moist soil, sun and a mulch through the summer. Propagated by cuttings made of half-ripened wood cut up at every eye, or by scraping the bark a little and layering the branches. If well watered, in the course of a year the cuttings will root at the joint covered, which may then be severed and planted before the growth begins in the spring. This vine is infested by two species of large rapacious beetles in the early autumn. See MINE ENEMIES, p. 126-7. They should be scraped into a can of water with a little kerosene in it.

DaHLIA (D. variabilis). 3-6 ft. Many varieties of Cactus, Pompon and Peony-flowered in white. While not a hardy plant, Dahlias are a favorite with many, and are easily grown. They are raised from seed or by division of the root, which is a cluster of tubers; but care must be taken that each division has an eye or bud. These are not distributed over the surface as the eyes of a potato, but are in a ring around the collar of the root. In a dry state these are not perceptible, and nurserymen often plant the whole root in a hotbed to start the eyes and then divide it. The blind tubers (those without eyes), while plump and healthy looking, will not start a growth. These are sometimes grafted with a growing shoot of a choice variety, but it is a difficult process. Dahlias should be started in gentle heat and planted out after all danger of frost is over. Give a rich sandy loam, much sun and water. After blooming, or when frost bitten, cut down and, a little later, on a dry day, lift the tubers and dry in a shady airy place. Turn every day and shake off the earth from the root. Store in sand or sawdust in a dry cellar. 


\section{JUNE}

\section{WHITE ANNUALS}

Alyssum. Sweet (A. maritimum, var. Benthami). I ft. One of the earliest of annuals, blooming the entire season; is covered with spikes of small white fragrant flowers, and is much used as an edging. Thrives best in sandy or gravelly soil; is self-sowing and transplants easily. Cutting back the bloom prolongs the flowering season.

Callandrinia (C. Menziesii). 6 in. A low border plant resembling Portulaca; flowers $I$ in. across, opening only in the sunshine. Sow seed where the plants are to remain, for they are difficult to transplant. Give full sun, and a light sandy soil. Also red and yellow varieties. June and September.

CANDyturt (Iberis umbellata, var. odorata). I ft. A self-sowing annual, bearing long spikes of pure-white fragrant flowers. $I$., var. Empress, has a more branching habit, like a candelabrum, with still longer spikes. It thrives in any soil and bears transplanting well. June to October.

Cynoglossum, Navelwort (Omphaloides linifolia). 6-i2 in. A delicate plant with loose racemes of white flowers resembling Forget-menot. By alternating it with Forget-me-not as a border plant, the bloom of the latter may be repeated, as Cynoglossum blooms from June to August. Give any good soil and sun; self-sowing.

Eschscholtzia, California Poppy (E. Californica, var. alba $f$. pl.). I ft. A white variety of this showy plant; has finely-divided leaves and large flowers tinged with pink borne on long stems. Sow the seeds as soon as ripe, else the plants may not flower if sown in the spring.

GyPSOPHILA ELEGANS. I ft. A low plant bearing little cup-shaped flowers on delicately branching stems; is valuable as a dressing to other cut flowers; self-sowing and bears transplanting well. If seed-vessels are cut off it will bloom again in the autumn. Grows in any good soil or any location. June to October.

Nasturtium. Dwarf (Tropaolum minus, var. Pearl). I ft. The easiest of all annuals to cultivate, and the one most commonly grown by amateurs. It thrives best in common soil, for if too rich it is inclined to run to leaf. However, if one wants a solid mass of bloom, fertilize 
heavily and keep the leaves picked back and the result is amazing in the size and quantity of bloom. Do not let seed-vessels form. For other varieties see Red and Yellow An., June. Slightly self-sowing, June to October.

NeMopHILA ( $N$. maculata). I ft. A low prostrate plant bearing white wheel-shaped flowers with a violet patch on each petal. Good as an edging plant. Does best in moist soil and partial shade. Selfsowing, June to August. See Blue An., June.

Poppy. California, see Eschscholtzia.

Poppy. Shirley (Papaver Rhoas, var. Shirley). $3 \mathrm{ft}$. If the seed is fall-sown, the Shirley Poppy blooms in June; if sown as soon as the ground is mellow in the spring, it does not bloom until July. By observing this and by planting a second or third time in the Spring one can have a long succession of these lovely flowers, which range through every tone of pure white, white with pale pink margins, shell pink, rose pink, scarlet and deep red. They last but a day owing to the rough way the bees wallow among the stamens; but if cut very early in the morning, they will last three days in the house. Of all the flowers in the garden none is more satisfactory than the Poppy, and of all Poppies the Shirley is the finest. I have had single plants that bore from 20 to 30 blooms a day for ten weeks. They are difficult to transplant, though I have done it successfully by watering the plant well, taking up some earth about the roots, and making a deep cut hole with a small pointing trowel, then dropping in the root full length. Cover with a Neponset pot for three or four days, removing the pot at night, keeping the plant well watered. Each plant should have at least four to six inches of ground to itself, which is enough if the coarse lower leaves are kept picked off. Save only the first perfect seed-vessel, and cut off all others as they form. Self-sown seeds make the strongest as well as earliest plants. Give full sun and any good soil.

SChizapetalon (S. Walkeri). 9 in. A singular plant with almondscented white flowers with cut petals, borne in terminal leafy racemes. Transplant very carefully so as not to injure the long tap root; if possible sow where it is to remain. Give a sandy loam. June to September.

Sweet Sultan (Centaurea moschata, var. alba). I $\frac{1}{2} \mathrm{ft}$. A plant allied to Bachelor's Button, bearing sweet-scented white fringed flowers on long stems; grows in any soil. June to September. Also yellow and blue varieties. 


\section{JULY}

\section{WHITE ANNUALS}

Abronia, Sand Verbena (A. fragrans). 6 in. A low prostrate border plant, with large flat heads of fragrant flowers resembling the Verbena, opening at sunset. Give a dry sandy soil in warm situation. Remove the outside papery husk from the seed when planting, else it will not germinate properly. June to August.

Ageratum, Painter's Brush (A. Mexicanum, var. album). Dwarf and tall, 6 in. $2 \mathrm{ft}$. A self-sowing branching plant bearing many small clusters of close-fringed flowers. A very free bloomer; does well in any soil or situation. Also blue and pink varieties. July to October.

Agrostemma, Rose of Heaven (A. coli-rosa). A species of Lychnis, but this generic name, Agrostemma, is the one now most used). $\quad \mathbf{I}_{2}^{\frac{1}{2}} \mathrm{ft}$. In pink and white this plant makes a beautiful showing with its numerous flowers borne on long stems. It is a hardy annual and flourishes in any good soil. July to October.

Arctotis, African DaIsy (A. grandis). $2 \frac{1}{2} \mathrm{ft}$. A tall rather sprawling plant with very handsome rayed flowers having petals that are white above, lilac beneath, and a golden circle about a steel blue center. It has glaucus grayish leaves. It should be planted apart, as it overshadows smaller plants because of its branching habit. Give it a rich loam in warm sunny location. It has intermittent ways of closing up its petals. July to October.

Argemone, Prickly Poppy, Mexican Poppy (A. Mexicana, var. alba flora). $2 \mathrm{ft}$. An ornamental plant with large white flowers like a Poppy. The plant spreads widely and needs a good deal of room; has glaucus leaves and is very showy. July to September.

Aster. China (Callistephus Chinensis-many horticultural varieties). I-4 ft. This indispensable plant has been so developed that it does not resemble the old China Aster of our grandmother's day. There is scarcely any choice in the many varieties offered. Sow the seed as soon as the ground is warm, and transplant, giving a space of from 4-8 in. to each plant. They do best in a light rich soil with plenty of sun and water; but as the roots grow near the surface, they must be mulched if the weather is dry. The Aster has two serious pests; one, the aphis, attacks the root, and wood ashes are recommended as a remedy; the other is a jet black beetle about $\frac{3}{4}$ of an inch long that will strip 


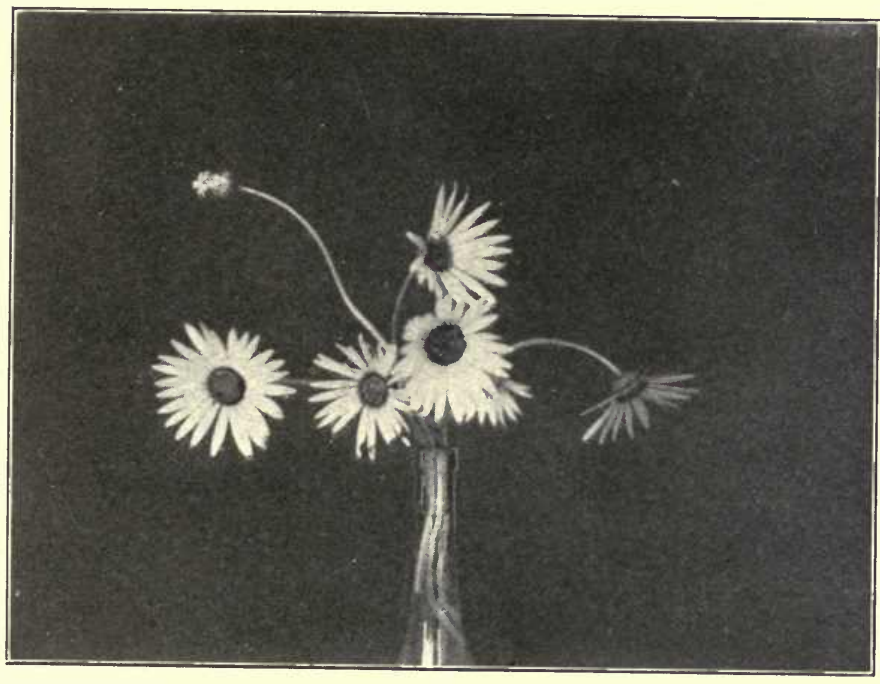

Arctotis, South African Daisy (Arctotis grandis) [P. 200]

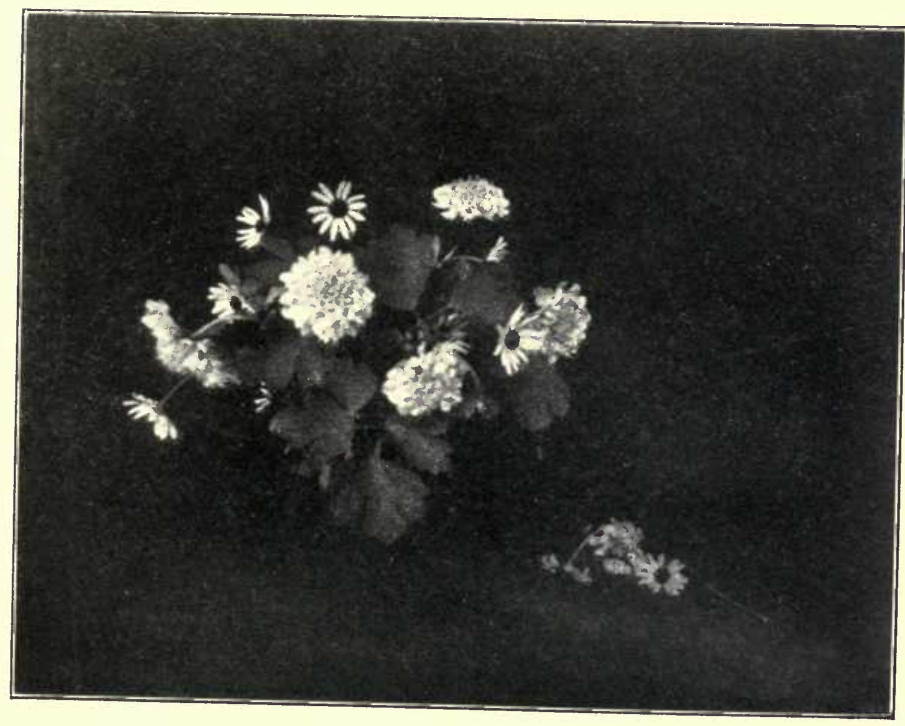

Sweet Scabious and Dog Fennel 
the petals to the center in a single night. Hand picking in the morning when the beetles are sluggish, and dropping them into a mixture of water and kerosene is the only sure way of getting rid of them. Look for this beetle also on the Michaelmas Daisy. As the Aster transplants easily, it is well to have a small bed of young plants to fill in any bare spaces made by cutting down early perennials. It comes in every color except yellow. July to October.

Balsam (Impatiens Balsamina, var. Perfection). I-I $\frac{1}{2} \mathrm{ft}$. A plant of leafy, bushy growth with many showy short-stemmed flowers. Its chief value is in furnishing amusement to children who love to snap the seed-vessels, which burst with a touch when ripe; hence its common name, Touch-me-not. Give plenty of room, sun and moisture. Careful growers never use seed until three years old. Other varieties in pink, red and purple. July to September.

Catchily, Sweet-William (Silene Armeria). I ft. The flowers resembling a Pink are borne in flat-topped clusters and open only in the sunshine. Give any good soil and full sun. Also a bright pink variety. July to September.

Centranthus, var. alba (?). I ft. A low branching plant with smooth glossy leaves and numerous terminal clusters of slender tubular fragrant white flowers; very hardy; blooming until heavy frosts. Give a moist loam and sun. Is self-sowing.

Clarkia (C. puchella). I ft. A graceful plant bearing several curving racemes of deeply lobed flowers that remain in bloom a long time. It is slightly self-sowing and does well in a moist, partly shaded location. Also a lilac variety. July to October.

Cleome, Spider Plant (C. pungens). $2 \mathrm{ft}$. A curious plant bearing large heads of white flowers with conspicuous orange stamens on long filaments, which give it its name, Spider Plant. It has a strong pungent unpleasant odor. It requires a rich light soil and full sun; selfsowing. July to October. Also a pink variety.

Corn-Flower, BAChelor's Button (Centaurea Cyanus, var. Margarite). $2 \mathrm{ft}$. A very beautiful variety of this common favorite, with large sweet-scented fringed flowers; thrives in any good soil and blooms for two months if the seed-vessels are picked off as they form. Also pink, lilac and deep blue varieties.

Cosmos, EarLy (C. bipinnatus, var. Early Hybrid). $3 \mathrm{ft}$. Unless one lives in a soutbern latitude, it is well to depend upon this early variety, which begins to bloom when only a few inches high and con- 
tinues until frost, if the seed-vessels are picked off as they form. The Anemone-shaped flowers are not so large nor the foliage so handsome as the tall varieties, but the latter are so frequently cut off by early frosts while still in bud that they are hardly worth trying except as a handsome feathery green background to other plants. Does well in moist rich soil and full sun; is self-sowing to a limited degree. Also a pure pink and a magenta red variety. July to October.

Datura (D. arborea, known also as D. Burgmansia). $3 \mathrm{ft}$. A tender perennial grown as an annual if started early in gentle heat. Has a coarse shrubby foliage with large trumpet-shaped fragrant white flowers from 6-I2 inches long. If housed through the winter it will make a new growth the following spring and will throw out great clusters of flowers as early as July. There are several other varieties to be treated as annuals, but not so handsome. Give a rich moist soil, and a warm sunny situation.

Dog-Fennel, Mayweed (Anthemis Cotula). $2 \mathrm{ft}$. This common weed is not native to my region, but under cultivation it makes an enormous growth and its finely divided leaves and numerous white rayed blossoms with golden centers are very effective among pink or red flowers. As a cut flower it is lovely with corn-flower and ferns. It is strongly scented, very branching and must not be allowed to seed itself too freely. July to October.

EUCHARIDIUM (E. concinnum, var. album). I ft. A low branching plant closely resembling Clarkia puchella, requiring the same culture.

ERITRICHIUM Nothofulvum. 6 in. A dainty sweet-scented hardy annual resembling the Forget-me-not. It requires a rich moist soil and partial shade. July to September.

Evening Primrose (Enothera acaulis). 6 in. A low annual form of Primrose with large silvery white flowers. It thrives in any good soil and is useful as a border plant.

Gaura, Butterfiy Flower (G. Lindheimeri). 2-4 ft. As an annual the Gaura grows from I-2 ft. high; as a perennial it reaches $4 \mathrm{ft}$. For description and culture see White Per., July.

Gillyflower, see Stock.

Godetia, Satin Flower (G. amana, var. Duchess of Albany). This species is often referred to Enothera. I-2 ft. One of our showiest and most beautiful annuals, bearing a profusion of large open flowers of satiny texture in many colors besides white. It makes a bushy growth if given space and rich soil when it runs to leaves; but in poor soil it 
produces the most brilliant colors, and is literally covered with bloom though the plant will be smaller and less vigorous. It transplants easily and is self-sowing to a degree. July to October.

ICE PLANT (Mesembryanthemum crystallinum). 4 in. A dwarf fleshy plant covered with glittering papulæ which make it look as if coated with ice crystals. Give a poor soil made of yellow loam, lime rubbish, sand and manure. Flowers open only on sunny days. Also rose-colored varieties. July to October.

LARKSPUR. Branching (Delphinium consolida). I ft. A branching form of Larkspur of great beauty. All Larkspurs should have the soil heavily enriched with manure; it should also be moist, in full sun. Sow seeds of annual Larkspur in autumn, as they are late in flowering if sown in spring. Self-sowing; also pink and blue varieties. July to October.

LARKSPUR. Rocket (Delphinium Ajacis). I ft. Another form of annual Larkspur with a dense spike of bloom. Also blue and pink varieties. For culture, see preceding paragraph.

LAVATERA ( $L$. trimestris alba). $3 \mathrm{ft}$. A tall bushy annual bearing large open funnel-shaped white flowers, delicately penciled with pink. It requires rich moist soil and sun. This is not so handsome as the pink variety, $L$. trimestris rosea, which is one of our most desirable pink annuals. July to October.

Lupine (L. mutabalis, var. Snow Queen). $3 \mathrm{ft}$. A tall smooth plant with palmate foliage, and many spikes of large fragrant pea-shaped flowers. Both the Lupine and Larkspur in annual forms are well worth growing and are good to fill spaces left after earlier flowers are cut back, particularly a pink var. (see Pink An., July) which blooms until heavy frost, but the seed should be sown where the plants are to remain as they do not transplant well. Give any good soil, full sun and moisture. July to the middle of October.

Malope ( $M$. trifida, cultivated at $M$. grandiflora). $3 \mathrm{ft}$. A very showy annual with open funnel-shaped flowers of beautiful gleaming texture both in white and pink, borne on slender stems. It begins to bloom when the plant is but a few inches high and continues blooming as the plant grows until killed by frost. July to October.

Mignonette (Reseda odorata, var. Parson's White). I ft. A plant of no beauty, but cultivated for the delicious odor of its greenish-white flowers. Sow in light sandy soil, as it loses its fragrance if grown in rich loam. It is better to sow the seed where the plants are to remain, as 
they do not transplant well. Two or three successive sowings will give bloom until frost; also the bloom is prolonged by free cutting. In dry seasons water thoroughly.

MOONFLOWER (Ipomea Bona-Nox; sold under various names). ${ }_{15} \mathrm{ft}$. A fragrant white variety of Morning-Glory opening at nightfall with enormous white fragrant flowers that open so rapidly that their unfolding can be seen. Curious, but of little value because the flowers are faded by early morning. Give good moist soil.

MORNING-GLORY (Ipomea purpurea, var. alba). 8-12 ft. A lovely variety of this favorite flower. It needs a rich moist soil and the seedvessels should be removed as fast as they are formed. If planted on the west or north side of a building where the morning sun cannot strike it until noon or later, the flowers will keep open until the sun reaches them. July to October.

NAsturtium (Tropaolum majus, var. Pearl). $6 \mathrm{ft}$. A tall running variety of Nasturtium which is very useful to cover walls, trellises and banks. For culture see Nasturtium. Dwarf, White An., June.

Nicotiana ( $N$. alata, known as $N$. affinis). $3 \mathrm{ft}$. A somewhat bushy plant bearing numerous white salver-shaped flowers with long tubes; deliciously fragrant at night. They open toward sunset and close through the day unless it is very dull weather. It requires a rich soil, partial shade, and moisture; and are propagated by seeds or offsets near the root. It is slightly self-sowing. For red variety, see Red. An. July to October.

Nigella, Fennel Flower, Love in a Mist, Ragged Lady, Jack in the Bush, Little Maiden in the Green ( $N$. Damascena, var. $a l b a)$. I ft. From the variety of names given this plant, it is evidently a favorite, with its notched petals fringed about with a feathery green involucre, succeeded by inflated seed-pods. It is particularly beautiful in a sky-blue variety. It grows in any good soil and is slightly selfsowing. For early flowering sow in autumn. July and August.

NyCTERINIA (Zaluzianskia selaginoides, sold as N. capensis). 6 in. A sweet-scented white flower, purplish-brown underneath, opening at twilight; not interesting save for its fragrance. July to September.

PANSy (Viola tricolor, many varieties in white as well as other colors). I ft. Sown in spring, as an annual, the Pansy blooms in July. For culture see White Per., April.

Petunia ( $P$. nyctaginiflora); in hybrid form, $P$. var. grandiflora, double and fringed. $2 \mathrm{ft}$. An old-fashioned favorite in the single 
form, but scarcely recognizable in the huge ruffled flowers of hybrids now produced. Of easy culture, thriving in common soil and responding wonderfully to any kindly attention. Keep seed-vessels from forming, cut back if inclined to grow long and weedy; self-sowing. As a winter house plant $I$ have seen the single fragrant white variety bearing forty blooms at a time. July to October. For pink variety see Pink An., August.

PHLox (P. Drummondii, var. grandiflora), also a fringed variety. $2 \mathrm{ft}$. This species of Phlox in the various colors is of great beauty, and planted in masses produces gorgeous effects. It thrives best in rich light soil and partial shade. It is self-sowing to a slight degree. Pinch back the plant if it grows tall and weedy. July to October.

PINK (Dianthus Heddewigii fl. pl., var. Double white). 18 in. If sown in spring this variety of Pink blooms late in July; if sown the year before, it blooms early in June as a biennial. For culture see White Per., June.

Poppy. Opium (Papaver somniferum in single and fringed varieties). 3-4 ft. A variety with long recurved glaucus leaves much notched, bearing at most from $4^{-6}$ large single blossoms; very beautiful but not so prolific nor so long in season as the Shirley. For culture see Poppy, White An., June. See Blue and Pink An., July.

Poppy. Shirley (Papaver Rhoeas, var. Shirley in single and semidouble varieties). $2 \mathrm{ft}$. If not sown until spring it blooms early in July. See White An., June.

Portulaca, Rose Moss ( $P$. grandiflora). 6 in. A low succulent plant bearing masses of single or double flowers in white, yellow and red. Opens in sunshine, and requires full sun, and a rather poor sandy soil. Do not sow seed until June. July to October.

RHodANtHE (Helipterum Manglesii, var. alba. Known also as $R$. maculata, var. alba). I $8 \mathrm{in} .-2 \mathrm{ft}$. An annual bearing everlasting flowers, which should be cut before fully expanded. If treated in the following manner it attains a marvelous size. Sow seed in April and transplant into tiny pots the first week of May. Shift to increasingly larger pots every two weeks, pinching off flower buds until the middle of August, by which time the plant will have attained a large bushy character, often four feet in circumference, bearing a thousand blossoms. The ordinary treatment is to sow the seed in April in rich light soil in a sunny location. Also a handsome pink variety. June to October. See Pink An., July. 
Schizanthus, Fringe Flower ( $S$. pinnatus, var. albus). I-2 ft. A very handsome branching plant bearing quantities of white, pale lilac and pink-fringed flowers with delicately spotted petals. Be careful in transplanting, as the roots are tender. Give a sheltered position, or tie plants to stakes, for they are brittle and easily broken in high winds. Give a light soil, not too much sun or moisture, as the young plants are liable to die unless conditions are favorable. It is slightly self-sowing with me. July to October. See Blue An., July.

SAPONARIA, SOAPWORT (S. calibrica, var. $a l b a$ ). I ft. A white variety of a dainty little bedding plant that literally covers the ground with its prostrate branches, bearing flowers that resemble Phlox sublata. Thrives in any good soil and full sun. Also a pink variety. July to October. See Pink An.

Schizapetalon (S. Walkeri). 9 in. An annual bearing sweetscented fringed white flowers that are curiously cut. Sow the seed where plants are to remain, as they have a long tap-root and do not transplant well. Give a deep rich soil, full sun. July to October.

SNAPDRAGON (Antirrhinum majus and minor, var. Queen of the North). I-2 ft. Snapdragon may be treated as an annual sown in early spring in the open ground when it will bloom late in July until frost. With protection it is also grown as a perennial. For culture see White Per., July.

Stock. Ten-Weeks, Gillyflower (Matthiola annua, var. Perpetual Perfection). I-2 ft. A much prized annual coming into bloom ten weeks after the seed is sown. The flowers are large, fragrant and borne on loose spikes in both single and double varieties. It comes in shades of pink, red, blue, lavender and purple. By sowing seed from February indoors and later in the open ground one can have Stock in bloom during the entire season. Give a rich, light soil, plenty of water and sun; is propagated also by cuttings. The name Gillyflower is a corruption of July-Flower as it usually blooms in July. See other an. lists, July.

Sweet Clover (Melilotus alba). $3 \mathrm{ft}$. A biennial cultivated as a bee plant, with sweet-scented foliage, and white pea-shaped flowers borne in loose racemes. Also a blue variety.

Sweet-Pea (Lathyrus odoratus, var. Dorothy Eckford). 4-8 ft. This well-known favorite, bearing loose clusters of deliciously sweet flowers, must be deeply rooted to endure the heat and drought of American summers. In sowing seed, dig a trench 6-8 in. deep, fill two inches with well-rotted manure, cover well with good loam, and 
plant seeds, covering them about half an inch. As the young shoots grow, pull in the earth from the sides of the trench until the peas have been rooted at least four inches deep. During the flowering season give plenty of water, and remove seed-vessels as fast as they form. For other varieties see other lists of annuals. July to October.

Whitlavia ( $W$. grandiflora, var. alba). More correctly known as Phacelia Whitlavia. I ft. A low free-blooming annual with clammy, coarsely-toothed foliage and loose racemes of bell-shaped flowers; also a purplish-blue variety. Give a good loam and full sun. July to October. See Blue An., June.

\section{AUGUST}

\section{WHITE ANNUALS}

Artemesia Annua, see Sweet-Fern.

Celosia (C. plumosa, var. spicata). $2 \frac{1}{2} \mathrm{ft}$. A very beautiful feathery variety of Cockscomb in which the lower part of the rose-pink spikes turn a silvery white. In order to increase the size of blooms sow early and transplant two or three times. Give a light soil and do not crowd, as it tends to a dwarf size if planted closely. July to October.

LEPTosipHon (Gilia androsea). I ft. A low California annual with narrowly-divided leaves, and open salver-shaped flowers in clustered heads. It endures cold better than heat, and should not have the hot sun; good as a border plant. Also yellow and lilac varieties. August to October.

Poppy. Peony (Papaver somniferum $f$. pl.). 4 ft. A double flowered variety resembling the peony, bearing heads often 5 in. across, that remain in bloom several days. This is a particularly handsome variety though it bears only from $4^{-8}$ blooms. It does not transplant well, and it is better to sow the seed thinly and thin out the plants. Autumn-sown seed make the strongest plants. Give full sun and rich, light soil. Self-sowing. August. See Blue and Pink An.

Scabious. Sweet (Scabiosa atropurpurea, var. White Pearl). $2 \mathrm{ft}$. A very beautiful variety of plant with large, handsome, flat heads of small flowers borne on long stems. The seed should be planted early. Fragrant. Give a rich soil and warm situation. It is also very beautiful in pure deep red, pale pink and lilac. August to October. See other An. lists for August. 
SweEt-FerN (Artemesia annua). 2-4 ft. A tall bushy plant with finely-divided fragrant leaves and flowers; the latter are like tiny balls of greenish color. Very pleasant as a dried herb to place among clothes. Self-sowing.

Verbena ( $V$. teucroides, var. candissima). I ft. A low, trailing plant that can be pegged down and made to cover quite an area with its fragrant flat heads of white flowers. If pruned it makes a thicker growth. It transplants easily and the whole species is excellent for house plants. Further south it is hardy with a little covering. It is easily propagated by cuttings, but blooms best from seed. Many other colors, see other An., lists for August. August to October.

Zinnia ( $Z$. elegans, var. cristata). Curled and crested varieties. $3 \mathrm{ft}$. A useful plant in the late autumn when other flowers are gone. Thrives in any good soil and sunny location. In choice varieties the Zinnia is effective, and it is only because of its solferino and magenta tones that it has fallen into disfavor in choice gardens. With selected colors it makes a fine display when the garden most needs it. August to October. See An. lists for August.

\section{SEPTEMBER}

\section{WHITE ANNUALS}

Cosmos (C. bipinnatus, var. Mammoth). 4-6 ft. A tall variety with an almost shrubby growth of feathery green foliage, but because of its late blooming in the north, it is seldom seen in perfection of bloom before it is killed by frosts. For its foliage alone, as a background to other plants, it is worth growing. The flowers resemble huge Japanese Anemones, and are borne in great profusion. I have known this plant when six feet high to be lifted carefully before the frosts, and placed in tubs and taken indoors, where it bloomed until Christmas. Give a rich, moist soil, a warm, sheltered position and moisture. For pink variety see Pink An., September.

Stevia ( $S$. serrata). $2 \mathrm{ft}$. This rather tender perennial is sometimes grown in the open as an annual, blooming in September until late frosts. It bears heads of small fragrant white flowers. Give a rich, sandy loam, propagate by seed and careful division of the root.

Vinca, Periwinkle (V. rosea, var. alba). $\mathrm{I}$ ft. A low border plant with handsome, almost evergreen, foliage and salver-shaped tubular 
flowers. To make it branch nip off the tips of the plant. Very attractive, but not quite hardy in the north. Give a rich moist soil. To propagate let the branches root at the joints by covering them with a little earth, and when rooted divide from the parent plant. Also pink and blue varieties. See Blue and Pink An., August. 


\title{
BLUE FLOWERS
}

\author{
APRIL \\ BLUE SHRUBS-None
}

\section{APRIL}

\section{BLUE PERENNIALS}

Crocus (C. vernis, var. Prince Albert). Blue, var. Sir John Franklin. Purple, var. Grand Lilas, Lilac. For culture, see Crocus, White Per., April.

Heart's-ease, Lady's Delight (Viola tricolor). 6 in. Probably the original of all modern Pansies. A friendly little plant, found blooming at the edge of melting snowbanks, and continuing in bloom all summer. While it makes a charming border plant, if newly set, it must be soon removed, for in rich ground it grows straggly and sows its seeds too widely for garden purposes. It thrives best in a poor dry gravelly soil and full sun. April to October.

Hyacinth (Hyacinthus orientalis). Many named varieties in all tones of clear blue, purple, violet and lilac. I ft. For culture, see Hyacinth, White Per., April.

Lungwort, Bluebelis, Virginian Cowslip (Mertensia Virginica). $2 \mathrm{ft}$. A very lovely plant with many stalks from the root bearing large yellowish-green leaves, and terminal drooping clusters of blue bellshaped flowers. Do not disturb, as it roots very deeply and does not divide well; but if done, it should be attended to in autumn; it may also be propagated by seed sown as soon as ripe. It is well to place a stake by this plant, for it dies away in summer, and is apt to be uprooted when digging over a bed. Give a rich moist sandy loam in full sun, but sheltered position.

Pansy (Viola tricolor, hybrid varieties in blue, purple and violet). I ft. For culture, see White Per., April. 
PASQUe Flower (Anemone pulsatilla). 6 in. One of the earliest spring flowers with finely divided leaves and handsome lilac or violet blossoms encircled with a fringe of bracts. It makes a tuft, and thrives best in a warm sheltered situation and dry calcareous soil. May be left in the ground several years without taking up.

Scilla, Squill or Wild Hyacinth (S. Sibirica). 8 in. Deep sky blue. This variety of Scilla is one of the rich blue flowers of the garden. It bears beautiful blossoms $\frac{3}{4}$ in. long, slightly drooping. It thrives best in sandy soil and partly shaded situation. Increased by offsets which should be removed and replanted in autumn when too thick: otherwise it should be undisturbed. For pink var., see Pink Per., April.

\section{MAY}

\section{BLUE SHRUBS}

Lilac. Common (Syringa vulgaris). 6-12 ft. The common variety. For culture, see Lilac, White Shrubs, May.

Lilac. Persian (Syringa Persica). Also many budded varieties in lavender, blue and lilac tones. For culture, see Lilac, White Shrubs, May.

\section{MAY}

\section{BLUE PERENNIALS}

Anchusa (A. Barrelieri). 3-4 ft. A coarse weedy plant bearing large racemed clusters of deep blue flowers resembling Forget-me-nots. It has great vitality, and once established it will sow its seeds all over the garden, besides increasing by suckers. Though beautiful in color and a free bloomer for many weeks, if cut back, it is only of value in the background or among shrubbery. Thrives in any soil and sunny location. Also an annual variety; see Blue Per. and An., July.

Aubretia ( $A$. deltoides, var. Eyrei). 4 in. A low branching edging plant bearing many clusters of violet-purple flowers resembling Verbena. Propagated by seed or layering the branches, by covering the joints with earth, when they will root freely; the plant may be divided after flowering. It grows in any good soil and is good for rock work.

Camass. Giant (Camassia cusicki). 3-4 ft. Bears long rather dense 
racemes of pale blue flowers numbering 30 to 40 to a stalk. It does best in a sheltered, partly shaded situation. Needs loam, leaf mold and sharp sand; also top-dress with manure each year. Let remain when once established; can be divided in autumn. Propagated by seeds or offsets removed when in a dormant condition.

Columbine (Aquilegia carulea). $3 \mathrm{ft}$. Sometimes called the Rocky Mountain Columbine, violet, blue and white $(A$. glandulosa). I $\mathrm{ft}$. Lavender and white.

Columbine (A. Olympica). $\mathrm{I}_{\frac{1}{2}} \mathrm{ft}$. White with delicate lavender spurs.

Columbine (A. vulgaris). I-3 ft. Purple and deep shining blue. In certain shades this last is particularly beautiful, as the color brings out a gleaming satiny texture. For culture, see Columbine, White Per., May. FORGET-ME-NOT (Myosotis alpestris, var. Victoria). I ft. A lovely sky-blue variety with golden yellow eye. Very hardy; self-sowing. Also pink and white varieties; see Pink and White Per., May.

FORGET-ME-NOT ( $M$. palustris grandiflora). I ft. Dark blue; not so hardy.

FORGET-ME-NOT ( $M$. palustris, var. semperflorens). Bright blue, not so hardy as $M$. alpestris, but blooms the first season from seed in July, and has a longer season of bloom when established as a perennial. For culture, see Forget-me-not, White Per., May.

Globe DAISy (Globularia tricosantha). $\frac{1}{2}-\mathrm{I}$ ft. A hardy plant with globe-shaped light-blue flowers. Leaves become blackish in autumn. Give a moist rich soil. Propagated by seeds or by cuttings.

Houstonia, Buuets (H. carulea). 6 in. A delicate little plant native to some portions of New England, bearing the daintiest of lightblue flowers with a yellow eye. Generally given as a perennial; Leavitt calls it a biennial. Requires rich moist soil, and is propagated by seeds. I transplanted a clump from Washington when in full flower and it bloomed for two months after.

Honesty, Satin Flower (Lunaria biennis). $2 \mathrm{ft}$. A biennial bearing pinkish-purple flowers in terminal racemes. Interesting for its large silvery flat seed-vessels. Thrives best in sandy soil. Propagated by seeds.

HyaciNTH. Grape (Muscari botryoides). 6 in. A variety with small deep-blue globular flowers; very pleasing when combined with Arabis albida. For culture, see Hyacinth, White Per., May.

IRIS. German (I. Germanica). 2-3 ft. A gorgeous variety in rich 
deep purple and also lavender. This form of Iris extends itself by running rootstocks on or near the top of the ground, and rots if it is covered too much or is in too moist a place. Give rich soil, full sun, a well-drained but moist situation. Propagated by division of the corms; do not break them too small, else it will take a year or more for them to get reëstablished enough to bloom. Divide early in autumn. Also white, pink and yellow varieties.

JACOB'S LADDER (Polemonium caruleum). I-2 ft. A desirable border plant with beautiful foliage and many terminal clusters of lavender blue flowers. Thrives in rich moist soil. It spreads so widely from the root that it is well to give most of your stock away each year, dividing a few strong plants and resetting them as an edging in the autumn.

PrLox. Creeping ( $P$. sublata atropurpurea). 6 in. A rosy purple variety of this charming border plant.

PHLox (P. sublata, var. G. F. Wilson). A light-blue variety. For culture, see $P$. sublata, White Per., May.

Phlox. Virginia $(P$. divaricata). Sometimes known as Wild Sweet-William. I ft. A taller light-blue fragrant variety growing more like Phlox Drummondii. Give rich soil, sun and moisture. Propagated by seeds and division of strong roots. Blooms about two months.

TuLIP (Tulipa, var. Eleonore). A violet variety with a white edge.

Tul.s ( $T$. var. Queen of the Violets). A rich violet variety; also another, T. Van der Mer. For culture, see Tulip, White Per., May.

Violer. English (Viola odorata, var. Princess of Wales). 4 in. Usually grown in hothouses for winter use, but can be grown in the open if given a good soil, partial shade and moisture, though I have also had strong plants that had sown themselves in a sunny exposed situation in dry yellow loam. It is self-sowing to a slight degree.

Wistaria. Chinese (W. Chinensis, var. Purple; sometimes called $W$. sinensis). 10-40 ft. A very beautiful but capricious vine with handsome smooth foliage and great clusters of pea-shaped blossoms during May and June, and bears in some places a smaller crop during August and September. It requires a dry sandy soil, yet it also requires watering during a dry season. It should be left severely alone when once planted, for it takes from three to eight years to feel enough at home to bloom. I have a vigorous specimen that has been planted six years, but shows no sign of flowering. As it branches freely, this variety may be trained to cover a wall or to follow under the eaves of a 
house or piazza, and the flower clusters allowed to droop, as is the Japanese custom; also very effective when allowed to climb trees, and run from one to another. Lovely when used thus over an entrance gateway; or twined about columns, if still in a young leafy state. Propagated by scraping a branch at a joint, covering it during the summer with soil, and separate the following spring. It can also be layered in a tub. The Wistaria is hard to transplant owing to deep roots and few fibers.

Wistaria ( $W$. Chinensis multijuga). Often passing under the name of sinensis, grows still longer clusters which are sometimes 3-4 ft. long. Not so vigorous of growth in this country as $W$. Chinensis. For culture, see preceding paragraph.

\section{JUNE}

\section{BLUE SHRUBS-None}

\section{JUNE}

\section{BLUE PERENNIALS}

Amsonta (A. Tabernamontana). $2-3 \mathrm{ft}$. A plant with smooth alternate leaves resembling the Olive; numerous pale-blue flowers borne in panicles, followed by soft hairy pods. Propagate by seed, division or cuttings. Sun, rich soil.

Bellflower, Campanula, many varieties in blue as follows:

C. persicifolia. $\mathrm{I}-2 \frac{1}{2} \mathrm{ft}$. with open bell-shaped corolla 2 in. long.

C. Carpatica. 6-1o in. high with erect bell-shaped flowers with corolla $\mathrm{I}$ in. long.

C. glomerata. $2 \mathrm{ft}$. Erect stems, bluish violet funnel-shaped flowers in dense terminal heads. Give a rich well-drained soil; propagate by seed and division of root. One of the best of Campanulas; also a white variety.

C. rapunculoides. A vigorous variety with many erect stalks of deep-blue flowers, coming late in June. For culture, see $C$. White Per., June.

C. turbinata. A dwarf variety also with erect flowers. For culture see Bellflower, White Per., June.

Blue-Eyed GRASS (Sisyrinchium angustifolium). I ft. A pretty native plant, narrow erect leaves, and deep-blue wheel-shaped flowers; makes a good clump under cultivation. 
Commeina (C. coelestis). I ft. A half hardy perennial, blooming the first season from seed in August, bearing deep-blue flowers that last but a day. It is not very satisfactory, save for its glorious blue color. The roots are small tubers, and can be kept over winter like Dahlias and planted out in the spring. Give a rich soil and partial shade. If in a sheltered position and roots are heavily mulched, they will stand the winter. I have carried mine over.

Galega, Goat's RuE (G. officinalis). $3 \mathrm{ft}$. A blue variety. For description and culture, see Galega, White Per., June.

Hesperis, DAME Rocket ( $H$. matronalis). $3 \mathrm{ft}$. A purplish-lilac variety; for culture, see Hesperis, White Per., June.

IRIS. Spanish (I.xiphium). 2 ft. Comes in blue, white and yellow; later than German Iris. For culture, see I. Spanish, White Per., June.

IRIS. English (I. xiphoides). $2 \mathrm{ft}$. In a rich reddish purple. For culture, see I. English, White Per., June.

IRIs. Siberian (I. Siberica). $2 \mathrm{ft}$. One of the best varieties when well established; bears light-blue flowers in great profusion. Culture the same as for other Iris.

KNAPWEED. Mountain (Centaurea nigra, var. montana; sold as Centaurea montana or Per. Corn-flower). $3 \mathrm{ft}$. A coarse weedy plant with large heads, but the ray flowers, though of a rich deep blue are thin and wizened, which makes the bloom of little value. Grows anywhere and is self-sowing.

LUPINE (Lupinus polyphyllus). $3 \mathrm{ft}$. A magnificent variety of perennial Lupine in deep blue, purple and a dull tone of blue, which bears from ro-20 great spikes of pea-shaped blossoms, followed by silvery woolly seed-pods. It blooms a second time if the spikes are cut down as soon as they are done blooming. For culture, see Lupine, White Per., June.

MEAdow Beauty (Rhexia Virginica). 9-12 in. Showy rosy purple flowers with golden anthers. Good in bog or wet place. Propagate by seed or division.

Peony (Paonia officinalis, var. Bayard). Clear violet; $P$. var. Arsene Meuret, lilac with violet border; $P$. var. Cameron, purple violet. For culture, see Peony, White Per., June.

Pentstemon ( $P$. ovatus). 2-4 ft. An early-flowered variety, blooming in autumn of the first year if seeds are planted by May. It bears open panicles of blue or purple flowers, and needs rich loam with manure, leaf mold and sand; should be watered if the season is dry, but 
it cannot bear wet and frost in winter. Cover during winter with ashes and mulch. Propagated by seeds, cuttings and division of root.

Rhexia Virginica, see Meadow Beauty.

Rocker. Sweet (Hesperis matronalis). A lilac variety, see White Per., June.

Scabiosa Caucasica. I ft. A desirable plant bearing flower heads of pale blue, 3 in. across. I find it somewhat difficult to raise this plant from seed and it is not always hardy. It should be well mulched.

S. CAUCASICA, var. perfecta. A superior variety with larger heads than the preceding variety. Culture the same; give a rich soil, sun and moisture, but not wet ground.

Verbascum, Moth Mullein (V. Blattaria, var. Phøiceum). $2 \mathrm{ft}$. A modest plant making a flat rosette of leaves from which rise branching racemes of flowers in a reddish purple, lilac pink and white I in. across. Pretty, rather than showy. Increased by seeds and division of the plant. Give any good soil.

\section{JULY}

\section{BLUE SHRUBS}

BURNING BUSH, WAAHOO (Euonymous atropurpureus). 6- $44 \mathrm{ft}$ Flowers in fours of dark purple; leaves bright green; fruit becomes a brilliant scarlet and covers the bush in autumn.

Indigo. False (Amorpha fruticosa). 6-8 ft. A stocky bush sending up numerous shoots. Flowers small, deep indigo blue or purple, borne in clustered spikes, two or three in a bunch at the ends of the branches, thus covering the bush with bloom. Give a sunny sheltered position and any good soil. Propagate by layering suckers or cuttings. See Lead Plant (Amorpha canescens), Blue Shrubs, Aug.

Smoke Tree, Venetian Sumach (Rhus cotinus). 5-9 ft. A very ornamental shrub that turns a beautiful color in the autumn. The light purple flowers are insignificant, but after blossoming the flower stems lengthen, bearing long plumy hairs which make a reddish feathery mist over the whole bush, and are mistaken for bloom. Foliage in autumn is a warm rosy crimson. It thrives in a dry situation, with good rich loam and is propagated by layering. Give plenty of room. 


\section{JULY}

\section{BLUE PERENNIALS}

Aconte. Wild, Climbing Monkshood (Aconitum unciatum). 3-5 ft. A pale blue variety with a slender weak stem inclined to climb. Flowers borne in loose panicles. Give a rich moist soil, sun and a support. Propagated by division of the root. With me this variety does not bloom until early September because the tips are eaten off, probably by grasshoppers, just as they are beginning to bud, but continues until hard frosts.

Acontte (A. Storkianum). 3-4 ft. A rich blue variety.

ADENOPHORA POTANINI. $2 \mathrm{ft}$. A plant bearing slender spikes of light-blue bell-shaped flowers resembling Campanula. Give a rich, light soil in a sunny dry situation. Do not disturb when established. Plant seeds as soon as ripe, or divide the roots. July and August.

AnchUSA ItALICA var. Dropmore. 3-4 ft. A rich gentian blue variety with prolonged bloom. Propagated by seed. See $A$. Blue Per. May.

Baptisia, False Indigo (B. australis). $3 \mathrm{ft}$. A vigorous plant bearing racemes of large purplish-blue pea-shaped flowers; rather a shy bloomer. Grows in any good soil; give sun; divide the root to increase the stock.

Bellflower. Japanese, see Platycodon.

Calimeris. Cut-leaved (Calimeris incisa also known as Aster in cisa). I-2 ft. An early variety of pale purple aster-like flower; bloom of long duration. Rich soil, sun. Propagate by seed or division.

Canterbury Bell (Campanula medium). 2 ft. Both double and single varieties in deep blue, pink and white. For culture see Canterbury Bell, White Per., July.

Catananche, Blue Succory (C. carulea). $2 \mathrm{ft}$. A slender plant bearing pale-blue daisy-shaped solitary flowers, 2 in. across, on long stems. It grows best in poor gravelly soil; also a white variety. Propagate by seeds.

Catananche (C. bicolor). A blue and white variety of the above, quoted by some as a perennial, others call it a biennial; culture the same as above.

Clematis (C. Jackmanni). A hybrid derived from C. languidosa of China and C. viticella from Europe. 4-ro ft. A desirable climber bearing large, handsome deep-blue, pale-blue or white flowers. Though 
it is killed to the ground by frost, it makes a vigorous new growth each year if the roots are mulched in winter. Give a rich light soil, and plenty of water during the blooming season. It is effective to train over a lattice or by the side of a piazza. Propagate by cuttings of young wood or by seeds. For culture see Clematis, White Per., July.

Clematis ( $C$. heracleafolia, var. Davidiana; closely allied to $C$. tubulosa). 3-4 ft. An herbaceous plant with erect stem almost woody, bearing pale-blue nodding flowers resembling hyacinths, with orangeblossom fragrance, large leaves; needs a support. Culture the same as for other varieties.

Clematis ( $C$. integrifolia). $2 \mathrm{ft}$. An earlier herbaceous species forming an erect bush; large single drooping blue flowers are borne at the ends of leafy stalks. Give rich, deep soil and sun. Propagate by seed and cuttings.

Dracocephalum, Dragon's Head (D. Ruyschianum). 2 ft. Bears dark violet-lipped flowers, I in. long, in whorls on erect stems. Requires a cool situation, moist and partly shaded; propagated by division of root and seeds, or by cuttings taken in May.

Eupatorium COElestinum. I-2 ft. A blue variety, bearing small flat heads of light-blue flowers. For culture see Eupatorium, White Per., July.

FAlse INDigo, see Baptisia australis; also Amorpha fruticosa, Blue Shrubs, July.

Gentian. Closed (Gentiana Andrewsii). 2 ft. A plant bearing large closed dark purplish-blue flowers. The reticence of this flower offends me, much as a too silent person embarrasses one. Grows natively in moist, shaded places.

Gentian. Fringed (Gentiana crinata). $2 \mathrm{ft}$. A plant bearing erect bell-shaped fringed flowers of a wonderful blue color. It is a biennial, requiring moist, sandy soil, most difficult to raise from seed, and given to strange disappearances even in its native haunts. I am still trying to raise it after futile efforts for several years. It is recommended to sow seed in large pots in which smaller pots, corked at the bottom and filled with water, are placed. This insures an even moisture without direct spraying. Where it is native the young seedlings may be transplanted for the second year of bloom. The seed is said to come up in about a week under favorable conditions, and when the plant has reached the third pair of leaves it is ready to be transplanted in a cool, shady location. 
Harebell, Blue Bells of Scotland (Campanula rotundifolia). 2 ft. A truly lovable plant with small, narrow leaves, slender branching stems and deep blue bell-shaped flowers. Its true name is "air-bell," whether because of its tender blue, or because of its elastic stem, that rises again when trodden upon, is not known. Does well in a rich, moist soil and partly shaded location. Spreads from the root.

HEDGE-Netrle, see Stachys lantana.

IRIS. Japanese (I. lavigata or I. Kampferi). $2 \mathrm{ft}$. Many named rarieties in deep, rich blue, lavender, violet, purple, white and yellow. For culture see I. Jap., White Per., July.

LARKSPUR. Bee (Delphinium elatum). 3-6 ft. A tall variety with deep-blue flowers and yellowish beard, borne in straight racemes, slightly branching; leaves 5-7 cleft with wedge-shaped lobes; spurs curved.

LARKSPUR. Great-Flowered, Chinese Larkspur (Delphinium grandiflorum). Known also as D. Chinense and D. sinense. I-2 ft. Deepblue flowers, $I_{2} \frac{1}{2}$ in. across, on spreading racemes; leaves palmately parted with many linear lobes; also a double-flowered variety.

LARKSPUR. Showy (Delphinium formosum, a hybrid form of $D$. cheilanthum). 2-3 ft. A deep-blue variety shaded with indigo; leaves alternate, downy, or grayish-green.

LARKSPUR ( $D$. formosum, var. celestina). 3-6 ft. A lovely azure-blue form of $D$. formosum with yellow-bearded throat, leaves lobed and notched, but not cleft.

If when done blooming, the stalks are cut down, and dressing applied at the roots, the plant will bloom in autumn. Divide every three years. For further culture of all the above varieties see Larkspur, White Per., July.

LAVENDER (Lavendula vera). $2 \mathrm{ft}$. A deliciously-scented herb bearing spikes of small bluish flowers. Requires a dry, calcareous soil and open situation. Propagated by seeds and cuttings taken in autumn. This plant is not hardy with me.

Liatris, Blazing Star (L. pycnostachya). 3-4 ft. A very showy plant bearing numerous dense cylindrical spikes of rosy purple-fringed flowers, springing from a low tuft of narrow leaves. Propagated by division of root or seeds sown in autumn or spring. Does well in a dry soil where few other plants will live.

Linaria, Alpine SNapdragon (L. alpina), 6 in. Forms dense tufts of whorled leaves and bears bluish-violet flowers with a yellow throat. Does well in stiff, poor soil, and a sunny, exposed situation. 
Obedient Plant (Physostegia Virginiana). $3 \mathrm{ft}$. A very beautiful plant with glossy, thick leaves, square stem and long, branching racemes of rosy lilac flowers. Also a variety ( $P$. imbricata or $P$. speciosa) that grows $5 \mathrm{ft}$. high is of even greater beauty and vigor; has larger flowers and broader leaves. The White variety is one of the most effective of all garden flowers; does well in full sun if soil is rich and moist. See Obedient Plant, White Per., July.

Pentstemon, Beard-tongue (P. acuminatus). $2 \mathrm{ft}$. Bears a long, pointed raceme of lilac or pale-violet flowers. Suffers in a damp location, particularly from the wet and cold of winter.

Pentstemon ( $P$. grandiflorus). 2-3 ft. The finest of all Pentstemons, bearing showy purple flowers. For culture see Pentstemon, Blue Per., June.

Physostegia, see Obedient Plant.

Platycodon, Wahlenbergia, Chinese Bellflower ( $P$. grandiflorum). $2 \mathrm{ft}$. A variety of Campanula bearing very large, showy blue flowers either solitary or but few at the top of branches. For culture see Platycodon, White Per., July.

Platycodon, var. Maresi. Shorter variety with even larger flowers; also a light-blue dwarf variety, P. Maresi, var. nana. For culture see paragraph above.

Periwinkle (Vinca minor, var. carulea). I ft. Many horticultural varieties, and sometimes erroneously called Myrtle. A trailing plant with shining leaves and sky-blue flowers $I$ in. across. As the flowers are borne on the new stock, nip the branches to make a bushy growth. Propagated by layering, when roots will be thrown out at the joints, and can be separated from the parent stock. "To make it seed the plant must be grown in a pot, and all lateral branches cut off. Requires loose, rich soil and moisture. Does well in shaded places. Sometimes treated as an annual, blooming in August.

SEA Holly (Eryngium amethystinum). $3 \mathrm{ft}$. Bears dense heads of amethyst-blue flowers on blue stalks; deeply cut, spiny foliage. Should be given a very sandy soil and sun. As it spreads badly from seeds, the seed-vessels should not be allowed to form. Propagated also by division.

Sea Lavender (Statice Limonium; also known as S. latifolia). $2 \mathrm{ft}$. The blue flowers are borne in a cloud on large, spreading panicles. It makes a deep root and needs space as it is killed out if crowded. Thrives in a deep, moist, sandy loam and leaf mold in a sunny situation; but 
the plant suffers in a dry exposed place. Propagated by division of the root and seeds in spring.

SPEeDwell, VeronicA (Veronica spicata). 2-4 ft. A vigorous plant bearing numerous tapering spikes of small, bright blue flowers. While it is thrifty and handsome and excellent for cutting it is also a nuisance, for a seedling will establish itself in a few years so completely that one cannot uproot it without tearing up a large area; and it sows itself all over the garden. It needs no attention; any garden soil is sufficient.

Stachys, Hedge Netrle (S. lantana). $\mathrm{I}-\mathrm{I} \frac{1}{2} \mathrm{ft}$. Bears purplestriped flowers in whorls, the upper ones forming almost a spike of bloom; forms a low tuft of leaves, thick, soft and covered with silverywhite wool, as is also the stem. Give a light, rich soil; propagate by seeds, cuttings or division of the root.

Stokesia or Stokes' Aster (S. cyanea, known also as S. Cartesia). $2 \mathrm{ft}$. An erect, branching perennial bearing solitary terminal flowers of lavender blue, often $4^{-5}$ in. across. Give a rich soil, mixed with sand, sunny location; propagate by seeds or division of the root. Protect in winter.

Veronica, see Speedwell, also Blue Per. Aug.

\section{AUGUST}

\section{BLUE SHRUBS}

BuddLeya Lindleyana. $3^{-6} \mathrm{ft}$. Bears terminal racemes of reddishpurple flowers. Authorities say do not prune, as it reduces the number and size of flowers; but mine dies to the ground every winter, and makes a new three-foot growth each year, blooming late in August. It grows in any good soil in a sunny sheltered position and is propagated by cuttings. When not killed back, it blooms in June or July. Several other varieties I have not tried.

Chaste Tree (Vitex agnus-castus). $3^{-6} \mathrm{ft}$. Flowers a bright blue or lilac, rising above a small, neat bush; foliage grayish beneath; gives off an aromatic fragrance. Some varieties are not hardy. Give a heavy mulch, cutting back the plant nearly to the ground, and the shoots that start vigorously in the spring from the base yield finer flowers than they would otherwise. This blue, variety is claimed to be more hardy than others; recently introduced from China.

Lead Plant (Amorpha canescens). I-3 ft A shrub with deep 
purple flowers in clustered terminal spikes several inches long. Foliage and stems whitish or lead-colored. Give a sheltered sunny position and deep rich soil; late in August.

SPIREA. Blue (Caryopteris mastacanthus). Shrub bearing conical spikes of lavender-blue flowers resembling blue larkspur. Can be cut down like an herbaceous herb and mulched over winter without injuring the next season's flowers. August and September. Flourishes by the seacoast. Plant with Sorbaria sorbifolia.

\section{AUGUST}

\section{BLUE PERENNIALS}

DAy Lily. Blue (Funkia ovata, var. carulea). 2 ft. A variety bearing light lilac-blue funnel-shaped flowers, not so large as $F$. subcordata, nor is it fragrant. For culture see Day Lily, White Per., August.

FLeabane (Erigeron glaucus). $\frac{1}{2}-\mathrm{Ift}$. A plant with pale foliage in a tuft, bearing large solitary terminal flowers, purple in color, resembling the China aster. In some places this variety is not quite hardy, and should either be lifted and placed in a cold frame, or covered deep with ashes. Propagate by seed or division; partial shade, any soil.

Lobelia. Great (Lobelia syphilitica). $2 \mathrm{ft}$. A hardy variety of Lobelia, bearing large pale-blue tubular flowers both axillary and terminal, forming a long raceme. It requires rich, moist soil and moisture; propagated by seeds and cuttings. My experience is that it is most difficult to raise from seed, and probably requires special conditions, as I have tried vainly for three years to get seedlings.

Pewox. Perennial ( $P$. paniculata, often called $P$. decussata, var. A.A.McKimmon). 3-4 ft. A purplish-lilac variety.

PHLOX ( $P$. paniculata, var. Eugene Danzanvilliers). A light-blue variety.

PHLox (P. paniculata, var. Le Mahdi). A steel-blue variety of great beauty.

For general culture of the above varieties see Phlox, White Per., August.

VERONICA. Long-leaved ( $V$. longifolia subsessilis). $2 \mathrm{ft}$. A bright blue variety of long bloom, especially recommended; see Speedwell, Blue Per., July. 


\section{SEPTEMBER}

\section{BLUE SHRUBS}

DesModium PENDULIFLORUM, see Lespedeza Sieboldi.

LESPEDEZA SIEBoldi (or Desmodium penduliforum). 3-6 ft. Shrub with long pendulous branches covered with long racemes of pink or rosy-purple flowers continuing until frost. Plant in a sheltered situation, and give protection in winter; also cut back almost to the ground, and the roots will be uninjured, and vigorous shoots will be thrown up in the spring. Thrives in any good soil.

\section{SEPTEMBER}

\section{BLUE PERENNIALS}

Aster, Michaelmas Daisy (A. tradescanti). $4 \mathrm{ft}$. A very beautiful free-flowering variety with branching clusters of rayed amethyst flowers, the petals often forming a thick double row about a golden center. It spreads badly at the root, and must be continually divided and reset. It is also liable to mildew, for which, see remedy for mildew, p. I3I. The Michaelmas Daisy comes in many named varieties, and is one of our most valued late flowers. Do not plant in very conspicuous places for it is only a green bush until autumn. Thrives in any good soil and any location. Is sometimes infested during the blooming season with a small black beetle that must be scraped off into kerosene.

Aster (A. Alpinus speciosus). $2 \mathrm{ft}$. Another species sometimes called Michaelmas Daisy, with large purple flowers blooming occasionally as early as June.

Aster (A. Nova-Anglice). $4 \mathrm{ft}$. A rosy-purple variety.

Aster (A. grandiflorus). $3 \mathrm{ft}$. A violet-purple variety.

Aster (A. Nova-Belgii). $3 \mathrm{ft}$. Mauve with golden center. All the above varieties require the same culture.

Boltonia (B. latisquima). 4-6 ft. A clear lavender-blue variety with flowers in large terminal panicles. Also a white and a pink variety. For culture, see Boltonia, White Per., September.

Liatris ( $L$. spicata). I-2 ft. A smaller and less showy variety than L. pycnostachya with rosy lilac flowers in spikes from 6-15 in. long; 
blooms several weeks later than the other variety. For culture, see Liatris, Blue Per., July.

Leadwort, Plumbago (Ceratostigma plumbaginoides-trade name Plumbago Larpente). I ft. A half-shrubby perennial with zigzag stem and close terminal heads of deep blue flowers changing to violet. It requires a light rich soil and is propagated by seed or division of root. Give a warm sheltered situation, and mulch in winter.

\section{JUNE}

\section{BLUE ANNUALS}

Asperula ( $A$. azurea setosa). I ft. A tender perennial treated as an annual, bearing terminal clusters of small tubular lavender-blue flowers. It thrives in any good soil and is self-sowing. June to September.

BACHELOR's Button, CORN-Flower (Centaurea cyanus, var. Emperor William). ${ }^{2-3} \mathrm{ft}$. Bears deep-blue flowers in the greatest profusion if the seed-vessels are picked off as they form; self-sowing. Autumn-sown seed produce the strongest plants and bloom in June, while spring-sown seed come a month later. For culture, see Bachelor's Button, White An., July.

CLARKIA (C. puchella). I ft. A low-growing variety bearing single deeply-lobed lilac flowers of great beauty; also a semi-double variety, and one in pink; self-sowing. Autumn-sown seed bloom in June; springsown seed in July. Allow from 6-9 in. to each plant. Give a rich moist soil. June to September.

Convolvulus. Dwarf (C. tricolor, also called $C$. minor). I ft. A dwarf variety with ascending branching stems and large showy flowers with rich blue corolla and white throat and yellow tube. Closely resembles Nolana. Opens only in sunshine. Culture the same as Morning-Glory.

Cynoglossum (Omphaloides linifolia, var. ceelestina, commonly called C. colestinum). I ft. A sky-blue variety bearing flowers that resemble Forget-me-nots. See Cynoglossum, White An., June.

Eutoca (E. viscida, known also as Phacelia viscida). 8 in. A rather coarse variety of Phacelia, clammy all over, bearing terminal racemes of deep-blue flowers less than an inch across, similar in flower but not so handsome as Phacelia. For culture, see Phacelia, White An., June. 
Fragrant Evening Stock (Matthiola odoratissima, erroneously called $M$. bicornis). I ft. A curious plant with stems much branched and inconspicuous leaves and deliciously fragrant flowers of a lilacwhite opening at sunset, but closed tightly during the day. It should be in every garden for the sake of its rich perfume, but should not be given a prominent place because through the day it is an awkward looking plant, apparently all stem. It grows in any good soil and is self-sowing. June to October.

MORNING-GLORY (Ipomea purpurea). 6-I2 ft. A variety with rich deep purple or blue flowers. For culture, see Morning-Glory, White An., June.

MORNING-GloRy. Japanese (Ipomea Imperialis). In a great variety of colors, white, pink, blue, purple, some fringed, others margined with another color. A much more tender variety than the preceding, but far more beautiful. Seeds are slow to germinate and it is well to file one side to hasten them, care being taken, however, not to injure the germ. Should have a rich soil and very sheltered situation, as it is hurt by early frost.

NEMOPHILA ( $N$. insignis). Sometimes endearingly called Baby Blue Eyes. 8 in. A variety with lovely sky-blue flowers with white center. Self-sowing. Give a moist rich soil, partial shade. White variety, see White An., June.

Nolana ( $N$. atriplicifolia). I $\frac{1}{2} \mathrm{ft}$. A rather fleshy-leaved plant, trailing and spreading, with handsome sky-blue wheel-shaped flowers 2 in. across with yellow centers and white throat. Closely resembles Convolvulus minor, and like it, opens only in sunshine. Sow seed in April or early May.

Peacelia ( $P$. campanularia). I ft. A pure deep-blue variety with open wheel-shaped corolla an inch across, borne on one-sided curving terminal clusters. Thrives in any good soil and partial shade; a most desirable plant. June to September.

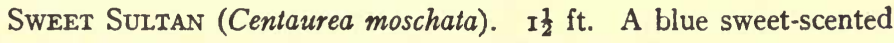
variety. For culture, see Sweet Sultan, White An., June.

Whitlavia (Phacelia Whitlavia; also known as Whitlavia grandiflora). I ft. Resembles $P$. viscida in foliage and growth, but bears small bell-shaped flowers with violet blue corolla and white bell throat; self-sowing. For culture, see Whitlavia, White An., June to October. 


\section{JULY}

\section{BLUE ANNUALS}

Ageratum (A. conyzoides, known as A. Mexicanum). I- $\mathrm{I} \frac{1}{2} \mathrm{ft}$. Many named varieties in light and dark blue. A very useful plant for cutting, blooming continuously until frost. Self sowing. For culture, see Ageratum, White An., July.

ANCHUSA ( $A$. capensis). I $1 \frac{1}{2} \mathrm{ft}$. An annual variety resembling the perennial forms, bearing scattering azure-blue flowers all summer. Not of much value, however. It is a biennial if protected in winter. Give a good soil and sun. July to September.

Aster (Callistephus). In many named varieties of light and deep blue, lavender and purple. For culture, see Aster, White An., July.

Bean, Hyacinth, Egyptian Bean (Dolichos lablab). io ft. A smooth twiner with long racemes of showy violet, purple or white flowers an inch long. Give a sandy loam and sun.

Candytuft (Iberis umbellata). I ft. A lilac purple variety of Candytuft. For culture, see C., White An., July.

Collinsia (C. bicolor). I ft. A stout plant with handsome lipped flowers of blue and white. Give a rich light loam and sun.

Grur (G. achillecefolia). $2 \mathrm{ft}$. A plant with ornamental cut foliage and clusters of deep-blue flowers on long stems. It is useful as it is one of the earliest flowers to bloom and does not die away and leave spaces as so many annuals do. Sow seeds in either autumn or spring in any good soil. Self-sowing. June to September.

Giria (G. capitata). 2 ft. Bears dense round heads of steel-blue flowers; foliage consists of almost thread-like divisions; very attractive flower for cutting.

Grila (G. tricolor). I ft. Is a free bloomer used as a border with smaller flowers; has a light purple margin, a deeper purple band inside, separating the margin from the canary-colored throat. Culture the same for all.

FORGET-ME-NOT (Myosostis sempervirens). 8 in. A perennial variety blooming the first season from seed so that it can be used as an annual; sky-blue in color. For culture, see Forget-me-not, White Per., May.

Linaria, Toadflax ( $L$. maroccana). I ft. A plucky little annual blooming continuously from June until late frosts if cut freely; self- 
sowing; bears an enormous number of long racemes covered with rosypurple spurred flowers. Thrives in full sun in stiff poor soil.

LUPINE (Lupinus affinis). An annual variety with deep-blue flowers. Sow seed where the plants are to grow as they do not transplant very well.

LUPINE (L. nanus). A bluish-purple variety.

Lupine (L. mutabilis). $2 \mathrm{ft}$. A sweet-scented violet-purple variety. Give a rich light soil, full sun and water.

Martynia, Unicorn Plant (M. fragrans). $3 \mathrm{ft}$. A coarse shrubby plant with large foliage and vanilla-scented violet-purple or mauve tubular flowers with beautiful yellow lyre-shaped markings in the throat. Grows in any good soil. Seed-vessels used for pickling.

Nasturtium. Tall (Tropaolum majus, var. regelianum). A violetpurple variety of this common favorite.

Nasturtium (T. Lobbianum, var. Lacombe Mercier). A purplishviolet variety of Lobb's Nasturtium which is considered the best species for rich coloring. For culture, see Nasturtium, White An., July.

Nigella, Fennel Flower ( $N$. Damascena). I ft. A sky-blue variety of this charming annual. Autumn-sown seed make the strongest plants. Make successive sowings in the spring to get flowers throughout the summer; does not transplant well; thrives in almost any situation in any good soil. For culture see Nigella, White An., July.

PANSy (Viola tricolor). Many hybrid varieties in rich tones of lavender, purple, violet and blue; blooms as an annual in six to eight weeks from seed, and continues as a perennial the second year. For culture see Pansy, White Per., April.

Petunia (P. violacea, var. Ruffled Giants). 2 ft. A purple-violet variety with enormous flowers with ruffled margins; also many hybrid varieties, both single and double, and fringed. See Petunia, White An., July.

Phlox ( $P$. Drummondii, var. grandiflora). Many named varieties in lavender and violet shades. For culture see Phlox, White An., July.

Poppy. Opium (Papaver somniferum). $3 \mathrm{ft}$. A single variety that comes in rich purple, lavender and a soft grayish-lavender with exquisite pale green stamens.

Poppy. Pæony (P. somniferum, var. paoniaflorum). $3 \mathrm{ft}$. Comes in clear tones of pinkish-lilac and purple; a magnificent plant to grow at the edge of a vegetable garden where there is plenty of room, and makes no gap when done blooming. Bloom lasts two weeks. For culture see Poppy, White An., June. 
Schizanthus (S. pinnatus, var. lilac). I ft. A lilac variety with violet spots. Sow in April in rich soil. For culture see Schizanthus, White An., June.

Stock, Gillyflower (Matthiola annua). I-2 ft. Many hybrid varieties in dark and light and purple. For culture see Stock, White An., July.

Sweet Clover (Melilotus carula). $2 \mathrm{ft}$. A sky-blue variety with fragrant flowers. See Sweet Clover, White An., July.

Sweer-Pea (Lathyrus odoratus). 4-6 ft. Many hybrid varieties in all shades of blue, violet and lavender. See Sweet-Pea, White An., July.

Venus' Looking-Glass (Specularia speculum). I ft. An annual variety of Campanula of curious beauty, with deep-blue flowers having silvery veining that gives a strange metallic effect; stems branch, and the branches bear three-flowered clusters. Grows in any good soil with sun and moisture. July to October.

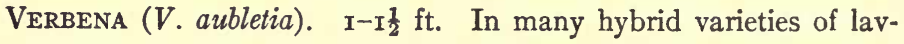
ender, purple and blue; for culture see Verbena, White An., July.

VISCARIA. Blue-Eyed (Lychnis oculata, var. carulea, a form of $L$. cali-rosa or Agrostemma, as it is known commonly). I ft. A bluishlavender variety; see Agrostemma, White An., July.

\section{AUGUST}

\section{BLUE ANNUALS}

ANAgalis (A. carulea, var. grandiflora). I ft. A low plant of spreading habit bearing a succession of intense blue wheel-shaped flowers an inch across. Give rich moist soil and partial shade; opens only in the sun.

Browallia (B. demissa, var. speciosa major [B. elata]). $2 \mathrm{ft}$. An erect plant with almost woody stems, bearing bright-blue flowers that somewhat resemble the violet. Give a rich soil and liquid manure when the buds appear. It should be picked back to promote a bushy growth. It is particularly desirable for a winter house plant, and should be taken up early in September before frost.

Commelina ( $C$. erecta). I I $\frac{1}{2} \mathrm{ft}$. Can be treated as an annual, but blooms better if grown as a tender perennial; bears flowers of a very lovely blue. For culture see Commelina, Blue Per., June. 
Commelina (C. colestis). A half-hardy perennial variety, which should be covered with ashes or sand and heavily mulched in winter. Culture the same as above.

LARKSPUR (Delphinium consolida). I-2 ft. A deep-blue branching variety in both tall and dwarf forms.

LARKSPUR. Rocket (Delphinium Ajacis). 2 ft. A deep-blue variety with flowers borne in close racemes. For culture of both varieties see Larkspur, White An., August.

LOBELIA (L. erinus, grown under many trade names). 3 in.-I ft. A dainty little plant used largely for edgings, baskets or vases, with lipped flowers ranging from dark to very light blue, mostly with a white throat. It requires rich moist soil.

ROCKET, see Larkspur.

SALVIA (S. patens). $2 \mathrm{ft}$. One of the best blue flowers grown; a tender perennial blooming the first year from seed, with a showy deepblue corolla over two inches long. Like all Salvias $S$. patens should have rich light soil, sun and much moisture.

Salvia (S. farinacea). $2 \mathrm{ft}$. A light-blue variety with hoary white leaves, spikes and calyxes. For culture see preceding paragraph.

Scabious, Mourning BRIDE (Scabiosa atropurpurea, var. grandiflora). I-3 ft. Both tall and dwarf varieties in deep purple, lavender and light blue. One of our most beautiful annuals in any color. See Scabious, White An., August.

Vinca, Periwinkie (Vinca minor carulea). A blue variety, that in sheltered places North may be treated as a perennial. As an annual it blooms in August, as a perennial it flowers in June or early July. See Periwinkle. Blue Per., July.

ZinNia (Z. elegans, var. cristata). 2-3 ft. Grows in purple, lilac and violet tones; see Zinnia, White An., August. 


\title{
YELLOW FLOWERS
}

\author{
APRIL \\ YELLOW SHRUBS-None in my climate
}

\section{APRIL}

\section{YELLOW PERENNIALS}

Crocus. Cloth of Gold (C. susianus). The earliest yellow variety. Crocus. Dutch (C. masiacus-C. aureus). A later variety. For culture see Crocus, White Per., April.

Pansy (Viola tricolor). Hybrid variety Golden Sun. For culture see Pansy, White Per., April.

\section{MAY}

\section{YELLOW SHRUBS}

Forsythia. Golden Bell ( $F$. viridissima). $3 \mathrm{ft}$. An erect vigorous shrub with bright yellow solitary drooping flowers distributed along the branches so as almost to cover the bush.

Forsythia. We ping, Golden Bell ( $F$. suspensa, known also as $F$. Fortuni). An earlier variety than the former, with long drooping slender branches, and is often treated as a climber; is less common. Give both varieties deep rich soil, and prune severely just after flowering to secure new growth, as flowers are borne on previous year's wood. If pruned in autumn or early spring the flowering wood is lost. This variety may be kept to a single stem and then allowed to spread over a trellis or trained over a doorway. Increased by layering the branches and division of the root. The drooping branches root easily at the tip if buried in earth.

Bush Honeysuckle (Diervilla sessilifolia). $5^{-8} \mathrm{ft}$. Of strong bushy growth, foliage rather downy of grayish green; many inconspicuous flowers of a pale yellow resembling the honeysuckle, but not fragrant. Thrives in any soil; throws up suckers. 


\section{MAY}

\section{YELLOW PERENNIALS}

ADonss. Spring (A. vernalis). 6-ז2 in. Bears large showy yellow flowers, leaves finely divided. Needs a rich moist soil well drained; can be propagated by seeds or division of root.

Alyssum. Rock (A. saxtile, var. compacta). 6- $\mathbf{I 2}$ in. An excellent border plant making a close spreading growth with its woolly leaves, and bears many clusters of fragrant bright yellow flowers. It thrives best in a sandy gravelly soil, as a wet soil is not adapted to it; yet if too dry the roots wither. It is well to renew every three or four years; propagated by seed, division of the root and cuttings.

Aquilegia, see Columbine.

Coldmbine. Golden-spurred (Aquilegia chrysantha). $3 \mathrm{ft}$. Bright yellow variety, stems many flowered; one of the best.

Columbine. Wild or Rock (Aquilegia Canadensis). $\quad \mathrm{I}-\mathrm{I} \frac{1}{2} \mathrm{ft}$. Yellow and scarlet; foliage tinted with red. Thrives in its native haunts among rocks and on ledges.

Columbine (A. Californica hybrida). 3-4 ft. Flowers yellow or orange-yellow with long slender orange spurs, leaves bluish green, stems red. A hybrid variety of $A$. formosa; one of the most beautiful kinds.

Columbine (A. Jaetschui). $3 \mathrm{ft}$. A very choice variety with yellow flowers and old rose spurs; handsome glaucus leaves.

For general culture of the above varieties see Columbine, White Per., May.

DAFFodIL, see Narcissus.

ERysimum, Hedge Mustard (E. puchellum). I ft. Makes a very compact growth, and from the dense tuft of foliage rise many-flowered terminal racemes of yellow blossoms. Thrives in a sandy loam; propagated by seed or division of the root.

Hyacintr (Hyacinthus orientalis). I ft. Single varieties-Ida and King of the Yellows. Double varieties-Goethe and Jaune Suprême. For culture, see Hyacinth, White Per., May.

ICEland Poppy (Papaver nudicaule). I ft. Single and double varieties in bright yellow. See Iceland P., White Per., May.

IRIs. German (Iris Germanica, var. flavescens). A creamy yellow variety-also other named varieties-see Iris, Ger., White and Blue Per., May. 
JoNQuil (Narcissus Jonquilla, var. Rugulosus and N. var. Campernelle). $\mathrm{I}_{\frac{1}{2}} \mathrm{ft}$. A bright yellow; fragrant; crown shallow and saucershaped; 2-6 flowers on a scape. For culture, see Narcissus, White Per., May.

NARcissus, Daffodil (N. pseudo-narcissus, var. Golden Spur and Princeps). Flowers solitary, sulphur-yellow with deep trumpet-shaped crowns. For culture, see $N$. poeticus, White Per., May.

Poppy. Alpine (Papaver alpinum). 6 in. Is practically the same as Iceland Poppy (P. nudicaule) only dwarfer in form. It is generally yellow, but there are also white and pink varieties. See Pink Per., May. Culture the same.

Poppy. Iceland, see Iceland Poppy.

TulIP (Tulipa - many hybrid varieties).

Early single-Goldfinch, Chrysolora and Mon Trésor.

Early double-Crown of Gold.

Late double-Yellow Rose.

TulIP. Parrot (Tulipa Dracontia, var. lutea major). For general culture, see Tulip, White Per., May.

\section{JUNE}

\section{YELLOW SHRUBS}

BARBERry. Common (Berberis vulgaris). 3-6 ft. Bright yellow flowers followed by tart red berries that are used for jelly. When favorably planted in full sun it spreads extensively.

BARBERRY. Japanese (Berberis Thunbergii). 3-6 ft. A low spreading bush with yellow flowers often tinged with red; berries a bright red, and in autumn the foliage becomes a glowing scarlet, orange or bronze, thrives in any good soil, and in the sun.

BARBERRy. Purple-leaved (Berberis vulgaris, var. atropurpurea). 4-6 ft. Flowers inconspicuous, foliage a rich purple; give full sun and rather dry soil.

Broom. Scotch (Cytisus scoparius). 3-5 ft. A shrub barely hardy in the North, with solitary showy yellow flowers in the axils of the leaves. Propagated by division and cuttings. Requires a gravelly soil and a warm sheltered position.

Broom. Dyer's Greenwood (Genista tinctoria). I-2 ft. A half shrubby species, flowering in spring and autumn; blossoms yellow in 
close racemes; the whole plant-particularly the flowers-yield a fine yellow dye. Requires a poor gravelly soil.

Rose. Austrian Brier ( $R$. Eglanteria). 2-4 ft. Resembles the SweetBrier in its prickly stem and small leaves; flowers clear yellow semidouble, not very large.

Rose. Golden Sun (R. Eglanteria, var. Soleil d'Or). A new French variety of rich golden yellow shaded with orange. Very choice.

Rose. Persian Yellow (Rosa Eglanteria, var. lutea). 3-5 ft. A very hardy variety with handsome double bright yellow flowers in clusters and very small leaves; vigorous in growth, and hardy.

Rose. Scotch (Rosa spinosissima). I-2 ft. A low very prickly variety with small smooth green leaves, single or semi-double small early flowers; very hardy. For white var., see White Per., June.

RosE. Wichuriana (Rosa Wichuriana, var. Gardenia). A variety of trailing Rose very useful for covering trellises, walls or banks, bearing deliciously-scented flowers 3 in. across that are yellow in the bud, but turn a cream color when open.

Rose. Yellow Rambler. A hybrid variety, vigorous and freeblooming; flowers double, yellow and fragrant, borne in great clusters; very hardy.

For culture of the above varieties, see Rose, White Per., June.

\section{JUNE}

\section{YELLOW PERENNIALS}

AsphodeL. Yellow (Asphodeline lutea, known commonly as Asphodelus luteus). $2-3 \mathrm{ft}$. Bears yellow fragrant flowers in spikes $\mathrm{I} f$. long, leaves grass-like attached to the flower-stalk. Requires a deep sandy loam and is easily propagated by suckers which it makes freely, or by seed.

BEDSTRAw. Lady's (Galium verum). I-3 ft. A spreading variety bearing tiny yellow flowers that resemble goldenrod; foliage finely cut and feathery. Propagate by division of root and seed; any soil and sunny location. A wild variety that repays cultivation. June to September. See white varieties, White Per., July.

Bittersweet (Celastrus scandens). 8-20 ft. A smooth climber bearing yellow flowers in terminal racemes in late June or early July, followed by handsome orange-red three-cornered berries. Propagated 
by layering the branches or cuttings of young wood in early autumn. Give a rich soil and full sun.

Buttercup, Bulbous, Cuckoo Buds, Gold Cup (Ranunculus bulbosus). $2 \mathrm{ft}$. A plant native to New England that thrives well under cultivation; bears very showy bright yellow flowers; needs a rich moist soil.

Buttercup. Tall (Ranunculus acris $p l . f_{\text {. }}$ ). $2-3 \mathrm{ft}$. A cultivated garden variety bearing golden yellow balls or buttons on long branching stems. Give sun and moist soil.

Calliopsis, see Coreopsis.

CoReopsis, TICKWEed (C. lanceolata, var. grandiflora). $2-3 \mathrm{ft}$. Forms a broad low tuft of leaves and stems that branch from the base; usually one-flowered; heads yellow with rayed petals are from $2-3$ in. across. Propagated by seed or division of root in autumn or spring. Give sun and any good soil.

DAy Lily. Yellow (Hemerocallis flava). $3 \mathrm{ft}$. One of our most desirable lilies bearing clusters of $3^{-8}$ pale golden yellow funnel-shaped flowers of delicious fragrance. It spreads freely from the root and is propagated by division. Give a sunny location with deep rich soil, but no manure must come in contact with the roots. Water freely through the blooming season.

Doronicum Caucasicum, see Leopard's Bane.

FLAX. Golden (Linum flavum). I ft. Bears transparent golden yellow flowers numerously produced in branched heads. Give a welldrained sandy loam in a warm sheltered position. Propagated by seeds, sometimes by division of root in spring.

Globe-Flower (Trollius Asiaticus pl. fl.). I ft. Very handsome dark yellow flowers from $\mathrm{I}-\mathrm{I} \frac{1}{2}$ in. across; plant very compact and manyflowered. Requires a heavy moist soil; propagated by seeds which do not germinate until the second year; or by division of root in September.

Helianthemum, see Sun Rose.

IRIS. German (I. Germanica, var. aurea and $I$. flavescens), 2-3 ft. Yellow varieties of this most desirable plant. For culture, see Iris, White Per., June.

IrIs. Spanish (I. Xiphium, var. Bella Chinoise). $2 \mathrm{ft} . \quad$ A variety of extraordinary beauty which looks like an orchid of clear mandarin yellow with long strap-shaped petals bearing heart-shaped appendages at the tips. Leaves slender, disappearing when the bulb is ripe. $\mathrm{Di}$ - 
vide often, give sheltered position. For culture, see I. Spanish, White Per., June.

LEOPARD's BANE (Doronicum Caucasicum). I ft. A showy plant with dark yellow flowers 3 in. across; root leaves heart-shaped; thrives in any common soil. Propagated by seed or division of the root.

LILY. Flava, see Day Lily, Yellow.

LinUm, see Flax. Golden.

LUPINE (Lupinus polyphyllus aureus). $3 \mathrm{ft}$. A yellow variety of this delightful plant; for culture, see Lupine, White Per., June.

MUllein. Italian, see Verbascum pannosum.

Penny (Paonia officinalis, var. Golden Harvest; also Candidissima). For culture, see Peony, White Per., June.

Potentilla $(P$. recta $) .2 \mathrm{ft}$. Hybrid varieties both single and double in yellow; for culture, see P. White Per., June.

Ranunculus (R. Asiaticus, double hybrid, var. Merveilleuse). Erect plant with stems branching at the base; bears large double flowers on long stems. It should have moist rich loam and shade during the heat of the day. Plant 2 in. deep in November, and give protection. When the plant flowers, the leaves wither and the roots should be taken up, dried in the shade and kept in a dry place until wanted for replanting. They grow easily from seed, also by offsets. Full sun makes a deficiency both in size and color. If left in the ground mulch through the summer. The Turban variety is coarser but hardier than the Persian.

Rocket. Yellow, or Wintercress (Barbarea vulgaris). $2 \mathrm{ft}$. I am not sure of this identification of a plant, found in Maryland and transplanted to my garden, where it flourished amazingly and bloomed for a month or more. Long glaucus leaves resemble the poppy, surmounted by a leafy stalk which bears a large branching terminal cluster of bright golden yellow flowers, almost an inch across, followed by slender upright pods enclosing little oval seeds. The flowers are showy enough to merit a place among shrubbery.

Sun Rose (Helianthemum alpestre). 6 in. A yellow variety of this hardy evergreen plant which bears numerous racemes of flowers opening only in the sun. It makes a bushy growth, but seedlings are slow to get established. Give a rich moist soil and sun. Propagated by seed. Needs a little protection in the winter.

Thermopsis ( $T$. Caroliniana). $3^{-6} \mathrm{ft}$. An erect herb with handsome smooth yellow-green foliage and many terminal spikes of bright yellow pea-shaped flowers. Give a rich deep well-drained soil. It is 
difficult to preserve; for when the root is divided, the plant often dies. Raise from spring or autumn-sown seed when possible; or divide only strong roots. A very striking plant when well grown; needs staking because the stems are brittle.

Verbascum, Mullein ( $V$. nigrum). $2 \mathrm{ft}$. A cultivated form with woolly stems and leaves woolly beneath, flowers yellow borne on a long simply-branched stem; will bloom a second time if cut down, early.

VERBASCUM ( $V$. pannosum). A hybrid variety with curious white foliage. See Mullein, Italian.

\section{JULY}

\section{YELLOW SHRUBS}

Oleaster (Elcagnus longipes, E. edulis). 3-5 ft. A shrub with slender branches covered with brown scales. In Japan it attains a height of $25 \mathrm{ft}$. Leaves green above, silvery beneath; flowers yellow and inconspicuous; fruit bright red covered with white dots, very abundant and showy as well as of agreeable flavor, some people prefer it to current or gooseberry; used in France for preserving.

Oleaster (Elcagnus umbellatus). Sometimes confounded with $E$. longipes, has foliage of a silvery cast, smaller amber fruit, which is acid at first, but becomes sweet and mellow, ripening in November, when other berries are gone. This variety is good as a foliage shrub, and further south the fruit would probably ripen.

Oleaster (E. parvifolius, Silver Tree or Silver Thorn). 8-12 ft. $E$. Canadensis is even more silvery white in foliage, and the flowers are fragrant, fruit dry and mealy, but considered desirable. Throws up many suckers.

HoNEYSUCKLE. Sweet-scented (Lonicera Periclymenum, also known as L. Belgica). 6-12 ft. A smooth climber with woody stems, bearing clusters of fragrant light buff flowers. Give a rich moist soil and sun. Propagated by layering or cuttings or division of the root.

Honeysuckle. Japanese (Lonicera Japonica. Known also as $L$. Halliana). Another variety fragrant at nightfall.

Kerria, Japanese Rose, Jew's Mallow ( $K$. Japonica, var. pl. $f$. .). $4^{-8 \mathrm{ft}}$. Said to be a hardy shrub, though mine dies almost to the ground every winter. Has slender branching bright green stems and leaves, and solitary flowers along the stems. The single flowered variety is more 
graceful and is nearly always in flower. Give a good rich soil. Propagate by division, cuttings or layering.

Sr. JoHN's-WorT (Hypericum calycinum). I-3 ft. A rapidly spreading low shrub with dark glossy leaves, large yellow flowers 3 in. across, and showy reddish stamens. Used as a carpet under trees in England. Prefers a sandy loam. Give sun or partial shade; protect in winter. Propagate by division of the root or cuttings.

ST. JoHN's-WorT ( $H$. densiflorum). 4-6 ft. A very branching variety with small conspicuous flowers, less than an inch across, in compound cymes; adapts itself to sandy barren soil, though it prefers better conditions.

ST. JoHN's-Wort (H. Moserianum). 2-3 ft. A recent introduction with slender branching and drooping stems, free flowering, though the blooms do not open at the same time; blossoms 2 in. across, of golden yellow, and brilliant reddish stamens. Blooms the entire season. Give a sheltered sunny position as it is not always hardy in New England. One of the best varieties.

ST. JoHN's-Wort ( $H$. prolificum). 4-6 ft. Shrub with widely spreading head, branches light red, flowers large and showy in terminal clusters.

\section{JULY}

\section{YELLOW PERENNIALS}

Asclepias, see Butterfly Weed.

Black-Eyed Susan, Cone Flower (Rudbeckia hirta). 2-3 ft. A branching variety of the native yellow Daisy with flat or broadly conical purplish-brown disk and brilliant yellow or orange rays. Under cultivation it makes a gorgeous showing in rich soil and full sun. It is excellent in dry situations. Do not let it go to seed.

BLANKET FLOWER, see Gaillardia.

Butterfly Weed (Asclepias tuberosa). I-2 ft. A very showy plant with bright orange flowers in umbels scattered along terminal stems that branch divergently at the top. Give a dry sandy soil and sunny situation. Disturb as little as possible; increase by division.

Chamomile (Anthemis tinctoria, var. Kelwayii). $\mathrm{I}_{2}^{\frac{1}{2}} \mathrm{ft}$. A bushy plant with a long season of bloom; has bright yellow rayed heads as large as the Ox-Eye Daisy; a tubular disk and much-divided leaves. Give any good soil and propagate by division or seed, and full sun. 
Clematis. Heavy scented (C. orientalis, known also as $C$. gravolens). A variety with yellow flowers $I \frac{1}{2}$ in. across. For culture, see C. White Per., July.

ERIGonum umbellatum. $3^{-I 2}$ in. A very showy plant bearing flatheads or cymes of light yellow flowers from 6-ro in. across; joints of stem downy. Thrives in rich light soil; increased by seed and division of root.

Evening Primrose (Enothera biennis, var. grandiflora). 4-5 ft. A biennial variety opening its large creamy yellow flowers at dusk in a striking manner, but the bloom fades by morning.

Evening Primrose (O. Missouriensis). 6 in. A variety with prostrate stems flowers opening just before sunset.

Evening Primrose (O. fruticosa, var. splendens [Sundrops]). $2 \mathrm{ft}$. Bears clusters of golden yellow terminal flowers which open only in bright sunshine, plant turns a rich red in autumn. For culture, see Evening Primrose, White Per., July.

Gaillardia, Blanket Flower ( $G$. aristata, known also as $G$. grandiflora). $3 \mathrm{ft}$. A very handsome perennial bearing showy yellowrayed flowers on long stems which cover the plant and remain long in bloom; requires a rich moist soil; propagate by seeds and division of the root.

Golden Glow (Rudbeckia laciniata pl. $f$ l.). 4-6 ft. A very beautiful variety recently introduced into the East and now commonly grown everywhere. Bears many loose terminal clusters of large golden yellow flowers resembling Dahlias. To keep the growth low pick back the tips when the plants are about a foot high; or the plant may be cut down when done blooming to get a second flowering. Grows in any soil, but thrives best in rich moist ground; increases rapidly by division of the root.

Goldenrod (Solidago juncea). $3 \mathrm{ft}$. One of the most beautiful varieties of this native genus, bearing dense racemes of small goldenyellow flowers that increase in size and become great plumy panicles. Thrives wonderfully under cultivation. Propagate by seed or suckers.

Hunnemannia. Tulip Poppy ( $H$. fumaricfolia). $2 \mathrm{ft}$. An erect perennial resembling Eschscholtzia with large single terminal yellow flowers. It is said to be only half hardy in some places and it is well to give it protection in winter. Sow seeds in Autumn or early spring. Give a moist rich soil. It blooms from July to October.

HyPERICUM, see St. John's-Wort. 
IrIs. Japanese (I. lavigata, also known as I. Kampferi, var. Samidare and Bandai-nonami). Two yellow varieties of this choice plant. For culture, see Iris, Jap., White Per., July.

LARKSPUR (Delphinium Zalil). $2 \mathrm{ft}$. A yellow variety with branching stem, dark green finely divided leaves, and large pale sulphuryellow flowers borne in long racemes on the branches from 8-16 in. long. For culture, see Larkspur, White Per., July.

LILy. Batemanii (Lilium fulgens). $3 \mathrm{ft}$. A species with reddish apricot flowers. It should be surrounded by white flowers, for its color strikes a false note with most colors in the garden. For culture, see Lily, White Per., July.

RuDBECKIA, see Black-Eyed Susan.

St. JoHn's-Wort. Common (Hypericum perforatum). I-2 ft. Makes a low spreading tuft of leafy stems, from which rise upright stems bearing leafy cymes of large golden-yellow flowers. Spreads by runners. Grows in poor soil and full sun; but is greatly improved if cultivated. Blooms a second time, if cut back. For shrubby var. see Yellow Shrubs, July and August.

ST. JoHN's-Wort. Golden (Hypericum aureum). $2 \mathrm{ft}$. A showy perennial with bright orange yellow flowers 2 in. across in loose terminal clusters.

ST. JoHN's-Wort. Great (Hypericum Ascryon). 2-5 ft. A strong woody herb with showy flowers, but smaller than the first named variety. St. John's-Wort was supposed to drive away evil spirits, and on this account was planted near dwelling houses. Thrives in any soil or situation, but prefers moisture and shade; does well when planted under the drip of trees. Propagate by seeds and division of the root. For other varieties see Yellow Shrubs, July and August.

Salvia, Flowering Sage (S. argentea). $2 \mathrm{ft}$. Has silvery white foliage, yellow flowers, and is of prostrate growth. All Salvias should have rich moist soil.

SNAPDRAGON (Antirrhinum majus, var. Golden Queen). A fine yellow dwarf variety. I ft. (A. var. Yellow) of the tall variety. $2 \frac{1}{2} \mathrm{ft}$. A tender perennial, but hardy with me when mulched. For culture see Snapdragon, White Per., July.

Sunflower. False, Pitcher's OX-eye (Heliopsis levis, var. Pitcheriana). 3-4 ft. A bushy plant, spreading $3 \mathrm{ft}$. Golden yellow cupshaped flowers 2 in. across. Give any good soil and sun. Propagate by seed and division. Blooms three months. 


\section{AUGUST}

\section{YELLOW SHRUBS}

ST. JoHs's-WorT. Shrubby (Hypericum patulum). 2 ft. A creeping, shrubby variety, excellent for covering bare spots; flowers bright yellow with a long season of bloom, from August to frost. Give a deep rich soil. For other varieties see $S$. Yellow Shrubs, July.

\section{AUGUST}

\section{YELLOW PERENNIALS}

Canna. Many hybrid varieties in yellow resulting from the crossing of $C$. Ehemanni and $C$. glauca, both tall and dwarf; also dark-leaved varieties. French Cannas are of compact dwarf growth; the Italian grow from $5^{-6} \mathrm{ft}$., and are good for tropical effects. For culture see Canna, White Per., August.

DAHLIA ( $D$. variabilis). Many hybrid varieties in yellow in single and double forms; also others known as Cactus and Pompon varieties. Further south it blooms in August, but with me it comes early in September. Culture given under Dahlia, White Per., September.

Gladiolus (G. Lemoinei, hybridized from G. purpurea-auratus in yellow varieties). $3 \mathrm{ft}$. For culture see Gladiolus, White Per., August.

HeLen Flower, SNEEZEweEd (Helenium autumnale superbum). 2-5 ft. One of our most beautiful autumn bloomers, with large terminal clusters of bright yellow rayed flowers, petals drooping, with a tufted yellow center. This plant is inclined to grow too tall, but by pinching off the tips when about a foot high, it makes a branching top and bears a greater abundance of flowers, though the bloom is a trifle later. It thrives in any good soil, and spreads rapidly from the root. The best results come from resetting in the spring. There are other varieties, but this is the best. August to October.

Helianthus, see Sunflower.

HollyHock (Althea rosea, var. Yellow). 3-8 ft. A clear soft yellow variety of this old favorite. For culture see Hollyhock, White Per., August.

Montbretia (Tritonia Potsii, var. grandiflora). 2-3 ft. An interesting bulbous plant bearing spikes of lily-shaped flowers, an inch across, 


\section{Yellow Flowers}

in pure yellow, yellow and orange, and yellow and red. Authorities say it should be lifted each autumn and replanted in the spring; but mine are hardy if planted in a warm sheltered position and well mulched. Give a well-drained soil in a sunny location, also moisture. There is a pink variety. See Pink Per., August.

Sunflower (Helianthus decapetalus multiflorus). $3^{-6} \mathrm{ft}$. A very choice variety of hardy Sunflower, bearing close heads of rayed yellow flowers resembling the Dahlia, in groups of three on branching terminal stems.

SUnflower ( $H$. latiflorus). 4-6 ft. Resembles the yellow Daisy in its flower, and comes just after it in time of blooming, but is taller and much handsomer. Spreads badly at the root.

SUNFLOWER ( $H$. mollis grandiflorus). A cultivated form of $H$. mollis with soft, woolly, whitish leaves and many small yellow-rayed flowers; must have a moist soil as it suffers from drought.

SUNFLOWER. Slender or Graceful (Helianthus orgyalis). 6-ro ft. A very tall, slender variety, not branching, with drooping lily-shaped leaves, surmounted by clusters of pale yellow flowers. If nipped when young, the plant will not grow so high, and it will induce a branching growth. Excellent to plant among tall shrubs. Give a rich loam, moisture and full sun.

For general culture give a rich soil, full sun and water during the blooming season. Keep seed-vessels picked off to promote bloom. Propagate by seed and division of the root which spreads freely.

TANSY (Tanacetum vulgare, var. crispum). $4 \mathrm{ft}$. A handsome variety with cut leaves, bearing many flat heads of pale yellow flowers. Any good soil is suitable; increased by division of the root.

\section{SEPTEMBER}

\section{YELLOW PERENNIALS}

ARTichoke. Jerusalem (Helianthus tuberosa). 5-6 ft. Usually grown for its root as a vegetable, but also can be used as a green background for lower plants. Bears flowers resembling the yellow Daisy. It spreads rapidly in all directions from the root and should not be planted where it cannot be controlled. Is good as a hedge. Give any good soil; propagated by its running tubers. 


\section{OCTOBER}

\section{YELLOW PERENNIALS}

Chrysanthemum. Hardy (C. sinense). 3-4 ft. A very desirable plant with handsome foliage, and heads of flowers resembling Asters. To increase bloom pick back the top when about a foot high to make the plant branch, which increases quantity, but reduces the size of the flowers and somewhat retards the bloom. Give a rich, deep soil, plenty of water and full sun. Propagate by division of the root which throws out in the spring many offshoots when well established. By giving a slight protection at night from frost the bloom may be prolonged until hard freezing weather sets in. Also red and pink varieties. See Pink and Red Per., October.

\section{JUNE}

\section{YELLOW ANNUALS}

Bartonta (Mentzelia Lindleyi, known also as Bartonia aurea). I-2 ft. Bears golden yellow flowers with a metallic luster when the sun shines upon them. It is seriously affected by drought, and does best when grown in masses so that the ground is well covered with the leaves. Give a rich moist soil. June to October.

BLANKET FLOWER, see Gaillardia.

Calendula, Pot Marigold (C. officinalis). I-2 ft. Many varieties in creamy yellow, lemon and orange-rayed flowers, 3 in. across, growing on long, stout stems. One of our most valuable annuals because of its long season of bloom and also it endures the heat and drought of summer better than most plants. Give a rich deep soil and moisture if possible; keep seed-vessels picked back. Self-sowing. June to October.

CALIFORNIA Poppy (Eschscholtzia Californica). I ft. A very handsome plant with finely cut foliage and large single yellow flowers several inches across. Also a white and pink variety. For culture see Eschscholtzia, White An., June, and Pink An., June.

Eschscholtzia, see California Poppy.

Gaillardia, Blanket Flower (G. picta, var. Golden Gem). 2 ft. A rich yellow variety of this free-blooming, showy annual. Also mixed red and yellow varieties, but the tones of pure yellow and pure red 
(G. Amblydon) are much more desirable. Thrives in any good soil. Sow seeds early as they are slow to germinate. June to October. See Red. An., June.

NASTURTIUM. Dwarf (Tropæeolum minor, var. Golden King). I ft. A fine deep yellow variety of this useful plant. For culture see Nasturtium, White An., June.

Pot MARigold, see Calendula.

SweEt Sultan (Centaurea moschata, known also as C. suaveolens). $I_{2}^{\frac{1}{2}} \mathrm{ft}$. A sweet-scented fringed clear yellow variety of Corn-flower; for culture see Sweet Sultan, White An., June. June to September.

\section{JULY}

\section{YELLOW ANNUALS}

Abronta, Sand Verbena (A. areneria). 6 in. A dwarf trailing plant with showy Verbena-like heads of fragrant lemon-yellow flowers. It is a half hardy perennial and under favorable conditions will survive the winter when well mulched. Sow seeds in autumn in pots and set in a cold frame; or sow in early spring. Peel off the papery husk of the seed when sowing, else it will not germinate well. Also white and rose varieties. July to October.

CANARY BIRD Flower (Tropaolum peregrinum, var. canariense). A climbing variety of Nasturtium, with cut leaves and light yellow flowers. For culture see Nasturtium, White An., July.

Coreopsis, Calliopsis, Golden Wave (C. Drummondii). $2 \mathrm{ft}$. A free-flowering plant with blossoms that resemble French Marigolds in that they have bright golden-rayed petals with a dark spot at the base of each; borne on long stems. Give any good soil. Self-sowing. July to October.

MARIGold. African (Tangetes erecta). $3 \mathrm{ft}$. Many single and double and quilled varieties in lemon and orange-yellow. One of our sturdiest plants, that thrive with little care in any soil. Bears showy heads of flowers. Give sun and moist rich soil and about eight inches of room to a plant for the best growth.

MARIGold. French (Tangetes patula). I ft. A small single variety with a dark marking about the center and finely cut leaves.

MARIGold. Single (Tangetes signata). I ft. A low much-branched variety with rays purple-spotted or striped with darker orange at the 
base of the petals. All require the same culture, and bloom from July to October.

NasturTium. Tall (Tropaolum majus, var. Nankeen Yellow). 8-ro ft. N. Lobbs (Tropaolum Lobbianum, var. aureum). $8 \mathrm{ft}$. Dark-leaved and richer in bloom than the common tall varieties; also the best for house culture. All the tall varieties bloom later than the dwarf kinds. For culture see N. White An., June.

Oxyura (Layia Calliglossa, known to the trade as O. Chrysanthemoides). 6 in. A low border plant with flowers having both the rays and disk of a bright yellow. Any good garden soil.

Pansy. May be grown as an annual; for varieties see Yellow Per., April; for culture see Pansy, White Per., April. Spring sown seeds bloom from July to October.

PHLox (P. Drummondii, var. grandiflora). Single and double varieties in yellow. I-2 ft. See Phlox, White An., July.

Portulaca, Rose Moss (P. grandiflora, var. Yellow). 6 in. Do not sow seeds until June. See Portulaca, White An., July.

SNAPDRAGon (Antirrhinum majus, var. Yellow). $2 \mathrm{ft}$. Treated as an annual sown in early spring it blooms from July to October. For culture see Snapdragon, White Per., July. Also pink and red varieties.

Stock. Ten weeks, Gillyflower (Matthiola annua, var. Perpetual

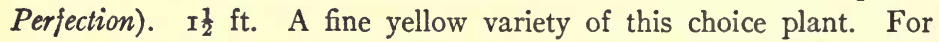
culture see White An., July. Also pink and red varieties.

SweEt-Pea (Lathyrus odoratus, var. Queen Victoria and Mrs. Eckford). $4 \mathrm{ft}$. Two yellow varieties that can be trusted. For culture see Sweet-Pea, White An., July.

\section{AUGUST}

\section{YELLOW ANNUALS}

Cocrscomb (Celosia cristata, dwarf var. Golden Yellow; also Light Yellow). 9 in. The common form which is showy in color and the flowers resemble a cock's comb. Has no delicacy nor grace.

Cockscomb (Celosia plumosa, var. Yellow). I $\frac{1}{2} \mathrm{ft}$. A very different growth from the above, the bloom consisting of long feathery plumes. To secure the largest blooms from Celosia transplant three or four times. Give any good soil and sun. August to September. Red variety see Red An., August. 
Datuza, Trumpet Flower (D. Meteloides, var. Yellow). $2 \frac{1}{2} \mathrm{ft}$. For description and culture see Datura, White An., July.

Erysimum Perofskinanum. I ft. Bears a quantity of deep reddishorange flowers resembling Wallflowers. Give a rich sandy loam. Sow seeds in September for spring flowering. One of our choicest hardy annuals.

Helianthus, see Sunflower.

LASTHENIA ( $L$. glabrata, known to the trade as L. Californica). $\mathrm{x} \mathrm{ft}$. A slightly downy plant with bright yellow flowers borne on branching stems. This, as well as the plant following, are good for edging a border. Give any good soil and sun.

Limnanthes (L. Douglasii). 6 in. A sweet-scented annual with pale yellow flowers merging into white at the edge of the rayed petals, and black stamens, which give a striking appearance. It has a spreading habit; give a good moist soil and sun. August to September.

SAlPIGLOSSIS (S. sinuata, var. grandiflora). $2 \mathrm{ft}$. Bears deep funnelshaped flowers in pale straw color, delicately veined with red or purple, borne either solitary or in small clusters at the end of branching stems. Give a sandy loam, and partially shaded location, for if the stem and root are exposed to the hot sun, it is apt to wither and die off suddenly. Frequent transplanting tends to make the plant bushy. For summer flowering sow seeds in early spring; for spring bloom, sow seeds in autumn. Also pink and red varieties.

Podolepis ( $P$. aristata; known also as $P$. chrysantha). I $\mathrm{ft}$. Has golden-yellow flowers with pink ray florets. It is very handsome for pot culture. Sow in May and transplant $\mathrm{I} f \mathrm{ft}$. apart; give a rich soil.

Scabious. Sweet (Scabiosa atropurpurea, var. Golden Yellow).

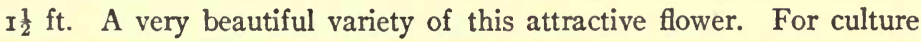
see Scabious, White An., August.

SUNFLower (Helianthus annuus). $3^{-8} \mathrm{ft}$. Many varieties with huge single terminal flowers often a foot or more across; others branching with many small blooms both double and single. Give any good soil or situation, provided plenty of space is given each plant.

Thunbergia ( $T$. alata, var. aurantica). $5 \mathrm{ft}$. A smooth climber bearing a curious flat flower with deep yellow corolla, a dark eye and tube turned inward. If the long shoots are pegged down over a bed they will send up innumerable flower stalks and cover the bed with bloom. Give a rich soil well drained and mixed with sand and plenty 
of water, as the plant will perish if kept too dry. Excellent as a house plant. August and September.

ZinNia (Z. elegans, many hybrid varieties). 2-4 ft. The usual tall curled and crested varieties in pure deep yellow; valuable for its wealth of bloom after many other plants are gone.

ZinNiA ( $Z$. angustifolia, known also as $Z$. aurea), 8 in. A dwarf variety from Mexico, sometimes called $Z$. Mexicana $p l$. $f$. A plant covered with small bright yellow flowers, the petals drooping and overlaying each other like a thatched roof. For culture, see Zinnia, White An., August. Also pink and red varieties. 


\section{PINK FLOWERS}

\section{APRIL \\ PINK SHRUBS-None in my climate}

\section{MAY}

\section{PINK PERENNIALS}

HyacintH (Hyacinthus orientalis, var. Maria Cornelia [single]); $H$. var. Lord Wellington (double). For culture, see Hyacinth, White Per., April.

Scilla (S. nutans, var. rosea). I ft. Leaves form a tuft with 6-I2 drooping pink flowers borne on a raceme. Give any good well-drained soil; plant in autumn and mulch during the winter. Propagated by offsets. April to June. Have not been successful with this.

\section{MAY}

\section{PINK SHRUBS}

Almond. Flowering (Prunus Japonica pl. fl., var. rosea). 4-6 ft. A rosy pink variety of this charming shrub. For culture and description, see Almond, White Per., May.

Andromeda, Wild Rosemary (A. perifolia). I5 in. Bears small pinkish-white drooping flowers in terminal umbels; margins of the narrow evergreen leaves turn under. It should be given a low wet situation; if on dry ground it becomes dwarfe Propagate by sowing seeds as soon as ripe or by pegging down the branches, covering the joint with soil, and they will root enough to separate in a year.

Azalea (A. vaseyi). 6-8 ft. Bears deep pink flowers before the leaves appear. None of the so-called hardy Azaleas have survived the winter with me. Give a deep, rich sandy well-drained loam, but it must never be allowed to become too dry. Azaleas thrive best in partial shade. 
Crab-Apple. Japanese Flowering (Pyrus floribunda [single] and Pyrus floribunda, var. Parkmanii [double variety]). ro ft. A bush or small tree with drooping branches, bearing sharply-toothed leaves and handsome red flower buds that are flesh colored or rosy pink when opened. Thrives best in an open airy situation apart from other trees. Rather subject to caterpillars during the leafing and flowering season. Give any good soil. Propagate by seeds or grafting on wild Crab, Pear or the Hawthorn.

Honeysuckle. Bush, or Upright (Lonicera fragrantissima). $3^{-8} \mathrm{ft}$. A fragrant bush form of Honeysuckle, bearing white, also pink flowers in numerous clusters, followed by brilliant scarlet berries; blooms on wood of previous year's growth, therefore prune just after flowering. All young shoots should be cut back to induce a bushy growth. Propagated by layering or cuttings; give any good soil. May and June.

Honeysuckle. Tartarian (Lonicera Tartarica). $3^{-6} \mathrm{ft}$. Shrub of slender elegant growth, and when properly trimmed makes an open bush; flowers abundant and beautiful, of pale pink turning to yellow. Fruit ripens in August and becomes a bright red berry that gives color to the bush until frost.

LILAC (Syringa, hybrid budded varieties, Virginite and Clair Cochet). Both handsome pink varieties, that, like all budded Lilacs, are apt to revert to the old stock upon which they are budded. It forms flower buds for the next season during the summer, so all seed-vessels must be removed promptly after flowering. For culture, see Lilac, White Per., May.

Peach. Japanese (Prunus Persica, var. rosea plena). 4-6 ft. A new form of this shrub much prized in Japan. It makes a full bushy growth, bears narrow pointed leaves like the common Peach and quantities of small handsome rosette flowers both in pink and deep red. Prune the new growth in the summer, and head in the old so as to harden the wood before winter. Give a rich soil, but no manure near the roots. A heavy mulch of wood ashes tends to harden the wood so that it withstands our severe winters; entirely hardy with me. Very choice indeed.

PinXter Flower (Rhododendron nudiflora). $2 \mathrm{ft}$. Bears rosypurple or lilac flowers resembling the Azalea, before the leaves appear. Requires rich moist soil and full sun. It is propagated by running root stocks, and may be increased by cutting close to the ground to throw the vitality into new growths, which may be reset in spring while dormant. 


\section{Pink Flowers}

Plum. Double Flowering, Japanese (Prunus triflora, sometimes called $P$. triloba). A very handsome shrub or small tree bearing pink flowers resembling pink roses; leaves finely serrated; fruit pointed, with firm flesh and a small stone. Culture the same as Crab-Apple.

RHODORA (R. Canadensis). I-2 ft. A low shrub, native to cold wet ground with handsome rose-pink or purplish-pink flowers that appear in clusters before the pale, rather hairy leaves. Culture the same as Pinxter Flower to which it is allied. Transplant in spring.

Rosemary. Wild, see Andromeda.

\section{MAY}

\section{PINK PERENNIALS}

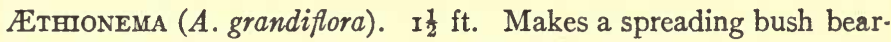
ing pink flowers in crowded racemes. Requires full sun and lime in the soil. Propagated by seeds and cuttings. May to August.

Aquilegia, see Columbine.

BLEEDING HEART (Dicentra spectabilis). $2 \mathrm{ft}$. Has very handsome foliage and curved terminal racemes of pink flowers with two blunt spurs. Give a rich deep soil, moisture, full sun and space to spread itself. Propagated by dividing crowns early in spring or cutting the fleshy roots in short lengths and starting them in sandy soil.

Campion. Alpine (Lychnis alpina). I ft. Lower leaves form a tuft from which rise close pink heads of pink flowers $\frac{1}{2}$ in. across, borne on stems from 6 in. to I $\mathrm{ft}$. high. Give full sun and rich soil. Propagate by seeds or division of the root.

Columbine (Aquilegia vulgaris, var. rosea). 2-3 ft. The Columbine comes in the loveliest tones of palest rose, salmon pink, deep pink, old rose and rose spurs with white crown, but it is impossible to secure these with any exactness from seed, owing to the cross-fertilizing by insects. Division of the root, or covering the plant during the flowering season is the only way to perpetuate the stock. For culture, see Columbine, White Per., May.

Dicentra, see Bleeding Heart.

EREMURUS (E. robustus). $8 \mathrm{ft}$. Leaves 4 in. wide make a huge tufted rosette several feet across, from which rises a tall scape from 4-8 ft. high ending in a terminal raceme of handsome peach-colored flowers resembling the Hyacinth. It dies to the ground after blooming, 
and the place should be marked lest it be disturbed by accident. It must have a deep well-drained soil, full sun and moisture during the blooming season, and much space. The roots are large, brittle and difficult to pack, and as the seeds take a year to germinate and several years to develop to the point of blooming, plants are very costly. If you are young and enthusiastic try raising it from the seed. After several years experiment I have four young plants out of nineteen, having lost several vintages through the brown cutworm. In four years more I may see bloom.

FORGET-ME-NOT (Myosotis alpestris, var. roseus). I ft. A lovely pale pink variety with small yellow eye, fragrant in the evening. For culture, see Forget-me-not, White Per., May.

IRIS. German (Iris Germanica, var. Queen of the May). A lilac pink variety, see White Per., May.

Lychnis. Alpine, see Campion. Alpine.

Lychnss. Early, Red L. (L. dioica, var. rosea). 2 ft. (A form of L. diurna.) This is a flower native to some parts of New England, but under cultivation is one of my most desirable plants, making a spreading bushy growth and the whole plant is covered with pale rose-pink flowers an inch across borne in branching panicles. I have three varieties of this; one, with broad green leaves and red woolly calyx and rather small reddish pink flowers, is the least desirable; another with narrower bright green leaves, somewhat rough, makes a splendid showing; another with darker smooth green leaves and reddish stem is not so good, though all are worth planting. Give a rich deep soil, full sun, and water during the flowering season. By free cutting the bloom is prolonged through the entire summer.

Moss-Pink, CReeping Pink (Phlox sublata). 4 in. A very desirable border or bedding plant literally covered with rose-pink flowers. For description and culture, see Phlox, Creeping, White Per., May.

Phlox sublata. Creeping Phlox, see Moss-Pink.

Poppy. Alpine (Papaver alpinum, var. Pink). I ft. A pink variety blooming from May to August. For culture, see Poppy. A Yellow Per., May.

Tunip (Tulipa suaveolens, var. Rose Luisante and Rose A plati [single]) Couronne des Roses (Double) represent a few pink varieties. For culture, see Tulip, White Per., May. 


\section{JUNE}

\section{PINK SHRUBS}

ACACIA. Rose (Robinia hispida). $5 \mathrm{ft}$. A dwarf shrub with drooping branches, smooth leaves tipped with a bristle, and thorny stem, drooping rose-pink pea-shaped flowers with a deeper red woolly calyx, borne in loose axillary racemes. Should have a position sheltered from the wind as the wood is brittle and the limbs are easily broken, give full sun, rich soil and moisture. Propagated by layering.

Azalea. Tree (A. arborescens). $4 \mathrm{ft}$. A handsome pale rose-pink variety; called hardy, but not so with me. Propagate by layering, but the branch must not be severed for two years. For culture, see Azalea, White Per., May.

Devtzia (D. Lemoinei). 3-4 ft. A pink variety with double flowers. See $D$. White Shrubs, June.

Diervilla, Weigelia (D. forida, also known as D. rosea). $6 \mathrm{ft}$. A graceful shrub spreading by suckers from the root, bearing abundant rosy flowers in axillary and terminal clusters. Give a rich moist soil and shaded position. Propagated by suckers.

JAPANESE Rose, see Rugosa Rose.

PEACH. Blood-leaved (Prunus Persica). A showy variety with blood-red foliage in spring, becoming purple in summer.

RosE. The perfect lily should be white and fragrant, so the perfect rose should be large, shell pink and fragrant. The following list is not exhaustive or even general, but it comprises the pink roses I have grown and find hardy in my small garden.

Rose. Baroness Rothschild-a cross between the Damask Rose and Rosa Indica, a Hybrid Perpetual of stocky growth, large globular flowers, pale pink and scentless. If given cultivation during the blooming season (June) and pruned slightly in July, it will yield some autumn bloom.

Rose. Cabbage, Provence (Rosa centifolia). One of the best and commonest varieties grown. Bears large fragrant very double pink flowers with incurving petals, on slender stalks, which produce a graceful nodding effect. Requires a richly manured soil and open situation.

Rose. Cinnamon (Rosa cinnamonea). 4-6 ft. A most vigorous variety inclined to run wild, with quantities of pale rose-pink flowers 3 in. across, borne along drooping stems. Very beautiful when in per- 
fection, but does not last at best over ten days, and is inclined to blight in the bud; has a spicy fragrance; spreads badly from suckers and should not be planted where it cannot be kept under control. Is particularly good against higher shrubbery, or on the lawn for distant effects; has fine autumn foliage of orange and coppery red.

Rose. Dorothy Perkins. 4-10 ft. A climber, a cross between $R$. Wichuriana and Gabriel Luizet ( $R$. Indica); one of the most beautiful varieties grown, with many clusters of shell-pink flowers 2 in. across borne at the ends of the branches. It makes an enormous growth which should be headed in to induce lateral growths that will bear the following year. Blooms only in June and is scentless.

Rose. Early Wild (Rosa blanda). I-3 ft. A low native rose with pale green foliage, hoary beneath, bearing clusters of $\mathrm{I}-3$ pale pink flowers resembling, but much larger than, the Sweetbrier. Spreads gradually from the root.

Rose. Gabriel Luizet. A Hybrid Perpetual; free bloomer with light silvery-pink fragrant flowers; hardy vigorous growth; one of the best.

Rose. La France. One of the best hybrid Teas, beautiful in bud and in full flower; of shell pink shading off at the edges to a silvery rose. Very free bloomer, every shoot bearing a flower; fragrant. Though hardy, it is well to give it, as well as all Hybrid Teas, a sheltered position, and well mulched roots in winter and deep covering of leaves.

Rose. Magna Charta. Hybrid Perpetual. Makes a vigorous upright growth with bright healthy foliage; bears large full bright pink fragrant flowers in June. Do not prune too closely for it runs to foliage instead of bloom.

Rose. Mrs. John Laing. Hybrid Perpetual. Of vigorous growth, bearing terminal clusters of three beautifully soft pink roses of fine form. Fragrant. A well-established favorite variety. Blooms again in autumn if pruned about one-half in July.

Rose. Paul Neyron. Is the largest flowered rose in cultivation; a prolific bloomer of clear deep rose, the flowers are sometimes 6 in. in diameter. Makes a vigorous growth, and if vigorously pruned in July, will bloom again in autumn.

Rose. Queen of the Prairie. A hybrid form of Rosa setigera. A vigorous free-growing climbing rose, throwing out many long lateral branches; bears small clusters of double deep rose flowers. Very hardy; blooms toward the end of June; not fragrant. 
Rose. Mrs. R. G. Sharman-Crawford. A hybrid Perpetual almost always in bloom and one of the best roses grown; bears deep shell-pink flowers the outer petals shading into flesh color; of vigorous growth.

Rose. Rugosa (Rosa rugosa, var. Conrad F. Meyer). Very large fragrant double flowers of clear silvery pink, the buds resemble La France. A choice variety. The Rugosas spread badly at the root and must be kept under control.

Rose. Sweetbrier, Eglantine (Rosa rubiginosa). A rose inclined to climb. I have had them run 8-9 ft. in a season, but they are often winter-killed unless in sheltered positions. To promote bloom keep pruned back to 4-5 ft. Foliage very fragrant, the small clear pink flowers numerous, single, with petals curving inward at the margin, handsome seed-vessels in autumn. Easily propagated by seed which self-sows; also spreads slightly at the root.

Rose (R. Wichuriana, var. Universal Favorite). A vigorous trailing rose suitable for covering banks, stone walls and trellises. Bright green glossy foliage and small double fragrant light pink flowers. Hardy and very good, but not so beautiful as Dorothy Perkins. For Rose culture, see Rose, White Per., June.

TAMARISK. African (Tamarix Africana or T. tetranda). Earliest hardy species with bright pink flowers borne in great profusion along the slender branches of the previous season's wood, in lovely contrast with the soft feathery foliage. Prune severely when the flowering season is over, as the long stems become bare, and both flowers and leaves spring from new wood only. For later variety see Pink Shrubs, August.

\section{JUNE}

\section{PINK PERENNIALS}

Allegheny Vine, Mountain Fringe (Adlumia cirrhosa). io ft. A biennial climber of the most delicate beauty. The first year it makes a low spreading growth of tender green leaves that resembles Maidenhair Fern. This dies down and the second year the plant begins to run as a vine, with smaller leaves and it bears numerous axillary racemes of small flesh-colored flowers. Very desirable and hardy. When once established it is self-sowing, and then becomes practically a perennial. Give a rich moist soil in a sheltered spot, with the roots shaded from the sun, and it will festoon an arbor in a few weeks. 
Armeria, Thrift ( $A$. elongata formosa-also known as A. cephalotis). $\quad \mathbf{I}_{2}^{\frac{1}{2}} \mathrm{ft}$. Makes a dense low tuft of leaves and close solitary heads of pink flowers. Give full sun and any good soil not too wet. Propagate by sowing seeds as soon as ripe, for the roots do not divide well.

ARMeria (Armeria vulgaris, A. elongata). Is often used as an edging instead of Box, as the seeds come up with much certainty, and it makes a close thick border. This variety is propagated by division of root also.

ARmeria. Plantain-leaved (A. plantaginea), 9 in. Bright rosecolored flowers in close heads on stems a foot or less high. Propagate by dividing roots into separate pieces and plant the pieces as you would cuttings in sandy soil under glass until well rooted.

Bowman's Root (Gillenia trifoliata). $\quad$ I8 in. A bushy plant with red stems and pink or white flowers resembling Spirea. Foliage divided. Give partial shade, any soil. Plant with Lilies or Japanese Iris. Propagate by seed or division.

Calystegia, Japanese Rose (C. pubescens pl. $f$.). Known also as Convolvulus Japonica and Calystegia Californicus. 3-4 ft. A twining vine with halbert-shaped leaves and beautiful pale rose-colored flowers resembling small roses. It has a bad habit of spreading from the root, and should be planted where it will not encroach on other plants; or it should have a tub to itself. Any portion of the slender white root buried will grow.

Catchfly. Autumn (Silene Shafta). 6 in. A low variety of C. bearing pink flowers, the stem becoming gradually covered with blossoms. Give any good soil and propagate by division of root, seeds or cuttings. Also annual varieties in pink; see Catchfly, Pink An., July.

Clematrs (C. coccinea, var. Duchess of Albany, and C. Jackmanni, var. Mme. Bacon Veillard). Two beautiful varieties of this showy flower. The Clematis is a gross feeder and needs manure both above and below ground and liquid manure during the blooming season. If raised from seed, save until spring and sow in sandy soil under glass; plant out and they will soon flower. Propagated also by cuttings, layering and by grafting scions on healthy roots. To aid layers in rooting, scrape the bark slightly before covering with earth.

Convolvulus Japonica, see Calystegia.

Crucianelia, Crosswort (C. Stylosa). i ft. An attractive low border plant which throws out numerous spreading stems bearing whorled leaves and terminal heads of small delicately-formed pink 
flowers. Give any good soil and propagate by seeds, or division of the root in spring or autumn. June to September.

Dianthus, see Pink.

FoXGLove (Digitalis purpurea, var. gloxinaflora). 3-4 ft. A pale pink variety with white throat spotted with red. It is much more beautiful in color than the common purplish-red Foxglove. Give a rich soil, sun and water during the blooming season. Cut back the plant when done blooming to induce a later crop of flowers. Increased by seed. I do not recommend the planting of offshoots formed at the root, for such plants are not so vigorous as new seedlings. Selfsowing.

Gillenia, see Bowman's Root.

Helianthemum, see Sun Rose.

InCARvillea, Hardy Gloxinia (I. Delavayi). $2 \mathrm{ft}$. A showy plant with coarse pinnate radical leaves which grow two feet long, and bears several terminal clusters of handsome large tubular deep rose-colored flowers. The root is tuberous and suffers from drought. Give a deep rich well-drained soil, partial shade. Propagate by seed and careful division of the root. Leaves die down in summer.

LUPINE (Lupinus polyphyllus, var. roseus). $3 \mathrm{ft}$. A pink variety of this strikingly beautiful plant. For culture, see Lupine, White Per., June. Also blue and yellow varieties.

Lupine (L. Douglasii). $3 \mathrm{ft}$. A new variety which is a cross between the annual and perennial Lupines, blooming the first season from seed, if planted early. Also blue and white varieties.

Lycrnss. Viscid (L. viscaria splendens). $3 \mathrm{ft}$. Makes a low broad tuft of narrow leaves and sends up several reddish stalks clammy or sticky at the joints, bearing showy heads of rose-pink flowers. Give any good soil. It is self-sowing and is best propagated by seeds. The young seedlings so closely resemble the common weed sorrel that one must not mistake them when weeding.

Mountain Fringe, see Allegheny Vine.

Peony (Pconia officinalis, var. rosea). A very early variety.

Penny ( $P$. albafora, var. fragrantissima). A very fragrant kind. ( $P$. var. King of Roses).

PEony ( $P$. var. Humeii rosea). The latest to bloom; these are but a few of many hybrid varieties in pink, single and double, some fragrant, some scentless. Give a deep rich soil, top-dress and water in summer while growth is being made. While roots can be and are di- 
pale pink satiny fringed flowers $2-3$ in. across, in terminal clusters. Give a deep rich soil and sun. Propagate by seed or division. Blooms for two months.

Silene Shafta, see Catchfly. Autumn.

Sun Rose (Helianthemum mutabile). 6 in. A pleasing little plant with evergreen leaves and slightly woody stems, bearing a profusion of pink flowers that open only in the bright sun. No value for cutting. Racemes are nodding before the flowers open, but erect themselves. Give a hot dry soil, and propagate by seeds or cuttings in a sandy soil kept shaded.

Sweet-William (Dianthus barbatus, var. Pale Pink.). I ft. This variety is not so tall as some of the red ones, but it bears enormous heads of showy pink flowers. To propagate any given color, give the plant special attention to induce new growths at the root, which can be divided the following spring. For brilliant new colors sow fresh seed annually and select stock when it blooms and transplant into its place according to color.

Tunica ( $T$. saxifraga). 8 in. A dainty little plant with small leaves, slender diffuse stems and tiny open bell-shaped pink flowers resembling the annual Gypsophila. Easily raised from seed, or increased by division of root. Give any good soil.

Thrift, see Armeria plantaginea.

Valerian, Jupiter's Beard (Centranthus ruber, var. Pink). $2 \mathrm{ft}$. An erect plant with smooth deeply-veined leaves and dense terminal cymes of long-tubed flowers; also coral red and white varieties. For culture see Valerian, White Per., June.

Verbascum (V. Blattaria). A pink variety, see $V$., Blue Per., June.

Verbena ( $V$. montana). I ft. A purplish-rose variety, of Verbena, said to be hardy, but does not survive the winter in my garden. I grow it as an annual which blooms in September. It makes a vigorous erect growth and is a free bloomer, but not to be relied upon as hardy.

\section{JULY}

\section{PINK SHRUBS}

LAUREL. Mountain, (Kalmia latifolia). $4 \mathrm{ft}$. A native evergreen shrub of great beauty with shining green leaves, arranged in a rosette beneath large clusters of showy rose-pink flowers. It is difficult to trans- 
plant; for, in its native haunts, it grows among stones buried in the leaf mold of oak forests, and its roots run far and are hard to secure. It is well worth cultivating; needs deep rich soil composed of three parts leaf mold and one part common loam; give partial shade. Can be propagated by seeds and cuttings.

LAUREL. Sheep (Kalmia angustifolia). 2-3 ft. A low native variety with narrow leaves, slender erect growth, bearing a terminal head of deep pink flowers. Thrives in sun or shade, and in any soil.

MEADOW-SWEET, see Spirea salicifolia.

RHODODENDRON. Great (R. maximum). 6-Io ft. This species is also native in restricted localities, and the only one that is hardy without protection in my vicinity. It bears great evergreen drooping leaves, and clusters of pale pink flowers with greenish throats. In its native place it grows in deep mold on shaded rocky ledges where water drips. Give a similar location if possible; prepare beds two feet deep, preparing the soil with chopped turf, rich compost, leaf mold and good garden loam mixed. The roots do not penetrate far, and the ground should be made porous; plant in spring; chalk or lime in the soil is very injurious to it.

Spirea, Common Meadow-Sweet (Spirea salicifolia). $3 \mathrm{ft}$. A native shrub making a bushy growth, with smooth serrated leaves and crowded panicles of pale pink flowers. It is self-sowing and also spreads from the root. Give any good soil and sun. It is a favorite diet of the rose-bug and should be carefully watched during June and July when trying to rid the garden of this pest.

Spirea (S. Japonica, known also as $S$. callosa, var. superba). $4^{-6} \mathrm{ft}$. Makes a very vigorous large bush, branches terminated by long pointed clusters of deep pink flowers. Much resembles $S$. salicifolia but is larger, handsomer and of deeper color.

\section{JULY}

\section{PINK PERENNIALS}

Canna (C. Ehemanni [Crozy]), var. Mlle. Berat and Salmon Queen. Two pink varieties of this tender perennial. For culture see Canna, White Per., July.

CANTerbury Bell (Campanula medium in single and double varieties; also $C$. var. calycanthema, Cup and Saucer variety). This de- 
lightful plant comes in lovely tones of pale rose pink and shell pink. For culture see C. Bells, White Per., July.

Centaury, see Sabbatia.

Chelone, Turtle Head (C. Lyoni). $2 \mathrm{ft}$. A plant allied to the Pentstemon, stem much-branched, bearing terminal clusters of purplish-pink flowers with lower lip bearded. Give a light rich soil. Propagate by seeds, cuttings and division of the root if done in August or September. If divided in spring the plants suffer.

Coronilla, see Crown Vetch.

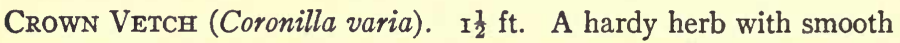
pinnate leaves, purplish-pink flowers borne in clusters of $16-20$ in the axils of the leaves. Pinch in the plants to induce a bushy growth. Give a rich soil of mixed loam, leaf mold and manure. Propagate by suckers from roots, or seeds planted as soon as ripe. Choice.

Gerardia. Hybrid variety probably derived from $G$. tenufolia. Said to be a half hardy perennial, but it survives the winter with me; leaves narrow, light green, stem much-branched, large tubular rose-colored flowers $1 \frac{1}{2}$ in. long. Give a sheltered position in light rich soil. Native Gerardias are difficult to transplant for they depend upon a certain parasitic growth only found in pine barrens. Propagated best therefore by seeds.

Holıуноск (Althea rosea). 4-8 ft. Single and semi-double varieties. From a little paper of seeds of single pink hollyhock given me several years ago $I$ have raised innumerable varieties in pink and cardinal red. The most beautiful was a pure shell pink, large and single with a little tuft of curled abortive petals about the center. For culture see Hollyhock, White Per., Aug.

Dictamnus, Fraxinella (Dictamnus albus, var. rosea). A pink variety not as pretty as the white. See White Per., July.

IRIs. Japanese (I. lavigata [I. Kampferi] var. Dick Webb). A rose variety with a yellow band at the base of petals.

IRIs (I. var. Mrs. D. E. Richardson). Double rose shading to white, with white center. For culture see Iris. Jap. White Per., July.

Mallow. Tall (Malva sylvestris). $2 \frac{1}{2} \mathrm{ft}$. A branching herb bearing sharply divided leaves and racemes of single and clustered pale pink flowers 2 in. across. Very showy. Propagated easily from seed. Thrives in any soil or situation; often escapes to the roadsides.

Mallow. Hollyhock (Malva alcea). Said to grow $3 \mathrm{ft}$., but mine grows eight feet unless pinched back two or three times each season. It 


\section{Pink Flowers}

makes a tremendous bushy growth in rich soil; leaves much divided, scattered flowers pink $\mathrm{I}$ in. across. Propagated by seeds and division of the root. Of small beauty and almost impossible to uproot.

Maliow. Musk (Malva moschata). $2 \mathrm{ft}$. A beautiful variety with pale rose-colored flowers having a faint musk odor. For description and culture see Mallow, Musk, White Per., July also a white variety.

MiLforr. Rosy (Achillea millefolium roseum). I-3 ft. A variety little known here but much prized in English gardens. Foliage much divided and fern-like; flowers borne on tall stems in flat heads of a deep rose color. Will thrive in any soil or situation and is propagated by seed or division of the root. July to Oct. In warmer climates from May to Oct.

Obedient Plant (Physostegia Virginiana). 2 ft. Already described under Blue Per. as a rosy lilac, but at times it is almost a pure pale pink. For culture see Obedient Plant, White Per., July.

ONONIS RotUndIFolia, see Rest Harrow.

PeA. Perennial (Lathyrus latifolius, var. Pink Beauty). $5 \mathrm{ft}$. A most desirable and vigorous plant, little cultivated in this country, but has several choice varieties white, white and pale pink, deep rose pink and red. Propagated by seeds which are self-sowing, or by careful division of the root in Spring. Blooms all summer. For cultivation see Pea. Per. White Per., July.

Pentstemon ( $P$. campanulatus, var. roseus). $\mathrm{I}-2 \mathrm{ft}$. This plant varies in cultivation from reddish purple to rose color and bears showylipped flowers in a one-sided cluster. While not difficult to cultivate, the Pentstemon suffers from wet more than cold during winter, and it should be planted in a well-drained location in a mixture of sand and rich loam. Propagated by seeds, cuttings or division of the root.

Physostegia, see Obedient Plant.

QUeEn of the Prairie (Spirea lobata; known also as S. vemuista and Ulmaria rubra venuista). $2-5 \mathrm{ft}$. One of our most beautiful perennials. Bears enormous pinnate leaves and a aloose branching panicle of pink flowers. It spreads readily from the root if given a deep rich soil, and is most effective when grown in masses. I once made the mistake of cutting away some of the coarse foliage in the spring to make room for other perennials, and in doing so cut the leaves from which spring the flower stalks, and thereby lost almost the entire bloom for that season. All the Spireas grow best in moist soil and present a poor 
stunted appearance if given soil that is dry or gravelly. Propagate by division of root in early spring.

REST HARRow (Ononis rotundifolia). I-2 ft. A very handsome and desirable plant making a somewhat bushy growth, and bears threeflowered clusters of pink pea-shaped flowers. Give a mixed soil of rich loam and sand. Propagate by seed and division of root.

Sabbatia. Centaury (Sabbatia chloroides, known also as $S$. campestris). I ft. A biennial resembling the annual Agrostemma cali-rosa. Stems branched and one-flowered; flowers bright pink, very handsome $\mathbf{I} \frac{1}{2}-2$ in. across; most of the Sabbatias grow naturally along sandy ponds and in low wet ground along the coast; this one prefers dry light soil. Sow seeds either in spring or autumn. I have never been able to raise this plant though I have tried for many seasons, and as it is only a biennial at best, I content myself with $A$. coli-rosa.

\section{AUGUST}

\section{PINK SHRUBS}

Steeplebush, Hardhack (Spirea tomentosa). 2-3 ft. A native variety with small serrate leaves, hoary beneath, and turning a beautiful orange and red in the autumn. The deep pink flowers are borne in a dense pointed panicle. Worthy of cultivation, for it comes when most shrubs are past their bloom and the flame-colored foliage is as lovely as a flower in late autumn.

TAMARISK. Late Flowering (Tamarix Indica). $6-8 \mathrm{ft}$. This later variety of Tamarisk must have special treatment, as it blooms on the wood of the same season's growth, so must be cut back closely in late autumn or early spring, when it will send forth long slender branches with soft fine foliage and a profusion of pink flowers through August and September. In foliage and blossom this variety and T. tetranda are alike, though each requires a different treatment. If $T$. Indica is not cut back it makes another growth of 6-8 $\mathrm{ft}$., leaving the long bare stems of the old wood at the end of which begins the new growth. Both varieties may be grown by the sea shore, and are not affected by wind or salt spray unless in excess. See T. tetranda. Pink Shrubs, June. 


\section{AUGUST}

\section{PINK PERENNIALS}

Bouncing BET, SoAPWort (Saponaria officinalis). $2 \mathrm{ft}$. A plant once cultivated but now largely run wild in New England. When wild the bloom is rather a dirty white, but under cultivation it bears clusters of large pale rose-pink double flowers. Its deep red fleshy rootstocks run badly and it should not be planted where it can interfere with other plants. Give any good soil and a sunny location. It repays well for good care, and is very effective planted with lilac Peony Poppies.

Canna. A later variety, Paul Marquant, blooms in August; salmon color. For culture, see Canna, White Per., July.

Crape Myrtle (Lagerstrcemia Indica). 2-4 ft. A shrub with smooth shining leaves, deep red stems and panicles of showy rose-pink or flesh-colored flowers, remarkable for the crisped petals and silky tufted stamens. Hardy only as far north as Washington. I brought mine from Florida and keep it in a large tub, wintering it in the cellar, and it thrives well. Turns a brilliant red in autumn.

Cyclamen. Autumn-flowering, Sowbread (C. Europaum). A hardy form of Cyclamen with a tuberous root, thick heart-shaped leaves marked with crimson and violet beneath, and bright rose-colored very fragrant flowers. It requires an open airy situation and a rich soil of mixed loam, manure, sand and leaf mold. Bears seeds freely and can be thus propagated.

DaHLIA (D. variabilis, var. Nymphea and A.D. Livoni). $5 \mathrm{ft}$. Both pure pink varieties of great beauty. While not hardy perennials the roots may be stored with other tuberous rooted plants, and be planted out in May. For culture, see D. White Per., September.

Eupatorium, Joe-Pye Weed (E. purpureum). 3-8 ft. Downy leaves large and borne in a whorl. Large purplish-rose flowers in corymbs from $5^{-9}$ flowered. A native to low wet grounds and salt marshes. Should be given a moist rich soil and sun.

Gladiolus (G. var. Childsii and Lemoine). In beautiful tones of pale and deeper pink with lavender stamens. See $G$. White Per., August.

Hibiscus. Rose MaLlow (H. moschentos, var. roseus). 3-4 ft. A handsome pink variety with large pink flowers from $4^{-6}$ in. broad with or without a dark center. For culture, see Hibiscus, White Per., August. 
LILy (Lilium, var. fulgens [L. Batemanii]). $2 \mathrm{ft}$. A vigorous variety with reddish-salmon flowers resembling the Flava Lily in form. Of peculiarly trying color unless well separated from others by white, as it harmonizes with nothing.

LILy (Lilium Japonicum, var. roseum [L. Krameri]). This lily varies from pure white to a deeper reddish pink. It is difficult to retain as the bulb rots if water gets into it. The Japanese plant this variety on its side, surrounding it with sand; thus the scales shed water and prevents water from entering the center of the bulb.

LILY (Lilium speciosum, var. roseum). ${ }^{2-} 3 \mathrm{ft}$. A beautiful pink variety of this choice fragrant lily. Is sometimes almost white or pale pink with carmine spots; blooms until late frosts. For culture, see $L$. speciosum, White Per., August.

Montbretia (Tritonia Potsii, var. rosea, known also as Montbretia Potsii). $2 \mathrm{ft}$. A deep salmon-pink variety of this autumn flowering plant. For culture, see Montbretia, Yellow Per., September.

Phlox. Perennial ( $P$. paniculata, var. Athis). A salmon-pink variety.

Phlox ( $P$., var. Margaret Slack). A bright pink variety. For culture, see Phlox, White Per., August.

Sedum. Showy (Sedum spectabile). $2 \mathrm{ft}$. Thick succulent plant with pale glaucus leaves and large branching flat-topped heads of pink flowers. All Sedums flourish natively among stones, so that an open loamy soil and a few loose stones furnish a favorable condition for it; blooms until frost.

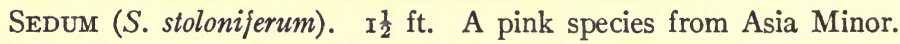
Flowers $\frac{3}{4}$ in. across in terminal clusters on a reddish stem.

\section{SEPTEMBER}

\section{PINK SHRUBS}

Lespedeza Sieboldi, a pink variety, see Lespedeza, Blue Shrubs, September.

Polygonum Baldschuanicum. $20 \mathrm{ft}$. A woody climber with pale green leaves, flowers rose color in terminal and axillary clusters. A very beautiful species. Give similar culture to $P$. multiflorum, White Shrubs, September.

Rose Mallow, Rose of Sharon, Shrubby Althea (Hibiscus 
Syriacus). I0-I2 ft. A straggling bush that needs the pruning knife to keep it in shape. Flowers very large in white, pink, red, and purple, or rather a raw magenta. In proper color a very beautiful shrub. Give a deep rich soil, sheltered position and mulch about the root as it is not always hardy in the far North.

\section{SEPTEMBER}

\section{PINK PERENNIALS}

Anemone (A. Japonica, var. elegantissima and Mont Rose). 2-3 ft. Two very beautiful pink varieties of this charming flower. They should have a well-drained location, which may be secured by digging a deep bed, with six inches of loose stones or broken rock at the bottom, then cover with eight inches of rich loam in which the roots are planted with sand about them, two inches deep with the bud-end up, then over the loam place three inches of cow manure, raking it smooth. Plant very early and water once or twice a day until they flower. This method of culture is said to produce plants of extraordinary vigor and enormous flowers. Do not let any manure come within two inches of the roots. See $A$. White Per., September.

Aster. New England (A. Nova-Anglice, var. rosea). 2 ft. A rosecolored variety of a native aster of great beauty under cultivation. Spreads at the root.

Boltonia (B. lavigata). $4 \mathrm{ft}$. A large rose-colored variety of a plant resembling the Aster, bearing large much-branched terminal heads of small rayed flowers; also a lavender variety, B. latisquima. For culture, see B. asteroides, White Per., September.

Chrysanthemum. Pompon (C. Indicum, var. roseum). $3 \mathrm{ft}$. A very hardy form of $\mathrm{C}$. with handsome foliage that turns a rich sap green and purplish red underneath and bears terminal clusters of old-rosecolored flowers. The general advice is to nip off the tips of stems in July or August to induce branching and more bloom; but it also retards the bloom somewhat, and where frosts come early and cut down a plant before it is in perfection of bloom, it may be better to let the plant develop naturally, depending upon a rich moist soil and full sun to develop fine blooms. Cheese-cloth covering is sufficient to protect the plants from the early light frosts. Propagate by suckers, division of the root in spring and by cuttings. See Yellow and Red Per., October. 
Chrysanthemum. Large-Flowered (C. sinense). 2-4 ft. This is the parent of the modern large-flowered hybrid varieties. The heads are much larger than formerly, the leaves thicker and less sharply cut. This like $C$. Indicum comes in yellow and white varieties as well as pink. Both are hardy and the culture the same. Cuttings, if well rooted, will bloom the same year. They do well to be shifted about from time to time and if pot grown the tops may be cut back. Changing to a pot but little larger from time to time will increase the size of bloom. Reset in spring.

\section{JUNE}

\section{PINK ANNUALS}

CANDytuFr (Iberis umbellata, var. Queen of Italy and Dwarf Rose). 6 in. Two pink varieties of this free-blooming and early annual. If seeds are sown in autumn, plants bloom in June. Self-sowing. For culture see Candytuft, White An., June.

Clarkia (C. elegans pl. fl.). $2 \mathrm{ft}$. Single and double varieties in shell pink. The double variety resembles the sprays of Flowering Almond, and are beautiful for cutting. For culture see Clarkia, White An., June.

MORNING-GloRy (Ipomea purpurea, var. Pale pink). A variety with delicate pink flowers of great beauty. For culture see MorningGlory, White An., June.

\section{JULY}

\section{PINK ANNUALS}

Abronia, SANd Verbena (A. umbellata grandiflora). I ft. A plant of prostrate habit, fleshy leaves, bearing dense terminal clusters of rosy pink flowers resembling the Verbena. As a greenhouse plant it is perennial, blooming in May. For culture see Abronia, White An., July. Also a yellow variety.

Agrostemma, Rose CAMPION-a species of Lychnis, but its generic name $\mathrm{A}$. is one most used; known also as $A$. cali-rosa (Rose of Heaven). $I_{\frac{1}{2}} \mathrm{ft}$. A plant resembling a Pink in foliage and bearing terminal flowers of rose pink that are effective grown in masses. For culture see Agrostemma, White An., July. Also a red var. Viscaria cardinalis and a blue one. V. carulea occulata.

Aster Canna (Calistephus Chinensis). I-4 ft. Many hybrid vari- 
eties in flesh pink, pale and deep rose, shell pink and cerise tones. For culture see Aster, White An., July.

Australian Star Flower (Cephalipterum Drummondii). I ft. A hardy annual recently brought to notice by Luther Burbank; bears clusters of fragrant star-shaped flowers ranging from light pink to crimson that retain form and color when cut; an everlasting. Give any good rich soil and sunny location.

Balsam (Impatiens balsaminea, var. Perfection pink). $\mathrm{I}-\mathrm{I} \frac{1}{2} \mathrm{ft} . \quad \mathrm{A}$ very double pink variety resembling small roses. For culture see B. White An., July.

BUtTERFly Flower, see Schizanthus.

CATChfly (Silene pendula). I ft. A plant of prostrate habit with reddish stems and calyx, with rose-pink flowers borne in the greatest profusion during the entire season. Self-sowing. Give any good soil and sun.

Catchfly (Silene, var. Double). 6 in. A more dwarf variety with double pink flowers.

Catchfly (S. compacta, $p l$. $f$.) makes a very low bushy green growth from which rise close heads of double pale pink flowers of great beauty. It is very hardy and I believe, in a sheltered warm spot, might prove a perennial.

Celosia, Feathered Cockscomb ( C. spicata). 2 ft. Bears pyramidal spikes of rosy bloom, the lower part turning a silvery white. For culture see Celosia, White An., Aug.

Cephalipterum, see Australian Star Flower.

Centaurea, see Corn-flower.

Centranthus. A shell pink annual variety with clusters of slender tubular flowers. For culture see Centrantbus, White An., July.

Cockscomb, see Celosia.

CORN-FLOWER (Centaurea cyanus, var. roseus). $2 \mathrm{ft}$. A variety bearing rose-pink flowers as beautiful in their way as the blue Corn-flower. For culture see Corn-flower, White An., July.

Cosmos (C. bipinnatus, var. Early Hybrid Pink). 3 ft. A variety with light rose-pink flowers that proves very useful in pink beds during the summer when so many pink perennials have ceased to bloom. See Cosmos, White An., July.

DeLPHINIUM, see Larkspur.

Eschscholtzia (E. Californica, var. carminea). I ft. A dwarf variety of soft yellowish pink of great delicacy and beauty. For culture see Eschscholtzia, White An., July. 
Fenzlia (Gilia dianthoides). 3-6 in. A low showy little plant suitable for borders, with narrow leaves, and pink flowers with a darker throat. Give a rich light soil.

Gillyflower, see Stock.

Godetia, Satin Flower (G. amana, var. Rosamond). I ft. A shellpink variety with a crimson spot at the base of each petal. For culture see Godetia, White An., July.

LARKSPUR (Delphinium Ajacis, var. Newport Rose). I ft.-I8 in. A soft rose-pink branching variety; give room to grow. Culture given under Larkspur, White An., July. July to Oct.

LAVATERA (L. trimestris, var. rosea). $3 \mathrm{ft}$. A bushy plant with abundant foliage and very lovely open funnel-shaped flowers of shell pink three inches across, throat and corolla veined with carmine. One of our most beautiful annuals. Give a rich light soil, sun and water. Keep the seedvessels picked off. July to Oct.

Lupine (Lupinus, var. Farquhar's Pink Annual). 2-3ft. A very desirable variety in pale pink with a deeper reddish spur, branching in habit and each branch bears long spikes of flowers until late frosts. Give a rich light deep soil, sun and water. Sow seed where the plants are to grow. July to Oct.

MALOPE. Three-lobed ( $M$. trifida, cultivated under the name of $M$. grandiflora). $3 \mathrm{ft}$. A pink annual form of Mallow bearing pale pink funnel-shaped flowers of satiny texture with green throat. Sow seed early in a sandy loam and sunny location. Flowers are solitary and borne on slender drooping stems. July to Oct.

NASTURTIUM (Tropaolum majus, var. von Moltke). 6-1o ft. A dark rose-colored variety.

Nasturtium (T. minus, var. Peach Blossom). I ft. A dwarf form in a soft pink tone. For culture see Nasturtium, White An., July.

PopPy. Anne Hathaway (Papaver somniferum, var. pconicflorum). $3 \mathrm{ft}$. An English strain from Anne Hathaway's garden in Shottery. Pale glaucus leaves and very large peony-shaped flowers of rose and shell pink, the outer petals or collar large and smooth, the inner ones are small, curled and twisted. A most beautiful variety and quite unlike our Peony Poppies that have the center petals cut or fringed. Thrives in any good soil, full sun, if the ground is kept cultivated. Rows of them in a vegetable garden add a graceful touch to utility.

POPPy. Peony (Papaver somniferum, var. paoniceforum). $3 \mathrm{ft}$. Comes in all tones of pale flesh pink, rose and shell pink and old rose 
with fringed petals alone, and with fringed center and smooth outside petals. Bears from 3-6 blossoms that remain in bloom several days. More showy but less permanent bloomers than the Shirley Poppy.

Poppy. Shirley (Papaver Rhceas, var. Shirley). $2 \mathrm{ft}$. A variety with branching stems and leaves resembling the tomato plant; bears from 5roo blossoms. I have been growing double Shirleys which are evidently crosses between the Shirley and Peony Poppy. For general culture see Poppy, White An., July.

PHLox ( $P$. Drummondii, var. grandiflora). $3 \mathrm{ft}$. Varieties in many tones of pink; also a fringed pink form. For culture see Phlox, White An., July.

RHoDANTHE (Helipterum Manglesii, var. pl. $f$ l.). I ft. An erect much-branching plant with glaucus clasping leaves and pink everlasting flowers with several rows of rayed petals overlapping each other; very attractive. Sow seeds in April in a rich soil and sunny location. For further culture see Rhodanthe, White An., July.

SALPiglossis (S. var. Rose). A pink golden-veined variety of great beauty. For culture see Salpiglossis, White An., July.

SAPONARIa, SoApwort (S. Calibrica). I ft. A low prostrate annual variety with reddish stems bearing a quantity of small rose-pink salvershaped flowers. An excellent plant for border or where a mass of color is desired. Give any good soil and sunny location.

Schizanthus, Butterfly Flower (S. Wisetonensis). $2 \mathrm{ft}$. A pale rose-pink form with part of the corolla spotted with red or purple. Sow seed early in Spring or autumn; for house plants sow seed in August in rich soil. Self-sowing. For culture see S. White An., July.

Sweet-William Catchfly (Silene Armeria). I ft. A bright pink variety already described under Silene Armeria, White An., July.

Stock (Matthiola annua). I ft. Many hybrid varieties in tones of shell and rose pink; see Stock, White An., July.

SwEET-PeA (Lathyrus odoratus, var. Katherine Tracy, Gladys Unwin, Lovely, Prima Donna). 4-6 ft. All of them beautiful pink varieties of this delightful flower.

TRIDAX (T. bicolor rosea). I ft.-I8 in. An erect plant bearing daisyformed pink-rayed flowers shading to yellow toward the center. A plant little known, but of value where a pure pink color is to be maintained during the hot dry summer months. Give a good rich soil, sun and the usual cultivation. July to Oct.

Verbena (V.teucroides-many hybrid varieties). Among them Mam- 
moth Pink is one of the best. To get good results from Verbenas they should be pegged down so that the prostrate stems many send out rootlets at every joint. By nipping off the tips of the branches they will spread and cover the ground with bloom. Give a rich soil and moisture. They make excellent house plants by cutting back blooming plants and taking them indoors before heavy frosts. July to Oct. See other lists.

\section{AUGUST}

\section{PINK ANNUALS}

Ageratum, Mist Flower (A. conyzoides, var. Lasseauxii). $2-3 \mathrm{ft}$. An erect branching plant bearing many clusters of small pink finelyfringed flowers. If seed is sown in autumn it will bloom early in July. Self-sowing. Many blue varieties. For culture see White An., July.

LARKSPUR (Delphinium Ajacis, var. Dwarf Branching). I ft. A rather late variety that branches freely and continues to bloom until late autumn. For culture see Larkspur, White An., July.

Palifoxia (Polypteris Hookeriana). $2 \mathrm{ft}$. Plant very bushy and bears loose clusters of rosy pink flowers resembling daisies. Self-sowing. Give any good soil. August to Oct.

Palava (P. flexuosa). 6-1o in. A member of the Malva family with solitary pink flowers having bright red anthers and red at the base of each petal. Give any good soil.

Pentstemon ( $P$. campanulatus). I-2 ft. A perennial blooming the first season, and may be treated as an annual. For description and culture see $P$. campanulatus, Pink Per., July.

Perrwinkie or Vinca (Vinca minor). I ft. An erect plant with glossy green leaves and terminal pink flowers. For description and culture see Vinca, White An., Aug. Also Blue An., Aug.

Petunia ( $P$. violacea). Many hybrid forms in pink, double and fringed. See Petunia, White An., Aug.

SCABrous. Sweet (S. atropurpurea, var. grandiflora). $2 \mathrm{ft}$. A lovely tone of flesh pink, also pale rose pink. See Scabious White An., Aug.

VInCA, see Periwinkle.

ZinNiA (Z. elegans). Hybrid varieties in pink, single and double, also a curled and crested variety. See Zinnia, White An., Aug. 


\section{Pink Flowers}

\section{SEPTEMBER}

\section{PINK ANNUALS}

Cosmos (C. bipinnatus, var. Mammoth Pink). 4-6 ft. A late variety in rose pink that will scarcely bloom before frost unless in a very sheltered position, but worth growing because of its beautiful fine-cut foliage. See Cosmos, White An., Sept. 


\title{
RED FLOWERS
}

\author{
APRIL \\ RED SHRUBS-None
}

APRIL

\section{RED PERENNIALS}

\section{Aubretia, see False Watercress.}

FALSE WAtercress (Aubretia deltoides, var. Leichtlinii). 6-I2 in. A hardy evergreen trailer bearing few-flowered racemes of rosy carmine flowers. Plants make a dense growth and can be layered, covering branches with sand and leaf mold, and will establish themselves by spring. After flowering the plant may be divided. Transplant in autumn. Propagate also by seeds and cuttings; give a deep rich soil.

\section{MAY}

\section{RED SHRUBS}

PeAch. Japanese (Prunus Persica, var. sanguinea plena). $3^{-8} \mathrm{ft}$. One of our most beautiful introductions from Japan, bearing blood red double flowers of great delicacy and beauty. Also a pink and a white variety. For description and culture see Peach. Japanese, Pink Shrubs, May.

Quince. Japan (Cydonia Japonica). Also known as Pyrus Japonica. $4^{-6} \mathrm{ft}$. A beautiful and well-known shrub with bright scarlet flowers produced for a long season. It can either be treated as a bush on the open lawn, or can be trained against a wall, or grown as a hedge. Also it can be pruned to a single standard with long upper branches. It can be grafted on a Pear, Hawthorn or common Quince. Layers are obtained by cutting down the old stock and when the young growth is firm enough can be bent down; or the old stock can be cut down and 
covered with soil, which will cause the old growth to rot and the young shoots to spring up at the base which can be detached by the autumn of the following year. It can also be increased by suckers and cuttings. The Pear grafted on a Quince increases its productiveness. Give a deep rich soil and any situation not too exposed. It is subject to San José scale.

Redbud, Judas Tree (Cercis Canadensis). ro-40 ft. Handsome leaves that open at the same time that the brilliant red or rose colored flowers expand, making a beautiful tree.

Redbud (C. Chinensis, or C. Japonica). 8-12 ft. A bushy grower with glossy leaves and larger and handsomer flowers that make a flame of color. Said not to be quite hardy far North; otherwise a more desirable species.

\section{MAY}

\section{RED PERENNIALS}

Aqullegra, see Columbine.

Columbine. Rock (Aquilegia Canadensis). $2 \mathrm{ft}$. A native variety in scarlet and yellow that thrives in any rich moist soil. It grows natively on wet ledges or near rocks

Columbine (A. vulgaris, var. rosea). $2 \mathrm{ft}$. A variety of the common garden Columbine in rich tones of old red.

Columbine (A. Skinneri). I-2 ft. A greenish orange with bright red spurs.

For culture see Columbine, White Per., May.

HyaciNTH (Hyacinthus orientalis, var. Garibaldi, $H$. var. Lord Macaulay and $H$. var. Roi des Belges). All red varieties. For culture see Hyacinth, White Per., May.

Lycanis. Scarlet, Maltese Cross (L. Chalcedonica). $2 \mathrm{ft}$. Like all the Lychnis family it is a tall rather weedy coarse plant with very dense flat-topped terminal clusters of brilliant scarlet flowers. Self-sowing. For culture see Lychnis, White Per., May.

TulIP (Tulipa suavolens, var. Artus [single]); Cochenille (double), varieties in pure red. For culture see Tulip, White Per., May. 


\section{JUNE}

\section{RED SHRUBS}

Calycanthus floridus, see Sweet-scented Shrub.

HoNeysuckle. Scarlet or Trumpet; also known as Woodbine (Lonicera sempervirens). $4-8 \mathrm{ft}$. An evergreen twining variety that is late in dropping its leaves in the North. It blooms throughout the entire season in clusters of brilliant scarlet tubular flowers, and though it has no fragrance is the most desirable and the handsomest of cultivated Honeysuckles. If heavily pruned looks almost like a bush against a wall. For culture, see Honeysuckle Shrubs, July.

Rose. Crimson Rambler. A comparatively new hybrid climbing rose that has become a general favorite. It makes a vigorous growth and bears many close clusters of deep red flowers less than 2 in. across. While it is hardy it thrives best in northern latitudes when trained against a south wall or given a sheltered position.

Rose. Anne de Diesbach. Hybrid Perpetual of vigorous upright growth with large fragrant carmine red blooms. Flowers again in the autumn if given a midsummer pruning.

Rose. Camille De Rohan. A hybrid Perpetual of vigorous growth and good foliage; blooms freely with deep velvety crimson fragrant flowers. Does best in cool weather and is liable to burn in the sun, and should be given a sheltered position away from the hot afternoon sun. Said to be the best of all the dark roses.

Rose. Jacqueminot. A Hybrid China of long-established excellence with large rich deep red fragrant blooms. One of the most satisfactory roses grown.

Rose Rugosa (Rosa rugosa rubra). A hardy variety making a spreading vigorous growth with glossy foliage. A free and continuous bloomer in both single and double varieties. The growth is rather large for an ordinary rose bed, as it sometimes attains $4-5 \mathrm{ft}$. in a single season and also spreads badly at the root.

RosE. Lancaster or Semi-double Red or Red Garden Rose. There is no local name for this survival of former days, which we find running wild about the old abandoned house sites in our neighborhood. But I am led to believe it is a form of the old Damask rose brought originally from Persia and adopted by the English House of Lancaster as its emblem; until it is disproved I shall call it the Lancaster rose. Under cul- 
tivation it attains a height of $2-3 \mathrm{ft}$., has rather rough foliage, few spines and often bears 40 blooms on a single plant. It looks as if it might be the parent of the American Beauty Rose which it much resembles when in bud, but when open is a brilliant crimson shading to a lighter center, is semi-double and has a thick cluster of golden yellow stamens. It has a clean spicy fragrance, is free from disease, is perfectly hardy, and blooms but once, for about three weeks, beginning late in June. It spreads from the root. Prune severely in late autumn or early spring. Subject to the green slug.

Rose. Ulrich Brunner. A Hybrid Perpetual with bright cherry red blooms of large size and firm petals; not subject to disease. It blooms early and continuously.

Rose. Dwarf Wild (Rosa lucida). A native rose brought from the coast of New Hampshire where the bloom is crimson, but in the mountains it has become a deep rose color. $3-5 \mathrm{ft}$. Has small thick shining leaves which turn a handsome orange red in autumn and flowers are solitary or few in a cluster. It is perfectly hardy and spreads from the root, and bears handsome fruit.

Sweet-scented Shrub (Calycanthus floridus). 3-5 ft. A hardy shrub with spreading branches, the wood and roots smelling strongly of camphor, the blossoms, of deep purplish red, two inches across, are borne either in axils of the leaves or solitary; leaves are soft and downy. Propagate by seeds sown in cold frames as soon as ripe, or by layering the branches in summer. Give a deep rich soil, moisture and a sunny location.

Weigelia (Diervilla, var. Othello; $D$. var. Floribunda and D. var. Abel Carriere). All red varieties. For culture see Weigelia, White Shrubs, June.

\section{JUNE}

\section{RED PERENNIALS}

Crown IMPerial (Fritillaria imperialis, var. Grown on Crown). I-2 ft. A bulbous-rooted plant with red flowers, hanging in whorls above each other in a sort of umbel beneath the terminal tuft or crown of leaves. Any good garden soil is suitable, but sandy loam is preferable. It takes from four to six years to flower if raised from seed and is best propagated by offsets which may be set out separately. The plant does not require lifting oftener than every three or four years. 
Fire Pink, Indian Pink (Silene Virginica). I-2 ft. Bears loose cymes of deep crimson flowers borne on slender stems. Give a light loamy soil. Propagate by seeds, cutting and division of the root.

Foxglove (Digitalis purpurea). $4 \mathrm{ft}$. The common variety of purplish red, not so choice as the pink or the white varieties already named, See Foxglove, White Per., June.

Fritillaria, see Crown Imperial.

HAWKBit, FALl DANDELion (Leontodon autumnale). I ft. A spreading plant that forms tufts of hairy leaves and sends up many tall stems bearing terminal clusters of orange-red flowers resembling the Dandelion. Any good soil. Propagate by seed or suckers.

LILy. Dahurian (L. davuricum.) 2-3 ft. A vigorous variety with green stems, sessile leaves and erect deep scarlet-red flowers from 3-5 in. across, borne in terminal clusters. For culture see Lily, White Per., June.

LiLy. Native Red (Lilium Canadense, var. rubrum). $2 \mathrm{ft}$. A native wild Lily of slender growth with whorled leaves, bearing a terminal cluster of orange-red or red flowers. It is found in moist meadows and at the edge of woods and should have similar conditions. Give the usual culture required by Lilies.

LycHNIs. Mullein (L. coronaria; known also as Agrostemma coronaria, var. atrosanguinea). $2 \mathrm{ft}$. A vigorous variety with whitish woolly leaves and brilliant dark crimson flowers borne in branching terminal clusters, opening a few at a time for a long season. It is self sowing. For culture see Lychnis, Pink Per., June.

Peony (Pceonia officinalis, var. Agida [early]; P. var. edulis [late]; $P$. var. rubra superba, latest of all). These are pure red types of Peony. For culture see Peony, White Per., June.

Pink. Indian, see Fire Pink.

PINk. Carnation (Dianthus caryophyllus, var. Grenadin Scarlet). $2 \mathrm{ft}$. A hardy form of red Carnation that requires a little protection in winter. See Pink. Carnation, White Per., June.

Pink. Chinese (Dianthus Chinensis, var. Heddewigii; known also as D. Heddewigii, var. atropurpureum). $2 \mathrm{ft}$. A biennial form blooming late in July the first season from seed, but in June the second year. Has large deep red flowers resembling Carnations, but has no fragrance. If in a dry sheltered spot may be kept for several years. For culture see Pink. Chinese, White Per., June.

Poppy. Oriental (Papaver orientalis, var. Parkmanii). $3 \mathrm{ft}$. A truly 
splendid plant with deeply incised foliage one foot long and large brilliant red flowers with a dark spot at the base of each petal, the bloom being often from 7-9 in. across. A plant bears from three to five blooms opening in succession. For culture see Poppy, Oriental, Pink Per., June.

Potentilla (P. Napalensis, var. Mars). $3 \mathrm{ft}$. A plant with grayishgreen foliage resembling the leaves of the Strawberry; flowers of deep red $\mathrm{I} \frac{1}{2}$ in. across. For culture see Potentilla, White Per., June.

SaPonaria, Soapwort (S. ocymoides, var. splendens). 6 in. A creeping, much-branched hairy variety with red or pink flowers and purplish calyx. Will grow in any good soil and is well suited to rock work. Propagate by seeds or division of root.

Silene Shafta, Autumn Catchfly, a brick red variety I 2 in. high; see Catchfly. Autumn Pink per., June.

SweEt-William (Dianthus barbatus). $2 \mathrm{ft}$. There are pure cardinal red varieties of this old favorite, which cannot be procured with any assurance from seed because of cross-fertilization by insects; but the strain is likely to appear in any collection, and may be perpetuated according to culture given under Sweet-william, White Per., June.

VALERIAN. Red (Centranthus ruber). $2 \mathrm{ft}$. A lovely coral-red variety of this delicate flower that blooms in terminal clusters and are of slender tubular form. For culture see Valerian, White Per., June.

\section{JULY}

\section{RED SHRUBS}

RASPBERRy. Purple-flowered, Bramble (Rubrus odoratus). $3^{-5} \mathrm{ft}$ erroneously called Mulberry. An ornamental shrub with leaves resembling the Maple and showy fragrant purplish rose-colored flowers I- 2 in. across, produced all summer; fruit red and flat. All the Brambles are short lived, though hardy, the stem dying down the second year like the common Raspberry. They send out suckers and are thus propagated. Give a shaded situation and moist soil, but not under the drip of trees.

SMoke-Tree (Rhus cotinus) see Blue Shrubs, July.

SPIREA. Anthony Waterer (S. bumalda, var. Anthony Waterer). 2-3 ft. Dwarf compact habit; first flowers appear in July, forming large flat heads while the plants are but a few inches high, and as they fade, if cut off, are replaced by others, somewhat smaller and continue to bloom un- 
til frost; color a bright red, but more often a magenta; very showy when planted in masses and relieved with white flowers.

SpIREA. Purple-tipped (Spirea superba). 3-4 ft. One of our most beautiful shrubs with lovely reddish-green foliage in early spring and rich coloring in autumn; of exceedingly vigorous growth, sending up many woody stems terminating in large flat heads of purplish-red flowers. For general culture see Bridal Wreath, White Shrubs, April.

\section{JULY}

\section{RED PERENNIALS}

Avens (Geum Chilonsis, var. atrosanguineum pl. fl.). I-2 ft. A hardy plant with leaves much lobed and cut, branching stems ending in panicles of scarlet flowers. Give a rich light soil and well-drained situation. Increase by seeds or division of the root.

Bee Balm, Oswego TeA (Monarda didyma). $2 \mathrm{ft}$. Bears brilliant red flowers in whorled heads supported by leafy bracts of pale green tinged with red. The plant looks better in masses than as single specimens. Give a rich moist soil, partial shade and divide roots in autumn. Propagated also by seed.

Bittersweet. Climbing; Waxwork (Celastrus scandens). 8-20 ft. A smooth climber, and though the flowers are greenish white and somewhat inconspicuous, the beauty of the vine is in the showy three-cornered orange-red berries borne in autumn, so I class it with red perennials. The leaves are thin and finely serrated. Give a good moist soil, sun; propagated by layering young shoots in autumn.

Canna (C. Ehemanni [Crozy], var. Mme. Crozy; Rubin, Pres. Cleveland and Comte de Sachs). 3-6 ft. All red varieties. For culture see Canna White Per., July.

Callirrhö̈, Mallow Poppy (C. involucrata, var. linearloba). I-3 ft. A low prostrate plant with cut heavy foliage and loose panicles of crimson flowers 2 in. across, blooms all the season. Give a rich light sandy soil and propagate by seeds or cuttings.

Cardinal Flower (Lobelia cardinalis). $3 \mathrm{ft}$. A plant native to some portions of New England, but can be grown successfully in gardens. In its native state it is found in low wet meadows or near shaded watercourses in rich heavy soil, but I have transplanted some, placing it in rich light deep soil, quite dry and in full sun, where the roots were shaded 
by the close growth of other plants. Under such treatment a single root has sent up four stalks three feet high, bearing leafy racemes of brilliant cardinal red flowers covering over a foot of the stem. It is one of the pure full red flowers of the garden and very beautiful when the plant is well established. I advise a little protection in winter such as a plant would get by the dying down and matting of vegetation about it.

Clematis coccinea, see Leather Flower, Red.

Clematis (C. Jackmanni, var. Ville de Lyon). 4-8 ft. A showy form of Clematis, very hardy, with slender stem and scant foliage, bearing large old red flowers. For culture see Clematis, White Per., July.

CORAL Bells (Heuchera sanguinea). I ft. A very handsome though not a large plant, with a low spreading growth of leaves, and long nodding loose panicles of coral-red flowers resembling the Begonia. Give a rich deep soil, full sun and water during the flowering season. Propagated by suckers and seed.

FRENCH HoNeYSUCKLE (Hedysarum coronarium). 3-4 ft. Leaves downy beneath and at the margins, flowers a deep red in spikes or crowded racemes. Give a sunny location and rich deep soil. Propagated by seed and division of the root.

Geum, see Avens.

Hedysarum, see French Honeysuckle.

Heuchera, see Coral Bells.

HоLцуноск (Althea rosea). 4-9 ft. Single and double varieties in pure cardinal red; for culture see Hollyhock, White Per., July.

LARKSPUR. Red (Delphinium nudicaule). $2 \mathrm{ft}$. Has but few leaves deeply cut with an irridescent surface when young; tall scape scattered with orange-scarlet flowers. Give protection in winter; also rich sandy loam. Increases but slightly at the root. Propagated by seed and division of root in strong plants. For further culture see Larkspur, White Per., July.

Leather Flower. Red (Clematis Viorna, var. coccinea). $2-5 \mathrm{ft}$. A slender branching herbaceous vine that bears thick leathery pointed buds, that, when open, curve outwards only at the tips, looking more like a calyx of a flower; of a good color, but a disappointment as a flower. For culture see Clematis, White Per., July.

Loosestrife. Spiked (Lythrum salicaria, var. roseum superbum); (L. roseum superbum). $2 \mathrm{ft}$. A vigorous plant sending up several leafy stalks, bearing purplish-red or pink flowers crowded in their axils, ending in a wand-like spike $6 \mathrm{in}$. long. It is of such a peculiar color that it does 
not harmonize with pure pink or red, but grown in a mass by itself, or when isolated from other plants by much green it is strikingly handsome in effect. Give any good soil, full sun, rather a dry situation, else it runs too much to leaf. Propagate by seed or division of the root.

LYTHRUM, see Loosestrife.

PeA. Perennial (Lathyrus latifolius, var. splendens). 4-6 ft. A bright red form of this most desirable plant. For description and culture see Pea. White and Pink Per., July.

Pentstemon ( $P$. barbatus, var. Torreyi). 3-4 ft. A tall twiggy plant with pale leaves and loose raceme or panicle of handsome drooping flowers with scarlet tubular corolla, the lower petals bearded in the throat; very desirable. For culture see Pentstemon, Blue Per., July.

Poppy Mallow, see Callirrhoë.

SNAPDRAgon (Antirrhinum majus, var. Giant Scarlet and Giant $R e d) . \quad 2 \mathrm{ft}$. Two very handsome varieties of scarlet and red in both the dwarf and tall forms. For culture see Snapdragon, White Per., July.

TRUMPET CREEPER (Tacoma radicans; known also as Bignonia radicans). A climber that rises by aërial rootlets, with handsome foliage and terminal corymbs of large scarlet tubular flowers $2-3$ in. long. It takes some time to get established and does best when trained against a wall with southern exposure. It may also be trained to a single standard with drooping branches to make a hedge. If seed-vessels are not permitted to form it will bloom almost the entire season. Give a rich light loamy soil. Propagate by layering, by root cuttings or cuttings of partly ripened wood.

\section{AUGUST}

\section{RED SHRUBS}

Smoke-BusH (Rhus cotinus). Classified under Blue Shrubs, July, as a purplish-red bush, is still in bloom.

\section{AUGUST}

\section{RED PERENNIALS}

Blazing-Star (Liatris scariosa). $2 \mathrm{ft}$. A purplish-red variety with heads 2 in. in diameter in the form of an elongated corymb. For culture see Liatris, Blue Per., Aug. 
Dahlia (D. variabilis, var. Standard Bearer, [scarlet]); Wm. Agnew (red); Lucifer, a curious new hybrid variety with black stems, brown leaves and single scarlet flowers; and many other hybrid varieties in scarlet, deep red and crimson. For culture see Dahlia, White Per., Aug.

Gladiolus (G. Childsii, var. Pres. Carnot). A brilliant flaming red variety with enormous flowers. The Gladiolus does well in a rose bed as it blooms so late that the color does not conflict with that of the roses, and the growth being slender does not interfere with rose roots. Plant several times to get a succession of bloom. For culture see Gladiolus, White Per., Aug.

LIATRIS, see Blazing Star.

LILy. Siberian Coral (L.tenufolium). $2 \mathrm{ft}$. A delicate and beautiful form with 15 or more nodding scarlet or crimson flowers with reflexed petals; is a very choice variety. Propagate by seed or offsets. Is one of the first to bloom from seed.

Montbretia (Tritonia Potsii, var. étoile de feu). $2 \mathrm{ft}$. A scarlet form of this showy autumn-blooming bulbous plant. For description and culture see Montbretia, Yel. Per., Aug.

Phlox. Per. ( $P$. paniculata, var. Coquelicot). $3 \mathrm{ft}$. A pure red variety; for culture see Phlox, White Per., Aug.

Tritoma, Red-Hot Poker, Flame Flower (Kniphofia Pfitzeri; known also as $T$. Pfitzeri). $3 \mathrm{ft}$. A hardy plant that needs a little protection in my latitude. Bears dense oblong spikes of drooping orangered flowers, very showy in effect. Droughts are fatal to it, and it should be mulched and watered during the summer. Propagated by dividing the corms in early spring. Give a deep rich moist soil and sun.

\section{SEPTEMBER}

\section{RED PERENNIALS}

Japanese Lantern Plant (Physalis Francheti). I-2 ft. Closely resembles the old $P$. Alkengi. A perennial with slender white creeping rootstocks, and leaves resembling the potato. Flowers small and inconspicuous, white, and the only beauty of the plant is the extraordinary calyx, which, when ripe, forms a small inflated oval balloon of coral red, and serves as a papery husk to the enclosed globular red berry. The stalks bearing these may be cut when the leaves fall in the autumn, and 
the husks will keep their form and color for years. A rich sandy loam is best for it. Give it winter protection. Propagate by seeds and division of the root.

\section{OCTOBER}

\section{RED PERENNIALS}

Chrysanthemum. Pompon (C. Indicum, var. Dundee). A scarletmaroon variety $2 \mathrm{ft}$. high.

Chrysanthemum. Large-flowered (C. sinensis, var. Peto). Brick red. $2 \mathrm{ft}$. For culture see Chrysanthemum, Yel. and Pink Per., Oct.

\section{JUNE}

\section{RED ANNUALS}

FLAX. Scarlet (Linum grandiflorum, var. rubrum). I ft. A tender perennial grown as an annual bearing showy red flowers. Give a light soil with leaf mold, and not too wet a location. June to Sept.

Poppy. Shirley (Papaver Rhoeas, var. Shirley). 2-3 ft. The wellknown variety with branching stems and many flowers in single and double varieties in pure deep red and red with a dark spot at the base of each petal. For culture see Poppy, Shirley, White An., June.

\section{JULY}

\section{RED ANNUALS}

Adonis, Pheasant's-Eye (Adonis cestivalis). I ft. A delicately beautiful plant with finely cut fern-like foliage and solitary terminal deep-red flowers an inch across with a dark spot at the base of each petal. Sow seeds in autumn or very early in spring as they are slow to germinate. Give any good soil and sun. The seeds will keep for years. July and Aug.

Alonsoa, Marsh Flower (A. incisifolia, known also as $A$. grandiflora). I ft. A smooth branching plant bearing brilliant orange scarlet flowers an inch across. It thrives in light rich soil and can be propagated by seeds or cuttings if grown as a house plant. These can be cut in early 
spring and set out in May. The plant suffers from too much moisture; also, if given too little, the roots wither and die. July to Oct.

Amaranth. Red (Amaranthus paniculatus). $3 \mathrm{ft}$. A rather coarse weedy plant with leaves tinged and veined with red, and deep crimson flowers arranged in axillary spikes which grow larger and more branching toward the top of the plant making in time an enormous terminal panicle. It begins to bloom when less than a foot high and blooms increasingly until frost. These blooms are said to retain their freshness for a long season when cut. The leaves turn a beautiful orange-red in autumn. Clumps of Amaranthus are effective on either side of an entrance to a garden, or against shrubbery. The leaves may be used as a pot herb to take the place of spinach and are said to have medicinal qualities. Give any good soil, sun and room to develop. Self-sowing to the point of being a pest. July to Oct.

Aster. China (Callistephus hortensis, var. Victoria), and many hybrid forms in old red, crimson and scarlet. For culture see Astor, White An., July.

Balsam (Impatiens Balsamina, var. Blood Red). 2 ft. A pure deepred variety. For culture see Balsam, White An., July.

BEAN. Scarlet, or Scarlet Runner (Phaseolus multiflorus). 6-8 ft. A twining plant with showy scarlet flowers; the seed-pods are excellent as a vegetable. Give any good soil. July to Sept. Also white and pink varieties.

Cacalia, see Tassel Flower.

Celosia, see Cockscomb.

ClaRkIA (C. elegans). $2 \mathrm{ft}$. Double and single varieties in deep red. For culture see Clarkia, Blue An., June.

Соскsсомв (Celosia plumosa, var. Thomson's Magnifica). $2 \mathrm{ft}$. A bushy variety with red and dark-green foliage and many branching pyramidal clusters of feathery red flowers. Does better for frequent transplanting; do not crowd if dwarf habit is desired. A light soil is preferred. For culture see Celosia, Pink An., June.

Callomia (Gilia coccinea), (C. coccinea). I ft. A rather coarse weedy plant bearing small tubular coral-red flowers in terminal clusters; not worth much except that it survives the early frosts and continues to bloom when almost everything else is gone. Thrives in any good soil; is selfsowing. June to Oct.

Cosmos (C. bipinnatus, var. Early Hybrid). 4 ft. A magenta-red variety which if placed properly will not clash with other tones, but the 
pink and white varieties are far prettier. Stake early and pinch back to make a branching growth. Self-sowing to a slight degree. June to Oct. For culture see Cosmos, White An., June.

Godetia. Satin Flower (G. amcena, var. Gloriosa; known also as $G$. Lindleyi and G. rubicunda). I ft. A variety with deep-red flowers of glistening silky texture. For culture see Godetia, Pink An., June. Selfsowing.

Mignonette (Reseda odorata, var. Excelsior). I ft. A coppery red variety and Goliath, a red form. For culture see Mignonette, White An., July.

Mesembryanthemum ( $M$. crystallinum). 4 in. A deep red variety of low succulent plants that open their flowers only in the sun. For culture see Mesembryanthemum, White An., July.

NASturtium. Dwarf (Tropaolum nor, var. Compact Lustrus). I ft. Deep red.

Nasturtium. Tall. (Tropaolum majus, var. coccineum). $4^{-6} \mathrm{ft}$. Bright scarlet.

NASTURTIUm. Lobb's (Tropaohım Lobbianum, var. Ivy-leaved). Bluish-green ivy-shaped foliage and deep-red fringed flowers. For culture see Nasturtium, White An., July.

Pink. Chinese, can be grown as an annual; for culture see Pink. Chinese, Red Per., June.

Petunia ( $P$. grandiflora $) .2 \mathrm{ft}$. Many hybrid varieties in crimson and magenta; very showy for those who like them. For culture see Petunia, White An., July.

Phlox (P. Drummondii grandiflora, var. Blood Red). 2 ft. A very beautiful form of this old favorite in pure cardinal red. For culture see Phlox, White An., July.

Poppy. Peony (Papaver somniferum). 3-4 ft. In both single and double varieties in pure cardinal red; one of the showiest flowers of the garden, but lasts only two or three weeks. For culture see Poppy, White An., July.

Portulaca (P. grandiflora, var. Scarlet). 6 in. See Portulaca, White An., July.

SATIN Flower, see Godetia.

Scabious. Sweet (Scabiosa atropurpurea, var. Blood Red). $2 \mathrm{ft}$. A beautiful variety of this very desirable flower. See Scabious, White An., July.

Snapdragon (Antirrhinum majus, var. Giant Scarlet). Can be grown as an annual. For culture see Snapdragon, Red Per., July. 
Srock. Ten Weeks (Matthiola annua, var. Victoria) in a deep rich red. See Stock, White An., July.

Sweet-PeA (Lathyrus odoratus, var. Phyllis Unwin). 4-6 ft. A red variety. See Sweet-Pea, White An., July.

TASSEL FlOWER (Emilia sonchifolia, var. coccinea; cultivated under the name Cacalia). $2 \mathrm{ft}$. An erect plant with opposite leaves clasping the stem and terminal clusters of brilliant orange-scarlet fringed flowers. It should be staked. Give any good soil. July to Oct.

Verbena ( $V$. chamcedrifolia, var. Defiance). 2-3 ft. A long established variety with brilliant red flowers; very hardy. It makes a valuable house plant if raised from seed; for, after blooming all summer, it may be cut back, and with a little period of rest, it will bloom all winter. Plants raised from seed are stronger than those from cuttings. Give a rich moist soil. July to Oct.

VISCARIA or Rock LyCHNIS. A red variety of Lychnis coli-rosa commonly called Agrostemma coli-rosa. For culture see Agrostemma, Pink An., July.

ZINNIA (Z. elegans). Hybrid varieties in scarlet, pure red and crimson. See Zinnia, White An., July.

\section{AUGUST}

\section{RED ANNUALS}

BLANket Flower (Gaillardia puchella; known also as Gaillardia picta, var. Amölyodon). I $\frac{1}{2} \mathrm{ft}$. A deep-red variety blooming until frost. For description and culture see Gaillardia, Yel. An., Aug.

Cypress-Vine (Ipomea quamoclit). 3-5 ft. A delicately beautiful vine with green thread-like leaves and star-shaped brilliant red flowers. Give a light well-enriched soil, full sun and moisture. It is killed by the first frost.

Gaillardia, see Blanket Flower.

Marvel of Peru (Mirabilis Jalapa). $3 \mathrm{ft}$. A coarse weedy plant with fragrant crimson flowers. The roots form tubers and can be kept over winter as Dahlias are and replanted the next year. Give a rich soil and moisture.

Nicotiana ( $N$. Sandera). $3 \mathrm{ft}$. A brilliant red variety, very free flowering and fragrant like $N$. affinis. For culture see Nicotiana, White An., Aug. 
Salpiglossis (S. simuata, var. Maroon Golden-veined). $3 \mathrm{ft}$. A red variety veined with yellow. See Salpiglossis, White An., Aug.

SALvia (S. splendens, var. Clara Bedman). 2 ft. A branching variety with dark-green leaves, and both the calyx and corolla of the flowers are brilliant red. Not a satisfactory house plant, though it may be raised from seed in the house and planted out in summer. Rather a tender plant in the North, but if protected from the first early frosts, will probably bloom until Oct. Give a deep rich soil and an occasional bath of soap-suds through the summer.

Wallflower (Chieranthus cheiri, var. Early Parisian). I-3 ft. A bright blood-red variety of this most delicious flower, whose fragrance is unequaled. When a plant is well established, it can be lifted, and taken indoors, where it will bloom almost continuously for months if the seedvessels are removed as fast as they form. Prune to secure a bushy growth. Give a deep rich soil, moisture and sun. Strong plants are secured from cuttings that root easily and make a woody growth in a year or two. Not quite hardy out of doors in the North. 
INDEX 



\section{INDEX}

Abronia, $A$. fragrans, 200; $A$. areneria, 243; A. umbellata, 266

Acacia, False, see Locust Tree; Rose, Robinia hispida, $25 \mathrm{r}$

Achillea, A. Ptarmica, I77

Aconite, wild, Aconitum unciatum, $2 \times 7$

Aconitum Nepallus, var. albus, Monkshood, white, r89; A. unciatum, Wild Aconite, 2I 7; $A$. storkianum, 2 I7

Adam, gifts to, $40,4 I$

Adam's Needle, see Yucca

Adam's statistics, r9, 20; hoeing, 47,48

Adenophora potanini, 217

Adlumia cirrhosa, Allegheny Vine, $75,76,253$

Adonis, Spring, A. vernalis, 23x; Pheasant's Eye, $A$. astivalis, 282

Adonis vernalis, Spring Adonis, 23I; $A$. astivalis, Pheasant's Eye, 282 Egopodium podigrarium, Goutweed, 180

Ethionema, A. grandiflora, 249

African Daisy, Arctotis grandis, 200

Ageratum, A. Mexicanum, 200; $A$. conyzoides, 226, 270

Ageratum Mexicanum, Ageratum, Painters' Brush, 200; A. conyzoides, Mist Flower, 226, 270

Agrostemma, Rose of Heaven, $A$. cæeli-rosa, 200, 266

Agrostemma coli-rosa, Rose of Heaven, 200; Red Viscaria, 285

Aim of book, I, 2

Allegheny Vine, Adlumia cirrhosa, 76,253

Almond, Flowering, Prunus Japonica, I66; var. rosea, 247

Alonsoa incisifolia, Marsh Flower, 282

Althea, see Rose Mallow

Althea rosea, Hollyhock, I93, 240, 260, 279
Althea, Shrubby, see Rose Mallow, I96, 264, 265

Alyssum, Rock, A. saxatile, 23I; sweet, A. maritimum, I98

Alyssum maritimum, Sweet Alyssum, x98; A. saxatile, Rock Alyssum, $23 \mathrm{I}$

Amaranth, Red, Amaranthus paniculatus, 283

Amateur work, 20

Ambrosia artemesiafolia, 69; $A$. Mexicanum, 78

Amelanchier Canadensis, Shad Bush, I67

American Cowslip, see Dodecatheon Amorpha canescens, Lead Plant, 8r, 22I; A. fruticosa, False Indigo, $2 \mathrm{I} 6$

Amsonia Tabernamontana, 214

Anagallis, A. carulea, 228

Anaphalis margaritacea, Immortelle, r94

Anchusa capensis, 226; A. Barrelieri, 67, 2II; $A$. Italica, var. Dropmore, $2 \mathrm{I} 7$

Andromeda, A. perifolia, 247

Anemone, Pennsylvania, A. Pennsylvanica, I26, I27, I78; Japanese, A. Japonica, 196, 265

Anemone Pennsylvanica, Penn. Anemone, I26, I27, I78; A. Japonica, Japanese Anemone, r96, 265; A. pulsatilla, Pasque Flower, 2 II

Angelica archangelica, Archangelica, I 78

Angelica Tree, Aralia spinosa, ror

Animal onchard, Margaret's, 48

Anniversaries, 40

Annuals, 46; fragrant, 72; selfsowing, 47, 6r; showiest in blue, pink, red, yellow and white, 84,85 , 86,87 ; sowing in hotbed, $5 \mathrm{r}$; best way to start, 52,53

Anthemis cotula, Dog-Fennel, 202 
Anthemis tinctoria, Chamonile, 237 Antirrhinum majus, Snapdragon, I9O, 206, 239, 244, 280, 284

Aphis, blue, ${ }^{132}$

Aquilegia Californica, California Columbine, 23I; $A$. carulea, Long Spurred Columbine, 21 $2 ; A$. Canadensis, Rock or Wild Columbine, 23I, 273; $A$. chrysantha, Spurred Columbine, I69, 23I; A. Jatschui, 23I; A. Olympia, 2I2; A. Skinneri, Mexican Columbine, 273; A. vulgaris, Common Garden Columbine, 21 2, 249, 273 Arabis albida, Rock Cress, I68, I7I; A. alpina, Alpine Rock Cress, I7 I Aralia spinosa, Angelica Tree, I9I; A. Chinensis, see Dimorphanthus Arbor, 46; seat, I4

Archangelica, Angelica archangelica, $88,89,178$

Arctotis grandis, African Daisy, 200 Argemone Mexicanum, Mexican Poppy, 200

Armeria cephalotes, Thrift, I83; $A$. elongata, 254; $A$. plantaginea, Plantain-leaved Armeria, 254; $A$. vulgaris, Common Thrift, 254

Arrowwood, see Snowball

Artemesia Abrotanum, Boy Love, 78, 184; $A$. annua, Sweet Fern, 78, 207, 208

Artichoke, Jerusalem, Helianthus tuberosa, 24I

Asclepias tuberosa, Butterfly Weed, 237

Ash, Mountain, Sorbus Americana, I73

Ashes, wood, 55, I29, I32

Asperula azurea setosa, Blue Asperula, 224; $A$. hexaphylla, II3, I78; $A$. odorata, Sweet Woodruff, I68, I7 2

Asphodel, White, Asphodelus albus, I08; Yellow, Asphodeline lutea, 233

Asphodeline lutea, Yellow Asphodel, 233

Asphodelus albus, White Asphodel, I68

Aster, Alpine, A. alpinus, 223; native white, $A$. paniculatus, 44, I96; New England, A. Nove-
Anglia, 223, 265; A. Novi-Belgii, 223; Michaelmas Daisy, $A$. tradescanti, 223

Aster alpinus, Alpine Aster, 223; A. Nova-Anglia, New England Aster, 223, 265; A. Novi-Belgii, 223; A. paniculatus, Native White Aster, 44, r96; $A$. tradescanti, Michaelmas Daisy, 223

Aster, China, Callistephus Chinensis, 200, 226, 266, 283

Aubretia, $A$. deltoides, 2II, 272

Aubretia deltoides, Aubretia, 2II, 272

Auratum Lily, Lilium auratum, III; disease of, I32; I94

Australian Star Flower, Cephalipterum Drummondii, 267

Autumn color in perennials, 79 ; in shrubs, 80

Avens, Geum Shilcensis, 278

Average woman, 2

Awning, 40

Azalea, smooth, A. mollis, 166; tree, $A$. arborescens, 25I; $A$. vaseyi, 247

Azalea arborescens, Tree Azalea, 25I; A. mollis, Smooth Azalea, I66; A. vaseyi, 247

Baby Blue Eyes, Nemophila insignis, 225

Baby's Breath, Gypsophila paniculata, 184, 185; Galium Mollugo, I85

Baby show in South, 136

Bachelor's Button, see Cornflower

Bacon, Lord, I45

Balm, see Bee Balm

Balsam, Impatiens Balsamina, 20r, 267,283

Baptisia, B. australis, 217

Barbarea vulgaris, Yellow Rocket, 235

Barberry, Common, Berberis vulgaris, 232; Japanese, B. Thunbergii, 232; purple-leaved, $B$. vulgaris, var. atropurpurea, 80 , 232

Bartonia, Mentzlia Lindleyi, 242

Bean, Hyacinth, Dolichos lablab, 220; scarlet, Phaseolus multiflorus, 283 
Beauty, perfect examples of, I 54

Beard Tongue, Pentstemon acuminatus, 220

Bear Grass, see Yucca

Bed, nursery, 57 ; preparing 4,5

Beds, annual seed, 52, 53

Bedstraw, Northern, Galium boreale, I78; Lady's, $G$. verum, 233; white, $G$. Mollugo, 185

Bee Balm, Monarda didyma, 278

Beech, Purple-leaved, Fagus sylvatica, var. purpurea, 80

Bees, r 28 ; bumble bees in hollyhocks, 128

Beetle, aster, I27; oil, I26; rose, I24, I 25

Beetle, May, 54, 55

Bellfower, see Campanula

Bellflower, Japanese, see Platycodon

Bellis perennis, English Daisy, 58, I69

Belvedere, Kochia scoparia, $78 ; K$. tricophila, 78

Berberis vulgaris, Common Barberry, 232; var. atropurpurea, Purple-leaved Barberry, 80, 232; $B$. Thunbergii, Japanese Barberry, 232

Bibio fly, 120

Bignonia radicans, Trumpet Creeper, 280

Bittersweet, Climbing, Celastrus, scandens, 233,278

Black-eyed Susan, Rudbeckia hirta, 237

Blanket Flower, see Gaillardia, 233, 242, 294

Blazing Star, see Liatris

Bleeding Heart, Dicentra spectabilis, 249

Blight, aster, I32; larkspur, II4; Government remedy for larkspur, I29; my remedy for, I30; Physostegia, I3I, I32; carnation, I32

Bloom, length of, 36 ; succession of, 9, 33; in blue beds, $34-36$

Blooming, record of, 37

Blue annuals, 35, 224-229; edging plants, $82-83$

Blue and white combinations, 35 , 36

Blue beds, 34 ; difficulties of, 35 ; white flowers in, 35
Bluebells, see Lungwort

Bluebells of Scotland, see Harebell

Blue-eyed Grass, Sisyrinchium angustifolium, 2I4

Bluets, see Houstonia

Blue Flowers, $210-229$

Blue Perennials, 2ro-2Ir, 2II-2I6, 2I 7-22I, 222, 223-224

Blue Shrubs, 2II, 221-222, 223

Blue Succory, see Catananche

Blue spring flowers, 36

Bocconia, B. cordata, 185

Boltonia, B. asteroides, ro3, r97; $B$. levigata, $265 ; B$. latisquama, 223

Boneset, see Thoroughwort

Book of Wisdom, I46, I47

Bordeaux mixture, I30; formula for, 129

Border plants for succession of bloom, 82

Botanical names, use of, 70 ; meaning of, $7 \circ$

Bouncing Bet, Saponaria officinalis, 263

Bowman's Root, Gillenia trifoliata, 254

Boy Love, Artemesia Abrotanum, 78,184 ,

Bridal Wreath, Spirea prunifolia, I66

Broom, Scotch, Cytisus scoparius, 232; see Dyer's Greenwood

Brotherhood in forest, II3; in Nature, 132

Browallia, B. demissa, 228

Browne, Sir Thomas, 59

Buddleya Lindleyana, $22 \mathrm{I}$

Bug, potato, 23, I 26, I 27

Burning Bush, Euonymous atropurpureus, 80 , '216

Bush Honeysuckle, see Honeysuckle, Bush

Buttercup, Gold Cup, Ranunculus bulbosus, 234; tall, $R$. acris pl. fl., 234.

Butterflies, II9

Butterfly Flower, Gaura Lindheimeri, 187, 202, 267, 269

Butterfly Flower, Schizanthus Wisetonensis, 269

Butterfly Weed, Asclepias tuberosa, 237 
Cacalia, see Tassel Flower

Calendula, Pot Marigold, $C$. officinalis, 242

California Poppy, see Eschscholtzia, I98, 242

Calimeris, Cut-leaved, C. incisa, 2I7

Calandrinia, C. Menziesii, I98

Calliopsis, see Coreopsis

Callirrhoë, 58; Poppy mallow, C. involucrata, 278

Callistephus Chinensis, China Aster, 200, 226, 266, 267, 283

Callomia, Gilia coccinea, 283

Calycanthus floridus, Sweet-scented Shrub, 273

Calystegia pubescens, C. Californica, Japanese Rose, 254

Camass, Giant, Camassia cusicki, 2 II

Camassia cusicki, Giant Camass, 2 II

Camera, I34; first use of, I36-137

Campanula, Bellflower, C. Carpatica, 214; C. glomerata, 214; C. Mariesi, ı85; C. medium, Canterbury Bells, 185, 2I7; C. rapunculoides, I85, 2I 4 ; C. rotundifolia, Harebell, 219; C. persicifolia, 185, 214; C. turbinata, I85, 2I4

Campion, Alpine, Lychnis alpina, 249; Rose, Agrostemma coli-rosa, 266

Canary Bird Flower, Tropaolum perigrinum, 243

Candytuft, Evergreen, Iberis sempervirens, I68; annual, Iberis umbellata, 198, 226, 266

Canna, C. Ehemanni, 192, 240, 258, 263,278

Canna Ehemanni, Canna, I92, 240, $258,263,278$

Canterbury Bells, Campanula medium, I85, 217, 259, 260

Caraway, Garden, Carum carui, I7 8

Cardinal Flower, Lobelia cardinalis, $75,278,279$

Carnation, see Pink; blight, 132

Carrot, Wild, Daucus carrota, I9o

Carum carui, Caraway, 178

Caryopteris mastacanthus, Blue Spirea, 212

Catalogues, 2, I2, I3
Catananche, Cupid's Dart, C. carulea, 2I 7 ; C. bicolor, 217

Catchfly, Sweet-William, Silene Armeria, 20I, 269; Autumn, $S$. shafta, 254, 277; S. pendula, 267; $S$. compacta, 267

Cats, I 2 I

Celastrus scandens, Bitter-sweet, Climbing, 233

Celosia plumosa, Cockscomb, 207, 244, 283; C. cristata, 244;C. spicata, 267

Centaurea moschata, Sweet Sultan, I99, 225, 243; C. nigra, Mountain Knapweed, 215; C. cyanus, Cornflower, 201, 224, 267

Centaury, see Sabbatia

Centranthus albus, 201, 267; C. ruber, 258, 277

Cephalipterum Drummondii, Australian Star Flower, 267

Ceratostigama plumbaginoides, Leadwort, Plumbago, 224

Cercis Canadensis, Red Bud, Judas Tree, 273; C. Chinensis, Chinese Red Bud, 273

Chamomile, Anthemis tinctoria, 237

Chance combinations, $33,44,45$

Chaste Tree, Vitex agnus-castus, 22 I

Cheese cloth coverings from frost, 53 ; frames, 57 ; awning for beds, $5^{8}$

Chelone, Turtle Head, C. Lyoni, 260 Cherokee Rose, IOI

Chieranthus cheiri, Wallflower, 286

Chionanthus Virginicus, White Fringe, I66

Chrysanthemum, Hardy, C. siense, 242, 266, 282; pompon, $C$. Indicum, 265, 282

Chrysanthemum coccineum, Pyrethrum, $257 ; C$. frutescens, Paris Daisy, I78; C. Indicum, Pompon Chrysanthemum, 265, 282; C. leucanthemum, Wild White Daisy, II9; C. latifolium, I86; C. maximum, I86; $C$. parthenium, Feverfew, I68; $C$. siense, Hardy Chrysanthemum, 242, 266, 282; C. uliginosum, Great Ox-Eye Daisy, 186

City bred, the, 46

Clarkia puchella, 20I, 224; C. elegans, 266, 283 
Clematis, Jackman's, C. Jackmanni, I3I, I85, 2 I7, 2I8, 254, 279; erect, C. recta, I78; Japanese, C. paniculata, 67, I97; heavy-scented, $C$. orientalis, C. gravolens, 238 ; red, or Leather Flower, C. Viorna, var. coccinea, 279; wild, or Traveler's Joy, C. Virginiana, I9o

Clematis coccinea, Jackman's Red Clematis, 254; C. recta, Erect Clematis, I78; C. Jackmanni, Jackman's Clematis, I3r, I85, 217, 218, 254, 279; C. gravolens, Heavy-scented Clematis, 238; $C$. Heraclafolia, var. Davidiana, 218; C. integrifolia, 218; C. orientalis, see C. gravolens; C. paniculata, Japanese Clematis, 67, r97; $C$. Virginiana, Wild Clematis or Traveler's Joy, I9o; C. viorna, var. coccinea, Red Clematis or Leather Flower, 279

Cleome pungens, Spider Plant, 201

Clethra alnifolia, Sweet Pepper Bush, I84

Close planting, I02, 103

Cockscomb, Celosia cristata, 244; C. plumosa, 244, 283; C. spicata, 267

Cold frame, 56

Collinsia, C. bicolor, 226

Color code for marking seeds, $6_{3}$

Color effects, arranging for, 37 ; in shrubs, $80,8 \mathrm{I}$; plants for general, 37 ; schemes, arranging, 74; separating, 74

Color, pure, 34; wave of, $36,61,62$; of stems, 62; autumn, in perennials, 99; autumn color in shrubs, 79,80 ; sheets of, 145; keynote of, in a garden, I46; my love of, I54; classification by, I63

Columbine, California, Aquilegia Californica, 23I; common, $A$. vulgaris, 212, 249, 273; rock or wild, A. Canadensis, 273; Mexican, A. Skinneri, 273; spurred, $A$. chrysantha, I69, 23I; long-spurred, A. corulea, 2I2; A. Jaetschui, 23I; A. Olympica, 212

Combinations, blue and white, 35 , 36 ; chance, 38 ; successful, 87,88 ; white in, 88
Commelina, $C$. coelestis, 215, 229; $C$. erecta, 228

Compost heap, 3I, 55, 93, I 2 I

Cone Flower, see Rudbeckia hirta, 237

Convallaria majalis, Lily of the Valley, r7o

Copper sulphate, I29, I3 I

Convolvulus, Dwarf, C. tricolor or C. minor, 224

Convolvulus tricolor, Dwarf Convolvulus, 224; C. Japonica, see Calystegia, 254

Coral Bells, Heuchera sanguinea, 279

Coreopsis, Tickseed, C. lanceolata, 234; Golden Wave, C. Drummondii, 243

Corn-flower, Centaurea Cyanus, 20I, 224, 267

Cornus florida, Flowering Dogwood, I72; C. paniculata, Dogwood, panicled, 184

Coronilla varia, Crown Vetch, 260

Corylus purpureus, Purple Hazel, 8I

Cosmos, early, C. bipinnatus, 22, I85, 267, 27I, 283; tall, as a background, 79; as a house plant, 79, 208

Cosmos bipinnatus, Cosmos, 22, 185 , 208, 267, 27 I, 283

Crab Apple, Japanese, Pyrus floribunda, 248

Crape Myrtle, Lagerstrcemia Indica, 263

Cratagus coccinea, Scarlet Thorn, r68

Crickets, 56

Crocus, $C$. vernis, 165, 2 10; Cloth of Gold, C. susianus, 230; Dutch, $C$. masiacus, 230

Crocus vernis, Crocus, I65, 210, 230; C. susianus, Cloth of Gold, 230; C. masiacus, Dutch Crocus, 230

Cross fertilization, I 16

Crosswort, Crucienella stylosa, 254

Crown Imperial, Frittilaria imperialis, 275

Crown Vetch, Coronilla varia, 260

Crucienella stylosa, Crosswort, 254

Cutting back tall plants, $\mathrm{IO}_{3}$

Cuttings, propagation by, 97, 98

Cutworms, 55, I20 
Cyclamen, Autumn-flowering, Sowbread, C. Europaum, 263

Cydonia Japonica, Japan Quince, 272,273

Cynoglossum, Omphaloides linifolia, I 8,224

Cypress Vine, Ipomea quamoclit, 285

Cytisus scoparius, Scotch Broom, 232

Daffodil, see Narcissus

Dahlia, D. variabilis, 197, 240, 263, $28 \mathrm{I}$

Dahlia variabilis, Dahlia, I97, 240, 263, 28I

Daisy, English, Bellis perennis, 58, r69; Paris, Chrysanthemum frutescens, I78; wild white, $C$. leucanthemum, 179; Great Ox-eye, $C$. uliginosum, 186

Damping off, 30,57

Datura, D. arborea, 202; D. metaloides, 245

Daucus carrota, Wild Carrot, I9o

Day Lily, Japan, Funkia subcordata, I92; blue, Funkia ovata, 222

Delphinium consolida, Branching Larkspur, 203, 229; D. Ajacis, Rocket Larkspur, 203, 229, 268, 270; D. elatum, Bee Larkspur, 2I9; $D$. formosum, Showy Larkspur, 2I9; $D$. formosum, var. ccelestinum, Azure Blue Larkspur, 2I9; $D$. grandiflorum, Great-flowered Larkspur, 219; D. grandiflorum, var. album, White Larkspur, 187

Desmodium penduliflorum, see Lespedeza, 223, 264

Deutzia, Slender, D. gracilis, 166; D. Lemoinei, 166, $23 \mathrm{I}$

Dianthus barbatus, Sweet-William, $183,258,277 ; D$. casius, Cliff Pink, $256 ; D$. caryophyllus, Carnation Pink, I82, 256, 276; $D$. Chinensis, 276; D. cruentus, 65; $D$. Heddewigii, Japanese Pink, I82, 205, 256; D. plumarius, Hardy Garden Pink, Pheasant's Eye, Feather Pink, I82, 257

Dicentra spectabilis, Bleeding Heart, 249

Dictamnus fraxinella, Fraxinella,
I86, I87; D. albus, var. rosea, 260

Diervilla florida, see Weigelia, I77, 25I; D. sessilifolia, Bush Honeysuckle, 230

Difficulties of stone heap, 15

Digitalis alba, White Foxglove, 58, 179; $D$. purpurea, Red Foxglove, 276; D. purpurea, var. gloxinaflora, Gloxinia-throated Foxglove, 255; D. lantana, Woolly Foxglove, I86

Dimorphanthus Mandschuricus, I9I

Distance between plants, IOI, IO2

Dodecatheon media, Shooting Star, I03, 179

Dog-fennel, Anthemis Cotula, 202

Dogs in a Garden, I2I

Dogwood, Flowering, Cornus florida, I72; panicled, C. pariculata, I84

Dolichos lablab, Hyacinth Bean, 226, 235

Doronicum Caucasicum, Leopard's Bane, 234

Dracocephalum, D. Rhyschianium, 218

Dropwort, Spirea filipendula, I79

Drought, effects of, 7

Drudgery, 157

Dry bed, 8; plants for, 8

Dyer's Greenwood, Broom, Genista tinctoria, 232, 233

Early efforts in gardening, 3, 4

Edging plants, blue, 82,83 ; pink, 83; red, 83; yellow, 83,84

Edgings for bed, 20

Eel worm, I3I

Eglantine, see Sweet Brier

Egyptian Bean, see Bean, Hyacinth Elcagnus longipes, Oleaster, 236; $E$. umbellatus, 236; E. parvifolius or $E$. argentea, Silver Berry, Silver Tree or Thorn, 8x, 236

Elder, Golden, Sambucus nigra, var. aurea, 80, 8I

Elderberry, Sambucus Canadensis, I84

Elizabeth Eliza Peterkin, I35

Emilia sonchifolia, Tassel Flower, 283,285

Encyclopædias as family records, I5I, I52 
English Daisy, Bellis perennis, 58, I69

Enthusiasm, effect of, 38, 39

Eremurus robustus, 64, 65, 249

Erigeron glaucus, Fleabane, 222

Erigonum umbellatum, 238

Eritrichium nothofulvum, 202

Eryngium amethystinum, Sea Holly, 220

Erysimum, Hedge Mustard, $E$. puchellum, 23I; E. Perofskinanum, 245

Erysimum puchellum, Hedge Mustard, 23I

Eschscholtzia, California Poppy, E. Californica, I98, 242, 267

Eucharidium concinnum, 202

Euonymous atropurpureus, Burning Bush, 80, 216

Eupatorium ageratoides, White Snakeroot, I95; E. colestinum, 218; $E$. perfoliatum, Thoroughwort, 19r; E. purpureum, Joe-Pye Weed, 263

Euphorbia corollata, Flowering Spurge, I86; E. heterophylla, Mexican Fire, 69; E. pulcherrima, Poinsettia, 69

Eutoca, E. viscida, or Phacelia viscida, 224.

Evening Primrose, CEnothera acaulis, 202; O. biennis, 238; O. Missouriensis, 238

Everlasting, Pearly, see Immortelle, I94

Evil, sources of, ro7

Exchange of plants, to

Exercise, value of, 8, I 56

Exochorda grandiflora, Pearl Bush, I67

Exposure, southern, 90

Fagus sylvatica, var. purpurea, Beech, Purple-leaved, 80

Fall Dandelion, see Hawkbit

False Indigo, see Baptisia, 217; Amorpha fruticosa, $2 \mathrm{I} 6$

False Miterwort, see Foam Flower, I79

False taste in parks, 73

Fennel Flower, see Nigella, 204, 227

Fenzlia, Gilia dianthoides, 268
Ferns, 75; transplanting, 75; with Oriental Poppy, 87, 88, 257

Feverfew, Chrysanthemum parthenium, 186

Fire Pink, Silene Virginica, 276

Flame Flower, see Tritoma, $28 \mathrm{I}$

Flax, Golden, Linum flavum, 234; scarlet, Linum grandiflorum, 182

Fleabane, Erigeron glaucus, 222

Flies, biting stems, I 28

Flowering Almond, Prunus Japonica, x66; var. rosea, 247

Flowers closing at night, 89 ; opening at night, 89; closing in sun, 89; cutting, 147; cut, 156 ; vulgar effects in, 69

Foam Flower, Tiarella cordifolia, I79

Foliage, stripping off large, IO2

Forces, use of, I4I

Forcing house, substitute for, $3 \mathrm{I}$

Forest Trees, 56, 57; secret purpose of, II3; showing twining propensitiès, II4

Forget-me-not, Myosotis alpestris, I69, 212, 250; M. palustris, 212; var. semperflorens, 2I2; M. sempervirens, 226

Forsythia, $F$. viridissima, 230; Weeping, $F$. suspensa, 230

Forsythia viridissima, Golden Bell, 230; $F$. suspensa, Weeping Forsythia, 230

Foxglove, White, Digitalis alba, 58, I79; red, D. purpurea, 276; woolly, D. lantana, I86; Gloxiniathroated, $D$. purpurea gloxiniceflora, 254

Fragrance in garden, 27, 7 1 ; of foliage, 69; near rustic seat, 45

Fragrant annuals, 73 ; herbs, 78 ; perennials, 72; shrubs, 72; vines, 72

Fragrant Evening Stock, Matthiola odoratissima or $M$. bicornis, 225

Fraxinella,' Dictamnus fraxinella, I86, 187, 250; D. albus, var. rosea, 260

Friendship offerings, to

Fringe Flower, Schizanthus bipinnatus, 206, 228

Fringe, White, Chionanthus Virginicus, 166 
Fritillaria imperialis, Crown Imperial, 275

Frosts, effects on house-bred seedlings, 32 ; protection against, 53 Fugi-yama, 91

Funkia subcordata, Japan Day Lily, I92; $F$. ovata, Blue Day Lily, 222

Gaillardia, Blanket Flower, $G$. aristata, 237, 238; G. picta, 242; G. puchella, 285

Galanthus nivalis, Snowdrop, I65

Galgea, $G$. officinalis, I79, I80, 215

Galium boreale, Northern Bedstraw, 178; G. Mollugo, Baby's Breath, I85; G. vernum, Lady's Bedstraw, 233

Galtonia, Summer Hyacinth, Hyacinthus candicans, 180

Garden, a choice, ro9; adding to, 9०; apologies for, I53; authors', I; arrangement of, 33; average, I47; background of, I4; diagrams for, 14 ; exercise in, $8, r_{5}$, experimental, I5I; extension of, 27; latest, extension of, I42, I43; arrangement of plants in, I43; facing west, $8 \mathrm{I}$; family history in, I52; first idea of, $1_{3}$; first size of, $2 \mathrm{I}$; real flower of, 158, 159; fragrance of, 24, 7x; green in, 73 , 74 ; green in winter, 42; keynote of color in, 146; lady in, 27, 28, 29; latitude of, I64; lay of, I7; neglect of, 26, II6; night aspects of, I43; relating garden to house, 9r; requirements of, I2; studying, I4I, 142, I59; present size of, 89; single specimens in, 153 ; soul of my, 159, I60; time given to, 89, 9o; varied conditions in, 33; walking in, 25

Gardener, tests of, II9; conventional, I45; too generous, I47; conservative, 150

Garden Heliotrope, Valeriana officinalis, II $3, \mathrm{I} 80$

Gardening, 68; in Minnesota, I2; defense of my aim in, I5I, I55

Garden site, advantages of, I6

Gas Plant, see Fraxinella

Gathering seeds, 63
Gaura Lindheimeri, Butterfly Flower, $65, \mathrm{II}_{3}, 202$

Genista tinctoria, Dyer's Greenwood, 232, 233

Gentian, Closed, Gentiana Andrewsii, 218; fringed, G. crinata, 60, 218; white, G. alba, $\mathrm{r}_{92}$

Gentiana crinata, Fringed Gentian, 60, 218; G. alba. White Gentian, I92; G. Andrewsii, Closed Gentian, 218

Gerardia, G. tenufolia, 260

Geum Chilcensis, var. atrosanguineum, Avens, 278

Gilia, G. achilleafolia, 226; G. androsea, Leptosophon, 207; G. capitata, 226; G.tricolor, 226; G. dianthoides, Fenzlia, 268; G. coccinea, Collomia, 283

Gillenia trifoliata, Bowman's Root, 254

Gillyflower, see Stock

Gingko Tree, Salisburia adiantifolia and $G$. Biloba, 79

Gladiolus, G. Childsii, I92; $G$. Lemoinei, 240, 263, 221

Gladiolus Childsii, 192, 263; C. Lemoinei, 240, 263, 28I

Globe Daisy, Globularia tricosantha, 212

Globe Flower, Trollius Asiaticus, 234

Globularia tricosantha, Globe Daisy, 2 I2

Gloves, 29

Gloxinia, Hardy, see Incarvillea, 255

Gluttonous visitors, I48

Goat's Beard, Spirea Aruncus, I8

Goat's Rue, see Galega, I79, I80

Godetia amæena, Satin Flower, 202, 268, 284

Golden Glow, Rudbeckia laciniata pl. $f$., 238

Goldenrod, Solidago juncea, 238

Golden Wave, Coreopsis Drummondii, 243

Goutweed, Agopodium podograrium, r8o

Grasshoppers, 57

Green, use of, in garden, 73

Ground covers, annuals as, 76 ; for beds, 76 ; Shirley poppies as, 76,77

Grubs, white, 54, 55, I 18 
Guelder Rose, see Snowball Tree, I76

Gypsophila, Baby's Breath, $G$. paniculata, I85; Steven's, $G$. Steveni, G. glauca, 187 ; annual, $G$. elegans, 198

Gypsophila paniculata, Baby's Breath, 185; G. Steveni, Steven's Gypsophila ( $G$. glauca), $187 ; G$. elegans, Annual Gypsophila, I98

Halesia tetraptera, Snowdrop Tree, I67

Hardhack, see Steeple Bush, 262

Harebell, Bluebell of Scotland, Campanula rotundifolia, $2 \mathrm{I} 9$

Hawkbit, Leontodon autumnale, 276

Hazel, Purple, Corylus purpureus, $8 \mathrm{I}$

Heart's-Ease, see Pansy, Viola tricolor, 210

Hedge Mustard, see Mustard, Hedge

Hedge Nettle, Stachys lantana, 2 I9

Hedysarum coronarium, French Honeysuckle, 279

Helen Flower, Helenium autumnale superbum, 103, 240

Helenium autumnale superbum, Helen Flower, I03, 240

Helianthemum, Rock Rose, $H$. mutabile, 180,258 ; Sun Rose, $H$. alpestre, 234

Helianthus, Sunflower, I03, 245; $H$. mollis, Smooth Sunflower, 67, 24I; $H$. decapetalus multiflorus, 24r; $H$. latiflorus, 24I; $H$. orgyalis, Graceful Sunflower, 24I; $H$. tuberosa, Jerusalem Artichoke, $24 \mathrm{I}$

Heliopsis lavis, False Sunflower, Pitcher's Ox-Eye, 239

Heliotrope, Garden, see Garden Heliotrope, 180

Helipterum Manglesii, Rhodanthe, 205,269

Hellebore, white, I 26

Hemerocallis flava, Yellow Day Lily, 234

Hercules Club, sec Angelica Tree, I9I

Hesperis matronalis, Sweet Rocket, $65,185,215$
Heuchera sanguinea, Coral Bells, 279

Hibiscus Swamp Rose Mallow, $H$. moscheutos, I93

Hibiscus moscheutos, Hibiscus or Rose Mallow Swamp, 263; $H$. Syriacus, Rose Mallow, 264, 265

Hobblebush, Viburnum lantanoides, I7 2

Hollyhock, Althea rosea, var. alba, I93, 240, 260, 279

Hollyhock, 9, 23, 44, 240; bumble bees in, I28; rust, II4, I29-130; permanganate of potassium for rust, I30; Bordeaux mixture for, I30

Honesty, Lunaria biennis, 69, 212 Honeysuckle, 97; Bush or Upright, Diervilla sessilifolia, 230; Fragrant Bush Honeysuckle, Lonicera fragrantissima, 248; Japanese, Lonicera Japonica (L. Halliana), 236; French, Hedysarum coronarium, 279; Scarlet, Lonicera sempervirens, 274; Sweet-scented, Lonicera Periclymenum, 239; Tartarian, L. Tartarica, 248

Hop Hornbeam, Ostrya Virginica, 80

Hop Vine, Humulus lupulus, 26, 45,77

Hotbed for annuals, $5 \mathrm{I}$; for perennial seeds, 54; making, 49; roots in, 57

Houstonia, $H$. ccrulea, 212

Humulus lupulus, Hop Vine, 26, 45,77

Hunnemannia, Tulip Poppy, $H$. fumariafolia, 238

Hunnemannia fumariafolia, Tulip Poppy, 238

Hyacinth, Hyacinthus orientalis, I69, 23I, 247, 273; Roman, $H$. albulus, I70; Summer, $H$. candicans, 65, I80; Grape, Muscari botryoides, $2 \mathrm{I} 2$

Hyacinthus candicans, Summer $\mathrm{Hy}$ acinth, 65,$180 ; H$. orientalis, Common Hyacinth, I69, I70, $210,231,247,273 ; H$. albulus, Roman Hyacinth, I70

Hydrangea, H. paniculata, I9I

Hypericum, St. John's Wort, $H$. 
Ascryon, Great St. John's Wort, 239; H. Aureum; Golden St. John's Wort, 239; $H$. calycinum, 237; $H$. densiflorum, 237; $H$. Moserianum, 237; $H$. patulum, Shrubby St. John's Wort, 240; $H$. perforatum, Common St. John's Wort, 239; H. prolificum, 237

Iberis sempervirens, Evergreen Candytuft, I68; I. umbellata, Candytuft, Common, I98, 226, 266

Iceland Poppy, Papaver nudicaule, I69, $23 \mathrm{I}$

Ice Plant, Mesembryanthemum crystallinum, 203

Idea, original, $\mathrm{x} 8$

Identifying plants, 65 ; by stem or leaf, 66

Immortelle, Anaphalis margaritacea, I94

Impatiens Balsamina, Balsam, 20I, 267,283

Incarvillea Delavayi, Hardy Gloxinia, 88, 103, 255

Indigo, False, Amorpha fruticosa, 2 I6

Ipomea Bona-nox, Moonflower, 204; I. Imperialis, Japanese MorningGlory, 225; $I$. purpurea, MorningGlory, 204, 266; I. quamoclit, Cypress Vine, 285

Iris, 9; English I. xiphoides, I80, 2I5; German, I. Germanica, 88, I70, 2I2, 23I, 234, 250; Japanese, I. lavigata, I87, 219, 239, 260; Siberian, I. Sibirica, 2I5; Spanish, I. Xiphium, I8I, 2I5, 234

Iris, 88, I70, I80, I8I; Iris Germanica, German Iris, 88, I70, 2I2, 23I, 234, 250; I. xiphoides, English Iris, 180, 215; I. Xiphium, Spanish Iris, I8I, 2I5, 234, 235; I. levigata, Japanese Iris, I87, 2I9, 239, 260; I. Sibirica, Siberian Iris, 215

Irish ancestor, 24, 28

Italian May, see St. Peter's Wreath, 23 I, $25^{\circ}$

Itea Virginica, 80, I73

Ivory soap for lice, 127 , for general insecticide, I30, for hollyhocks and larkspurs, I30
Jack in the Bush, see Nigella, 204, 227

Jacob's Ladder, Polemonium caruleum, $2 \mathrm{I}_{3}$

Japanese effect, 44

Japanese Lantern Plant, Physalis Francheti, 69, 28I

Japanese Plume, Poppy, see Bocconia, 185

Japanese Rose, Calystegia pubescens pl. fl., 254

Japanese Rose, see Kerria, 236

Japanese Sophora, see Pagoda Tree, I96

Jew's Mallow, see Kerria, 236

Joe-Pye Weed, Eupatorium purpureum, 263

Judas Tree, Red Bud, Cercis Cana:densis, 273

Juneberry, see Shad Bush, I67

Jupiter's Beard, see. Valerian, 258, 277

Kalmia latifolia, Mountain Laurel, 258, 259; $K$. angustifolia, Sheep Laurel, 259

Kerosene, 125, 126, I27; emulsion, I 27

Kerria, $K$. Japonica, 236

Knapweed, Mountain, Centaurea nigra, 2 I5

Kochia scoparia, Belvedere, 78; $K$. tricophila, 78

Labrador Tea, Ledum latifolium, I73

Lady's Delight, see Heart's Ease, 2 ro

Lagerstrcmia Indica, Crape Myrtle, 263

Lancaster Rose, 6, 274

Larkspur, blight, I I4, I29; Government remedy for, I 29; my remedy for, I30; crown rot in, I29

Larkspur, Bee, Delphinium elatum, 2I9; Branching, D. consolida, 203, 229; Great-flowered, D. grandiflorum, 219; Red, D. nudicaule, 279; Rocket, D. Ajacis, 203, 229, 268, 270; Showy, $D$. formosum, 2 I9; Azure Blue, $D$. formosum, var. coelestinum, 2 I9; White, D. grandiflorum, var. album, 287; Yellow, D. Zalil, 239

Lasthenia, L. glaberata, 245 
Lathyrus latifolius, Perennial Pea, I89, 26r, 280

Lathyrus odoratus, Sweet-Pea, 206, $228,244,269,284$

Lattice of laths, 58

Laurel, Mountain, Kalmia latifolia, 258, 259; Sheep, $K$. angustifolia, 259

Lavatera trimestris, 203, 268

Lavender, Lavendula vera, 2 I9

Lavendula vera, Lavender, 219

Lawn, spotting a, II

Layering, 96, 97

Layia Calliglossa, Oxyura, 244

Lead Plant, Amorpha canescens, 8I, 22 I

Leadwort, Ceratostigama plumbaginoides, 224

Leather Flower, Clematis Viorna, var. coccinea, 279

Leaves in autumn, 56 ; seed, 66 ; succulent, 66; woolly, 66

Ledum latifolium, Labrador Tea, $\mathrm{I} 73$ Leontodon autumnale, Hawkbit, 276

Leopard's Bane, Doronicum Caucasicum, 234, 235

Leptosophon, Gilia androsea, 207

Lespedeza Sieboldi, Bush Clover, 223, 264

Leucothoë Catesbai, I67

Liatris, I03; L. pycnostachya, 219; L. spicata, 223; L. scariosa, 280

Lifting Perennials, 74; Shrubs, 75; time for, plants, 98

Lilac, Common, Syringa vulgaris, 2Ir, 248; Persian, Syringa Persica, 2 II; White, Syringa vulgaris, var. $a l b a$, I67

Lilies, fastidious, rog

Lilium auratum, III; disease of, I32; remedy for, I32, I94; L. Canadense, Native Red Lily, 276; $L$. candidum, Madonna Lily, III; cause of disease of, and remedy, I32, I88; L. Batemanni, Bateman's Lily, 239, 263; L. Krameri, Kramer's Lily, 264; L. davuricum, Dahrian Lily, 276; L. speciosum, var. album, White, 67, 194; var. roseum, Pink speciosum, 264; $L$. tenufolium, Siberian Lily, 28r

Lily, Auratum, Lilium auratum, II r, I32, I94; Dahurian, Lilium davu- ricum, 276; Day, Yellow, Hemerocallis flava, 234; Day Lily, Japan, Funkia subcordata, 192; Madonna, Lilium candidum, I88; Native red, Lilium Canadense, 276; Plantain, see Funkia; Siberian, Lilium tenufolium, 28r; White Speciosum, $L$. speciosum album, 67, I94; Pink Speciosum, L. speciosum roseum, 264; Bateman's L. fulgens, var. Batemanni, 237, 264; Kramer's L. Krameri, 264

Lily of the Valley, Convallaria majalis, 170

Lime, I28, I29; for rose bed, I26; in Bordeaux mixture, 130 ; for mildew, I3I, I32

Limnanthes, L. Douglasii, 245

Linaria alpina, Alpine Snapdragon, 219; $L$. maroccana, Toadflax, 226 Linum flavum, Golden Flax, 234; L. grandiflorum, Scarlet Flax, 282 Live Oak in Florida, 82

Loam, 92

Lobelia, Great, L. syphilitica, 222; L. erinus, 229

Locust Tree, Robinia pseudacacia, I73

Lonicera, Honeysuckle, 97 ; $L$. fragrantissima, Fragrant Bush Honeysuckle, $248 ; L$. Japonica ( $L$. Halliana), Japanese Honeysuckle, 236; L. Periclymenum, Sweetscented Honeysuckle, 236; $L$. sempervirens, Scarlet Honeysuckle, 274; L. Tartarica, Tartarian Honeysuckle, 248

Loosestrife, Rosy, Lythrum roseum superbum, 65; Spiked, L. salicaria, 279

Louse, Green, 127

Love in a Mist, see Nigella, 204, 227

Lunaria biennis, Honesty, 69, 212

Lungwort, Virginia Cowslip, Mertensia Virginica, 2 ro

Lupine, Lupinus affinis, 227; Douglass, L. Douglasii, I81, 255; Sweet, L. mutabilis, 203, 227, 268; Dwarf, $L$. nanus, 227; White Manyleaved, L. polyphyllus, 18r; Blue, 215; Yellow, 235; Pink, 255

Lupinus affinis, 227; L. Douglasii, I8I, 255; L. mutabilis, Sweet 
Lupine, 203, 227, 268; L. nanus, Dwarf, 227; L. polyphyllus, Manyleaved Lupine, 18I, 215, 235, 255 Lychnis, Alpine Campion, L. alpina, 249; Day-blooming or Early Red, L. dioica rosea, 250; L. Chalcedon$i c a$, Scarlet or Maltese Cross, 273; Red, Agrostemma coeli-rosa, I85; Red or Mullein, L. coronaria, 67 , 276; L. Flos-cuculi, Ragged Robin, 257; Viscid, L. viscaria splendens, 255; White, $L$. vespertina, I88

Lychnis alpina, Alpine Campion, 249; L. Chalcedonica, Scarlet Lychnis, 273; L. coronaria, Red or Mullein Lychnis, 67, 276; $L$. dioica rosea, Early Red or Day-blooming Lychnis, 250; L. Flos-cuculi, Cuckoo Flower, Ragged Robin, 257; L. occulata, Blue-eyed Viscaria, 228; L. vespertina, White Lychnis, I88; L. viscaria, Viscid Lychnis, 255

Lythrum roseum superbum, Rosy Loosestrife, 65; L. Salicaria, Spiked Loosestrife, 279

Madonna Lily, see Lily, Madonna Maidenhair Fern Tree, see Gingko, 79

Mallow, Hollyhock, Malva alcea, 43, 26o, 26r; Musk, M. moschata, I8I, I88, 26r; Rose, see Hibiscus; Swamp, see Hibiscus; Poppy, see Callirrhoë; Tall, $M$. sylvestris, 260

Malope, Three-lobed, $M$. trifida, 203, 268

Maltese Cross, see Lychnis Chalcedonica, 273

Malva alcea, Hollyhock Mallow, 43, 26o, 26r; $M$. moschata, Musk Mallow, I8I, I88, 26r; M. sylvestris, Tall Mallow, 260

Man's methods, ro6

Manure producing grubs, 55

Marigold, African, Tangetes erecta, 38, 243; French, T. patula, 243; Single, $T$. signata, 243, 244

Marking seeds, 62; seed vessels, 62; plants, 74

Marsh Flower, Alonsoa incisifolia, 282

Marsh Mallow, see Hibiscus, I93
Martynia, Unicorn Plant, $M$. fragrans, 227

Marvel of Peru, Mirabilis Jalapa, 285

Matthiola annua, Ten Weeks Stock, 202, 206, 228, 244, 269, 285; $M$. odoratissima, Fragrant Evening Stock, 225

May beetle, 54

Mayweed, see Dog-fennel, 202

Meadow Beauty, Rhexia Virginica, 215

Meadow-Rue, Thalictrum adiantifolium, I8r; $T$. cornui, $\mathrm{I} 8 \mathrm{r} ; T$. polygonum, I8I

Meadow Sweet, Spirea salicifolia, 259

Meliloius alba, Sweet Clover, 206; M. carula, 228

Mentalia Lindleyi (Bartonia aurea), Bartonia, 242

Mertensia Virginica, Lungwort, Virginia Cowslip, I03, 2 ro

Mesembryanthemum crystallinum, Ice Plant, 203, 284

Mexican Fire, Euphorbia heterophylla, 69; Poppy, Argemone Mexicanum, 200

Mice, field, I00, I24; tarred paper for, 124

Michaelmas Daisy, see Aster, 223

Mignonette, Reseda odorata, 203, 284

Mildew, I29; cause of, I3I; Bordeaux mixture for, I3I; on roses, I3I; sulphide of potassium for, I 3 I; sulphur and soot for, I3r

Milfoil, Rosy, Achillea millefolium, $26 \mathrm{r}$

Milla multiflora, see Star Flower, I88, I89

Mirabilis Jalapa, Marvel of Peru, 285

Mite, white, I32

Mock Orange, see Syringa, I77

Moles, I21, I23; moth balls for, I23

Monkshood, Climbing, Aconitum unciatum, 2I7; White, A. Nepallus, var. alba, I88; A. Storkianum, 217

Montbretia, Tritonia Pottsii, Ior, 240, 24I; var. rosea, 264, 28I

Moonflower, I pomea Bona-nox, 204 Morning Glory, I pomea purpurea, 
204, 225, 266; Japanese, I. Imperialis, 225

Moss Pink, see Phlox, Creeping, I7 I, 213

Moth balls for moles, 123

Moth Mullein, Verbascum Blattaria, $216,25^{8}$

Mountain Ash, see Ash, I73

Mountain Feather Fleece, Stenanthium robustum, I95

Mountain Fleece, Polygonum amplexicaule, I95

Mountain Fringe, see Allegheny Vine, 253

Mountain Laurel, see Laurel, Mountain, 258

Mountain view as a defence, $\mathbf{I} 44$

Mulch, 93, 98, 99; use of, 99; manure as, 99; hay or straw as, 99; pine boughs as, 99; coal ashes as, 100; leaves as, 100; snow as, 100

Mullein, 23, 69; Italian, Verbascum pannosum, 235; Moth, V. Blattaria, 216; V. nigrum, 236

Muscari botryoides, Grape Hyacinth, 212

Mustard, Hedge, Erysimum puchellum, 231

Myrica gale, Sweet Gale, I84

Myosotis, Forget-me-not, $M$. alpestris, 169, 212, 250; $M$. semperflorens, $212 ; M$. sempervirens, 226; M. palustris, 2 I2

Names, beautiful, of plants, 70; botanical, 70; meaning of specific, 70

Narcissus, $N$. pseudo-narcissus, 23I, 232; Poet's, $N$. poeticus, I7I; double, $N$. poeticus, var. alba plena, I7 I

Narcissus poeticus, Poet's Narcissus, I7I; $N$. poeticus alba plena, Double Narcissus, I7 I; $N$. pseudonarcissus, Narcissus or Jonquil, 23I, 232; $N$. jonquilla, Jonquil, 232

Nasturtium, Dwarf, Tropaolum minus, I98, 199, 243, 268, 284; Tall, Tropaolum majus, 204, 227, 244, 268, 284; Lobb's Tropaolum Lobbianum, 227, 284

Nature, changes in, I40; perfect repose in, I40, I4I; nature's methods, 104, 105, 106

Navelwort, see Cynoglossum, I98

Nemophila, Baby Blue Eyes, $N$. insignis, 225; White, N. maculata, I99

Nemophila insignis, Baby Blue Eyes, 225; N. maculata, White Nemophila, I99

Neponset pots, 30,52

Nicotiana, $N$. affinis, 22, 23, 65, II3, 127, 204; $N$. alata, 204; Sander's N. Sandera, 285

Nigella, Jack in the Bush, Little Maiden in the Green, Love in a Mist, N. Damascena, 204, 227

Night effects, I43

Nolana, $N$. atriplicifolia, 225

Nomenclature, sources of, $16_{3}$

Nursery bed, 57

Nurserymen, reliable, $64, \mathrm{r} 64$

Nycterinia, Zaluzianskia selaginoides, 204

Obedient Plant, Physostegia Virginiana, 66, 220, 26r; White, P. Virginiana alba, 189

Enothera acaulis, Evening Primrose, 202; O. biennis, Common Primrose, 238; O. Missouriensis, 238; O. fruticosa, Sundrops, 238

Oil beetle, ${ }_{2} 6$

Old Man, see Boy Love, I84

Oleaster, Elcagnus longipes, 236; $E$. umbellatus, 236; Silver Thorn, $E$. parvifolius, 236

Omphaloides linifolia, Cynoglossum, I 98,224

Ononis rotundifolia, Rest Harrow, 262

Ostrya Virginica, Hop Hornbeam, 8I

Oswego Tea, see Bee Balm, 278

Overcrowding plants, 45

Oxyura, Layia Calliglossa or $O$. Chrysanthemoides, 244

Paonia officinalis, Common Pæony, I8I, 21 5, 235, 255, 276; P. moutan, Tree Pæony, 256; $P$. albaflora, 255

Pæony, Common, Paonia officinalis, I8I, 2I5, 235, 255, 276; Tree, Paonia moutan, 256 
Pagoda Tree, Sophora Japonica, I96 Palava flexuosa, 270

Palifoxia, Polpyteris Hookeriana, 270 Pansy, Viola tricolor, 165, 204, 210, 227, 230, 244

Papaver Alpinum, Alpine Poppy, $232,25 \circ ; P$. nudicaule, Iceland Poppy, I69, 23I; $P$. orientalis, Oriental Poppy, 257, 276; $P$. Rhoeas, Shirley Poppy, 199, 205, 269,$282 ; P$. somniferum, Opium Poppy, 7I, 205, 227; P. somniferum pl. $f$ l., Pæony Poppy, 207, 227; var. paonaflorum, Anne Hathaway Poppy, 268, 269

Paris green for cutworms, I20; for potato-bugs, 126

Pasque Flower, Anemone pulsatilla, 2 II

Pea, Perennial, Lathyrus latifolius, I89, 261, 280

Pea, Sweet, Lathyrus odoratus, 206, $244,269,285$

Peach, Blood-leaved, Prunus Persica, 8I, 25I; Japanese, P. Persica, var. rosea pleno, 248; P. Persica, var. sanguinea, pl., 272

Pearl Bush, Exochorda grandiflora, I67

Pellitory, see Feverfew, I86

Pentstemon, 22; $P$. acuminatus, Beard Tongue, 220; P. barbatus, var. Torreyi, $280 ; P$. campanulatus, 26I, 270; P. grandiflorus, 220; $P$. ovatus, 215

Perennials, close planting, I2; deeprooted, 42, 43; division of, 96 ; fragrant, 72 ; self-sowing, 6o, 6r; showiest in blue, pink, red, yellow and white, 84, 85, 86, 87; spring blooming, $5^{8}$

Perennial seeds sown in spring, 57 ; planting early, 94; slow to germinate, 95

Periwinkle, Vinca minor, 208, 220, 229, 270

Permanganate of potassium, 130

Petunia, White, $P$. nyctaginiflora, 204; $P$. grandiflora, $284 ; P$. violacea, 227, 270

Petunia grandiflora, $284 ; P$. nyctaginiflora, White Petunia, 204; $P$. violacea, 227, 270
Phacelia Whitlavia, Phacelia, 206, 225; $P$. campanularia, 225

Phaseolus multiflorus, Scarlet Bean, 283

Philadelphus coronarius, Syringa, I77

Phlox, Annual, Phlox Drummondii, 205, 227, 244, 269; Creeping, Phlox sublata, I7I, 213, 250; Perennial, Phlox paniculata, I95, 222, 264, 28I; Virginia, Phlox divaricata, $2 \mathrm{I} 3$

Phlox divaricata, Virginia Phlox, 2I3; P. Drummondii, Annual Phlox, 205, 227, 244, 269; $P$. paniculata, Perennial Phlox, I95, 222, 264, 28r; $P$. sublata, Creeping Phlox, I7I, 213, 250

Photography, memorandum of, I37; records of, I37; time of exposure in, I38; Wager Scale for, I38, I39; color filter for, I39; exposure for colors, 139; for trees and flowers, I39; patience in, I40; conditions observed in, I42; subjects for, I 44

Physalis Francheti, Japanese Lantern Plant, 69, 28I

Physocarpus (Spirea) opulifolia, var. aurea, Golden Spirea, I76

Physostegia Virginiana, Obedient Plant, 66, 220, 26r; var. alba, 189

Pink annuals, 266-27I

Pink beds, 38 ; edging plants for, 83 ; showiest annuals in, 85 ; showiest perennials in, 85

Pink, Dianthus, Carnation or Clove, Dianthus caryophyllus, I82, 256, 276; Chinese, D. Chinensis, 276; Cliff, D. casius, 256; Garden, Feather, $D$. plumarius, I82, 257; Grass or Maiden, $D$. deltoides, 256, 257; Japanese, D. Heddewigii, I82, 205, 256; D. cruentus, 65

Pink Flowers, 247-27I

Pink, Indian, see Fire Pink, 276

Pink Perennials, 247, 249-250, 253-258, 259-262, 263-264, 265

Pink Shrubs, 247, 249, 25I-253, 258-259, 262, 264-265

Pinxter Flower, Rhododendron nudi flora, 248 
Planter's outfit, 50

Planting early, 50

Plants, hardening, 5I; identifying, 65; beautiful names of, 70 ; poetic names of, 70 ; use of tall, 74; of slender growth, 89; sulky, 92; distance for setting, ror, IO2; cutting down early, I02; late in coming up, I03; that sucker badly, IO7; distributing, I $54, I 55$

Platycodon, Japanese Bellflower, $P$. grandiflorum, I89, 220; $P$. Maresi, 220; var, nana, 220

Plum, Japanese, Prunus triflora, 249; Purple-leaved, P. Pissardi, I67

Podolepis, $P$. aristata, 245

Polemonium ccruleum, Jacob's Ladder, 212

Polygonum amplexicaule, Mountain Fleece, 195; P. Baldschuanicum, 264; $P$. multiflorum, 196

Polypteris Hookeriana, Palifoxia, 270

Poppy, Alpine, Papaver Alpinus, 232, 250; Anne Hathaway, $P$. somniferum paoniaflorum, 268; California, see Eschscholtzia, I98; Iceland, $P$. nudicaule, 169, 23I; Opium, $P$. somniferum, 7I, 205, 227; Oriental, $P$. orientale, 257, 276; Pæony, $P$. somniferum pl. $f$. 207, 227, 268, 269, 284; Shirley, $P$. Rhceas, 199, 205, 269

Portulaca, P. grandiflora, 205, 244, 284

Potato bug, I 27

Potentilla, Red, P. Nepalensis, 277; White, $P$. alba, 189; Yellow, $P$. recta, 235

Potentilla alba, White Potentilla, I89; $P$. recta, Yellow Potentilla, 235; P. Nepalensis, Nepal or Red Potentilla, 277

Pot Marigold, see Calendula, 242

Pots, Neponset, 52

Predatory wealth in garden, $\mathrm{IO}_{7}$

Prickly Poppy, see Argemone, 200

Prolific plants, 107,108

Prunus Japonica, Flowering Almond, I66; var. rosea, Pink Flowering Almond, 247

Prunus Persica, Blood-leaved Peach, 8I, 25I; var. rosea plena, Japanese
Peach, 248; var. sanguinea, Red Japanese Peach, 272

Prunus triflora, Japanese Plum, 249; P. Pissardi, Purple-leaved Plum, I67

Pyrethrum, Chrysanthemum coccineum, 257

Pyrus floribunda, Japanese Crab Apple, 248

Queen of the Prairie, Spirea lobata or Ulmaria rubra venuista, 26I Quince, Japan, Cydonia Japonica, 272, 273

Ragged Robin, Lychnis Flos-cuculi, 257

Ranunculus bulbosus, Buttercup, Gold Cup, 234; $R$. acris pl. fl., Tall Buttercup, 234; $R$. Asiaticus, Garden Ranunculus, 235

Raspberry, Purple-flowered, Bramble, Rubrus odoratus, 277

Record of blooming, 37

Red, arranging, flowers in garden, 74; using white flowers with, 74; edging plants, 83 ; showiest annuals in, 86; showiest perennials in, 85 , 86

Red Annuals, 282-286

Red Bud, Cercis Canadensis, 273; Chinese, C. Chinensis, 272, 273

Red Flowers, 272-286

Red Perennials, 272, 273, 275-277, 278-280, 28I, 282

Red Shrubs, 272-273, 274-275, 277278,280

Remedy, for cutworms, I20; grubs, I2I; mice, I24; moles, I23; green louse, I 27, I 28; rose-bug, I 25, I 26; potato-bug, 126; green slug, I 26; oil beetle, I26; aster beetle, 126; hollyhock rust, I29-130; larkspur blight, I29-I30; mildew, I3I; mites in lilies, I32; wasps, I27; aster blight, I32; carnation blight, 132; Physostegia blight, I3I, I32 Reseda odorata, Mignonette, 203, 284

Response to environment, 153

Rest Harrow, Ononis rotundifolia, 262

Rhexia Virginica, Meadow Beauty, 215 
Rhodanthe, Helipterum Manglesii, 205, 269; $R$. maculata, 205

Rhododendron, Great, $R$. maximum 259

Rhododendron maximum, Great Rhododendron, 259; $R$. nudiflora, Pinxter Flower, 248

Rhodora, $R$. Canadensis, 249

Rhus cotinus, Smoke Tree, 2I6, 277, 280; $R$. glabra, Smooth Sumach, $177 ; R$. glabra, var. laciniata, Fern-leaved Sumach, I77

Robinia hispida, Rose Acacia, 251

Rock Cress, Arabis albida, r68; Alpine, A. alpina, I7 I

Rocket, Sweet, Hesperis matronalis, 183, 215; Yellow, Barbarea vulgaris, 235

Rock heap, advantages of, 19

Rock Rose, see Helianthemum, I80

Romneya Coulteri, 183

Roots in hotbed, 57 ; dividing, 96; twining, 96

Rose, Cabbage or Provence, Rosa centifolia, 25I; Cherokee, R. lavigata, ror; Cinnamon, $R$. cinnamonea, 25I; Climbing, $R$. setigera, Queen of the Prairie, 252; Dwarf Wild, $R$. lucida, 275; Early Wild, $R$. blanda, 252; Eglantine, $R$. Eglanteria, Austrian Brier, 233; Golden Sun, var. Soleil d'Or, 233; Persian Yellow, var. lutea, 233

Hybrid: Perpetual, hybrids of $R$. Indica, $R$. Damascena:-Anne de Diesbach, 274; Margaret Dickson, 175; Frau Karl Druschki, I75; Mabel Morrison, 175; Baroness Rothschild, 25I; Gabriel Luizet, 252; Magna Charta, 252; Paul Neyron, 252; Mrs. John Laing, 252; Mrs. R. G. SharmanCrawford, 253; Camille de Rohan, 274; Ulrich Brunner, 275

India: $R$. Indica:-Captain Christy, I75; Madame Plantier, I75; La France (Hybrid Tea), 252; Jacqueminot (Hybrid China), 274

Japanese: $R$. rugosa, var. Conrad Meyer, $253 ; R$. rugosa rubra, 274; Lancaster, $R$. Damascena, 6, 274, 275; Rambler, see Wichuriana;
Scotch, $R$. spinosissima, 233; Sweet Brier, $R$. rubiginosa, 253; White, $R$. alba, I76; Unknown variety from Virginia, I75

Wichuriana, Manda's Triumph, 176; var. Gardenia, 233; Dorothy Perkins (hybrid W. and Indica), 252; $W$., var. Universal Favorite, 253; Crimson Rambler, 274; Yellow Rambler, 233

Rosa alba, White Rose, I76; $R$. blanda, Early Wild, 252; $R$. centifolia, Cabbage, 25I; $R$. cinnamonea, Cinnamon, 25I; $R$. Damascena, Lancaster or Red, 274,275

$R$. Eglanteria, Austrian Brier, 233; Golden Sun, var. Soleil d'Or, 233; Persian Yellow, var. lutea, 233

R. Hybrid Perpetual:-Margaret Dickson, I75; Frau Karl Druschki, 175; Mabel Morrison, I75; Baroness Rothschild, 25I; Gabriel Luizet, 252; Magna Charta, 252; Paul Neyron, 252; Mrs. John Laing, 252; Mrs. R. G. Sharman-Crawford, 253; Camille de Rohan, 274; Anne de Diesbach, 274; Ulrich Brunner, 275

$R$. Indica, Captain Christy, 175; Madame Plantier, 175; La France, 252; Jacqueminot, 274

$R$. lavigata, Cherokee, ror; $R$. lucida, Dwarf Wild, $275 ; R$. rubiginosa, Sweet Brier, 253; $R$. rugosa, Japanese, var. Conrad Meyer, 253; var. rubra, 274; $R$. setigera, Climbing, Queen of the Prairie, 252; $R$. spinosissima, Scotch, 176

$R$. Wichuriana, var. Manda's Triumph, 176; var. Gardenia, 233; Dorothy Perkins, 252; Universal Favorite, 253; Crimson Rambler, 274; Yellow Rambler 233

Rose-beds, Gladiolus for, 76; Per. Phlox for, 77; soil for, 93

Rose-bug, 79, II3, I24, I 26, remedy for, 126

Rose cuttings, rooting, 98

Rose Mallow, Hibiscus Syriacus, 264 
Rose of Sharon, see Rose Mallow, 264

Rosemary, Wild, see Andromeda, 247

Rose Moss, see Portulaca, 205

Roses, general culture of, I73, I74; slipping, 98; Ivory soapsuds for, I 28, I3I; mildew on, I3I

Rows, marking, $5 \mathrm{I}$

Rubrus odoratus, Purple-flowered Raspberry, 277

Rudbeckia, $67 ; R$. hirta, Black-eyed Susan, 237; $R$. laciniata $p l$. $f$., Golden Glow, 238

Rust, Hollyhock, II4, I 29

Rustic seat, 45; fragrant flowers near, 45; vines over, 45

Sabbatia, S. chloroides, 260, 262

Sage, Flowering, Salvia argentea, 239

Salpiglossis, S. simuata, 244, 269, 286

Salvia, S. farinacea, 229; $S$. patens, 229; S. argentea, Flowering Sage, 239; S. splendens, 286

Sambucus nigra, var. aurea, Golden Elder, 80, 8I; S. Canadensis, Elderberry, 184

Sand, 21, 30, 33, 46, 57, 93, 97, 98, I3I, I32, I 73, I74

Saponaria, Soapwort, $S$. Calibrica, 206, 269; S. ocymoides, 257, 277; var. splendens, 277; Bouncing Bet, S. officinalis, 263

Saponaria Calibrica, Soapwort, 206, 269; S. ocymoides, 257; var. splendens, 277; S. officinalis, Bouncing Bet, 263

Satin Flower, Godetia amœna, also Enothera, 202, 284

Saxifrage, Early, Saxifraga Virginiensis, I7 I

Saxifraga Virginiensis, Early Saxifrage, I7 I

Scabiosa atropurpurea, Sweet ScabiOus, 207, 229, 245, 270, 284; $S$. Caucasica, 216; var. perfecta, 216

Scabious, Sweet, Scabiosa, atropurpurea, 207, 229, 245, 270, 284

Schizanthus bipinnatus, Fringe Flower, 206, 228; S. Wisetonensis, 269 Schizapetalon, S. Walkeri, 199, 206
Scilla, S. Sibirica, 211; S. nutans, 247

Sea Holly, Eryngium amethystinum, 220

Sea Lavender, Statice Limonium, 220

Sea Pink, see Thrift, I83, 254

Sedum spectabile, Showy Stonecrop, 66,$264 ;$ S. stoloniferum, 264

Seed-bed, permanent, 57

Seed firms, reliable, 63,164

Seedlings, hardening, $3 \mathrm{I}$; transplanted, 52, 53; walk-grown, 46

Seed rows, marking, 52

Seed vessels, marking, 62,63

Seeds, 30 ; chance, 34 ; cheap, 63 ; code for marking, 63 ; color of, 62 ; covering, $5 \mathrm{I}$; gathering, 63 ; hard to germinate, 59; leaves, 66; marking, 62; perennial, 57; perennial slow to germinate, 95 ; planting indoors, 30 ; outdoors, 53; planting perennial, 94; price of, 94; self-sowing annual, $6 \mathrm{r}$; selfsowing perennial, $60,6 \mathrm{r}$; selfsown, 53 ; slow to germinate, 60 ; small, 5I; sowing, 2I; sown thinly, 53; watering, 52

Self-sowing annuals, 6r; perennials, $60,6 \mathrm{r}$

September views, 68

Shad Bush, Amelanchier Canadensis, 167

Shirley Poppy, Papaver Rhceas, 76, I99, 205, 269, 282

Shooting Star, see Dodecatheon, I03, I79

Shrubbery, first, 9; for autumn effects, 79, 80, 8I, I42, I43

Shrubs, colored foliage in, $80,8 \mathrm{r}$; fragrant, 72 ; resetting, 75

Sidalcea malvaflora, var. Listeri, 257

Silene Armeria, Sweet-William Catchfly, 20r, 269; S. Shafta, Autumn Catchfly, 254, 277; $S$. pendula, 267; S. compacta, 267; S. Virginica, Fire Pink, 275

Silk Grass, see Yucca, 184

Silver Bell, see Snowdrop Tree, I67

Silver Thorn or Tree, Silver Berry, Elagnus parvifolia, 81, 236

Sisyrinchium angustifolium, Blueeyed Grass, 2I4 
Site, choosing a garden, $4 \mathrm{I}$

Smoke Tree, Rhus cotinus, 69, 8r, 216, 277, 280

Snakeroot, White, Eupatorium ageratoides, I95

Snapdragon, Antirrhinum majus, I9O, 206, 239, 244, 280, 284; Alpine, Linaria alpina, 219

Sneezeweed, see Helenium, I03, 240

Sneezewort, see Achillea, I77

Snowball, Arrowwood, Viburnum dentatum, I72; Tree or Guelder Rose, V. opulis, r76; Japanese, $V$. tomentosum, I76

Snowdrop, Galanthus nivalis, 165

Snowdrop Tree, Halesia tetraptera, I67

Soapwort, Saponaria calibrica, 206, 269; see Bouncing Bet, $S$. officinalis, $263 ; S$. ocymoides, 257 , var. splendens, 277

Soil, New Hampshire, 19, 20; for beds, 5, 21, 32, 33; for roses, 93; preparing, 92, 93; sour, 92, 93; virgin, 93

Solidago juncea, Goldenrod, 238

Sophora Japonica, Pagoda Tree, 196

Sorbaria sorbifolia, see Spirea sorbifolia, I9I, I92

Sorbus Americana, Mountain Ash, 173

Southernwood, see Boy Love, 184

Specularia speculum, Venus Looking Glass, 228

Speedwell, see Veronica, 221, 222

Spencer, Herbert, I53

Spider Plant, Cleome pungens, $20 \mathrm{r}$

Spirea, Anthony Waterer, S. Bumalda, 277; Blue, Caryopteris mastacanthus, 222; Bridal Wreath, $S$. prunifolia, I66; Dropwort, $S$. (Ulmaria) filipendula, I79; Goat's Beard, S. astilbe or S. Aruncus, IIO, I80; Golden, $S$. (Physocarpus) opulifolius, var. aurea, 8I; Japanese, S. Japonica, 259, also S. callosa, var. superba, 259; Italian May, St Peter's Wreath, S. hypericifolia, I68; Meadow Sweet, S. salicifolia, 259; Purpletipped, S. superba, 278; Queen of the Prairie, S. lobata, Ulmaria rubra venuista, 26r; Steeple Bush,
$S$. tomentosa, 262; Thunberg's, $S$. Thunbergii, r68; Van Houtte's, S. Van Houtei, I68; S. arguta, I67; S. sorbifolia, or Sorbaria sorbifolia, I9I, I92

Spirea arguta, 167; S. Aruncus, S. Astilbe, Goat's Beard, I1о, I80; S. Bumalda, Anthony Waterer, 277; S. callosa, var. superba, Meadow Sweet, 259; $S$. (Ulmaria) filipendula, Dropwort, I79; $S$. hypericifolia, Italian May, St. Peter's Wreath, I68; S. lobata (Ulmaria rubra venuista), Queen of the Prairie, 26r; S. Japonica, Japanese, 259; $S$. (Physocarpus) opulifolius, var. aurea, Golden, I8I; $S$. prunifolia, Bridal Wreath, II6; S. salicifolia, Meadow Sweet, 259; S. sorbaria, or Sorbaria sorbifolia, I9r, I92; $S$. superba, Purpletipped, 278; $S$. Thunbergii, Thunberg's, I68; $S$. tomentosa, Steeple Bush, 262; S. Van Houtei, Van Houte's, I68

Spirit, coöperating with, I5I; in plants, II2, I52; matter as symbol of, I57

Sports in garden, I33

Spray, a general, I30

Spurge, Flowering, see Euphorbia, I86

Squill, see Scilla, 2 II

Stachys lantana, Hedge Nettle, 219, 22 I

Statice Limonium, Sea Lavender, 220 St. John's Wort, Common, Hypericum perforatum, 239; Golden, $H$. aureum, 239; Great, $H$. Ascryon, 239; Shrubby, H. patulum, 240; $H$. calycinum, $237 ; H$. densiflorum, 237; H. Moserianum, 237; H. prolificum, 237

St. Peter's Wreath, Italian May, Spirea hypericifolia, I68

Star Flower, Milla multiflora or Triteleia laxa, 89, I53, I88, 189

Steeple Bush, Spirea tomentosa, 262

Stems, color of, 62

Stenanthium robustum, Mountain Feather Fleece, I95

Stephenandra flexuosa, I76

Stevia serrata, Stevia, 208 
Stirring earth, I03

Stock, enlarging, I9

Stock, Ten Weeks, Matthiola annua, 202, 206, 228, 244, 269, 284

Stokesia, Stokes' Aster, S. cyanea, $S$. Cartesia, 22 I

Stokes' Aster, see Stokesia, 22I

Stone heap, advantages of, 43

Stone walls, 2I, 32, 4I, I57

Stones, Japanese use of, 42

Styrax Japonica, I76

Succession of bloom, $9,33,82$; in blue beds, 34-36; of poppies, 94

Succulent leaves, 66

Suckers, plants making, 96

Sucking insects, I 27

Sulphate of copper, I 29

Sulphide of potassium, I3I

Sulphur, I3I, I32

Sumach, Fern-leaved, Rhus glabra, var. laciniata, 8I, I77; Smooth, $R$. glabra, 177

Sundrops, CEnothera fruticosa, 238

Sunflower, Annual, Helianthus annuus, 245; False, Heliopsis lavis, 239; Perennial, Helianthus decapetalus, 24I; H. latiflorus, 24I; $H$. mollis, 24I; Graceful, H. orgyalis, 24I

Sun Rose, see Helianthemum, I80; Helianthemum alpestre, 234, 235; $H$. mutabilis, Sun Rose, 180,258

Sweet Clover, Melilotus alba, 206; M. carula, 228

Sweet Fern, Artemesia annua, 78, 207, 208

Sweet Gale, Myrica gale, 184

Sweet Pea, Lathyrus odoratus, 206, 228, 244, 269, 284

Sweet Pepper Bush, Clethra alnifolia, I84

Sweet-scented Shrub, Calycanthus floridus, 274

Sweet Sultan, Centaurea moschata, I99, 225, 242

Sweet William, Dianthus barbatus, II6, I83, 258, 277

Sweet Woodruff, Asperula odorata, I68, 172

Syringa, Philadelphus coronarius, I77

Syringa vulgaris, Common Lilac, 2II, 248; var. alba, White Lilac,
167; S. Persica, Persian Lilac, 2 II

Tacoma radicans, Trumpet Creeper, 280

Tamarix Africana, or T. tetrandra, African Tamarisk, 253; T. Indica, Late-flowering Tamarisk, 262

Tamarisk, African, Tamarix Africana ( $T$. tetrandra), 253; Lateflowering, $T$. Indica, 262

Tanacetum vulgare, var. crispum, Tansy, 24I

Tangetes erecta, African Marigold, 243; $T$. patula, French Marigold, 243; $T$. signata, Single Marigold, 243,244

Tansy, Tanacetum vulgare, var. crispum, 24I

Tarred paper for mice, I 24

Tassel Flower, Cacalia or Emilia sonchifolia, 283, 285

Tender perennials, shelter for, IOI

Terraced driveway, 78

Terraces, making, 33

Thalictrum adiantifolium, $\mathrm{I} 8 \mathrm{r} ; T$. cornuti, 18r; $T$. polygonum, Meadow Rue, I8I

Thermopsis Caroliniana, Carolina Pea, 235

Thorn, Scarlet-fruited, Cratagus coccinea, 168

Thoroughwort, Eupatorium perfoliatum, 190

Thrift, Armeria cephalotes, 183; A. elongata, 254; A. vulgaris, 254; Plaintain-leaved, $A$. plantaginea, 254

Thunbergia, $T$. alata, 245

Tiarella cordifolia, Foam Flower, I79

Tickseed, see Coreopsis, 234, 243

Toadflax, Linaria maroccana, 226, 227

Toads, I24

Tools for work, $\mathrm{I} 8$

Transplanting, 52 ; poppies, 52; perennials and shrubs, 74,75

Traveler's Joy, Clematis Virginiana, I9I

Trees as windbreaks, $9 \circ$

Tridax, $T$. bicolor rosea, 269

Triteleia laxa, Star Flower, 89, I53, 188, 189 
Tritoma, Red Hot Poker, Flame Flower, Kniphofia Pfitzeri, 281

Tritonia Potsii, Montbretia, 240, 24I; $T$, var. rosea, 264, 28I

Trollius A siaticus, Globe Flower, 234

Tropaolum minus, Dwarf Nasturtium, 198-199, 243, 268, 284; $T$. majus, Tall Nasturtium, 204, 244, 268, 284; T. Lobbiannum, Lobb's Nasturtium, 227; $T$. peregrinum, Canary Bird Flower, 243

Trumpet Creeper, Tacoma radicans, 280

Tulip, Tulipa gesneriana, I72, 213, 232; Parrot, T. Dracontia, 232; $T$. suaveolus, 250, 273

Tulipa Dracontia, Parrot Tulip, 232; $T$. gesneriana, Common Tulip, I7 2, 2I3; $T$. suaveolus, 250, 273

Tulip Poppy, see Hunnemannia, 238

Tunica saxifraga, $25^{8}$

Turtlehead, see Chelone, 260, 284

Types, new, r32, I33

Ulmaria (Spirea) filipendula, Dropwort, 179; Ulmaria rubra venuista (Spirea lobata), Queen of the Prairie, $102,103,261$

Unicorn Plant, see Martynia, 227

Valerian, Jupiter's Beard, Centranthus ruber, 258, 277; Spurred, Centranthus albus, 183

Valeriana officinalis, Garden Heliotrope, 180

Venetian Sumach, see Smoke Tree, 216

Venus' Looking Glass, Specularia speculum, 228

Verbascum, Blattaria, Moth Mullein, 2I6, 258; V. pannosum, Italian Mullein, 235; V. nigrum, 236

Verbena, $V$. teucroides, 208, 269, 270; $V$. montana, 258; Red, V. chamedrifolia, 285; V. aubletia, 228

Verbena aubletia, 228; V. chamadrifolia, Red Verbena, 285; V. teucroides, 208, 269, 270

Verbena, Sand, Abronia fragrans, 200; $A$. areneria, 243

Veronica spicata, Speedwell, 45, 76, $22 \mathrm{I}$; $V$. longifolia, var. subsessilis, Long-leaved Veronica, 222
Viburnum dentatum, Arrowwood, I72; V. lantanoides, Hobblebush, I72; V. opulis, Snowball, I76; $V$. tomentosum, Japanese Snowball, I76; V. cassinoides, Withe Rod or Withe Tree, I77

Vinca minor, 229, 270; V. rosea, 208

Vines, fragrant, 72 ; a protection to house, 77,78 ; as social climbers, II 4

Viola tricolor, Pansy, r65, 204, 2 Io, 227, 230, 244; V. odorata, English Violet, 2 I3

Violet, English, Viola odorata, 2 I3

Virginia Cowslip, see Lungwort, 2 ro

Virginia Creeper, 8, 77; pruning, 77; two varieties, 78

Virginia Phlox, see Phlox divaricata, $2 I_{3}$

Virgin's Bower, see Traveler's Joy, I9I

Viscaria, Blue-eyed, Lychnis oculata, 228; Red, Agrostemma, cali-rosa, 285

Vistas beyond garden, 9

Visitors, gluttonous, I48; inconvenient, 148

Vitex agnus-castus, Chaste Tree, $22 I$

Waahoo, see Burning Bush, 80, 216

Wager Scale for photography, I38, I39

Wahlenbergia, see Platycodon, I89, 220

Walks, disorderly 47; clean, 48; sand for, 46; laying out curved, 90

Wallflower, Chieranthus cheiri, 286

Walls, value of, in dry exposure, 42; snow in spring under, 42

Wasps, 127; remedy for, I 27

Water Cress, False, Aubretia deltoides, 272

Watering seeds, 52; in time of drought, IO4

Waxwork, Roxbury, see Bittersweet, 233, 278

Wayfaring Bush, see Hobblebush, I72

Wedding gift, 40

Weeding, I I 5

Weeds resembling garden plants, 65; as beggars, I I4, II 5 


\section{Index}

Weigelia, Diervilla florida, I77, 25I, 275

Whale oil soap, I27

White Alder, see Sweet Pepper Bush, I84

White Annuals, 198-209

White edging plants, 84

White flowers, $165^{-209}$

White flowers in blue beds, 35 ; in red beds, 74 ; airy, 74 ; in combinations, 88

White grubs, 54 ; in hotbed, 55,118 , I 2 I

White mites, I32

White, showiest annuals in, 87 ; showiest perennials in, 86,87

White Perennials, I65-I66, I68-I72, I77-I84, I84-I90, I92-I95, I96, I97

White Shrubs, I66-I68, I72-I77, I84, I9I-I92, I96

Whiteweed, see Daisy, I79

Whitlavia, Phacelia Whitlavia, 225

Whitlavia, $W$. grandiflora, 206

Wild Hyacinth, see Scilla, 2 I I

Wild Rosemary, see Andromeda, 247

Windbreaks, trees as, 90

Window shelves for seedlings, 3 I

Winter Cress, see Rocket, Yellow, 235

Winter-killing, cause of IOO, IOI
Winter occupations, II

Wistaria, Chinese, $W$. Chinensis, 2I3; $W$. siensis, 45, 46, 97, 213; W. Chinensis, var. multijuga, $2 \mathrm{I} 4$ Withe Tree or Rod, Viburnum cassinoides, $\mathrm{I} 77$

Wood ashes, 55

Work, love of, ${ }^{5} 6$

Worm, green, on roses, I26; eel, I3I

Yellow Annuals, 242-246

Yellow Bed, 37, 38; edging plants for, 83,84 ; other colors in, 37 ; showiest annuals in, 86; showiest perennials in, 86

Yellow Flowers, 230-246

Yellow Perennials, 230, 231-232, 233-236, 237, 240, 24I, 242

Yellow Shrubs, 230, 232, 233, 236, 237,240

Yucca, Adam's Needle, Yucca filamentosa, I84

Zaluzianskia selaginoides, Nycterinia, 204

Zinnia, Curled and Crested, $Z$. elegans, 208, 229, 245, 270, 285; Mexican, $Z$. angustifolia, 246

Zinnia elegans, Curled and Crested Zinnia, 208, 229, 245, 270, 285; $Z$. angustifolia, Mexican Zinnia, 246 



\section{THE AMERICAN NATURE SERIES}

In the hope of doing something toward furnishing a series where the nature-lover can surely find a readable book of high authority, the publishers of the American Science Series have begun the publication of the American Nature Series. It is the intention that in its own way, the new series shall stand on a par with its famous predecessor.

The primary object of the new series is to answer questions which the contemplation of Nature is constantly arousing in the mind of the unscientific intelligent person. But a collateral object will be to give some intelligent notion of the "causes of things."

While the coöperation of foreign scholars will not be declined, the books will be under the guarantee of American experts, and generally from the American point of view; and where material crowds space, preference will be given to American facts over others of not more than equal interest.

The series will be in six divisions :

\section{NATURAL HISTORY}

This division will consist of two sections.

Section A. A large popular Natural History in several volumes, with the topics treated in due proportion, by authors of unquestioned authority. 8 vo, $7 \frac{1}{2} \times 10 \frac{1}{4}$ in.

The books so far publisht in this section are:

FISHeS, by David Starr Jordan, President of the Leland Stanford Junior University. $\$ 6.00$ net; carriage extra.

AMERICAN INSECTS, by Vernon L. Kelloge, Professor in the Leland Stanford Junior University. $\$ 5.00$ net; carriage extra.

BIRDS OF THE WORLD. A popular account by Frank $\mathbf{H}$. Krowlton, M.S., Ph.D., Member American Ornithologists Union, President Biological Society of Washington, etc., etc., with Chapter on Anatomy of Birds by Frederic A. Lucas, Chief Curator Brooklyn Museum of Arts and Sciences, and edited by Robert Rideway, Curator of Birds, U. S. National Museum. $\$ 7.00$ net; carriage extra.

Arranged for are:

SEEDLESS PLANTS, by George T. Moore, Head of Department of Botany, Marine Biological Laboratory, assisted by other specialists.

WILD MAMMALS OF NORTH AMERICA, by C. HART MerRIAM, Chief of the United States Biological Survey.

REPTILES AND BATRACHIANS, by Leonhard Stejneger, Curator of Reptiles, U. S. National Museum. 
A M E R I A N N A T U E SER IES (Continusd)

\section{NATURAL HISTORY (Continued)}

Section B. A Shorter Natural History, mainly by the Authors of Section A, preserving its popular character, its proportional treatment, and its authority so far as that can be preserved without its fullness. Size not yet determined.

\section{CLASSIFICATION OF NATURE}

1. Library Series, very full descriptions. 8 vo. $7 \frac{1}{2} \times 101$ in.

Already publisht:

NORTH AMERICAN TREES, by N. L. BRITTON, Director of the New York Botanical Garden. \$7.00 net; carriage extra.

FERNS, by Campbell E. Waters, of Johns Hopkins University, $\$ 3.00$ net; by mail, $\$ 3.30$.

2. Pocket Series, Identification Books-“How to Know," brief and in portable shape.

\section{FUNCTIONS OF NATURE}

These books will treat of the relation of facts to causes and effects - of heredity and the relations of organism to environment. 8 vo. $6 \frac{5}{8} \times 8 \frac{7}{8}$ in.

\section{Already publisht:}

THE BIRD : ITS FORM AND FUNCTION, by C. W. BEEBE, Curator of Birds in the New York Zoological Park. \$3.50 net; by mail, $\$ 3.80$.

$$
\text { Arranged for: }
$$

THE INSECT: ITS FORM AND FUNCTION, by VERNON L.

Kellog, Professor in the Leland Stanford Junior University.

THE FISH : ITS FORM AND FUNCTION, by H. M. Sмrтн, of the U. S. Bureau of Fisheries.

\section{WORKING WITH NATURE}

How to propagate, develop, care for and depict the plants and animals. The volumes in this group cover such a range of subjects that it is impracticable to make them of uniform size.

\section{Already publisht:}

NATURE AND Health, by Edward Curtis, Professor Emeritus in the College of Physicians and Surgeons. 12mo. \$1.25 net; by mail, $\$ 1.37$.

THE FRESHWATER AQUARIUM AND ITS INHABITANTS. A Guide for the Amateur Aquarist, by OTto Eqgening and Frederick Ehrenberg. Large 12mo. \$2.00 net; by mail, \$2.19. 
A M E R I A N N A T U R E S R I ES (Continued)

IV. WORKING WITH NATURE (Continued)

THE LIFE OF A FOSSIL HUNTER, by Charles H. Sternaerg. Large 12mo. $\$ 1.60$ net; by mail, $\$ 1.72$.

SHELL-FISH INDUSTRIES, by James L. Kelloge, Professor in Williams College. Large 12mo. $\$ 1.75$ net; by mail, $\$ 1.93$.

THE CARE OF TREES IN LAWN, STREET AND PARK, by B. E. Fernow, Professor of Forestry, University of Toronto. Large 12mo. $\$ 2.00$ net; by mail, $\$ 2.17$.

HARDY PLANTS FOR COTTAGE GARDENS, by Helen R. Albee. Large $12 \mathrm{mo}$. $\$ 1.60 \mathrm{net}$; by mail, $\$ 1.73$.

INSECTS AND DISEASE, by Rennie W. Doane, Assistant Professor in the Leland Stanford Junior University. \$1.50 net; by mail, $\$ 1.62$.

\section{Arranged for:}

PHOTOGRAPHING NATURE, by E. R. SANBorn, Photographer of the New York Zoological Park.

ChEMistry of DAILY Life, by Henry P. Talbot, Professor of Chemistry in the Massachusetts Institute of Technology.

\section{DIVERSIONS FROM NATURE}

This division will include a wide range of writings not rigidly systematic or formal, but written only by authorities of standing. Large 12mo. $5 \frac{1}{2} \times 8 \frac{1}{8}$ in.

Already publisht:

INSECT STORIES, by Vernon L. Kelloge. $\$ 1.50$ net; by mail, $\$ 1.62$.

Fish Stories, by Charles F. Holder and David Starr Jordan. $\$ 1.75$ net; by mail, $\$ 1.87$.

BIRD NOTES, by C. W. BEEBE.

$$
\text { Arranged for: }
$$

\section{THE PHILOSOPHY OF NATURE}

A Series of volumes by President Jordan, of Stanfora University, and Professors Brooks of Johns Hopkins, LuLl of Yale, THosson of Arberdeen, Przibram of Austria, zUr Strassen of Germany, and others. Edited by Professor Kelroge of Leland Stanford. 12mo. $5 \frac{1}{8} \times 7 \frac{1}{2}$ in.

Arranged for:'

THE STABILITY OF TRUTh, by David Starr Jordan.

HENRY HOLT AND COMPANY, NEw YoRK JANOARY, '11. 


\section{THE AMERICAN NATURE SERIES}

(Prospectus of entire Series on request)

\section{INSECTS AND DISEASE}

By R. W. DoAne, of Stanford University. Illustrated. $\$ 1.50$ net; by mail, \$1.62.

"Describes lucidly and entertainingly, in language that all may understand, the discoveries in the disease-bearing qualities of insects, the successful fights that have been made in consequence against yellow fever, malaria and plague, and the present state of the investigations." $-N e w$ York Sun.

\section{THE CARE OF TREES IN LAWN, STREET, AND PARK}

By B. E. FERnow, of the University of Toronto. Illustrated. $\$ 2.00$ net; by mail, $\$ 2.17$.

Written for amateurs by a forester, this volume furnishes information such as the owner of trees or the "tree warden" may need.

"Truly admirable . . . eminently practical. . . His list of trees desirable for shade and ornament is a full and most valuable one, and the illustrations are enlightening."-New York Tribune.

\section{HARDY PLANTS FOR COTTAGE GARDENS}

By Helen R. Albee, Author of "Mountain Playmates." Illustrated. I2mo. \$1.60 net; by 1i.uil, \$1.75.

"Eminently practical and well arranged. .. . Lists giving manner of growth, height, time of blooming, exact color, special requirements of soil and moisture are provided, and proper classifications and indexes make the book one of the most valuable yet offered to the garden grower."-Boston Transcript.

\section{SHELL-FISH INDUSTRIES}

By James L. Kellogg, of Williams College. Illustrated. $\$ 1.75$ net; by mail, \$1.9r.

"Interests all classes, the biologist, the oyster grower, the trader and the eater of oysters. The whole book is very readable."'-New York Sun.

FISH STORIES: Alleged and Experienced, with a Little History, Natural and Unnatural

By Charles F. Holder and David Starr Jordan. With colored plates and many illustrations from photographs. $\$ 1.75$ net; by mail, $\$ 1.87$.

"A delightful miscellany, telling about fish of the strangest kind. Nearly everything that is entertaining in the fish world is touched upon and science and fishing are made very readable." - New York Sun.

\section{INSECT STORIES}

By Vernon L. Kellogg. Illustrated. \$1.50 net; by mail, \$r.62.

"The author is among a few scientific writers of distinction who can interest the popular mind. No intelligent youth can fail to read it with delight and profit."-The Nation.

\begin{tabular}{llrl}
\hline H E N R Y & HOL T A N D C O M P A N Y \\
PUBLISHERS & NEW YORK
\end{tabular}




\section{BRITTON'S NORTH AMERICAN TREES}

By Nathaniel Lord Britton, Director-in-Chief of the N. Y. Botanical Garden, assisted by J. A. Shafer, Custodian of the Museums of the N. Y. Botanical Garden, 775 illustrations, 894 pp., $\$ 7.00$ net.

The most comprehensive and profusely illustrated single volume on the trees known to grow independently of cultivation in North America north of the West Indies and Mexico. With a minimum of technical terms, a glossary of the botanical terms, keys for identification and a 29-page index.

"This splendid book."-The Dial.

"It is a most thoroly admirable book, and one which I shall find personally of the greatest use. There is nothing of the kind better in any language either in method or appearance of text."-President David Starr Jordan, Leland Stanford University.

"This superb volume. . . Seldom does one find a book which merits more enthusiastic enconiums than this. No slightest aspect of the subject untouched; yet there is not a superfluous phrase, scarcely a superfluous word. . Invaluable to all serious students. . . Excellent paper, admirable type and abundant illustrations."-Providence Journal.

\section{KERNER AND OLIVER'S NATURAL HISTORY OF PLANTS.}

From the German of Anton Kerner von Marilaun, Professor of Botany in the University of Vienna, by F. W. Oliver, Quain Professor of Botany in University College, London, with the assistance of Marian Bush and Mary E. Ewart. 4to. 2 vols. The set, $\$ 11.00$ net.

A work for reference or continuous reading, at once popular and, in the modern sense, thoroly scientific. The new edition is practically identical with the former four-volume edition except that the colored plates in the latter have been omitted. The wood engravings, over two thousand in number, have been retained.

"Professor Kerner has brought the most recent researches within reach of the intelligent reader, and in a style so charming that even the professiona! teacher may learn a lesson in the art of presentation."-Prof. JоHN M. Coulter, in The Dial.

\section{Prospectuses of the above on request.}

\section{H E N R Y H O L T A N D C O P A N Y \\ 34 West 33D ST. \\ NEW YORK}






THIS BOOK IS DUE ON THE IAST DATE STAMPED BELOW

AN INITIAL FINE OF 25 CENTS WILL BE ASSESSED FOR FAILURE TO RETURN THIS BOOK ON THE DATE DUE. THE PENALTY WILL INCREASE TO 50 CENTS ON THE FOURTH DAY AND TO \$1.00 ON THE SEVENTH DAY OVERDUE.

OCT 271932
OCT 281932
SEP 21935 :

NOV 151939

FED 31944

29]Ul' $49 H L B$

\section{JUN 51947}

\section{$29001^{150 C D}$}

\section{MAY2ก1953 LU}

3
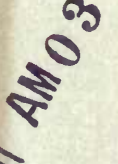

26Apr5oMN

Due end of ALL Quarter

subject to recall aftar -

Nov $1 \div 172$

LD 21-50m-8, 32 
fores he

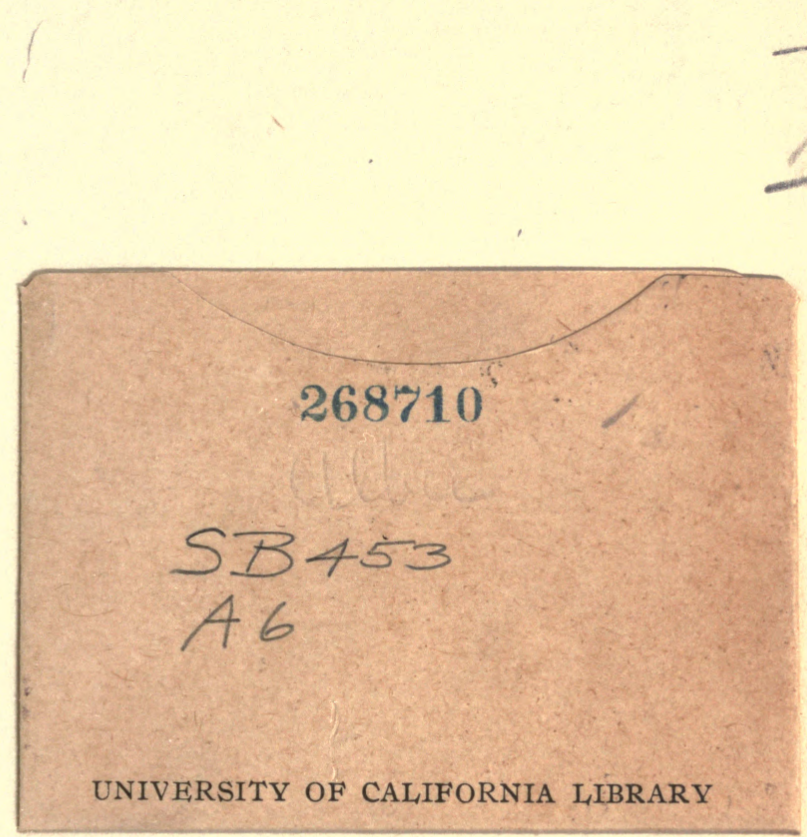


3

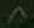

is

5 